\title{
Sexual Addiction 25 Years On: A Systematic and Methodological Review of Empirical Literature and an Agenda for Future Research
}

Joshua B. Grubbs, ${ }^{1}$ K. Camille Hoagland, ${ }_{1}^{1}$ Brinna N. Lee, ${ }^{1}$ Jennifer T. Grant, ${ }^{1}$ Paul Davison, ${ }^{1}$ Rory C. Reid, ${ }^{2}$ and Shane W. Kraus ${ }^{3}$

${ }^{1}$ Department of Psychology, Bowling Green State University, Bowling Green, Ohio, U.S.A.

${ }^{2}$ Department of Psychiatry and Biobehavioral Sciences, University of California Los Angeles, Los Angeles, California, U.S.A

${ }^{3}$ Department of Psychology, University of Nevada, Las Vegas, Las Vegas, Nevada, U.S.A.

In 1998, Gold and Heffner authored a landmark review in Clinical Psychology Review on the topic of sexual addiction that concluded that sexual addiction, though increasingly popular in mental health settings, was largely based on speculation, with virtually no empirical basis. In the more than two decades since that review, empirical research around compulsive sexual behaviors (which subsumes prior research about sexual addiction) has flourished, ultimately culminating in the inclusion of a novel diagnosis of Compulsive Sexual Behavior Disorder in the eleventh edition of the World Health Organization's International Classification of Diseases. The present work details a systematic review of empirical research published between January 1'st, 1995 and August 1 1', 2020 related to compulsive sexual behaviors, with a specific focus on evaluating the methodologies of that literature. This review yielded 371 papers detailing 415 individual studies. In general, the present review finds that, although research related to compulsive sexual behaviors has proliferated, much of this work is characterized by simplistic methodological designs, a lack of theoretical integration, and an absence of quality measurement. Moreover, the present review finds a virtual absence of high-quality treatment-related research published within this time frame. Implications of these findings for both clinical practice and future research are discussed.

Keywords: Behavioral Addiction; Hypersexuality; Pornography Addiction; Sexual Addiction; Compulsive Sexual Behavior Disorder

A little more than two decades ago, Gold and Heffner (1998) published a pivotal paper in Clinical Psychological Review about the nature of "sexual addiction." At the time, the concept—popularized by Patrick Carnes fifteen years earlier (Carnes, 1983) —was gaining increasing attention in clinical settings and in popular media. However, after thoroughly reviewing the available empirical literature, Gold and Heffner concluded that, "The literature on this topic [sexual addiction] consists largely of theory and conjecture based almost entirely on clinical observation rather than on research findings" (Gold \& Heffner, 1998, p. 379).

Since 1998, much has changed in clinical understandings of various phenomenon that might be related to sexual addiction. Research into compulsive, addictive, impulsive, or out-of-control sexual behavior has proliferated. The fifth edition of the American Psychiatric Association's Diagnostic and Statistical Manual of Mental Disorders (hereafter: DSM-5) only narrowly excluded the diagnosis of Hypersexual Disorder, and the World Health
Organization recently elected to include the diagnosis of Compulsive Sexual Behavior Disorder (hereafter: CSBD) in the forthcoming eleventh edition of the International Classifications of Diseases (hereafter: ICD-11). In short, the knowledge base regarding non-paraphilic out-ofcontrol sexual behaviors has indeed moved substantially forward in the past two decades. ${ }^{1}$ As such, the purpose of the present work was to conduct a systematic review of literature published since 1995 on behaviors that might fall under the greater umbrella of sexual addiction, provide an updated summary of research with a particular focus on methodology, and discuss areas of consideration for both clinical translation and research focus.

\section{Evolution of Sexual Addiction in Research Literature}

Out of control sexual behaviors have been described by physicians since the early 19 th century (Rush, 1812), though descriptions of people with excessive or voracious sexual appetites can be found in various histories and mythologies that long predate such medical attention. However, it was not until the latter half of the $20^{\text {th }}$ century

\footnotetext{
${ }^{1}$ Given the recognition of CSBD in the ICD-11, for the remainder of the present work, we use Compulsive Sexual Behavior (or CSB) to refer to non-paraphilic out-of-control or dysregulated sexual behavior patterns, despite past literature's use diverse terms such as sexual addiction, compulsive sexual behavior, hypersexuality, and similar terms.

Grubbs, J. B., Hoagland, K. C., Lee, B. N., Grant, J. T., Davison, P., Reid, R. C., \& Kraus, S. W. (2020). Sexual addiction 25 years on: A systematic and methodological review of empirical literature and an agenda for future research. Clinical Psychology Review, 82, 101925. https://doi.org/10.1016/j.cpr.2020.101925
} 
that these ideas began to receive academic attention, with some of the earliest works on out of control sexual behaviors labeling the presentation of these phenomena "hypersexuality." Although the early literature and case reports describing hypersexuality often lacked rigor, substance, or clarity (Orford, 1978), these works underscored the potential for hypersexuality to be of research and clinical importance and led to novel conceptualizations of problematic sexuality, especially that of "sexual addiction."

In 1983, Patrick Carnes first introduced the concept of sexual addiction to clinical audiences in his work Out of the Shadows: Understanding Sexual Addiction, which intensified interest in excessive sexual behaviors. This work provided clinical descriptions, etiological speculations, and treatment recommendations based on Carnes's experiences in treating what he had labeled sexual addiction (Carnes, 1983). At the time, little empirical work supported his claims, and initial reactions to Carnes' work and the general notion of sexual addiction were mixed (c.f., M. Levine \& Troiden, 1988). Even so, a steady trickle of research described excessive or out of control sexual behaviors followed Carnes' early writings.

In the early to mid-1990s, a number of studies began to emerge detailing various aspects of "sexual addiction," "sexual compulsivity," and "compulsive sexual behavior." Much of this work was in the form of theoretical speculation (Goodman, 1992; Pincu, 1989; Sunderwirth et al., 1996) or case reports (Coleman, 1991, 1992). However, some empirical studies were conducted around this time (Hecker et al., 1995; Lundy, 1994), and the notion of sexual compulsivity (particularly among men who have sex with men) was the subject of various studies (Kalichman et al., 1994; Kalichman \& Rompa, 1995).

Beginning in the late 1990s, research into out of control sexual behaviors began to accelerate, in part due to the advent of the internet and its subsequent uses for sexual purposes (Cooper, Putnam, et al., 1999; Delmonico \& Carnes, 1999). Specifically, some empirical studies emerged at this time with a clear focus on the possibility for some people to get caught in patterns of compulsive or addictive sexual behaviors facilitated by technological mediums (Cooper, Scherer, et al., 1999; Delmonico, 1997; Delmonico \& Carnes, 1999). Termed "cybersex," online activities such as chat rooms, digital infidelity, and internet pornography consumption were posited as being potential expressions of out-of-control sexual behavior (Delmonico, 2002). Indeed, empirical work during the same time supported this notion, showing that some people did report that their online sexual behaviors were excessive (Cooper, Delmonico, et al., 2000; Delmonico \& Miller, 2003).

At the time, many of these problems were attributed to what Cooper and colleagues termed the "Triple A Engine," or the Anonymity, Affordability, and
Accessibility of online sexual behaviors (Cooper, 1998; Cooper, McLoughlin, et al., 2000; Cooper, Scherer, et al., 1999). According to this model, the internet presented a unique space for out-of-control sexual behaviors due to the ease at which sexual content online could be accessed (accessibility), the privacy afforded by at-home internet service (anonymity), and the relatively low cost (affordability) of online sexual behaviors in comparison to more traditional means of engaging in such behaviors (i.e., buying pornography videos or magazines; soliciting prostitutes; frequenting strip clubs). Although intuitive, this model was not without its critics, and the only empirical study to actually test the model did not find support for it (Byers et al., 2004). Even so, research into out-of-control sexual behaviors, including, but not limited to, online sexual activities, continued to progress.

Interest into CSBs reached a tipping point during the development of the American Psychiatric Association's DSM-5. At this time, the diagnosis of Hypersexual Disorder was proposed for inclusion in the DSM-5 (Kafka, 2010). Conceptualized as being related to both addictive disorders and sexual desire disorders, Hypersexual Disorder followed highly similar diagnostic criteria to those seen in other syndromes outlined in earlier versions of the DSM, namely Pathological Gambling, which was considered an impulse control disorder in the DSM-IV and later classified as an addictive behavior called Gambling Disorder in the DSM5 and substance use disorders. Specifically, this proposed diagnosis required that the recipient of the diagnosis experience repetitive and impairing sexual behaviors, urges, or fantasies that consumed excessive time, were in response to negative emotions or stress, were uncontrollable despite efforts to control or reduce these symptoms, and that disregarded the well-being or safety of the self or others (Kafka, 2010). Importantly, to meet criteria for Hypersexual Disorder, sexual behaviors could not be attributable drug use or to the side effects of prescription drug use or manic episodes as these behaviors must have occurred as a result of the sexual urges themselves instead of being caused by external factors.

Field trials of Hypersexual Disorder found the disorder to be useful, reliably applied, and generally wellreceived by clinicians (Reid et al., 2012). However, Hypersexual Disorder was ultimately excluded from the DSM-5 due to a range of concerns related to diagnostic accuracy, moral and cultural confounds, and general skepticism from the psychiatric community (Kafka, 2014). Regardless, in the time since that decision, research into this domain has flourished, ultimately culminating in diagnostic recognition of specific cases of out-of-control sexual behaviors, as we explore below.

\section{Compulsive Sexual Behavior Disorder in the ICD-11}

The landscape of research related to out-of-control sexual behaviors again changed with the proposal and 
subsequent inclusion of Compulsive Sexual Behavior Disorder (hereafter: CSBD) in the ICD-11. Similar to the appropriate classification of such behaviors (for example, see: Grubbs, Kraus, et al., 2020; Klein et al., 2019).

Table 1. Diagnostic criteria for Compulsive Sexual Behavior Disorder for ICD-11

Essential (required) features for compulsive sexual behavior disorder:

- A persistent pattern of failure to control intense, repetitive sexual impulses or urges resulting in repetitive sexual behavior, must be manifested in one or more of the following:

$\circ$ 1a. Engaging in repetitive sexual activities has become a central focus of the person's life to the point of neglecting health and personal care or other interests, activities, and responsibilities (yes/no).

$\circ \quad 1 b$. The person has made numerous unsuccessful efforts to control or significantly reduce repetitive sexual behavior (yes/no)

- 1c. The person continues to engage in repetitive sexual behavior despite adverse consequences (e.g., repeated relationship disruption, occupational consequences, negative impact on health) (yes/no).

$\circ 1 \mathrm{~d}$. The person continues to engage in repetitive sexual behavior even when the individual derives little or no satisfaction from it (yes/no).

- 2. The pattern of failure to control intense, sexual impulses or urges and resulting repetitive sexual behavior is manifested over an extended period (e.g., 6 months or more) (Must be met)

- 3. The pattern of repetitive sexual behavior causes marked distress or significant impairment in personal, family, social, educational, occupational, or other important areas of functioning (Must be met). Note for rule out. Distress that is entirely related to moral judgments and disapproval about sexual impulses, urges, or behaviors is not enough to meet this requirement.

excluded diagnosis of Hypersexual Disorder for the DSM5, CSBD refers to persistent, repetitive engagement in sexual behaviors that results in impairment in one's life in addition to failed attempts to reduce or stop such behaviors (Kraus et al., 2018). The diagnostic criteria for this new disorder are included in Table 1.

The inclusion of CSBD in the ICD-11 has not been without its controversy, generating more commentary and critique than any other novel diagnosis considered for the ICD-11 (Fuss et al., 2019). This controversy in the public sphere mirrors the longstanding history of controversy around CSB related notions more generally, such as the use of such diagnoses to stigmatize some sexual behaviors and debates about how and when to consider certain sexual behaviors problematic. Dating back to early work on sexual addiction, attempts to diagnose excessive sexual behaviors as a discrete syndrome have been met with criticism for a variety of reasons (Levine \& Troiden, 1988; S. B. Levine, 2010). Some critiques have focused on the potential of such diagnoses to stigmatize non-conforming sexual behaviors (Halpern, 2011), arguing that the choice to conceptualize certain behaviors as problematic is inherently biased against non-traditional sexual behaviors. Others have argued that the evidence in support of such disorders is lacking (Ley et al., 2014; Prause et al., 2017). Still, others have noted that application of such diagnoses may be complicated by extraneous variables such as client or therapist religiosity or client sexual orientation (Droubay \& Butters, 2019; Grubbs, Kraus, et al., 2020; Klein et al., 2019). Despite these controversies, the recognition of this new disorder has highlighted the need for rigorous research into out-of-control sexual behaviors and has generated new interest within clinical psychology with regards to the

\section{Conceptualizations of CSB}

At present, CSBD has been included in the ICD-11 as an impulse control disorder. Even so, there is ongoing debate as to whether or not CSBs are rightly considered addictive, impulsive, or compulsive. The Working Group on Obsessive-Compulsive and Related Disorders proposed a conceptualization of CSBD as an impulse control disorder because individuals exhibiting this behavior repeatedly failed to resist such sexual impulses, drives, and urges which were, at some point, rewarding, despite long-term harm (Kraus, Krueger et al. 2018). Building on this conceptualization, the diagnostic criteria are written in such a way that essential features of CSBD are intended to be less rigid because they rely less on arbitrary cut-offs or symptom counts, rely more on objective indicators of impairment and dysregulation, and are meant to support the exercise of clinical judgment in assigning the diagnosis (First et al., 2015). However, one of the current challenges is drawing the clear distinction between addiction, impulsivity, and compulsivity, as these concepts overlap because impulses or urges to engage in repetitive behaviors are core features of addiction.

Strong impulses or compulsions are distinctive from addictions in that addiction is typically associated with additional features caused by the substance or behavior, including tolerance and withdrawal, whereas in impulse control disorders (e.g., kleptomania and pyromania) or compulsive disorders (e.g., obsessive compulsive disorder) the assumption is that the pathology lies primarily within the individual. Some evidence suggests that persons with CSB exhibit significantly higher levels of impulsiveness than healthy controls (Antons et al., 2019; Mechelmans et al., 2014; Miner et al., 2009; Reid et al., 2015), however, similar associations have been 
observed in people with other addictive disorders, such as gambling (Specker et al., 1995), alcohol (Lejoyeux et al., 1999), or cocaine (Li et al., 2008) use disorders. In short, impulsivity is a feature of most addictive disorders, which suggests that distinguishing between impulse control disorder and addiction is not a straightforward endeavor.

Further, there are some studies on patients with CSBD that show comparable levels of impulsivity to patients with addictive disorders (gambling and drug use disorders) while also finding that only half of patients in all these groups show clinically elevated scores on measures of impulsivity (Reid, Cyders et al, 2014). Other studies have found no difference compared to healthy controls in terms of general impulsivity, but only specific increased sensitivity for erotic cues among individuals with CSBD (Gola et al., 2017). Such specific increases of sensitivity towards one category of cues is typical for addictive behaviors and has been well described by incentive salience theory as a main factor underlying craving in addiction (Olney et al., 2018). These studies, most of which use addiction related experimental paradigms, have sought to better understand the neurobiological underpinnings of CSB. In general, these studies have found that CSB is associated with altered functioning in brain regions and networks implicated in sensitization, habituation, diminished impulse control, and reward processing in patterns like substance, gambling, and gaming addictions (Kowalewska et al., 2018; Stark et al., 2018). In addition, studies looking at dopamine replacement therapies used for individuals with Parkinson's disease have also produced similar patterns of impulse control problems that resemble CSBD (Weintraub et al., 2010). As such, there is some research which suggests that, although CSBD fits the characteristics of an impulse control disorder, it also exhibits some of the same behavior specific impulses and reward processing as an addictive disorder.

Similar critiques can be made with regards to role of compulsivity in CSB and other addictive disorders. Specifically, addictions are inherently characterized by compulsions to seek a substance or behavior that provides neurological rewards (Koob, 2017). Although compulsions may characterize other disorders as well (e.g., compulsive checking in obsessive compulsive disorder), the compulsivity associated with CSBs more closely resembles the compulsivity seen in addictive disorders. Future research on CSBD may find more evidence to support an addictive classification in which case CSBD may follow a similar trajectory as pathological gambling which has transitioned from an impulse control disorder characterized by compulsive engagement in gambling to an addictive classification renamed gambling disorder in the DSM-5.

Moving beyond the substantive debates about the correct conceptualization of CSBD, there is evidence that the majority of laypeople view CSBs, such as excessive pornography use, as addictions (Burke \& MillerMacPhee, 2020; Perry, 2019; Taylor, 2019). Many people believe that sexual behaviors can be addictive (Lang \& Rosenberg, 2017, 2018), and when describing their own experiences with CSBs, addiction seems to be the most commonly used explanation (Cavaglion, 2008, 2009; Wordecha et al., 2018). In short, public perceptions of out-of-control sexual behaviors are most often couched in terms associated with addiction, regardless of the formal distinctions still debated in the research literature. This latter difference is not surprising, as scientists are focused on finding the most parsimonious theoretical model to explain a phenomenon while members of the public are typically interested in getting help for the phenomenon regardless of how it may be classified.

There is also considerable evidence that many people may interpret their sexual behaviors as addictive, compulsive, or out-of-control, even when their behaviors do not objectively appear to be dysregulated or clinically impairing (Burke \& Haltom, 2020; Grubbs \& Perry, 2019). That is, several studies (particularly in the U.S.) have found that many people are likely to experience moral qualms about their sexual behaviors which, in turn, seem to promote feelings of addiction or compulsion (Griffin et al., 2016; Hook, Farrell, Davis, et al., 2015; Hook, Farrell, Ramos, et al., 2015). Recently, in reference to pornography use specifically, this has been described as moral incongruence, which specifically refers to feelings that arise when one's actual pornography use behaviors are not in line with one's beliefs about pornography use (Grubbs, Perry, et al., 2019; Grubbs \& Perry, 2019). Importantly, this moral incongruence can appear in clinical settings among those seeking help for their self-perceived out-of-control sexual behaviors (Cantor et al., 2013; Kraus \& Sweeney, 2019).

\section{The Present Study}

Building on the above history, the purpose of the present work was to conduct a systematic review of published empirical literature since 1995 on the topic of CSB, broadly defined. The primary aims of the present work are 1) to examine the development of the CSB literature since Gold and Heffner's 1998 review, 2) describe the sample and general methodological characteristics of studies of CSB, 3) summarize clinical knowledge and recommendations for the assessment and treatment of CSB, and 4) identify areas of CSB research in need of further development.

Although reviews of CSB related topics have been conducted in the past, the majority of these reviews have been concerned with issues of conceptualization and assessment of CSB (i.e., Karila et al., 2014; MontgomeryGraham, 2017), pornography related behaviors only (i.e., de Alcarón et al., 2019; Efrati, 2020; Böthe, VaillancourtMorel, et al., 2019), or conceptual frameworks for 
understanding CSB (i.e., Walton et al., 2017; Briken, 2020). The present work seeks to more exhaustively review the literature in ways that more comprehensively establish the state of the science in this domain, with a particular emphasis on methodology. The present work also avoids systematically drawing conclusions about the legitimacy of CSB or CSBD as a distinct clinical syndrome or psychiatric diagnosis, nor does it evaluate the veracity of the novel CSBD diagnosis (or any previously proposed diagnoses) or how it should best be classified. Such debates are generally justified and are indeed occurring in various literatures at present (for examples, see: Kraus et al., 2016; Potenza et al., 2017; Prause et al., 2017; Reid \& Grant, 2017). Regardless of these debates, however, research on CSB has proliferated over the past several decades. Accordingly, the present work seeks to summarize empirical literature related to CSB from the past 25 years, with a goal of broadly evaluating the methodological rigor and clinical implications of such literature.

As alluded to previously, the advent of the internet substantially changed the course of research related to CSB. As such, any serious consideration of CSB research must also consider technologically mediated CSBs. Additionally, given evidence that CSBs encountered in clinical practice are most often related to pornography use and concomitant masturbation (de Tubino Scanavino et al., 2013; Mitchell et al., 2005; Reid et al., 2012; Short et al., 2016), we specifically elected to include studies that purported to measure impulsive, compulsive, or addictive use of pornography.

\section{Method}

To accomplish the aforementioned aims, we conducted a systematic review of the literature published from January $1^{\text {st }}, 1995$ to August $1^{\text {st }}, 2020$. We followed the Preferred Reporting Items for Systematic Reviews and Meta Analyses (PRISMA) guidelines in conducting and reporting our results (Moher et al., 2009). We did not complete a meta-analysis of results because the variety of methods and measures used in this area of research (as we examine below) would make such an analysis nearly impossible to conduct in any meaningful way. Our primary searches were conducted via PsycInfo, PubMed, Academic Search Complete, Academic Search Premier, Health Source: Nursing/Academic Edition, MEDLINE, Psychology and Behavioral Sciences Collection, and SocINDEX. We also conducted supplemental searches via Google Scholar and consulted with subject matter experts in the field to identify any missing studies. Our search process is described below and summarized in our PRISMA diagram depicted in Figure 1.

Search Terms. Given the proliferation of research on $\mathrm{CSB}$, as described above, we included a range of search terms for the present study. These terms were derived through consultation with subject matter experts, review of available literature, and iterative searching procedures where terms consistently encountered in reviewed literature were themselves searched. Search terms were as follows: Hypersexuality, Hypersexual Behavior, Hypersexual Disorder, Hypersex*, Compulsive Sexual Behavior, Sex Addict*, Pornography Addict*, Problematic Pornography Use, and Sexual Compulsivity. Using these terms, we identified 2,007 papers somehow relevant to CSB that were subject to further review. Additional literature reviews performed by the authors of the paper identified 102 additional potential references for review. We also conducted supplementary searches looking at alternative terms for pornography such as "impulsive sexual behavior," "excessive pornography use," "Visual Sexual Stimuli" and "Sexually Explicit Material," and "Sexually Explicit Online Material." These searches did not yield any new results not already encompassed by previous terms. The first five authors of this paper collaboratively reviewed these identified papers and abstracts and extracted the data reported in supplemental tables. For all studies, we sought to extract and summarize key methodological information regarding study design, research paradigms, sample characteristics, specific focus of research, and measures of CSB included.

Exclusion criteria. After eliminating duplicates, we limited our review to works published in academic journals (i.e., excluding dissertations, books, magazines, and non-academic periodicals), which reduced the number of studies eligible for title and abstract review to 1,369. Studies were only included if they featured an empirical analysis of non-paraphilic CSB. Studies that primarily focused on paraphilias or pedophilia were excluded from analyses, as past literature suggests that there are unique aspects of these disorders that differ from non-paraphilic CSB, despite the fact that individuals with paraphilia also often exhibit CSB (Efrati et al., 2019; Kafka \& Hennen, 2003). Case studies and qualitative studies were similarly excluded, as they did not provide quantitative summaries salient to current understandings of CSB. Studies of CSB that clearly did not meet criteria for CSBD or adjacent disorders were also excluded. Specifically, studies of CSB in the context of Parkinson's disease, bipolar disorder, or dopamine agonist pharmacotherapy were not included, as current criteria for CSBD and past proposed criteria for Hypersexual Disorder both noted diagnostic exclusions for such types of CSB. Finally, we excluded studies for which CSBs were secondary to substance use (i.e., CSB in substance use rehabilitation populations; CSBs in the context of illicit drug use).

Using the above criteria, review of titles and abstracts resulted in 766 papers eligible for full-text review. Of those, 371 papers subsuming 415 individual studies met 
inclusion criteria and were included in our full review. ${ }^{2}$

Below, we summarize findings from these materials.

${ }^{2}$ Among these 415 studies, we were able to identify 89 that were duplicate reports from the same data sets. That is, our review found that at least 89 papers were reports from the same data reported in other papers, representing only 36 data collection efforts. Based on these findings, it appears that there are, at most, 362 unique data collection efforts represented in the literature. Additionally, it is likely that some of the remaining 362 studies are duplicates as well, though it was not possible to ascertain such information from materials reported in the texts of those studies. 


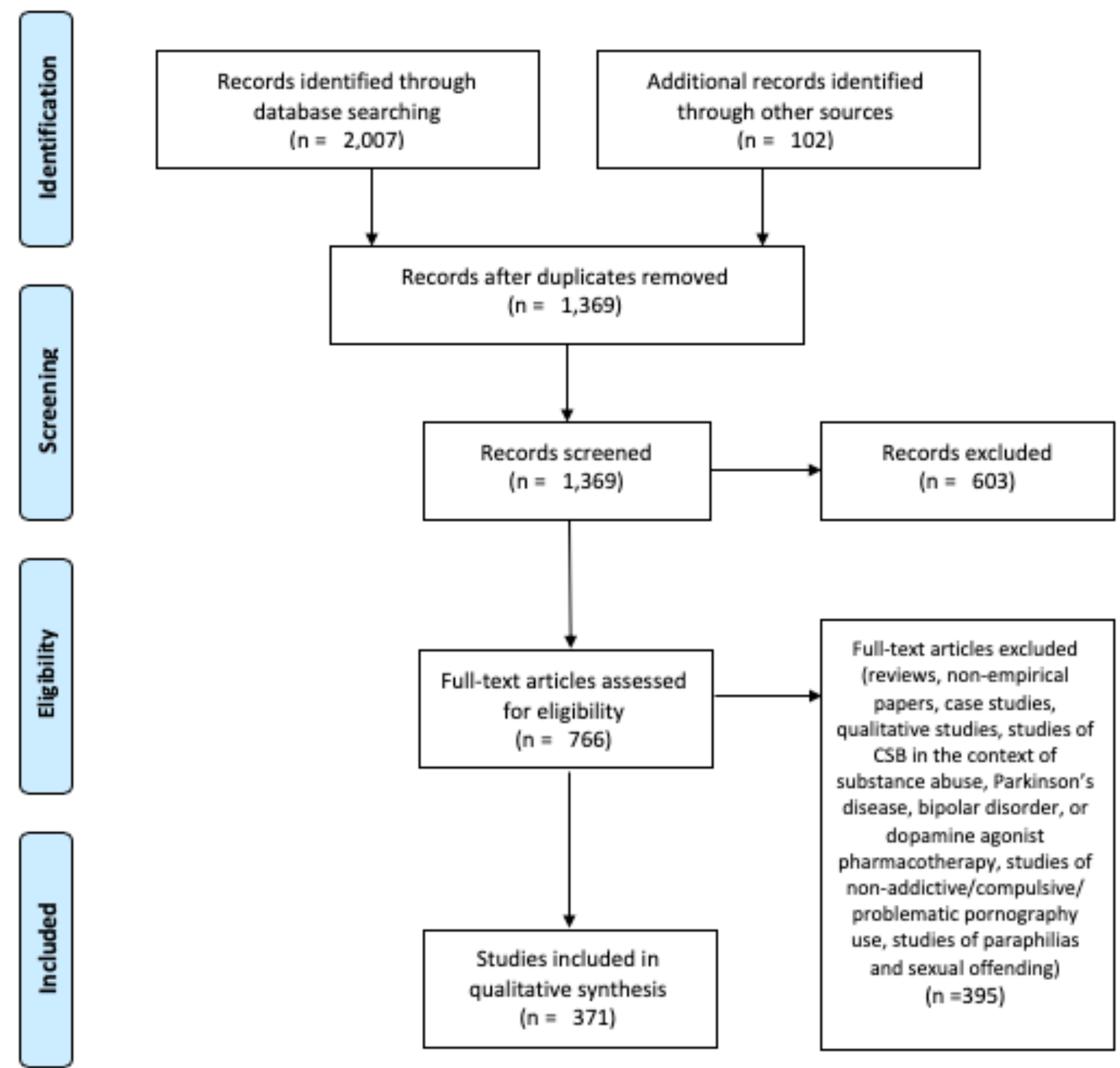

Figure 1. Preferred Reporting Items for Systematic Reviews and Meta-Analyses flow diagram illustrating article selection process

\section{Results}

A primary finding of the present work is the rapid acceleration of CSB-relevant research in the past 10 years. This general trend is summarized in Figure 2. In the ten years from 1995 to 2004, 25 empirical papers were published that met criteria for the present review, for an average of 2.5 papers per year. From 2005 to 2014, an additional 119 papers were published, for an average of 11.9 papers per year. Finally, from 2015 until August 1 $^{\text {st }}$, 2020 (5.58 years) an additional 227 papers were published, for an average of 40.7 papers per year.

Below, we summarize key findings related to the types and settings of studies conducted, the behaviors subsumed by CSB research, and the treatment 
recommendations that have resulted from this body of research. A full summary of included papers can be found in Supplemental Table 1. This table reports sample sizes, demographic variables, study methodology, subject of focus, and key measure of CSB for each study.

\section{Demographic Summary.}

The age ranges covered by studies were variable, with 73 studies exclusively reporting results from college student populations, an additional 13 studies reporting results from studies of adolescents, and the remaining 331 studies covering a range of ages. In general, there was an overrepresentation of studies entirely comprised of men, with almost half of all studies being limited to participants who identified as men $(k=197 ; 47.4 \%)$. In contrast, only $2.6 \%$ of studies exclusively examined women $(k=11)$. However, as we review in more detail later, nationally representative works in a number of countries do suggest that men are more likely to report CSB than women.

With regards to sexual orientation, $33.7 \%(k=140)$ of studies did not report sexual orientation. A small subset of studies exclusively examined CSB in heterosexual individuals $(9.4 \% ; k=39)$, whereas a larger number of studies $(16.6 \% ; k=69)$ examined CSB in predominately or exclusively sexual minority (bisexual; gay; lesbian) or men who have sex with men (MSM) populations. The remainder of studies reported a blend of sexual orientations.

Regarding relationship status, the majority of studies did not report marital or relationship status $(51.1 \%$; $k=212$ ). One study exclusively focused on married individuals (Muise et al., 2013), and two studies reported exclusively focusing on unmarried individuals (Luo et al., 2018; Yeagley et al., 2014). However, among studies reporting relationship status, many of the studies reviewed consisted entirely or predominantly of individuals who reported being unmarried (i.e., studies about adolescents; studies of undergraduate students, studies focusing exclusively on men who have sex with men).

The present review identified 27 unique countries in which research related to CSB has been conducted in the past 25 years. A very large portion of research on CSB has been conducted in the U.S., with approximately $47.2 \%(k=$ 196) of published studies being comprised of entirely or majority U.S. samples. After the U.S., the most common countries of CSB related research were Germany $(k=29)$, Israel $(k=28)$, multinational origin $(k=24)$, Canada $(k=$ $19)$, Hungary $(k=19)$, Sweden $(k=12)$, Spain $(k=12)$, and Poland $(\mathrm{k}=10)$. Only a relatively small number of studies $(7.9 \% ; k=33)$ were taken from countries from the Global South (e.g., Mexico, Brazil, Indonesia, China, India, Malaysia, Nigeria, Bangladesh).

\section{Behaviors subsumed by CSB}

General CSB. The majority of studies reviewed $(65.1 \% ; k=270)$ examined CSB generally. Such studies may subsume compulsive pornography use or online sexual behaviors (discussed below), but may also subsume solicitation of sex workers, compulsive casual sex, or compulsive solicitation of adult entertainment venues (e.g., strip clubs). Moreover, in most cases, these studies made no specific designation of the types of behaviors that were of focus.

Pornography Use. Of the studies reviewed, 29.9\% ( $k=124)$ focused primarily or exclusively on problematic pornography use. In many cases, this use was restricted to internet pornography use, whereas, in other cases, the media by which pornography was consumed was not specified. Even so, evidence from relatively recent research suggests that virtually all pornography use is consumed via the internet (for reviews, see: Grubbs, Wright, et al., 2019; Kohut et al., 2019). We also note that most studies likely implied masturbation, as the use of pornography is almost always accompanied by masturbation (e.g., Grubbs, Wright, et al., 2019; Prause, 2019), though most studies did not mention masturbation. This is of importance as there is also evidence that problematic associates of excessive pornography are often more related to compulsive masturbation (Perry, 2020).

Cybersex. A number of studies, particularly those from the late 1990s and early 2000s (e.g., Cooper, Delmonico, et al., 2000) specifically mentioned or focused on "cybersex" or "online sexual activities" more generally. This term has persisted even into recent literature (e.g., Ballester-Arnal et al., 2017; Wery \& Billieux, 2017). However, this term seems to be idiosyncratically used across a range of studies (Wery \& Billieux, 2017). For example, early use of cybersex referred to any number of sexually focused online activities such as sexual chats in chatrooms, sexually themed games, or online pornography (Carvalheira \& Gomes, 2003; Delmonico, 1997). Yet, more recent works have used it to refer exclusively to online pornography use (Laier et al., 2013, 2014; Snagowski et al., 2015). For the purpose of this review, we considered studies to be concerned with online sexual activities if the study explicitly mentioned a focus on social sexual behaviors online (i.e., sexual chatrooms; sexual video calls; live sexual cam shows) or a general focus on online sexual behaviors that were not exclusively limited to pornography use. Using these criteria, we found that $5.1 \%(k=21)$ of studies focused on cybersex or online sexual activities broadly, which may include pornography use among other behaviors. 


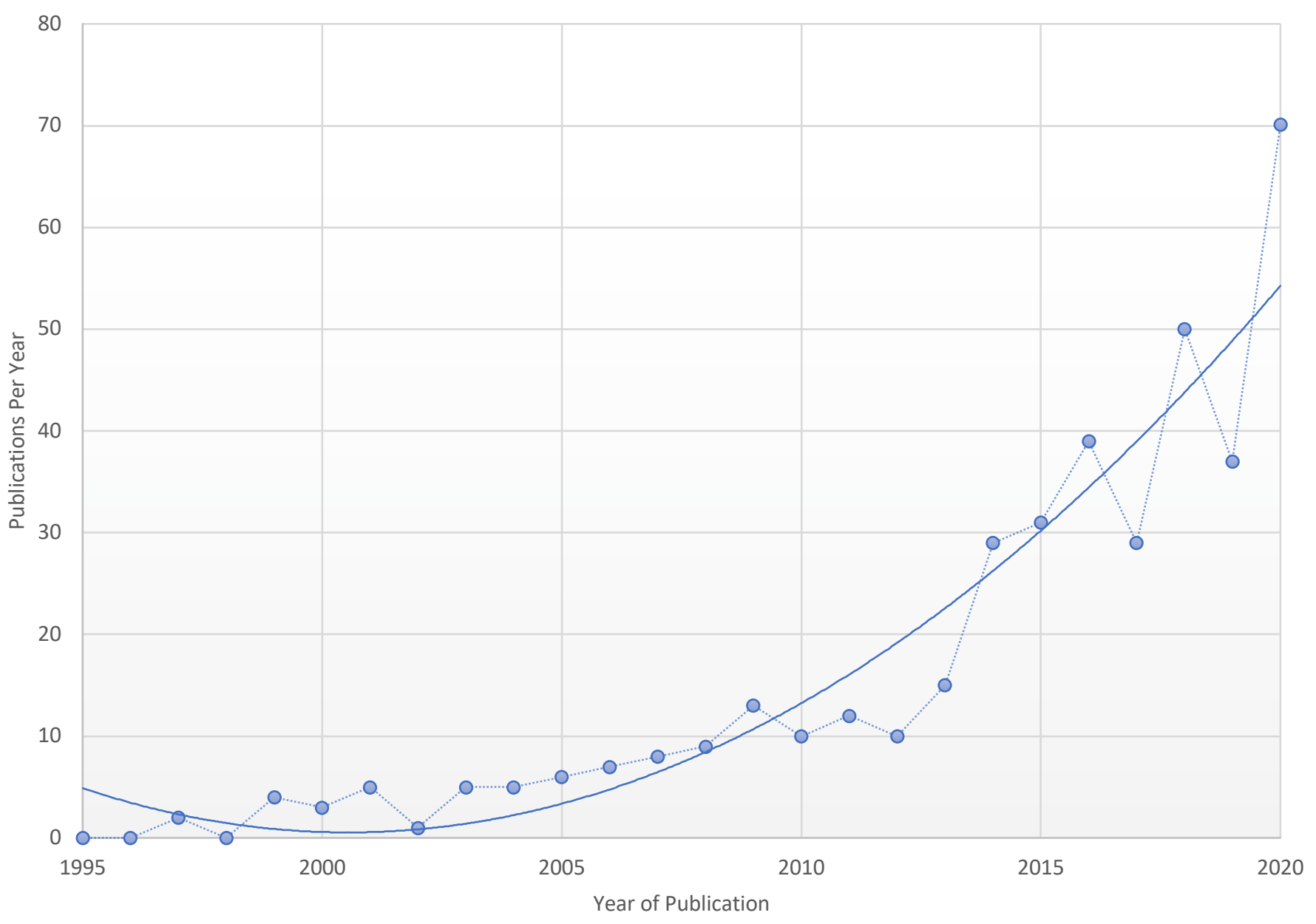

Figure 2. Summary of included publications related to CSB published over the past 25 years. Data point for 2020 estimated by multiplying the count of articles published from January $1^{\text {st }}, 2020$ to August $1^{\text {st }}, 2020$ by 1.71 (1 and 5/7).

\section{Prevalence of CSB}

To date, there have been no epidemiological studies of CSB and few population level studies of CSB. Among population samples, all are limited to Western countries and cultures. Only two of these population samples have examined CSB broadly, with the remainder examining selfperceived addiction to pornography specifically. Below, we summarize these studies in detail.

In 2018, a U.S. national probability survey $(\mathrm{N}=$ 2,325), recruited by KnowledgePanel (GfK Research), found that $10.3 \%$ of men and $7.0 \%$ of women reported at least occasional subjective feelings of distress over difficulty controlling sexual behaviors, impulses, or desires (Dickenson et al., 2018). Of note, that study (Dickenson et al., 2018) found that both sexual and racial minorities were much more likely to report such concerns and were disproportionately represented among positive screens. However, we also note that the measure used for this study (the Compulsive Sexual Behavior Inventory) was developed prior to the proposal or inclusion of the CSBD diagnosis for the ICD-11 and does not fully map onto the diagnostic criteria for the disorder.

Similar rates are also evident in recent samples of the Hungarian population (Böthe, Potenza, et al., 2020). Specifically, in a probability sample of Hungarian participants $(N=473), 5.2 \%$ of men and $3.3 \%$ of women scored above critical cutoff scores on the novel Compulsive Sexual Behavior Disorder Inventory-19, which indicates a high risk of CSBD symptoms. Importantly, analyses of this inventory suggest that up to one quarter of people in this high-risk category may not, in fact, have CSBD. Even with such a reduction, however, prevalence estimates suggest a small but sizable portion of the Hungarian population is likely at risk of CSBD.

Moving beyond CSBs generally, there have been a number of studies of self-perceived addiction to pornography in nationally representative samples. For example, in a nonprobability sample matched to U.S. norms $(N=2,075)$ conducted in 2018 and recruited via Qualtrics Omnibus service, $11 \%$ of men and $3 \%$ of women reported that they at least "somewhat agree" with the statement "I am addicted to 
pornography" (Grubbs, Kraus, et al., 2019). This study also found that the greatest predictors of such agreement were male gender, greater religiousness, greater moral disapproval of pornography, and greater frequency of pornography use. Later re-analysis of this sample (Grubbs, Kraus, et al., 2020) found that moral disapproval of pornography substantially interacted with pornography use to predict self-reports of addiction. That is, use was more strongly related to selfreports of addiction among those that morally disapproved of pornography use than it was among those who did not morally disapprove of such use. Such findings highlight earlier discussed findings regarding the role of moral incongruence in predicting self-reported problematic pornography use. Moreover, these findings suggest that selfreports of CSB in national samples may be influenced by religiosity and morality in ways that may complicate straightforward interpretations of self-reports.

The above findings are consistent with another nonprobability sample matched to U.S. norms (e.g., Sample 4 of Grubbs, Grant, et al., 2019). Specifically, in a sample of adults $(N=1,063)$ in the U.S. recruited via TurkPrime (now known as Cloud Research; Litman et al., 2017), 5.4\% of respondents reported that the statement: "I believe I am addicted to internet pornography" was true of them (Grubbs, Grant, et al., 2019). Subsequent regression analyses found that male gender, moral disapproval of pornography use, and self-reported frequency of use emerged as robust predictors of agreement with that statement. Again, such findings demonstrate that self-reports of CSB in broad-based nationally representative samples are likely to be influenced by morality in ways that may artificially inflate prevalence estimates.

The above findings were further reiterated by another (Grubbs, Lee, et al., 2020) national sample in the U.S., recruited via YouGov America polling and matched to U.S. demographic norms. Somewhat surprisingly, in this sample, $18.3 \%$ of men and $4.7 \%$ of women indicated at least some agreement with the statement "I believe I am addicted to pornography." Additionally, $10.1 \%$ of men and $3.1 \%$ of women obtained a mean score of at least 5 (on a scale of 1-7, where 4 equals "neither agree or disagree") on the Cyber Pornography Use Inventory-4, which measures selfperceived addiction to or compulsivity in pornography use. Importantly, these findings were strongly influenced by the religiousness of participants. Specifically, this work found that religion moderated the relationship between pornography use and self-perceived addiction or selfreported problems. The relationship between pornography use and self-perceived problems was dramatically stronger for more religious participants in comparison with less religious ones.

Similar prevalence rates to the above studies have also been found in nationally representative cross-sections of the Polish population (Lewczuk et al., 2020). In this sample
$(\mathrm{N}=1,036)$, roughly $6 \%$ of lifetime pornography users $(\mathrm{N}=$ $880 ; 55.1 \%$ men; Mage $=43.69, \mathrm{SD}=14.06$ ) indicated at least some agreement with the statement "I am addicted to pornography." Further analysis of this sample reported that only $3 \%$ of women endorsed agreement with such an item, whereas $8.7 \%$ of men did. Importantly, consistent with the above reported studies, these works also found that religiousness and moral incongruence were positively predictive of both self-reported problems with pornography use and self-perceived addiction.

Finally, in a nationally representative sample of the Australian population $(N=20,094)$, among lifetime pornography users, $4.4 \%$ of men and $1.2 \%$ of women reported that they agreed with the statement "You feel that you are addicted to pornography" (Rissel et al., 2017). Importantly, these rates were only among those who reported ever viewing pornography. Subsequent analyses indicated that being male, being between the ages of 16 and 19 or between the ages of 30 and 39, or living in a more rural area were all associated with greater odds of self-reporting such feelings of addiction.

\section{Types of studies.}

Across studies reviewed, we noted a diverse range of methodologies. Below, we summarize those methodologies. Where appropriate, we also highlight key findings.

Non-Clinical, Cross-Sectional Studies. The majority of studies included in the present review made use of non-clinical cross-sectional samples $(60.4 \% ; k=252)$. These samples ranged from college students, to individuals recruited to complete paper-and-pencil surveys at social events, to crowdsourced online samples, to online snowball samples, to population samples recruited to match demographic norms of various regions. Even so, these studies focused on populations with relatively low levels of CSBs and overwhelmingly used survey-based methods and selfreported measures of CSBs to draw inferences about the nature, prevalence, and structure of CSBs.

Clinical and Treatment-Seeking Samples. Among studies included in the present review, 25.2\% $(k=105)$ made use of clinical or treatment seeking samples broadly defined. The majority $(k=65)$ of these studies are cross-sectional in nature, though 19 reported results of neuroscience studies (see below), 4 reported results of neurocognitive testing, 2 were longitudinal in nature, and 15 reported results of treatment efforts (see below). A full summary of crosssectional studies from clinical samples is available in Supplemental Table 2.

Longitudinal Studies. Including treatment outcome studies $(k=15)$, our search identified a number $(k=44)$ of longitudinal studies of CSB. Excluding treatment studies (examined more thoroughly below), these longitudinal studies $(k=29)$ are summarized in Supplemental Table 3. We observed a variety of intervals in longitudinal studies, ranging from as little as one (Noor et al., 2014) or two weeks 
(Fernandez et al., 2017) up to 2.5 years (Kohut \& Stulhofer, 2018), 4 years (Thompson et al., 2015), and 10 years (Skegg et al., 2010).

Among longitudinal studies, few involved more than a single follow-up, with only two papers involving four waves of data collection over a year (Grubbs, Kraus, et al., 2020; Grubbs \& Gola, 2019), one examining five follow-ups over 2.5 years (Kohut \& Stulhofer, 2018), and another examining four waves of data collection over four years (Thompson et al., 2015). These studies are particularly significant as they are the only studies, to date, to use growth curve modeling or latent growth mixture modeling to examine the growth or change in CSBs over time. That is, the above four papers are the only papers identified in our search that actually seek to model trajectories of CSB over time. We also noted that three studies made use of intensive longitudinal methods such as daily diary studies (Grov et al., 2010; Rendina et al., 2018; Wordecha et al., 2018). However, no studies made use of more recent advances in experience sampling, ecological momentary assessment, or ambulatory assessment methods.

Neuroscience studies. Across included studies, we identified 21 studies (5\%) using neuroscience methods, broadly defined. These studies are summarized in Supplemental Table 4. Methods across studies involved structural magnetic resonance imaging among individuals with CSB (Schmidt et al., 2017), functional magnetic resonance imaging among individuals with CSB (e.g., Banca et al., 2016; Gola et al., 2017), and electroencephalograms among individuals with CSB (e.g., Prause et al., 2015). Across neuroimaging studies, the majority of this research seems to be in its nascency, without adequate controls for confounds (e.g. comorbid conditions such as ADHD) and samples consisting of predominantly heterosexual men (for a review, see: Kowalewska et al., 2018).

\section{Cognitive/Experimental/Quasi-Experimental.}

Among studies included in our review, 23 used experimental/quasi-experimental methods to specifically study cognitive and executive functioning aspects of CSBs. Methods included classical conditioning studies (Hoffmann et al., 2014), modified Stroop tasks (Albery et al., 2017), dotprobe tasks (Mechelmans et al., 2014), implicit association tests (Snagowski et al., 2015), and a range of other laboratory based experimental procedures. Full details regarding these studies and their associated experimental paradigms are available in Supplemental Table 5.

\section{Assessments of CSB}

Perhaps not surprisingly, given the heterogeneity of behaviors that comprise CSB and the lack of theoretical unity in conceptualizations of CSB, there is wide discrepancy in the measurement of CSB. Consistent with recent reviews (e.g., Fernandez \& Griffiths, 2019; Grubbs et al., 2017; Hook et al., 2010; Womack et al., 2013), we also found a large number of assessment techniques $(\mathrm{n}=39)$ as measures of
CSB. These results are summarized in Supplemental Table 6. Additionally, we found that $5.3 \%(k=22)$ of studies relied on idiosyncratic measures of CSB, such as single-item measures like "I am addicted to pornography" (e.g., Grubbs, Kraus, et al., 2019; Rissel et al., 2017). Finally, 5.3\% of studies $(k=20)$ provided no details regarding assessment at all, instead noting that the presence of CSBs was confirmed via clinician interview. Although some scales are clearly much more popular than other scales (e.g., the Sexual Compulsivity Scale, $k=140$, Kalichman \& Rompa, 1995; the Hypersexual Behavior Inventory, $k=64$, Reid et al., 2011), the wide variety of scales currently used to measure CSB suggests a domain of study with a lack of clear unifying standards. More details regarding these problems in measurement and the proliferation of redundant measures are available in a number of recent reviews (Fernandez \& Griffiths, 2019; Kohut et al., 2019; Marshall \& Miller, 2019)

\section{Treatment of CSB}

Of the articles reviewed, only $3.5 \%(k=15)$ recounted empirical studies of the treatment of CSB, although many more case studies of treatments do exist (e.g., Gola \& Potenza, 2016; Kraus et al., 2015). We also noted that the majority of articles detailing the treatment of CSBs were conducted in samples that were $100 \%$ men $(k=10 ; 66 \%$ of treatment studies), with an additional two studies that were more than $90 \%$ men, two more being at least $70 \%$ men, and one not reporting gender at all. These studies are summarized in Supplemental Table 7.

Treatment modalities reported across studies were highly variable, with Acceptance and Commitment Therapy based treatments and Cognitive Behavioral Therapy based treatments appearing most often. Of treatment studies, two are reports of the same single pharmacological treatment study (Muench et al., 2007; Savard et al., 2020; Wainberg et al., 2006), one reports an online psychoeducational program (Hardy et al., 2010), and the remainder report, with varying degrees of detail, psychotherapy-based treatment programs. Importantly, only three studies published to date have made use of a double-blind (Wainberg et al., 2006) or randomized control trial (Crosby \& Twohig, 2016; Hallberg et al., 2019) design to evaluate treatment for CSB.

\section{General Discussion}

At the outset of the present work, we set out to conduct a systematic review of empirical research on CSBs that had been published since Gold and Heffner's (1998) review of sex addiction in Clinical Psychology Review. In service of this goal, we reviewed all empirical research related to this topic published since 1995. Importantly, our review was limited to searches concerned with general CSB, cybersex, and pornography use. It is possible that there is additional literature examining other forms of CSB that were not captured by our search terms (i.e., excessive masturbation without pornography; excessive solicitation of sex workers; excessive use of "hook up" apps). However, we believe this 
is generally unlikely, given the breadth of search terms we Accordingly, we believe the results of the present review employed for this work. Below, we discuss the implications of our review for clinical practice and research moving forward.

\section{Clinical Implications}

Despite the lack of large-scale epidemiological work related to CSB, a variety of nationally representative samples conducted in the U.S., Poland, and Australia all suggest that self-perceived problems with CSB are at least as common as other major mental illnesses. Self-perceptions of addiction to pornography range from $1 \%$ of women in Australia (Rissel et al., 2017) up to $11 \%$ of men in the U.S (Grubbs, Kraus, \& Perry, 2019). Similarly, general distress over compulsive, excessive, or seemingly out-of-control sexual behaviors has been reported by $7 \%$ of adult women and $11 \%$ of adult men in the U.S. (Dickenson et al., 2018). Even though none of the above statistics were derived from epidemiological work and all are based on self-reported perceptions of one's own behavior, such numbers suggest that substantial portions of the populace in a number of Western countries are expressing concerns about their ability to regulate their sexual behaviors. Such prevalence is not necessarily proof of the existence of CSBD or confirmation of its utility as a psychiatric diagnosis; however, it does provide growing support for the conclusion that many people feel out-of-control in their sexual behaviors and that clinicians might encounter such problems in practice.

In clinical settings, there is growing evidence that CSBs are relatively common, though representative samples of mental health providers have not yet been examined. For example, in a study of post-deployment U.S. military veterans, results suggested that up to $13.8 \%$ of men and $4.3 \%$ of women report some experiences of CSB (Kraus et al., 2017). Additionally, some studies suggest that CSBs are commonly encountered by mental health providers. Specifically, in a non-representative, snowball sample of mental health providers in the U.S. $(N=183), 39.4 \%$ reported having seen someone with "sex addiction" and 48.8\% percent reported having seen someone with "problematic internet pornography use" (Short et al., 2016). This finding mirrors results from a 2003 survey of mental health providers that found that $65 \%$ of providers had treated internet related problems in their clientele, of which $61 \%$ were related to internet pornography, for a total of $39.6 \%$ of mental health providers who had treated online pornography related problems in 2003 (Mitchell et al., 2005). Of note, in some clinical settings, these estimates are even higher, with a 2015 survey of mental health providers in college counseling centers finding that $84 \%$ of respondents reported treating CSBs, in some form, in the 12 months prior to the survey (Giordano \& Cashwell, 2018).

Given the above estimates of clinical encounters with CSBs, there is a clear need for evidence-based recommendations for front-line mental health providers.

have clinical implications for practitioners. Below, we examine these findings and implications, and provide clear recommendations for further advancement in these domains.

Lack of Treatment Studies. The overarching finding of the present review with regards to the clinical treatment of CSB and related disorders is the paucity of rigorous outcome research using gold-standard approaches such as RCTs Although previous reviews on this topic have concluded that there are some promising treatments for CSB (Dhuffar \& Griffiths, 2015; Hook et al., 2014; Miles et al., 2016), our conclusion from the present review are much more qualified. Specifically, despite almost four decades of clinical attention to the notion of CSB, the current body of research demonstrates little systematic evaluation of treatment for such behaviors. Arguably, this is at least in part due to the novelty of the CSBD diagnosis and the absence of a comparable diagnosis prior to CSBD. We suspect that there is likely an absence of quality treatment studies for CSB because, until recently, there was no formal recognition of such behavior as a mental health disorder. Even so, the lack of empirical treatment studies is quite concerning, particularly for a cluster of behaviors that have been discussed in clinical literature since the 1970s. For a behavioral syndrome or psychiatric disorder to be discussed in clinical literature for roughly four decades without any substantive treatment literature suggests a longstanding history of non-evidence-based treatment delivery.

Consistent with Gold and Heffner's (1998) conclusions over two decades ago, the need for quality, empirically-based treatment continues to be tantamount. As they (p. 379; 1998) stated, "If sexual addiction exists, the benefits to both the individual and society of devising a demonstrably effective treatment protocol could be enormous." At present, the former aspect of this statement is largely settled. That is, an abundance of evidence of literature clearly demonstrates that CSB is a real phenomenon. Though conceptualizations of CSB vary, the existence of a syndrome that matches the criteria defined by the CSBD diagnosis in the ICD-11 is well supported. Even so, there has been no demonstration of an effective treatment protocol for such a syndrome. Currently, the absence of effective treatment protocols for CSBD reflects significant gaps in healthcare for treatment-seeking persons. This gap is somewhat disconcerting given several high-profile treatment facilities have been charging exorbitant prices for residential care yet failing to divert some of these revenues to developing evidence-based protocols for CSB.

Despite our concerns about the current state of the treatment literature, the results of the present review do demonstrate that the treatment of CSBs is an area ready for rigorous treatment studies. Such studies should be evaluated through the use of randomized clinical trials designed to address issues surrounding efficacy and acceptability when 
working with diverse clinical populations. Based on the preliminary studies reviewed, there seems to be some evidence for the continued evaluation of Acceptance and Commitment Therapy based strategies, Cognitive Behavioral Strategies, and pharmacological management in the treatment of CSB. Given the success of such strategies in treating other behavioral addictions (i.e., gambling disorder; Petry et al., 2017), there is cause for cautious optimism for future treatment studies of CSBs and CSBD, particularly if such studies are adequately powered and utilize diverse samples of both men and women, as well as ethnic and sexual minority groups.

Lack of Clinically Validated Assessments. Similar to our above concerns regarding the treatment of CSBs and CSBD, as we noted earlier, there is currently no gold standard assessment for CSB. Several prior reviews have examined such assessments and provided clear recommendations for which assessments show the most promise for clinical utility (e.g., Fernandez \& Griffiths, 2019). Particularly, at present, the Hypersexual Behavior Inventory (HBI) seems to be a well-validated and clinically useful assessment of CSB (Reid et al., 2011). However, the HBI was developed alongside the proposed DSM-5 diagnosis of Hypersexual Disorder and has not yet been fully evaluated in the context of the novel $I C D$ 11 diagnosis of CSBD. Although the diagnoses are quite similar, there are key differences in their conceptualization and symptoms, which suggests that assessments designed for Hypersexual Disorder may not fully capture the symptoms and presentation of CSBD. This concern may be ameliorated by the recent publication of the CSBD-19 inventory (Böthe, Potenza, et al., 2020), as it was developed to specifically match the criteria for CSBD. As such, it is likely a useful measure for clinicians seeking to assess the diagnostic criteria of CSBD. However, this assessment remains quite novel and more time is needed to determine if it becomes widely used by the field.

We also note that a number of recent studies have highlighted the need for precision in the assessment and diagnosis of CSBs, as frequent sexual behaviors may not necessarily be problematic. Specifically, several studies have now documented the possibility for individuals to engage in even high levels of sexual behaviors like pornography use, without adverse consequences (Böthe, Tóth-Király, et al., 2020). Similarly, other studies have found that frequency of pornography use is largely unrelated to sexual dysfunction, even though self-reported problems with pornography use are (Grubbs \& Gola, 2019; Bőthe, et al., 2021; Landripet \& Stulhofer, 2015). Similarly, at least some research suggests that problems associated with pornography use are better accounted for by other variables, such as masturbation frequency (Perry, 2020). Collectively, such findings suggest that assessment of CSBs needs to carefully account for both objective quantity of behavior, as well as subjective distress and more general impairment.
Moral Incongruence and CSB. As we have alluded to at several points in the present review, there is clear evidence that self-perceptions of sexual behaviors are influenced by personal morality and religiousness. This is particularly true of self-perceptions regarding CSBs. Moral and religiously based beliefs about sexual behavior seem to be particularly related to self-perceptions of CSB for many people (Grubbs \& Perry, 2019; Walton, 2019). To date, CSBs are the only addictive or compulsive behavior pattern for which there is a clear body of empirical research suggesting that self-perceptions of addiction/compulsion are driven, in many cases, by personal religiousness or morality. This is not to say that personal morality or religiousness may not similarly influence self-perceptions of other behavioral or substance addictions but rather, religiousness and morality seem especially related to self-perceptions of CSB.

To the credit of the CSBD working group and the World Health Organization, the diagnostic criteria for CSBD make explicit the possibility that morally based distress might present as self-reported CSB or CSBD. Moreover, the criteria make it clear that self-reported distress over sexual behaviors that stems exclusively from moral or religious qualms is not sufficient for a diagnosis of CSBD, even if such distress is impairing. In this regard, as prior works have stated (Grubbs, Kraus, et al., 2020; Grubbs, Lee, et al., 2020), if mental health professionals remain faithful to the diagnostic criteria for CSBD, the possibility of misdiagnosis should be dramatically lessened. However, as we explore below, there is also evidence that religious/moral values may cloud clinician judgment in the assessment or treatment of $\mathrm{CSBs} / \mathrm{CSBD}$. Additional research seeking to identify clinicians' misperceptions toward CSBD diagnosis should be explored, particularly as it applies to groups where misdiagnosis may occur (e.g., ethnic and sexual minorities, highly religious/devout individuals).

Possibility of Therapeutic Bias. We also note that the present review suggests the possibility of therapeutic bias in the assessment and treatment of CSB. Specifically, there is evidence that both client and therapist individual differences might influence the application of the CSBD diagnosis. This finding is hardly novel, as work from the late 1990s noted that sex addiction was a more commonly used diagnosis among religious therapists (Hecker et al., 1995). Similarly, much more recent work has found that religious social workers are more likely to see sexual behaviors as addictive or compulsive (Droubay \& Butters, 2019). Taken with the above reviewed findings about individual religiosity and morality often contributing to feelings of addiction or compulsivity in sexual behaviors, these findings suggest that therapists need to be particularly self-aware of how personal beliefs and values might influence their conceptualizations of clients. Such a statement - that therapists should be aware of how their personal beliefs influence diagnosis and treatment - is not limited to the treatment of CSBs or CSBD. 
All therapeutic endeavors likely involve self-awareness with paraphilic CSBs without much regard for the specific regards to personal biases. However, $\mathrm{CSBs} / \mathrm{CSBD}$ are an area theoretical and etiological implications of such terms. that might be particularly prone to such biases, and mental Perhaps more concerningly, a large number of studies seem health professionals should be aware of such a possibility as they seek to assess and treat clients reporting issues with CSB.

We further note that recent research suggests that therapists might allow other aspects of client identity to shape their assessment and treatment of clients presenting with excessive sexual behaviors. Specifically, in a study of mental health professionals, participants were more likely to view sexual behaviors as compulsive or pathologically excessive in heterosexual men and women than they were in gay men or women (Klein et al., 2019). This tendency was documented, even though all other aspects of clinical presentation were held constant. In other words, clinical evaluations were influenced strongly by whether or not a client identified as a sexual minority, with many therapists expecting these individuals to be naturally more compulsive. Such a finding is concerning, particularly in light of the new CSBD diagnosis. More research is needed examining the influence of gender and sex roles (i.e., heteronormativity) on clinicians' attributions when determining the appropriateness of CSBD diagnosis for a client.

\section{Research Implications}

Beyond the clinical implications of the current body of literature, there are clear implications for current and ongoing programs of research related to this topic. Many of the below implications and critiques may be largely secondary to the absence of clear diagnostic recognition of and criteria for CSB and may naturally improve with the recent inclusion of CSBD in the ICD-11. However, the current state of empirical literature does lead to the following clear conclusions.

Lack of Theoretical Integration. Psychological science broadly (Muthukrishna \& Henrich, 2019) and clinical psychological science specifically (Borsboom, 2013; Borsboom et al., 2019) suffer from a lack of strong unifying theoretical frameworks that are essential characteristics of a mature science. Accordingly, it is not surprising that CSBrelated research similarly lacks a strong theoretical underpinning. Yet, even by the standards of psychological science, current theoretical understandings of CSB are particularly underdeveloped.

Despite our decision to review all literature falling under the general umbrella of CSB, our work found little consistency in the definition, classification, and theoretical conception of CSB. As alluded to earlier, a number of studies conceptualized CSB as an impulse control disorder, whereas others consider it to be an addictive disorder, and still others refer to it as simply an issue of compulsivity. In most cases, as past works have noted (Reid \& Grant, 2017), it seems terms are entirely interchangeable in their use, with various research groups using diverse terms to encompass nonto approach CSB without any regard for its theoretical underpinnings at all. That is, many studies do not even address whether or not CSBs are best characterized as issues of addiction, impulsivity, or compulsivity or seek to frame CSB within larger frameworks for understanding of psychopathology and mental illness. Although some exceptions to this exist (e.g., network models of CSB; Böthe, Lonza, et al., 2020), there is still a paucity of research seeking to integrate understandings of CSB into larger theoretical frameworks.

The authors of the present review have, in the past, repeatedly noted that there is currently a lack of evidence to conclude that CSB is an addictive disorder (Kowalewska et al., 2018; Kraus et al., 2016; Potenza et al., 2017; Reid, 2016; Reid \& Grant, 2017). The present review is no exception to that conclusion. Regrettably, despite past assertions that there is a need for programmatic research testing the best theoretical understandings of non-paraphilic CSB, virtually no such research exists. In order for CSB-related research to make substantive advances in the coming years, there must be sustained efforts to systematically study the psychological, social, environmental, and neurocognitive mechanisms underlying the disorder. This type of research will likely involve high-quality epidemiological studies, long term longitudinal research, intensive longitudinal methods (i.e., ecological momentary assessment; ambulatory assessment), and larger scale neuroscientific research. More importantly, however, such approaches should be conducted in a cumulative manner, with diverse research groups seeking to build on past findings instead of simply attempting to conduct such research in isolation.

CSB related research needs to move past its veritable hodge-podge of conceptualizations and seemingly random use of terminology and move toward systematic attempts to develop a strong theoretical understanding of CSBs and related syndromes. Such a systematic approach would allow for robust research efforts to examine the environmental, psychosocial, and neurobiological underpinnings of CSBD and provide important insights for the development of effective treatments (e.g., psychotherapy, pharmacotherapy) for affected persons. It is beyond the scope of the present review to propose or evaluate what such a strong theoretical understanding of CSB might look like, but it is abundantly clear that such theoretical organization is needed to substantively move understandings of CSB forward. Recent attempts at such an understanding of CSB, such as the Dual Control Model and Sexual Tipping Point Model (e.g., Briken, 2020) may serve to fill this need, as might other proposed theoretical models (e.g., the Sexhavior Cycle, Walton et al., 2017). Additionally, recent theoretical and empirical models for understanding psychopathology 
broadly may be of use too (i.e., Network Theory of Mental behavior may vary based on a range of individual and cultural Disorders; Borsboom, 2017; Borsboom et al., 2019; Hierchical Taxonomy of Psychopathology; Kotov et al., 2017).

differences, which may complicate efforts to both define and assess CSBs.

Although the diagnosis of CSBD, by design,

The Role of Neuroscience. As reviewed above, neuroscientific studies of CSB remain in their infancy. Given the lack of diagnostic recognition for CSB until recent years, this is to be expected, and we do expect this research to expand substantially in the near future. However, we also note that, while neuroimaging is often given special status in scientific research, imaging technology is an instrument that is subject to many of the same limitations, measurement errors, and challenges with interpretation common among traditional measures used in the field of psychological research (Button et al., 2013; Elliott et al., 2020; Fröhner et al., 2019). There are also concerns in the field of imaging research that many studies are being conducted with small sample sizes which raises some challenges for imaging research among individuals with CSB that need to be addressed (Szucs \& Ioannidis, 2019; Turner, Paul, Miller, \& Barbey, 2018). Insofar as the fields of addiction, impulsivity, and compulsivity are still evolving (along with their operationalized measures), it is difficult for neuroimaging to elucidate the most parsimonious conceptualization of CSB, including questions related to how CSB might best be classified (e.g., addiction, compulsion, impulse control disorder). Nevertheless, as the field continues to grow, neuroimaging will help highlight possible neurobiological mechanisms implicated in patterns of CSB, brain-behavior relationships, and their associated features. In short, we advocate for the use of neuroscience as an important component of systematic research into $\mathrm{CSB}$, rather than as being seen as a definitive ruling on the nature of CSB.

Definition and Assessment. Building on the above problems with theoretical understandings of CSBs, existing literature on CSB seems to lack any semblance of consistency with regards to the definition of what behaviors and symptoms constitute CSB. In some regards, this is to be expected, given that diagnostic recognition of CSBD only occurred recently and the proposed criteria for CSBD were only made public shortly before that. Even so, this inconsistency within the literature has hampered the advancement of the field. At present, a study purporting to measure CSB might refer to slightly elevated rates of pornography use, excessive use of sexual "hook-up" applications, or compulsive solicitation of sex workers. More concerningly, studies of CSB often do not specify at all what behaviors are of interest in the sample being described, instead focusing entirely on self-reported feelings of being out-of-control. We also note that there is at least some evidence that behaviors that are problematic for one individual might be wholly unproblematic for another individual (Grubbs, Lee, et al., 2020). In short, it seems likely that what is considered a compulsive or problematic sexual encompasses a range of sexual behaviors, a lack of consistency in describing the behaviors that warrant the diagnosis makes it exceedingly difficult to systematically evaluate the presence, presentation, and associates of CSBs or to articulate if different presentations of CSB warrant different clinical approaches. For example, differences in clinical presentations with CSBD patients may require further refinement of treatment approaches for patients, particularly for individuals engaging in high risk sexual behaviors (e.g., condomless sex with paid sex workers or casual sexual partners) or those who have co-occurring psychiatric disorders (e.g., substance use, trauma). Yet, given the lack of consistency in prior literature, it is not known whether such a supposition is true. More simply, definitional and assessment inconsistencies have hampered evidencebased treatment recommendations.

A consolidation of definitions for CSB and the assessments of CSB is a necessary pre-requisite for future research in this domain. Although the systematic evaluation of various definitions and models of CSB is an important domain of research that merits continued investment, the adoption of a standard definition of CSB is necessary if researchers seeking to study CSB want to develop this field into a mature science. The inclusion of CSBD in the ICD-11 offers a unique opportunity to accomplish this aim. That is, given the diagnostic recognition of CSBD, there is now a standard diagnostic framework that can be used to develop more consistent definitions for CSB itself and behavior specific forms of CSB (i.e., compulsive pornography use; compulsive masturbation).

Flowing from the above inconsistencies in definitions, alongside the seeming exponential growth of studies related to CSB over the past two decades, there has also been a proliferation of assessments related to CSB and similar phenomena. As has been highlighted in numerous past reviews (Duffy et al., 2016; Fernandez \& Griffiths, 2019; Kohut et al., 2019; Marshall \& Miller, 2019), there is inconsistency with regards to how constructs related to CSB are defined and measured by such assessments. That is, at present, there are few, if any, well-validated measures of CSB that have been clearly tested and validated across a range of methodologies and samples (Grubbs et al., 2017).

Rather than attempting to shoehorn conceptualizations of CSB or CSBD into past assessments (for example, see: Carnes et al., 2014), there is a need for research that methodically tests new assessments in a variety of diverse samples and settings against the criteria for CSBD, as the novel CSBD-19 has done quite well (Böthe, Potenza, et al., 2020). Some existing measures also seem particularly well-poised for such evaluation. The widely used HBI-19 
(Reid et al., 2011) has been extensively tested in both clinical The results of the present review clearly demonstrate that at and non-clinical populations and translated into several least some of these goals have been realized. Over the past languages for administration (Ballester-Arnal et al., 2019; Bothe et al., 2019). Similarly, the Brief Pornography Screen (Kraus et al., 2020) has been tested in nationally representative samples in both the United States (Grubbs, Lee, et al., 2020) and Poland (Lewczuk et al., 2020), as well as in treatment seeking samples in Poland and in clinical samples in the United States (Kraus et al., 2020). We also note that one recent review (Fernandez \& Griffiths, 2019) concluded that the Problematic Pornography Consumption Scale (Böthe et al., 2018) and the Problematic Pornography Use Scale (Kor et al., 2014) are both well-validated measures of PPU.

Rigorous Research Design. Finally, we note that there is a need for more rigorous research design in the study of CSB. At present, most CSB research is in cross-sectional samples of non-clinical populations. Although such research may provide information about CSBs in a variety of groups, such research designs preclude any substantive causal, mechanistic, or predictive inferences. Moreover, despite the fact that at least five studies of CSB have used samples matched to various population norms, there has been no true epidemiological research related to CSB conducted in the United States or elsewhere. This has prevented any substantive conclusions being drawn on the true prevalence of CSB in any population, or the psychiatric, social, cultural, or economic factors that characterize CSB. Based on the above problems, there is a clear and ongoing need for rigorous longitudinal research, systematic epidemiological research, and continued research in clinical and treatment seeking samples.

\section{Conclusions}

We began the present review by noting the primary conclusions of Gold and Heffner's (1998) work in Clinical Psychological Review about the nature of "sexual addiction." Chiefly, they found that the majority of work related to "sexual addiction" was based on theoretical conjecture and limited case observations. As evidenced by the present work, this criticism of the field is no longer universally true. In the past two decades, empirical research into the nature of CSB has increased at an accelerating rate, and there is clear evidence that CSB is a real phenomenon with clinical implications.

Importantly, we note that the rapid acceleration of research into this domain will likely only increase with the recognition of CSBD in the ICD-11. Indeed, as is evidenced in Figure 1, the projected number of publications on CSBs for the year 2020 will likely exceed any prior year. In their work, Gold and Heffner concluded that, "Only with the execution of controlled empirical research on etiology, symptom patterns, course, related difficulties and their consequences, and treatment, is our knowledge base in this area likely to substantially move forward" (1998, p. 379). twenty-five years, research into "sexual addiction" has proliferated immensely. In the present study alone, we reviewed 415 empirical studies of compulsive, impulsive, or excessive sexual behaviors that may rightly fall under the greater umbrella of "sexual addiction." Moreover, despite the impressive rise in research in this domain, the inclusion of CSBD in the $I C D-11$ is likely to spur accelerating expansion of research in this domain. Yet, despite these advances, research related to "sexual addiction" remains in its infancy. A lack of theoretical integration, deficits in methodological rigor, a paucity of clinical samples, over reliance on convenience samples (i.e., university students or Mechanical Turk samples), the complete absence of epidemiological studies, widespread inconsistencies in the definitions and measurements of CSB, and a lack of treatment studies all still plague the literature related to "sexual addiction." If scientists, researchers, and clinicians in this domain want to bring the field forward and provide evidence-based care to people who report out-of-control sexual behaviors, all of the above are needed.

References
Albery, I. P., Lowry, J., Frings, D., Johnson, H. L., Hogan,
C., \& Moss, A. C. (2017). Exploring the
Relationship between Sexual Compulsivity and
Attentional Bias to Sex-Related Words in a Cohort
of Sexually Active Individuals. European Addiction
Research, 23(1), 1-6.
https://doi.org/10.1159/000448732

Antons, S., Mueller, S. M., Wegmann, E., Trotzke, P., Schulte, M. M., \& Brand, M. (2019). Facets of impulsivity and related aspects differentiate among recreational and unregulated use of Internet pornography. Journal of Behavioral Addictions, $8(2), 223-233$. https://doi.org/10.1556/2006.8.2019.22

Ballester-Arnal, R., Castro Calvo, J., Gil-Llario, M. D., \& Gil-Julia, B. (2017). Cybersex Addiction: A Study on Spanish College Students. Journal of Sex \& Marital Therapy, 43(6), 567-585. https://doi.org/10.1080/0092623X.2016.1208700

Ballester-Arnal, R., Castro-Calvo, J., Gil-Julia, B., Gimenez-Garcia, C., \& Gil-Llario, M. D. (2019). A Validation Study of the Spanish Version of the Hypersexual Behavior Inventory (HBI): Paper-andPencil Versus Online Administration. Journal of Sex \& Marital Therapy, 45(4), 283-302. https://doi.org/10.1080/0092623X.2018.1518886

Banca, P., Morris, L. S., Mitchell, S., Harrison, N. A., Potenza, M. N., \& Voon, V. (2016). Novelty, conditioning and attentional bias to sexual rewards. Journal of Psychiatric Research, 72, 91-101. 
Borsboom, D. (2013). Theoretical Amnesia. http://osc.centerforopenscience.org/2013/11/20/theo retical-amnesia/

Borsboom, D. (2017). A network theory of mental disorders. World Psychiatry, 16(1), 5-13. https://doi.org/10.1002/wps.20375

Borsboom, D., Cramer, A. O. J., \& Kalis, A. (2019). Brain disorders? Not really: Why network structures block reductionism in psychopathology research. Behavioral and Brain Sciences, 42, e2. https://doi.org/10.1017/S0140525X17002266

Bőthe, B., Kovacs, M., Tóth-Király, I., Reid, R. C., Griffiths, M. D., Orosz, G., \& Demetrovics, Z. (2019). The Psychometric Properties of the Hypersexual Behavior Inventory Using a LargeScale Nonclinical Sample. Journal of Sex Research, 56(2), 180-190. https://doi.org/10.1080/00224499.2018.1494262

Böthe, B., Lonza, A., Štulhofer, A., \& Demetrovics, Z. (2020). Symptoms of Problematic Pornography Use in a Sample of Treatment Considering and Treatment Non-Considering Men: A Network Approach. The Journal of Sexual Medicine. https://doi.org/10.1016/j.jsxm.2020.05.030

Böthe, B., Potenza, M. N., Griffiths, M. D., Kraus, S. W., Klein, V., Fuss, J., \& Demetrovics, Z. (2020). The development of the Compulsive Sexual Behavior Disorder Scale (CSBD-19): An ICD-11 based screening measure across three languages. Journal of Behavioral Addictions, 9(2), 247-258. https://doi.org/10.1556/2006.2020.00034

Bőthe, B., Tóth-Király, I., Griffiths, M. D., Potenza, M. N., Orosz, G., \& Demetrovics, Z. (2021). Are sexual functioning problems associated with frequent pornography use and/or problematic pornography use? Results from a large community survey including males and females. Addictive Behaviors, 112, 106603.

https://doi.org/10.1016/j.addbeh.2020.106603

Bőthe, B., Tóth-Király, I., Potenza, M. N., Orosz, G., \& Demetrovics, Z. (2020). High-Frequency Pornography Use May Not Always Be Problematic. The Journal of Sexual Medicine. https://doi.org/10.1016/j.jsxm.2020.01.007

Bőthe, B., Tóth-Király, I., Zsila, Á., Griffiths, M. D., Demetrovics, Z., \& Orosz, G. (2018). The Development of the Problematic Pornography Consumption Scale (PPCS). The Journal of Sex Research, 55(3), 395-406. https://doi.org/10.1080/00224499.2017.1291798

Bőthe, B., Vaillancourt-Morel, M.-P., Bergeron, S., \& Demetrovics, Z. (2019). Problematic and NonProblematic Pornography Use Among LGBTQ Adolescents: A Systematic Literature Review.
Current Addiction Reports, 6(4), 478-494. https://doi.org/10.1007/s40429-019-00289-5

Briken, P. (2020). An integrated model to assess and treat compulsive sexual behaviour disorder. Nature Reviews Urology, 17(7), 391-406. https://doi.org/10.1038/s41585-020-0343-7

Burke, K., \& Haltom, T. (2020). Created by god and wired to porn: Redemptive masculinity and gender beliefs in narratives of religious men's pornography addiction recovery. Gender \& Society, (in press).

Burke, K., \& MillerMacPhee, A. (2020). Constructing Pornography Addiction's Harms in Science, News Media, and Politics. Social Forces, soaa035. https://doi.org/10.1093/sf/soaa035

Button, K. S., Ioannidis, J. P., Mokrysz, C., Nosek, B. A., Flint, J., Robinson, E. S., \& Munafò, M. R. (2013). Power failure: Why small sample size undermines the reliability of neuroscience. Nature Reviews Neuroscience, 14(5), 365-376.

Byers, L. J., Menzies, K. S., \& O’Grady, W. L. (2004). The impact of computer variables on the viewing and sending of sexually explicit material on the internet: Testing Cooper's “Triple-A Engine." Canadian Journal of Human Sexuality, 13(3/4), 157-169.

Cantor, J. M., Klein, C., Lykins, A., Rullo, J. E., Thaler, L., \& Walling, B. R. (2013). A treatment-oriented typology of self-identified hypersexuality referrals. Archives of Sexual Behavior, 42(5), 883-893. https://doi.org/10.1007/s10508-013-0085-1

Carnes, P. J. (1983). Out of the shadows: Understanding sexual addiction. CompCare Publications.

Carnes, P. J., Hopkins, T. A., \& Green, B. A. (2014). Clinical Relevance of the Proposed Sexual Addiction Diagnostic Criteria: Relation to the Sexual Addiction Screening Test-Revised. Journal of Addiction Medicine, 8(6), 450-461. https://doi.org/10.1097/ADM.0000000000000080

Carvalheira, A., \& Gomes, F. A. (2003). Cybersex in Portuguese Chatrooms: A Study of Sexual Behaviors Related to Online Sex. Journal of Sex \& Marital Therapy, 29(5), 345-360. psyh. https://doi.org/10.1080/00926230390224729

Cavaglion, G. (2008). Voices of coping in an Italian selfhelp virtual community of cyberporn dependents. CyberPsychology \& Behavior, 11(5), 599-601. https://doi.org/10.1089/cpb.2007.0204

Cavaglion, G. (2009). Cyber-porn dependence: Voices of distress in an italian Internet self-help community. International Journal of Mental Health and Addiction, 7(2), 295-310. https://doi.org/10.1007/s11469-008-9175-z

Coleman, E. (1991). Compulsive Sexual Behavior. Journal of Psychology \& Human Sexuality, 4(2), 37-52. https://doi.org/10.1300/J056v04n02_04 
Coleman, E. (1992). Is Your Patient Suffering from Compulsive Sexual Behavior? Psychiatric Annals, 22(6), 320-325. https://doi.org/10.3928/0048-571319920601-09

Cooper, A. (1998). Sexuality and the Internet: Surfing into the new millennium. CyberPsychology \& Behavior, 1(2), 187-193. https://doi.org/10.1089/cpb.1998.1.187

Cooper, A., Delmonico, D. L., \& Burg, R. (2000). Cybersex users, abusers, and compulsives: New findings and implications. Sexual Addiction \& Compulsivity, 7(1-2), 5-29. https://doi.org/10.1080/10720160008400205

Cooper, A., McLoughlin, I. P., \& Campbell, K. M. (2000). Sexuality in cyberspace: Update for the $21 \mathrm{st}$ century. CyberPsychology \& Behavior, 3(4), 521536. https://doi.org/10.1089/109493100420142

Cooper, A., Putnam, D. E., Planchon, L. A., \& Boies, S. C. (1999). Online sexual compulsivity: Getting tangled in the net. Sexual Addiction \& Compulsivity, 6(2), 79-104. https://doi.org/10.1080/10720169908400182

Cooper, A., Scherer, C. R., Boies, S. C., \& Gordon, B. L. (1999). Sexuality on the Internet: From sexual exploration to pathological expression. Professional Psychology: Research and Practice, 30(2), 154.

Crosby, J. M., \& Twohig, M. P. (2016). Acceptance and Commitment Therapy for Problematic Internet Pornography Use: A Randomized Trial. Behavior Therapy, 47(3), 355-366. https://doi.org/10.1016/j.beth.2016.02.001

de Alarcón, R., de la Iglesia, J. I., Casado, N. M., \& Montejo, A. L. (2019). Online Porn Addiction: What We Know and What We Don't-A Systematic Review. Journal of Clinical Medicine, 8(1), 91. https://doi.org/10.3390/jcm8010091

de Tubino Scanavino, M., Ventuneac, A., Abdo, C. H. N., Tavares, H., do Amaral, M. L. S., Messina, B., dos Reis, S. C., Martins, J. P. L. B., \& Parsons, J. T. (2013). Compulsive sexual behavior and psychopathology among treatment-seeking men in Sao Paulo, Brazil. Psychiatry Research, 209(3), 518-524.

https://doi.org/10.1016/j.psychres.2013.01.021

Delmonico, D. L. (1997). Cybersex: High tech sex addiction. Sexual Addiction \& Compulsivity, 4(2), 159-167.

https://doi.org/10.1080/10720169708400139

Delmonico, D. L. (2002). Sex on the Superhighway. In P. J. Carnes \& K. Adams (Eds.), Clinical management of sex addiction (pp. 239-254). Brunner-Routledge.

Delmonico, D. L., \& Carnes, P. J. (1999). Virtual sex addiction: When cybersex becomes the drug of choice. Cyberpsychology \& Behavior : The Impact of the Internet, Multimedia and Virtual Reality on Behavior and Society, 2(5), 457-463. https://doi.org/10.1089/cpb.1999.2.457

Delmonico, D. L., \& Miller, J. (2003). The Internet Sex Screening Test: A comparison of sexual compulsives versus non-sexual compulsives. Sexual and Relationship Therapy, 18(3), 261-276. https://doi.org/10.1080/1468199031000153900

Dhuffar, M. K., \& Griffiths, M. D. (2015). A Systematic Review of Online Sex Addiction and Clinical Treatments Using CONSORT Evaluation. Current Addiction Reports, 2(2), 163-174. https://doi.org/10.1007/s40429-015-0055-x

Dickenson, J. A., Gleason, N., Coleman, E., \& Miner, M. H. (2018). Prevalence of distress associated with difficulty controlling sexual urges, feelings, and behaviors in the united states. JAMA Network Open, l(7), e184468. https://doi.org/10.1001/jamanetworkopen.2018.446 8

Droubay, B. A., \& Butters, R. P. (2019). Pornography, religiosity, and social work. Journal of Social Work, 1468017319852599. https://doi.org/10.1177/1468017319852599

Duffy, A., Dawson, D. L., \& das Nair, R. (2016). Pornography Addiction in Adults: A Systematic Review of Definitions and Reported Impact. The Journal of Sexual Medicine, 13(5), 760-777. https://doi.org/10.1016/j.jsxm.2016.03.002

Efrati, Y. (2020). Problematic and Non-problematic Pornography Use and Compulsive Sexual Behaviors Among Understudied Populations: Children and Adolescents. Current Addiction Reports, 7(1), 68-75. https://doi.org/10.1007/s40429-020-00300-4

Efrati, Y., Shukron, O., \& Epstein, R. (2019). Compulsive sexual behavior and sexual offending: Differences in cognitive schemas, sensation seeking, and impulsivity. Journal of Behavioral Addictions, 8(3), 432-441. https://doi.org/10.1556/2006.8.2019.36

Elliott, M. L., Knodt, A. R., Ireland, D., Morris, M. L., Poulton, R., Ramrakha, S., Sison, M. L., Moffitt, T. E., Caspi, A., \& Hariri, A. R. (2020). What Is the Test-Retest Reliability of Common Task-Functional MRI Measures? New Empirical Evidence and a Meta-Analysis. Psychological Science, 095679762091678.

https://doi.org/10.1177/0956797620916786

Fernandez, D. P., \& Griffiths, M. D. (2019). Psychometric Instruments for Problematic Pornography Use: A Systematic Review. Evaluation \& the Health Professions, 163278719861688. https://doi.org/10.1177/0163278719861688 
Fernandez, D. P., Tee, E. Y. J., \& Fernandez, E. F. (2017). Do Cyber Pornography Use Inventory-9 scores reflect actual compulsivity in internet pornography use? Exploring the role of abstinence effort. Sexual Addiction \& Compulsivity, 24(3), 156-179. https://doi.org/10.1080/10720162.2017.1344166

First, M. B., Reed, G. M., Hyman, S. E., \& Saxena, S. (2015). The development of the ICD-11 Clinical Descriptions and Diagnostic Guidelines for Mental and Behavioural Disorders. World Psychiatry, 14(1), 82-90. https://doi.org/10.1002/wps.20189

Fröhner, J. H., Teckentrup, V., Smolka, M. N., \& Kroemer, N. B. (2019). Addressing the reliability fallacy in fMRI: Similar group effects may arise from unreliable individual effects. NeuroImage, 195, 174-189. https://doi.org/10.1016/j.neuroimage.2019.03.053

Fuss, J., Lemay, K., Stein, D. J., Briken, P., Jakob, R., Reed, G. M., \& Kogan, C. S. (2019). Public stakeholders' comments on ICD-11 chapters related to mental and sexual health. World Psychiatry, 18(2), 233-235. https://doi.org/10.1002/wps.20635

Giordano, A. L., \& Cashwell, C. S. (2018). An Examination of College Counselors' Work With Student Sex Addiction: Training, Screening, and Referrals. Journal of College Counseling, 21(1), 43-57. https://doi.org/10.1002/jocc.12086

Gola, M., \& Potenza, M. N. (2016). Paroxetine Treatment of Problematic Pornography Use: A Case Series. Journal of Behavioral Addictions, 5(3), 529-532. https://doi.org/10.1556/2006.5.2016.046

Gola, M., Wordecha, M., Sescousse, G., Lew-Starowicz, M., Kossowski, B., Wypych, M., Makeig, S., Potenza, M. N., \& Marchewka, A. (2017). Can Pornography be Addictive? An fMRI Study of Men Seeking Treatment for Problematic Pornography Use. Neuropsychopharmacology, 42(10), 20212031. https://doi.org/10.1038/npp.2017.78

Gold, S. N., \& Heffner, C. L. (1998). Sexual addiction: Many conceptions, minimal data. Clinical Psychology Review, 18(3), 367-381. https://doi.org/10.1016/S0272-7358(97)00051-2

Goodman, A. (1992). Sexual Addiction: Designation and Treatment. Journal of Sex \& Marital Therapy, 18(4), 303-314. https://doi.org/10.1080/00926239208412855

Griffin, B. J., Worthington, E. L., Leach, J. D., Hook, J. N., Grubbs, J. B., Exline, J. J., \& Davis, D. E. (2016). Sexual congruence moderates the associations of hypersexual behavior with spiritual struggle and sexual self-concept. Sexual Addiction \& Compulsivity, 23(2-3), 279-295. https://doi.org/10.1080/10720162.2016.1150924
Grov, C., Golub, S. A., Mustanski, B., \& Parsons, J. T. (2010). Sexual compulsivity, state affect, and sexual risk behavior in a daily diary study of gay and bisexual men. Psychology of Addictive Behaviors : Journal of the Society of Psychologists in Addictive Behaviors, 24(3), 487-497. https://doi.org/10.1037/a0020527

Grubbs, J. B., \& Gola, M. (2019). Is pornography use related to erectile functioning? Results from crosssectional and latent growth curve analyses. The Journal of Sexual Medicine, 16(1), 111-125. https://doi.org/10.1016/j.jsxm.2018.11.004

Grubbs, J. B., Grant, J. T., \& Engelman, J. (2019). Selfidentification as a pornography addict: Examining the roles of pornography use, religiousness, and moral incongruence. Sexual Addiction \& Compulsivity, 25(4), 269-292. https://doi.org/10.1080/10720162.2019.1565848

Grubbs, J. B., Hook, J. N., Griffin, B. J., Penberthy, J. K., \& Kraus, S. W. (2017). Clinical assessment and diagnosis of sexual addiction. In T. Birchard \& J. Benfield (Eds.), Routledge International Handbook of Sexual Addiction (1 edition). Routledge.

Grubbs, J. B., Kraus, S. W., \& Perry, S. L. (2019). Selfreported addiction to pornography in a nationally representative sample: The roles of use habits, religiousness, and moral incongruence. Journal of Behavioral Addictions, 8(1), 88-93. https://doi.org/10.1556/2006.7.2018.134

Grubbs, J. B., Kraus, S. W., Perry, S. L., Lewczuk, K., \& Gola, M. (2020). Moral incongruence and compulsive sexual behavior: Results from crosssectional interactions and parallel growth curve analyses. Journal of Abnormal Psychology, 129(3), 266-278. https://doi.org/10.1037/abn0000501

Grubbs, J. B., Lee, B. N., Hoagland, K. C., Kraus, S. W., \& Perry, S. L. (2020). Addiction or transgression? Moral incongruence and self-reported problematic pornography use in a nationally representative sample. Clinical Psychological Science, online first. https://doi.org/10.1177/2167702620922966

Grubbs, J. B., \& Perry, S. L. (2019). Moral incongruence and pornography use: A critical review and integration. Journal of Sex Research, 56(1), 29-37. https://doi.org/10.1080/00224499.2018.1427204

Grubbs, J. B., Perry, S. L., Wilt, J. A., \& Reid, R. C. (2019). Pornography problems due to moral incongruence: An integrative model with a systematic review and meta-analysis. Archives of Sexual Behavior, 48(2), 397-415. https://doi.org/10.1007/s10508-018-1248$\mathrm{x}$

Grubbs, J. B., Wright, P. J., Braden, A. L., Wilt, J. A., \& Kraus, S. W. (2019). Internet pornography use and sexual motivation: A systematic review and 
integration. Annals of the International

Communication Association, 43(2), 117-155. https://doi.org/10.1080/23808985.2019.1584045

Hallberg, J., Kaldo, V., Arver, S., Dhejne, C., Jokinen, J., \& Oberg, K. G. (2019). A Randomized Controlled Study of Group-Administered Cognitive Behavioral Therapy for Hypersexual Disorder in Men. The Journal of Sexual Medicine, 16(5), 733-745. https://doi.org/10.1016/j.jsxm.2019.03.005

Hardy, S. A., Ruchty, J., Hull, T. D., \& Hyde, R. (2010). A Preliminary Study of an Online Psychoeducational Program for Hypersexuality. Sexual Addiction \& Compulsivity, 17(4), 247-269. https://doi.org/10.1080/10720162.2010.533999

Hecker, L. L., Trepper, T. S., Wetchler, J. L., \& Fontaine, K. L. (1995). The influence of therapist values, religiosity and gender in the initial assessment of sexual addiction by family therapists. The American Journal of Family Therapy, 23(3), 261-272. https://doi.org/10.1080/01926189508251356

Hoffmann, H., Goodrich, D., Wilson, M., \& Janssen, E. (2014). The role of classical conditioning in sexual compulsivity: A pilot study. Sexual Addiction \& Compulsivity, 21(2), 75-91. https://doi.org/10.1080/10720162.2014.895460

Hook, J. N., Farrell, J. E., Davis, D. E., Tongeren, D. R. V., Griffin, B. J., Grubbs, J. B., Penberthy, J. K., \& Bedics, J. D. (2015). Self-forgiveness and hypersexual behavior. Sexual Addiction \& Compulsivity, 22(1), 59-70. https://doi.org/10.1080/10720162.2014.1001542

Hook, J. N., Farrell, J. E., Ramos, M. J., Davis, D. E., Karaga, S., Tongeren, D. R. V., \& Grubbs, J. B. (2015). Religiousness and congruence between sexual values and behavior. Journal of Psychology and Christianity, 34(2), 179-189.

Hook, J. N., Hook, J. P., Davis, D. E., Worthington, E. L. J., \& Penberthy, J. K. (2010). Measuring sexual addiction and compulsivity: A critical review of instruments. Journal of Sex \& Marital Therapy, $36(3), 227-260$. https://doi.org/10.1080/00926231003719673

Hook, J. N., Reid, R. C., Penberthy, J. K., Davis, D. E., \& Jennings, D. J. 2nd. (2014). Methodological review of treatments for nonparaphilic hypersexual behavior. Journal of Sex \& Marital Therapy, 40(4), 294-308. https://doi.org/10.1080/0092623X.2012.751075

Kafka, M. P. (2010). Hypersexual disorder: A proposed diagnosis for DSM-V. Archives of Sexual Behavior, 39(2), 377-400. https://doi.org/10.1007/s10508009-9574-7

Kafka, M. P. (2014). What happened to hypersexual disorder? Archives of Sexual Behavior, 43(7),
1259-1261. https://doi.org/10.1007/s10508-0140326-y

Kafka, M. P., \& Hennen, J. (2003). Hypersexual desire in males: Are males with paraphilias different from males with paraphilia-related disorders? Sexual Abuse: A Journal of Research and Treatment, 15(4), 307-321. https://doi.org/10.1177/107906320301500407

Kalichman, S. C., Johnson, J. R., Adair, V., Rompa, D., Multhauf, K., \& Kelly, J. A. (1994). Sexual sensation seeking: Scale development and predicting AIDS-risk behavior among homosexually active men. Journal of Personality Assessment, 62(3), 385-397. https://doi.org/10.1207/s15327752jpa6203_1

Kalichman, S. C., \& Rompa, D. (1995). Sexual sensation seeking and Sexual Compulsivity Scales: Reliability, validity, and predicting HIV risk behavior. Journal of Personality Assessment, 65(3), 586-601. https://doi.org/10.1207/s15327752jpa6503_16

Karila, L., Wery, A., Weinstein, A., Cottencin, O., Petit, A., Reynaud, M., \& Billieux, J. (2014). Sexual addiction or hypersexual disorder: Different terms for the same problem? A review of the literature. Current Pharmaceutical Design, 20(25), 40124020.

Klein, V., Briken, P., Schröder, J., \& Fuss, J. (2019). Mental health professionals' pathologization of compulsive sexual behavior: Does clients' gender and sexual orientation matter? Journal of Abnormal Psychology, 128(5), 465-472. https://doi.org/10.1037/abn0000437

Kohut, T., Balzarini, R. N., Fisher, W. A., Grubbs, J. B., Campbell, L., \& Prause, N. (2019). Surveying pornography use: A shaky science resting on poor measurement foundations. The Journal of Sex Research, 1-21. https://doi.org/10.1080/00224499.2019.1695244

Kohut, T., \& Stulhofer, A. (2018). The role of religiosity in adolescents' compulsive pornography use: A longitudinal assessment. Journal Of Sex \& Marital Therapy. https://doi.org/10.1080/0092623X.2018.1466012

Koob, G. F. (2017). Antireward, compulsivity, and addiction: Seminal contributions of Dr. Athina Markou to motivational dysregulation in addiction. Psychopharmacology, 234(9-10), 1315-1332. https://doi.org/10.1007/s00213-016-4484-6

Kor, A., Zilcha-Mano, S., Fogel, Y. A., Mikulincer, M., Reid, R. C., \& Potenza, M. N. (2014). Psychometric development of the Problematic Pornography Use Scale. Addictive Behaviors, 39(5), 861-868. https://doi.org/10.1016/j.addbeh.2014.01.027 
Kotov, R., Krueger, R. F., Watson, D., Achenbach, T. M., Althoff, R. R., Bagby, R. M., Brown, T. A., Carpenter, W. T., Caspi, A., Clark, L. A., Eaton, N. R., Forbes, M. K., Forbush, K. T., Goldberg, D., Hasin, D., Hyman, S. E., Ivanova, M. Y., Lynam, D. R., Markon, K., ... Zimmerman, M. (2017). The Hierarchical Taxonomy of Psychopathology (HiTOP): A dimensional alternative to traditional nosologies. Journal of Abnormal Psychology, 126(4), 454-477. https://doi.org/10.1037/abn0000258

Kowalewska, E., Grubbs, J. B., Potenza, M. N., Gola, M., Draps, M., \& Kraus, S. W. (2018). Neurocognitive mechanisms in Compulsive Sexual Behavior Disorder. Current Sexual Health Reports, 10(4), 255-264. https://doi.org/10.1007/s11930-018-0176$\mathrm{Z}$

Kraus, S. W., Gola, M., Grubbs, J. B., Kowalewska, E., Hoff, R. A., Lew-Starowicz, M., Martino, S., Shirk, S. D., \& Potenza, M. N. (2020). Validation of a Brief Pornography Screener across multiple samples. Journal of Behavioral Addictions. https://doi.org/10.1556/2006.2020.00038

Kraus, S. W., Krueger, R. B., Briken, P., First, M. B., Stein, D. J., Kaplan, M. S., Voon, V., Abdo, C. H. N., Grant, J. E., Atalla, E., \& Reed, G. M. (2018). Compulsive sexual behaviour disorder in the ICD11. World Psychiatry, 17(1), 109-110. https://doi.org/10.1002/wps.20499

Kraus, S. W., Martino, S., Potenza, M. N., Park, C., Merrel, J. D., \& Hoff, R. A. (2017). Examining Compulsive Sexual Behavior and Psychopathology Among a Sample of Postdeployment U.S. Male and Female Military Veterans. Military Psychology, 29(2), 143156. https://doi.org/10.1037/mil0000147

Kraus, S. W., Meshberg-Cohen, S., Martino, S., Quinones, L. J., \& Potenza, M. N. (2015). Treatment of compulsive pornography use with naltrexone: A case report. American Journal of Psychiatry, 172(12), 1260-1261. https://doi.org/10.1176/appi.ajp.2015.15060843

Kraus, S. W., \& Sweeney, P. J. (2019). Hitting the target: Considerations for differential diagnosis when treating individuals for problematic use of pornography. Archives of Sexual Behavior, 48(2), 431-435. https://doi.org/10.1007/s10508-018-13019

Kraus, S. W., Voon, V., \& Potenza, M. N. (2016). Should compulsive sexual behavior be considered an addiction? Addiction (Abingdon, England), 111(12), 2097-2106. https://doi.org/10.1111/add.13297

Laier, C., Pawlikowski, M., Pekal, J., Schulte, F. P., \& Brand, M. (2013). Cybersex addiction: Experienced sexual arousal when watching pornography and not real-life sexual contacts makes the difference. Journal of Behavioral Addictions, 2(2), 100-107. https://doi.org/10.1556/JBA.2.2013.002

Laier, C., Pekal, J., \& Brand, M. (2014). Cybersex addiction in heterosexual female users of internet pornography can be explained by gratification hypothesis. Cyberpsychology, Behavior and Social Networking, 17(8), 505-511. https://doi.org/10.1089/cyber.2013.0396

Landripet, I., \& Stulhofer, A. (2015). Is Pornography Use Associated with Sexual Difficulties and Dysfunctions among Younger Heterosexual Men? The Journal of Sexual Medicine, 12(5), 1136-1139. https://doi.org/10.1111/jsm.12853

Lang, B., \& Rosenberg, H. (2017). Public perceptions of behavioral and substance addictions. Psychology of Addictive Behaviors, 31(1), 79-84. https://doi.org/10.1037/adb0000228

Lang, B., \& Rosenberg, H. (2018). Nonprofessionals' perceptions of the causes of behavioral and substance addictions. Journal of Addictive Diseases, 37(1-2), 102-108. https://doi.org/10.1080/10550887.2019.1574187

Lejoyeux, M., Feuché, N., Loi, S., Solomon, J., \& Adès, J. (1999). Study of impulse-control disorders among alcohol-dependent patients. The Journal of Clinical Psychiatry, 60(5), 302-305. https://doi.org/10.4088/JCP.v60n0506

Levine, M., \& Troiden, R. R. (1988). The myth of sexual compulsivity. The Journal of Sex Research, 25(3), 347-363. https://doi.org/10.1080/00224498809551467

Levine, S. B. (2010). What is sexual addiction? Journal of Sex \& Marital Therapy, 36(3), 261-275. https://doi.org/10.1080/00926231003719681

Lewczuk, K., Glica, A., Nowakowska, I., Gola, M., \& Grubbs, J. B. (2020). Evaluating Pornography Problems Due to Moral Incongruence model. The Journal of Sexual Medicine, 17(2), 300-311. https://doi.org/10.1016/j.jsxm.2019.11.259

Ley, D. J., Prause, N., \& Finn, P. (2014). The emperor has no clothes: A review of the 'pornography addiction' model. Current Sexual Health Reports, 6(2), 94105. https://doi.org/10.1007/s1 1930-014-0016-8

Li, C. R., Huang, C., Yan, P., Bhagwagar, Z., Milivojevic, V., \& Sinha, R. (2008). Neural Correlates of Impulse Control During Stop Signal Inhibition in Cocaine-Dependent Men. Neuropsychopharmacology, 33(8), 1798-1806. https://doi.org/10.1038/sj.npp.1301568

Litman, L., Robinson, J., \& Abberbock, T. (2017). TurkPrime.com: A versatile crowdsourcing data acquisition platform for the behavioral sciences. 
Behavior Research Methods, 49(2), 433-442. https://doi.org/10.3758/s13428-016-0727-z

Lundy, J. P. (1994). Behavior patterns that comprise sexual addiction as identified by mental health professionals. Sexual Addiction \& Compulsivity, $1(1), 46-56$. https://doi.org/10.1080/10720169408400027

Luo, M., Zhu, L., Dong, Y., Wang, Z., Shen, Q., Mo, D., Du, L., Zhang, Z., \& Cai, Y. (2018). Sexual compulsivity and its relationship with condomless sex among unmarried female migrant workers in Shanghai, China: A cross-sectional study. $B M C$ Women's Health, 18(1), 181. https://doi.org/10.1186/s12905-018-0670-5

Marshall, E. A., \& Miller, H. A. (2019). Consistently inconsistent: A systematic review of the measurement of pornography use. Aggression and Violent Behavior. https://doi.org/10.1016/j.avb.2019.08.019

Mechelmans, D. J., Irvine, M., Banca, P., Porter, L., Mitchell, S., Mole, T. B., Lapa, T. R., Harrison, N. A., Potenza, M. N., \& Voon, V. (2014). Enhanced Attentional Bias towards Sexually Explicit Cues in Individuals with and without Compulsive Sexual Behaviours. PLoS ONE, 9(8), e105476. https://doi.org/10.1371/journal.pone.0105476

Miles, L. A., Cooper, R. L., Nugent, W. R., \& Ellis, R. A. (2016). Sexual addiction: A literature review of treatment interventions. Journal of Human Behavior in the Social Environment, 26(1), 89-99. https://doi.org/10.1080/10911359.2015.1062672

Miner, M. H., Raymond, N., Mueller, B. A., Lloyd, M., \& Lim, K. O. (2009). Preliminary investigation of the impulsive and neuroanatomical characteristics of compulsive sexual behavior. Psychiatry Research, 174(2), 146-151.

https://doi.org/10.1016/j.pscychresns.2009.04.008

Mitchell, K. J., Becker-Blease, K. A., \& Finkelhor, D. (2005). Inventory of Problematic Internet Experiences Encountered in Clinical Practice. Professional Psychology: Research and Practice, 36(5), 498-509. https://doi.org/10.1037/07357028.36.5.498

Moher, D., Liberati, A., Tetzlaff, J., \& Altman, D. G. (2009). Preferred Reporting Items for Systematic Reviews and Meta-Analyses: The PRISMA Statement. PLoS Medicine, 6(7), 6.

Muench, F., Morgenstern, J., Hollander, E., Irwin, T., O'Leary, A., Parsons, J. T., Wainberg, M. L., \& Lai, B. (2007). The Consequences of Compulsive Sexual Behavior: The Preliminary Reliability and Validity of the Compulsive Sexual Behavior Consequences Scale. Sexual Addiction \&
Compulsivity, 14(3), 207-220. https://doi.org/10.1080/10720160701480493

Muise, A., Milhausen, R. R., Cole, S. L., \& Graham, C. (2013). Sexual Compulsivity in Heterosexual Married Adults: The Role of Sexual Excitation and Sexual Inhibition in Individuals not Considered "High-Risk." Sexual Addiction \& Compulsivity, 20(3), 192-209. https://doi.org/10.1080/10720162.2013.786661

Muthukrishna, M., \& Henrich, J. (2019). A problem in theory. Nature Human Behaviour, 1. https://doi.org/10.1038/s41562-018-0522-1

Noor, S. W., Simon Rosser, B. R., \& Erickson, D. J. (2014). A Brief Scale to Measure Problematic Sexually Explicit Media Consumption: Psychometric Properties of the Compulsive Pornography Consumption (CPC) Scale among Men who have Sex with Men. Sexual Addiction \& Compulsivity, 21(3), 240-261. https://doi.org/10.1080/10720162.2014.938849

Orford, J. (1978). Hypersexuality: Implications for a theory of dependence. The British Journal Of Addiction To Alcohol And Other Drugs, 73(3), 299-210.

Perry, S. L. (2020). Is the link between pornography use and relational happiness really more about masturbation? Results from two national surveys. The Journal of Sex Research, 57(1), 64-76. https://doi.org/10.1080/00224499.2018.1556772

Perry, S. L. (2019). Addicted to lust: Pornography in the lives of conservative protestants. Oxford University Press.

Petry, N. M., Ginley, M. K., \& Rash, C. J. (2017). A systematic review of treatments for problem gambling. Psychology of Addictive Behaviors, 31(8), 951.

Pincu, L. (1989). Sexual Compulsivity in Gay Men: Controversy and Treatment. Journal of Counseling \& Development, 68(1), 63-66. https://doi.org/10.1002/j.1556-6676.1989.tb02495.x

Potenza, M. N., Gola, M., Voon, V., Kor, A., \& Kraus, S. W. (2017). Is excessive sexual behaviour an addictive disorder? The Lancet Psychiatry, 4(9), 663-664. https://doi.org/10.1016/S22150366(17)30316-4

Prause, N. (2019). Porn Is for Masturbation. Archives of Sexual Behavior. https://doi.org/10.1007/s10508019-1397-6

Prause, N., Janssen, E., Georgiadis, J., Finn, P., \& Pfaus, J. (2017). Data do not support sex as addictive. The Lancet Psychiatry, 4(12), 899. https://doi.org/10.1016/S2215-0366(17)30441-8

Prause, N., Steele, V. R., Staley, C., Sabatinelli, D., \& Hajcak, G. (2015). Modulation of late positive potentials by sexual images in problem users and 
controls inconsistent with "porn addiction". Biological Psychology, 109, 192-199. https://doi.org/10.1016/j.biopsycho.2015.06.005

Reid, R. C. (2016). Additional challenges and issues in classifying compulsive sexual behavior as an addiction. Addiction (Abingdon, England), 111(12), 2111-2113. https://doi.org/10.1111/add.13370

Reid, R. C., Berlin, H. A., \& Kingston, D. A. (2015). Sexual Impulsivity in Hypersexual Men. Current Behavioral Neuroscience Reports, 2(1), 1-8. https://doi.org/10.1007/s40473-015-0034-5

Reid, R. C., Carpenter, B. N., Hook, J. N., Garos, S., Manning, J. C., Gilliland, R., Cooper, E. B., McKittrick, H., Davtian, M., \& Fong, T. (2012). Report of findings in a DSM-5 field trial for hypersexual disorder. The Journal of Sexual Medicine, 9(11), 2868-2877.

Reid, R. C., Cyders, M. A., Moghaddam, J. F., \& Fong, T. W. (2014). Psychometric properties of the Barratt Impulsiveness Scale in patients with gambling disorders, hypersexuality, and methamphetamine dependence. Addictive Behaviors, 39(11), 16401645. https://doi.org/10.1016/j.addbeh.2013.11.008

Reid, R. C., Garos, S., \& Carpenter, B. N. (2011). Reliability, validity, and psychometric development of the Hypersexual Behavior Inventory in an outpatient sample of men. Sexual Addiction \& Compulsivity, 18(1), 30-51. https://doi.org/10.1080/10720162.2011.555709

Reid, R. C., \& Grant, J. E. (2017). In Search of a Parsimonious Model to Explain Hypersexual Behavior. Archives of Sexual Behavior, 46(8), 2275-2277. https://doi.org/10.1007/s10508-0171074-6

Rendina, H. J., Millar, B. M., Dash, G., Feldstein Ewing, S. W., \& Parsons, J. T. (2018). The Somatic Marker Hypothesis and Sexual Decision Making: Understanding the Role of Iowa Gambling Task Performance and Daily Sexual Arousal on the Sexual Behavior of Gay and Bisexual Men. Annals of Behavioral Medicine, 52(5), 380-392. https://doi.org/10.1093/abm/kax006

Rissel, C., Richters, J., Visser, R. O. de, McKee, A., Yeung, A., \& Caruana, T. (2017). A profile of pornography users in Australia: Findings from the Second Australian Study of Health and Relationships. Journal of Sex Research, 54(2), 227-240. https://doi.org/10.1080/00224499.2016.1191597

Rush, B. (1812). Medical Inquiries and Observations, Upon the Diseases of the Mind. Kimber \& Richardson, no. 237, Market street. Merritt, printer, no. 9, Watkin's alley.

Savard, J., Öberg, K. G., Chatzittofis, A., Dhejne, C., Arver, S., \& Jokinen, J. (2020). Naltrexone in Compulsive
Sexual Behavior Disorder: A Feasibility Study of Twenty Men. The Journal of Sexual Medicine, 17(8), 1544-1552. https://doi.org/10.1016/j.jsxm.2020.04.318

Schmidt, C., Morris, L. S., Kvamme, T. L., Hall, P., Birchard, T., \& Voon, V. (2017). Compulsive sexual behavior: Prefrontal and limbic volume and interactions. Human Brain Mapping, 38(3), 11821190. https://doi.org/10.1002/hbm.23447

Short, M. B., Wetterneck, C. T., Bistricky, S. L., Shutter, T., $\&$ Chase, T. E. (2016). Clinicians' beliefs, observations, and treatment effectiveness regarding clients' sexual addiction and internet pornography use. Community Mental Health Journal, 52(8), 1070-1081. https://doi.org/10.1007/s10597-0160034-2

Skegg, K., Nada-Raja, S., Dickson, N., \& Paul, C. (2010). Perceived "out of control" sexual behavior in a cohort of young adults from the Dunedin Multidisciplinary Health and Development Study. Archives of Sexual Behavior, 39(4), 968-978. https://doi.org/10.1007/s10508-009-9504-8

Snagowski, J., Wegmann, E., Pekal, J., Laier, C., \& Brand, M. (2015). Implicit associations in cybersex addiction: Adaption of an Implicit Association Test with pornographic pictures. Addictive Behaviors, 49, 7-12. https://doi.org/10.1016/j.addbeh.2015.05.009

Specker, S. M., Carlson, G. A., Christenson, G. A., \& Marcotte, M. (1995). Impulse control disorders and attention deficit disorder in pathological gamblers. Annals of Clinical Psychiatry: Official Journal of the American Academy of Clinical Psychiatrists, 7(4), 175-179.

Sunderwirth, S., Milkman, H., \& Jenks, N. (1996). Neurochemistry and sexual addiction. Sexual Addiction \& Compulsivity, 3(1), 22-32. https://doi.org/10.1080/10720169608400097

Szucs, D., \& Ioannidis, J. P. A. (2019). Sample size evolution in neuroimaging research: An evaluation of highly-cited studies (1990-2012) and of latest practices (2017-2018) in high-impact journals. bioRxiv, DOI: 10.1101/809715

Taylor, K. (2019). Nosology and metaphor: How pornography viewers make sense of pornography addiction. Sexualities, 136346071984213. https://doi.org/10.1177/1363460719842136

Thompson, M. P., Kingree, J. B., Zinzow, H., \& Swartout, K. (2015). Time-Varying Risk Factors and Sexual Aggression Perpetration Among Male College Students. The Journal of Adolescent Health : Official Publication of the Society for Adolescent Medicine, 57(6), 637-642. https://doi.org/10.1016/j.jadohealth.2015.08.015 
Turner, B. O., Paul, E. J., Miller, M. B. \& Barbey, A. K. (2018). Small sample sizes reduce the replicability of task-based fMRI studies. Communications Biology, 1: 62. https://doi.org/10.1038/s42003-0180073-z

Wainberg, M. L., Muench, F., Morgenstern, J., Hollander, E., Irwin, T. W., Parsons, J. T., Allen, A., \& O'Leary, A. (2006). A double-blind study of citalopram versus placebo in the treatment of compulsive sexual behaviors in gay and bisexual men. The Journal of Clinical Psychiatry, 67(12), 1968-1973. https://doi.org/10.4088/JCP.v67n1218

Walton, M. T. (2019). Incongruence as a variable feature of problematic sexual behaviors in an online sample of self-reported "sex addiction". Archives of Sexual Behavior, 48(2), 443-447. https://doi.org/10.1007/s10508-018-1305-5

Walton, M. T., Cantor, J. M., Bhullar, N., \& Lykins, A. D. (2017). Hypersexuality: A Critical Review and Introduction to the "Sexhavior Cycle". Archives of Sexual Behavior, 46(8), 2231-2251. https://doi.org/10.1007/s10508-017-0991-8

Weintraub, D., Koester, J., Potenza, M. N., Siderowf, A. D., Stacy, M., Voon, V., Whetteckey, J., Wunderlich, G. R., \& Lang, A. E. (2010). Impulse control disorders in Parkinson disease: A cross-sectional study of 3090 patients. Archives of Neurology, 67(5), 589-595. https://doi.org/10.1001/archneurol.2010.65

Wery, A., \& Billieux, J. (2017). Problematic cybersex: Conceptualization, assessment, and treatment. Addictive Behaviors, 64, 238-246. https://doi.org/10.1016/j.addbeh.2015.11.007

Womack, S. D., Hook, J. N., Ramos, M., Davis, D. E., \& Penberthy, J. K. (2013). Measuring Hypersexual Behavior. Sexual Addiction \& Compulsivity, 20, 65-78. https://doi.org/10.1080/10720162.2013.768126

Wordecha, M., Wilk, M., Kowalewska, E., Skorko, M., Lapinski, A., \& Gola, M. (2018). "Pornographic binges" as a key characteristic of males seeking treatment for compulsive sexual behaviors: Qualitative and quantitative 10-week-long diary assessment. Journal of Behavioral Addictions, 7(2), 433-444. https://doi.org/10.1556/2006.7.2018.33

Yeagley, E., Hickok, A., \& Bauermeister, J. A. (2014). Hypersexual behavior and HIV sex risk among young gay and bisexual men. Journal of Sex Research, 51(8), 882-892. https://doi.org/10.1080/00224499.2013.818615 
Supplemental Table 1

Complete summary of all papers included in the present review

\begin{tabular}{|c|c|c|}
\hline Study & Design & $\begin{array}{c}\text { Subject of Focus and } \\
\text { Measurement }\end{array}$ \\
\hline (Achterbergh et al., 2020) & $\begin{array}{l}\text { A sexual education intervention study of } \\
\text { adult men who have sex with men in the } \\
\text { Netherlands }(\mathrm{N}=155)\end{array}$ & $\begin{array}{l}\text { General CSB as measured } \\
\text { by the Kalichman Sexual } \\
\text { Compulsivity Scale }\end{array}$ \\
\hline (Albery et al., 2017) & $\begin{array}{l}\text { A quasi-experimental study of adults in the } \\
\text { U.K. }(N=55 ; 50.9 \% \text { men; Mean age }=28.4 \text {, } \\
S D=10.4)\end{array}$ & $\begin{array}{l}\text { General CSB as measured } \\
\text { by the Kalichman Sexual } \\
\text { Compulsivity Scale }\end{array}$ \\
\hline (Allen et al., 2017) & $\begin{array}{l}\text { A cross-sectional study of adults in } \\
\text { Australia }(\mathrm{N}=192 ; 94.8 \% \text { men; Mean age }= \\
26.65, \mathrm{SD}=8.52)\end{array}$ & $\begin{array}{l}\text { PPU as measured by the } \\
\text { Problematic Pornography } \\
\text { Use Scale and the } \\
\text { Pornography Craving } \\
\text { Questionnaire }\end{array}$ \\
\hline (Andreassen et al., 2018) & $\begin{array}{l}\text { A cross-sectional study of adults in Norway } \\
(\mathrm{N}=23,533 ; 35 \% \text { men; Mean Age }=35.8 \\
\mathrm{SD}=13.3)\end{array}$ & $\begin{array}{l}\text { General CSB as measured } \\
\text { by the Bergen-Yale Sex } \\
\text { Addiction Scale }\end{array}$ \\
\hline (Antons \& Brand, 2018) & $\begin{array}{l}\text { An experimental study of adult men in } \\
\text { Germany }(\mathrm{N}=50 ; \text { Mean age }=23.30, \mathrm{SD}= \\
4.08 ; 100 \% \text { heterosexual }) \text { recruited } \\
\text { predominantly from a university setting }\end{array}$ & $\begin{array}{l}\text { Online CSB as measured by } \\
\text { the Short Internet Addiction } \\
\text { Test modified for Cybersex } \\
\text { Use }\end{array}$ \\
\hline $\begin{array}{c}\text { (Antons, Mueller, et al., } \\
\text { 2019) }\end{array}$ & $\begin{array}{l}\text { A cross-sectional study of adult men in } \\
\text { Germany }(\mathrm{N}=1,498 ; \text { Mean age }=31.76, \mathrm{SD} \\
=11.26 ; 100 \% \text { heterosexual })\end{array}$ & $\begin{array}{l}\text { PPU as measured by the } \\
\text { short Internet Addiction Test } \\
\text { and the Craving Assessment } \\
\text { Scale for Behavioral } \\
\text { Addictions-Porn version. }\end{array}$ \\
\hline $\begin{array}{l}\text { (Antons, Trotzke, et al., } \\
\text { 2019) }\end{array}$ & $\begin{array}{l}\text { A cross-sectional study of adult men in } \\
\text { Germany }(\mathrm{N}=1,498 ; \text { Mean age }=31.76, \mathrm{SD} \\
=11.26 ; 100 \% \text { heterosexual })\end{array}$ & $\begin{array}{l}\text { PPU as measured by the } \\
\text { short Internet Addiction Test } \\
\text { and the Craving Assessment } \\
\text { Scale for Behavioral } \\
\text { Addictions-Porn version. }\end{array}$ \\
\hline (Baggio et al., 2018) & $\begin{array}{l}\text { A nationally representative, cross-sectional } \\
\text { study of adult men in Switzerland }(\mathrm{N}= \\
3,404 \text {; Mean age }=25.4 ; \mathrm{SD}=1.2)\end{array}$ & $\begin{array}{l}\text { Online CSB as measured by } \\
\text { the Internet Sex Screening } \\
\text { Test }\end{array}$ \\
\hline $\begin{array}{c}\text { (Ballester-Arnal et al., } \\
\text { 2017) }\end{array}$ & $\begin{array}{l}\text { A cross-sectional study of university } \\
\text { students in Spain }(\mathrm{N}=1,557 ; 35.6 \% \text { men; } \\
\text { Mean age }=20.37, \mathrm{SD}=1.98 ; 94.2 \% \\
\text { heterosexual, } 3.6 \% \text { bisexual, } 2.2 \% \\
\text { homosexual) }\end{array}$ & $\begin{array}{l}\text { Online CSB as measured by } \\
\text { the Internet Sex Screening } \\
\text { Test }\end{array}$ \\
\hline $\begin{array}{l}\text { (Ballester-Arnal et al., } \\
\text { 2020) }\end{array}$ & $\begin{array}{l}\text { A cross-sectional study of university } \\
\text { students }(48.8 \% \text { men; } 86 \% \text { heterosexual, } 9 \% \\
\text { homosexual, } 5 \% \text { bisexual) in Spain with } \\
\text { CSBD }(n=68 ; \text { Mean age }=20.63, \mathrm{SD}= \\
2.26) \text { and without CSBD }(\mathrm{n}=315 ; \text { Mean } \\
\text { age }=20.89, \mathrm{SD}=2.12)\end{array}$ & $\begin{array}{l}\text { General CSB as measured } \\
\text { by the Hypersexual Behavior } \\
\text { Inventory, the Kalichman } \\
\text { Sexual Compulsivity Scale, } \\
\text { and the Sexual Addiction } \\
\text { Screening Test }\end{array}$ \\
\hline $\begin{array}{c}\text { (Ballester-Arnal et al., } \\
\text { 2013) }\end{array}$ & $\begin{array}{l}\text { A cross-sectional study of university } \\
\text { students in Spain }(\mathrm{N}=1,196 ; 24.5 \% \text { men; } \\
\text { Mean age }=20.22, \mathrm{SD}=2.11 ; 95.5 \% \\
\text { heterosexual), with a one-week longitudinal } \\
\text { follow-up }(\mathrm{N}=100)\end{array}$ & $\begin{array}{l}\text { General CSB as measured } \\
\text { by the Sexual Compulsivity } \\
\text { Scale }\end{array}$ \\
\hline
\end{tabular}


A cross-sectional study of medical students

(Baltieri et al., 2016) in Brazil $(\mathrm{N}=205 ; 48.8 \%$ men: Mean age $=$ 21.42, $\mathrm{SD}=3.02 ; 51.2 \%$ women: Mean age $=21.18, \mathrm{SD}=1.99$ )

A functional magnetic resonance imaging study of men $(\mathrm{N}=22$; Mean age $=25.14$,

(Banca et al., 2016) $\mathrm{SD}=4.68 ; 100 \%$ heterosexual) with CSB in the U.K. compared with healthy controls ( N $=40$ )

A cross-sectional study of women in

(Baranowski et al., 2019) Germany $(\mathrm{N}=485$; Mean age $=25.79, \mathrm{SD}=$ 7.27)

A cross-sectional study of adults in the U.S.

(Benotsch, 2001) 7.4)

A cross-sectional study in the U.S. of HIV-

(Benotsch et al., 1999) positive men who have sex with men $(\mathrm{N}=$ 112 ; Mean age $=34.6, \mathrm{SD}=8.6$ )

A cross-sectional study of college students in Bosnia, Serbia, and Herzegovina $(\mathrm{N}=$ 1,$711 ; 37.9 \%$ men; Mean age $=21.88, \mathrm{SD}=$ 1.67)

A cross-sectional study $(\mathrm{N}=362 ; 86.7 \%$ men) of patients at a urology clinic that predominantly served active duty military

(Berger et al., 2019) personnel in the U.S. military (Men: Mean age $=30.7, \mathrm{SD}=5.9,97.8 \%$ heterosexual; Women: Mean age $=28.1, \mathrm{SD}=6.3,81 \%$ heterosexual)

A cross-sectional study of individuals with self-identified problems with CSB in the U.S. $(\mathrm{N}=36$; Mean age $=27, \mathrm{SD}=8)$ A cross-sectional study of gay and bisexual men in the U.S. $(\mathrm{N}=182$; Mean age $=$ $35.99, \mathrm{SD}=8.33 ; 90 \%$ gay, $10 \%$ bisexual) A cross-sectional study of young adults in (Blum et al., 2018) the U.S. $(\mathrm{N}=54 ; 67.3 \%$ men, Mean age $=$ 23.6, $\mathrm{SD}=3.5$ )

A cross-sectional study of university

(Blum et al., 2019) students in the U.S. ( $\mathrm{N}=3,659 ; 36.5 \%$ men Mean age not reported; sexual orientation not reported)

A cross-sectional study of adults in the U.S.

(Borgogna, Duncan, et al., 2018)

(Borgogna et al., 2020) 757; $33 \%$ men; Men: Mean age $=24.2$ $\mathrm{SD}=9.9,86 \%$ heterosexual; Women: Mean age $=24.1, \mathrm{SD}=10.7 ; 83.2 \%$ heterosexual) A cross-sectional study of heterosexual men in the U.S. recruited via snowball sampling $(\mathrm{N}=294 ; 69 \%$ men; Mean age $=40.5, \mathrm{SD}=$

PPU as measured by the Pornography Consumption Inventory

General CSB as measured by psychiatrist diagnosed CSB

PPU as measured by the short Internet Addiction Test modified for online sexual activities

General CSB as measured by the Kalichman Sexual Compulsivity Scale

General CSB as measured by the Kalichman Sexual Compulsivity Scale

General CSB as measured by the Kalichman Sexual Compulsivity Scale

PPU as measured by the Pornography Craving Questionnaire

General CSB as measured by the Compulsive Sexual Disorders Interview

General CSB as measured by the Compulsive Sexual Behavior Inventory General CSB as measured by the Minnesota Impulsive Disorders Interview

General CSB as measured by the Minnesota Impulsive Disorders Interview

PPU as measured by the Problematic Pornography Use Scale methods $(\mathrm{N}=244$; Mean age $=19.63, \mathrm{SD}=$ 6.22)
PPU as measured by the Cyber-Pornography Use Inventory-9 
A cross-sectional study of women in the

U.S. recruited via snowball sampling

(Borgogna, Lathan, et al., 2018)

(Borgogna, McDermott, et al., 2018)

(Borgogna \& Aita, 2019)

(Borgogna et al., 2019)

(Bőthe et al., 2018)

(Bőthe, Koós, et al., 2019)

(Bőthe, Kovács, et al., 2019)

(Bőthe, Lonza, et al., 2020)

(Böthe, Potenza, et al., 2020; Sample 1)

(Böthe, Potenza, et al., 2020; Sample 2)

(Böthe, Potenza, et al., 2020; Sample 3)

(Böthe, Potenza, et al., 2020; Sample 4)
A cross-sectional study of adults in Hungary recruited via an online questionnaire $(\mathrm{N}=$ 14,$043 ; 70 \%$ men; Mean age $=33.5, \mathrm{SD}=$ $10.9 ; 82.9 \%$ heterosexual)

A cross-sectional study of adults in Hungary recruited via an online questionnaire $(\mathrm{N}=$

thods $(\mathrm{N}=949 ;$ Mean age $=22.8, \mathrm{SD}=$ $8.5 ; 82.2 \%$ heterosexual, $10.5 \%$ bisexual, $4.2 \%$ other, $3.1 \%$ lesbian)

A cross-sectional study of adults in the U.S. recruited via snowball sampling methods $(\mathrm{N}$ $=779 ; 39.7 \%$ men; Men: Mean age $=32.93$, $\mathrm{SD}=16.01 ; 76.8 \%$ heterosexual, $10.6 \%$ bisexual, $8.4 \%$ gay; Women: Mean age $=$ $28.89, \mathrm{SD}=12.70 ; 76.3 \%$ heterosexual, $14.1 \%$ bisexual, $3.2 \%$ lesbian)

A cross-sectional study of adults in the U.S. recruited via snowball sampling methods $(\mathrm{N}$ $=769$; Men: Mean age $=24.22, \mathrm{SD}=9.89$;

$86.2 \%$ heterosexual, $5.5 \%$ bisexual, $5.1 \%$ gay; Women: Mean age $=24.20, \mathrm{SD}=$ $10.96 ; 82.9 \%$ heterosexual, $3.1 \%$ lesbian, $9.7 \%$ bisexual)

A cross-sectional study of men in the U.S. recruited via snowball sampling methods $(\mathrm{N}$ $=520$; Mean age $=25.46, \mathrm{SD}=11.99$; $83.1 \%$ heterosexual, $8.7 \%$ gay, $5.2 \%$ bisexual)

A cross-sectional study of adults in Hungary recruited via an online questionnaire $(\mathrm{N}=$ 18,$034 ; 65.4 \%$ men; Mean age $=33.6, \mathrm{SD}=$ $11.2 ; 83.6 \%$ heterosexual) 18,$034 ; 65.4 \%$ men; Mean age $=33.6, \mathrm{SD}=$ $11.2 ; 83.6 \%$ heterosexual)

A cross-sectional study of adult men in Hungary $(\mathrm{N}=4,253$; Mean age $=38.33, \mathrm{SD}$ $=12.40)$

A cross-sectional study of internet using adults in Hungary ( $\mathrm{N}=7995 ; 64.8 \%$ men; Mean age $=36.25 ; \mathrm{SD}=12.14$ )

A probability sample matched to nationally representative norms in Hungary $(\mathrm{N}=473$; $48.3 \%$ men; Mean age $=40.22, \mathrm{SD}=11.79$ ) A cross-sectional sample of Mechanical Turk workers in the U.S.A. $(\mathrm{N}=477 ; 53.9 \%$ men; Mean age $=38.25, \mathrm{SD}=11.04$ ) A cross-sectional sample of internet using adults in Germany $(\mathrm{N}=380 ; 38.4 \%$ men; Mean age $=27.81, \mathrm{SD}=7.73$ )
PPU as measured by the Problematic Pornography Use Scale

PPU as measured by the Problematic Pornography Use Scale

PPU as measured by the Problematic Pornography Use Scale

PPU as measured by the Problematic Pornography Use Scale

General CSB as measured by the Hypersexual Behavior Inventory

General CSB as measured by the Hypersexual Behavior Inventory and PPU as measured by the Problematic Pornography Consumption Scale

General CSB as measured by the Hypersexual Behavior Inventory

PPU as measured by the Problematic Pornography Consumption Inventory General CSB as measured by the Compulsive Sexual Behavior Disorder Scale -19 General CSB as measured by the Compulsive Sexual Behavior Disorder Scale -19 General CSB as measured by the Compulsive Sexual Behavior Disorder Scale -19 General CSB as measured by the Compulsive Sexual Behavior Disorder Scale -19 
(Bőthe, Tóth-Király,

Demetrovics, et al., 2020; Sample 1)

(Bőthe, Tóth-Király,

Demetrovics, et al., 2020; Sample 2)

(Bőthe, Tóth-Király, Demetrovics, et al., 2020; Sample 3)

(Bőthe, Tóth-Király, et al., 2019)

(Bőthe, Tóth-Király,

Potenza, et al., 2020; Sample 1)

(Bőthe, Tóth-Király, Potenza, et al., 2020; Sample 2)

(Bőthe, Tóth-Király, Potenza, et al., 2020; Sample 3)

(Bradley et al., 2016)

(Brahim et al., 2019)

(Brakoulias et al., 2020)

(Brand et al., 2011)

(Brand et al., 2016)

(Brown et al., 2016)
A cross-sectional sample of adults in

Hungary $(\mathrm{N}=15,051 ; 70.3 \%$ men; Mean age $=33.2, \mathrm{SD}=11.0 ; 82.5 \%$ heterosexual $)$

A cross-sectional sample of adults in

Hungary $(\mathrm{N}=760 ; 92.7 \%$ men; Mean age $=$ $39.6, \mathrm{SD}=9.7 ; 79.3 \%$ heterosexual)

A cross-sectional sample in a clinical setting of adults in Hungary $(\mathrm{N}=266 ; 97 \%$ men;

Mean age $=37.2, \mathrm{SD}=12.3 ; 69.2 \%$ heterosexual)

A cross-sectional study of adults in Hungary recruited via an online questionnaire $(\mathrm{N}=$ 18,$034 ; 65.4 \%$ men; Mean age $=33.6, \mathrm{SD}=$ $11.2 ; 83.6 \%$ heterosexual)

A cross-sectional study of adults in Hungary recruited via an online questionnaire $(\mathrm{N}=$ 14,$006 ; 70 \%$ men; Mean age $=33.2, \mathrm{SD}=$ $10.9 ; 92.6 \%$ heterosexual)

A cross-sectional study of adults in Hungary recruited via an online questionnaire $(\mathrm{N}=$ $483 ; 89.9 \%$ men; Mean age $=27.7, \mathrm{SD}=$ 9.3)

A cross-sectional study of adults in Hungary recruited via an online questionnaire $(\mathrm{N}=$ $672 ; 93.6 \%$ men; Mean age $=39.6, \mathrm{SD}=$ 9.6; $90.2 \%$ heterosexual)

A cross-sectional study of adults in the U.S. recruited via Amazon's Mechanical Turk (N $=713 ; 51.9 \%$ men; Mean age $=30.2, \mathrm{SD}=$ 9.9)

A cross-sectional study of adults recruited primarily from Switzerland (68\%) and France $(25 \%)$, as well as other countries (N $=306 ; 49 \%$ men; Mean age $=32.63$; $\mathrm{SD}=$ $10.83 ; 84 \%$ heterosexual)

A cross-sectional sample of adults seeking treatment for obsessive compulsive disorder in multiple countries $(\mathrm{N}=6,919 ; 51.7 \%$ men; Mean age $=34.5, \mathrm{SD}=12.1$ )

A quasi-experimental study of heterosexual men (university students) in Germany $(\mathrm{N}=$ 89 ; Mean age $=23.98, \mathrm{SD}=4.09$ )

A functional magnetic resonance imaging study of heterosexual men in Germany $(\mathrm{N}=$ 19 ; Mean age $=25.05, \mathrm{SD}=1.43$ )

A cross-sectional study in the U.S. of men who have sex with men $(\mathrm{N}=338$; Mean age $=42.1, \mathrm{SD}=11.0$ )
PPU as measured by the Problematic Pornography Consumption Inventory PPU as measured by the Problematic Pornography Consumption Inventory

PPU as measured by the Problematic Pornography Consumption Inventory

General CSB as measured by the Hypersexual Behavior Inventory

PPU as measured by the Problematic Pornography Consumption Scale

PPU as measured by the Problematic Pornography Consumption Scale

PPU as measured by the Problematic Pornography Consumption Scale

PPU as measured by the Cyber-Pornography Use Inventory-9

Online CSB as measured by the Compulsive Internet Use Scale modified for cybersex

General CSB as measured by clinician diagnosis

PPU as measured by the Internet Addiction Test modified for sexual use of the internet

PPU as measured by the short Internet Addiction Test modified for online sexual activities and general CSB as measured by the Hypersexual Behavior Inventory General CSB as measured by the Compulsive Sexual Behavior Inventory 
A cross-sectional study in the U.S. of HIVpositive men who have sex with men $(\mathrm{N}=$ 266; Mean age $=43.6, \mathrm{SD}=10.5$ )

A cross-sectional study of adults in

(Burri, 2017)

(Carnes et al., 2012; Sample 2) Sample 1)

(Carnes et al., 2014)

(Carvalho, Guerra, et al., 2015)

(Carvalho, Stulhofer, et al., 2015)

(Cashwell et al., 2018)

(Castro-Calvo et al., 2018; Sample 1)

(Castro-Calvo et al., 2018; Sample 2)

(Castro-Calvo et al., 2020; Sample 1)
Switzerland $(\mathrm{N}=279 ; 30.8 \%$ men; Mean

age $=32.0, \mathrm{SD}=10.6$ )

A cross-sectional sample including outpatients ( $\mathrm{n}=646 ; 86.8 \%$ men; Mean age $=43.4, \mathrm{SD}=11.4$; Women: Mean age $=$ $37.9, \mathrm{SD}=10.8)$, inpatients $(\mathrm{n}=63 ; 100 \%$ men; Men: Mean age $=41.3, \mathrm{SD}=11.2)$, and university students $(n=203 ; 23.2 \%$ men; Men: Mean age $=21.65, \mathrm{SD}=5.6$; Women: Mean age $=19.9, \mathrm{SD}=2.8)$ in the U.S.

A cross-sectional sample of patients receiving inpatient treatment for CSB between 1996 and $2004(\mathrm{~N}=1,118 ; 69.6 \%$ men) and a sample of university students ( $\mathrm{N}$ $=790 ; 24.3 \%$ men; Mean age $=20.60, \mathrm{SD}=$ 3.88)

A cross-sectional sample of patients receiving treatment for CSB in the U.S. $(\mathrm{N}=$ 4,$492 ; 88 \%$ men)

A cross-sectional sample of heterosexual women university students in Portugal $(\mathrm{N}=$ 235; Mean age $=23.35, \mathrm{SD}=7.91$ )

A cross-sectional sample of adults in Croatia $(\mathrm{N}=4,597 ; 43.5 \%$ men; Mean age $=31.1$, $\mathrm{SD}=9.67 ; 66.7 \%$ heterosexual)

A cross-sectional study of undergraduates in the U.S. $(\mathrm{N}=337 ; 40.1 \%$ men; Mean age $=$ $23.18, \mathrm{SD}=5.04 ; 92.2 \%$ heterosexual)

A cross-sectional study of adults in Spain (N $=1,585 ; 43.1 \%$ men; Mean age $=20.58, \mathrm{SD}$ $=2.17 ; 92.2 \%$ heterosexual)

A cross-sectional study of adults in Spain (N $=943 ; 50.9 \%$ men; Mean age $=24.21, \mathrm{SD}=$ $5.49 ; 68.4 \%$ heterosexual)

A cross-sectional sample of university students in Span $(\mathrm{N}=1,581 ; 43.1 \%$ men; Mean age $=20.58, \mathrm{SD}=2.17 ; 92 \%$ heterosexual)
General CSB as measured by the Compulsive Sexual Behavior Inventory General CSB as measured by the Kalichman Sexual Compulsivity Scale

General CSB as measured by the Sexual Addiction Screening Test Revised and the brief screening measure PATHOS

General CSB as measured by the Sexual Addiction Screening Test Revised and the brief screening measure PATHOS

General CSB as measured by the Sexual Addiction Screening Test Revised and clinician diagnosis General CSB as measured by the Kalichman Sexual Compulsivity Scale General CSB as measured by the Hypersexual Behavior Consequences Scale General CSB as measured by the Sexual Addiction Screening Test Revised and the brief screening measure BODIES

General CSB as measured by the Sexual Addiction

Screening Test, the

Kalichman Sexual

Compulsivity Scale, and the

Hypersexual Behavior Inventory

General CSB as measured by the Sexual Addiction

Screening Test, the

Kalichman Sexual Compulsivity Scale, and the Hypersexual Behavior Inventory

General CSB as measured by the Hypersexual Beahvior Inventory, the Kalichman Sexual Compulsivity Scale, 


\section{(Castro-Calvo et al., 2020; Sample 2)}

(Chaney \& Burns-
Wortham, 2014)

(Chaney \& Burns-

Wortham, 2015)

(Chatzittofis et al., 2016)

(Chatzittofis et al., 2017)

(Chatzittofis et al., 2020)

(Chen et al., 2018)

(Chen \& Jiang, 2020)
A cross-sectional community sample of adults in Spain $(\mathrm{N}=1,318 ; 56.4 \%$ men; Mean age $=32.37, \mathrm{SD}=12.42 ; 73.7 \%$ heterosexual)

A cross-sectional study in the U.S. of men who have sex with men $(\mathrm{N}=517$; Mean age $=40, \mathrm{SD}=11.95$ )

A cross-sectional study in the U.S. of men who have sex with men $(\mathrm{N}=517$; Mean age $=40, \mathrm{SD}=11.95$ )

A cross-sectional study in the U.S. of men who have sex with men $(\mathrm{N}=314$; Mean age $=34.31, \mathrm{SD}=7.99$ )

A neuroendocrinological study of hypersexual men $(n=67$; Mean age $=39.2)$ in contrast with healthy controls $(n=39$; Mean age $=37.5$ ) in Sweden
A cross-sectional study of hypersexual men $(\mathrm{n}=67$; Mean age $=39.2, \mathrm{SD}=11.5)$ in contrast with healthy controls $(n=39$; Mean age $=37.5, \mathrm{SD}=11.9)$ in Sweden
A neuroendocrinological study of hypersexual men in Sweden ( $=67$; Mean age $=39.2, \mathrm{SD}=11.5)$ in comparison with healthy controls $(\mathrm{N}=39$; Mean age $=37.5$; $\mathrm{SD}=11.9$ )

A cross-sectional study of university students in China ( $\mathrm{N}=808 ; 57.7 \%$ men; Mean age $=18.54, \mathrm{SD}=0.75$ )

A cross-sectional sample of adults in China $(\mathrm{N}=972 ; 57.6 \%$ men; Mean age $=24.8, \mathrm{SD}$ $=7.2 ; 92.7 \%$ heterosexual)

A cross-sectional sample of internet using adults men in China $(\mathrm{N}=695$; Mean age $=$ 25.39, $\mathrm{SD}=7.18 ; 94.4 \%$ heterosexual) and the Sexual Addiction

Screening Test

General CSB as measured by the Hypersexual Beahvior Inventory, the Kalichman Sexual Compulsivity Scale, and the Sexual Addiction Screening Test Online CSB as measured by the Internet Sex Screening Test

Online CSB as measured by the Internet Sex Screening Test

Online CSB as measured by the Internet Sex Screening Test General CSB as measured by the Hypersexual Disorder Screening Inventory, the Kalichman Sexual Compulsivity Scale, and the Hypersexual Disorder: Current Assessment screening interview General CSB as measured by the Hypersexual Disorder Screening Inventory, the Kalichman Sexual Compulsivity Scale, and the Hypersexual Disorder: Current Assessment screening interview General CSB as measured by the Hypersexual Disorder Screening Inventory, the Kalichman Sexual Compulsivity Scale, and the Hypersexual Disorder: Current Assessment Scale PPU as measured by the Problematic Internet Pornography Use Scale PPU as measured by the Problematic Pornography Consumption Scale, the Problematic Pornography Use Scale, and the Internet Addiction Test for Sex. PPU as measured by the Problematic Pornography Consumption Scale; the Brief Pornography Screener; 
and the Kalichman Sexual

Compulsivity Scale

PPU as measured by the

(Chen et al., 2021;

Sample 2)

(Chen et al., 2021;

Sample 3)

(Chowdhury et al., 2018)

(Coleman et al., 2000)

(Coleman et al., 2010)

(Coleman et al., 2001)

(Cooper, Delmonico, et al., 2004)

(Cooper et al., 2000)

(Cooper, Galbreath, et al., 2004)

(Cooper et al., 2001)

(Cooper et al., 2002)

(Cooper et al., 2006)

(Cooper et al., 1999)

(Crosby \& Twohig, 2016)
A cross-sectional sample of adult men in China $(\mathrm{N}=4,651$; Mean age $=22.7, \mathrm{SD}=$ 4.33 ; $93.1 \%$ heterosexual)

A cross-sectional sample of adult men in China $(\mathrm{N}=9,395$; Mean age $=23.4 \mathrm{SD}=$ 3.34; $93.1 \%$ heterosexual

A cross-sectional sample of university students in Bangladesh $(\mathrm{N}=299 ; 70.6 \%$ men)

A retrospective intervention study on the efficacy of pharmacological treatment for CSB $(\mathrm{N}=14 ; 100 \%$ men; Mean age $=45)$ A cross-sectional study in the U.S. of men who have sex with men $(\mathrm{N}=2,716$; Mean age $=29.0, \mathrm{SD}=8.3$ )

A cross-sectional study in the U.S. of men with non-paraphilic CSB ( $\mathrm{n}=15$; Mean age $=38$ ), in comparison with men with paraphilic CSB $(n=35$, Mean age $=36)$, and healthy controls $(n=42$, Mean age $=$ 43)

A cross-sectional study of internet users in the U.S $(\mathrm{N}=7,037 ; 84.1 \%$ men $)$

A cross-sectional study of adult internet users in the U.S. ( $\mathrm{N}=9,265 ; 86 \%$ men; $86.5 \%$ heterosexual)

A cross-sectional study of adult men internet users in the U.S. ( $\mathrm{N}=384$; Mean age $=33$, $\mathrm{SD}=10.44 ; 88 \%$ heterosexual)

A cross-sectional study of internet using adults in the United States $(\mathrm{N}=7,037$; $84.1 \%$ men; Mean age $=33.73$ )

A cross-sectional study of internet using adults in the United States $(\mathrm{N}=7,037$; $84.1 \%$ men; Mean age $=33.73$ )

A cross-sectional study of internet using adults in the U.S. $(\mathrm{N}=3,466$; no other demographics reported)

A cross-sectional study of internet using adults in the U.S. ( $\mathrm{N}=9,177 ; 86 \%$ men; Mean age $=34.96, \mathrm{SD}=11.62 ; 87 \%$ heterosexual)

A treatment study evaluating the efficacy of Acceptance and Commitment Therapy in treating PPU in men in the U.S. $(\mathrm{N}=28$; Mean age $=29.3, \mathrm{SD}=11.4$ )
Problematic Pornography

Consumption Scale; the Brief Pornography Screener; and the Kalichman Sexual Compulsivity Scale PPU as measured by the Problematic Pornography Consumption Scale PPU as measured by idiosyncratic questions to this study and face-to-face interviews with researchers

General CSB as measured by clinician diagnosis

General CSB as measured by the Compulsive Sexual Behavior Inventory

General CSB as measured by the Compulsive Sexual

Behavior Inventory

General CSB as measured by the Kalichman Sexual Compulsivity Scale Online CSB and general $\mathrm{CSB}$ as measured by the Kalichman Sexual Compulsivity Scale Online CSB as measured by idiosyncratic items unique to this research project Online CSB as measured by the Kalichman Sexual Compulsivity Scale Online CSB as measured by the Kalichman Sexual Compulsivity Scale Online CSB as measured by the Kalichman Sexual Compulsivity Scale

Online CSB as measured by the Kalichman Sexual Compulsivity Scale

PPU as measured by the Kalichman Sexual Compulsivity Scale and the Cognitive and Behavioral 
A cross-sectional survey of adult internet users in Sweden $(\mathrm{N}=1,458 ; 45.1 \%$ men;

(Daneback et al., 2006)

(Das et al., 2017)

(Davidson et al., 2017)

(De Boni et al., 2018)

(Delmonico \& Miller, 2003)

(Derbyshire \& Grant, 2015)

(Dew \& Chaney, 2005)

(Dhuffar et al., 2015)

(Dhuffar \& Griffiths, 2014)

(Dickenson et al., 2018)

(Dilley et al., 2008)

(do Amaral et al., 2015)

(Dodge et al., 2004)
$90 \%$ heterosexual; Men: Mean age $=29.7$, $\mathrm{SD}=10.3$; Women: Mean age $=31.5, \mathrm{SD}=$ 9.8)

A cross-sectional survey of adult outpatients of a psychiatric hospital in India $(\mathrm{N}=75$; $60 \%$ men; Mean age $=26.57, \mathrm{SD}=6.50$ )

A cross-sectional study of patients in a psychiatric hospital setting in New Zealand $(\mathrm{N}=100 ; 63 \%$ men; Mean age $=35.88, \mathrm{SD}$ $=12.54)$

A cross-sectional study of men who have sex with men receiving PrEP treatment in Brazil $(\mathrm{N}=421$; Mean age $=29)$

A cross-sectional study of visitors to an English language sexual health website $(\mathrm{N}=$ 6,$088 ; 82.2 \%$ men)

A study of neurocognitive functioning in adults with CSB ( $\mathrm{n}=13$; no other demographics reported) in comparison with healthy controls $(n=13)$

A cross-sectional study of men who have sex with men in the U.S. $(\mathrm{N}=513$; Mean age $=36.1, \mathrm{SD}=11.44$ )

A cross-sectional study of university students in the U.K. $(\mathrm{N}=165,40.6 \%$ men; Mean age $=28.0, \mathrm{SD}=7.7$ )

A cross-sectional study of women university students in the U.K. $(\mathrm{N}=102 ; 87.3 \%$ heterosexual)

A nationally representative, cross-sectional, probability sampling study of the U.S. population $(\mathrm{N}=2,325$; matched to U.S. norms)

A longitudinal (12 months) efficacy study for a HIV counseling intervention study among a sample of U.S. men who have sex with men $(\mathrm{N}=336)$

A cross-sectional study of men seeking treatment for CSB in Brazil ( $\mathrm{N}=69$; Mean age $=35.2, \mathrm{SD}=802$ )

A cross-sectional study of undergraduates in the U.S. $(\mathrm{N}=876 ; 37.1 \%$ men; Mean age $=$ $20.2, \mathrm{SD}=0.87$ )
Outcomes of Sexual

Behavior Scale

Online CSB as measured by the Kalichman Sexual

Compulsivity Scale

PPU as measured by the Pornography Addiction Screening Tool

General CSB as measured by the Hypersexuality in Psychiatric Conditions Observer-Rated Scale General CSB as measured by the Kalichman Sexual Compulsivity Scale Online CSB as measured by the Internet Sex Screening Test

General CSB as measured by the Minnesota Impulsive

Disorders Interview

General CSB as measured by the Compulsive Sexual Behavior Inventory General CSB as measured by the Hypersexual Disorder Questionnaire and the Hypersexual Behavior Consequences Scale General CSB as measured by the Hypersexual Disorder Questionnaire and the Hypersexual Behavior Consequences Scale

General CSB as measured by the Compulsive Sexual Behavior Inventory

General CSB as measured by the Kalichman Sexual Compulsivity Scale

General CSB as measured by clinician diagnosis and the Kalichman Sexual Compulsivity Scale General CSB as measured by the Kalichman Sexual Compulsivity Scale 
A cross-sectional study of U.S. men who have sex with men $(\mathrm{N}=504$; Mean age $=$ $34.7, \mathrm{SD}=10.6$ )

A cross-sectional study of U.S. men who

(Downing et al., 2014) have sex with men $(\mathrm{N}=265$; Mean age $=$ $32.9, \mathrm{SD}=12.5$ )

A functional magnetic resonance imaging study of heterosexual men in Poland $(\mathrm{N}=$ 98; Mean age $=34.5, \mathrm{SD}=6.5$ )

A cross-sectional study of university students in Poland $(\mathrm{N}=6,463 ; 40.7 \%$ men; Mean age $=22.1, \mathrm{SD}=1.7$ )

A cross-sectional study of Israeli adolescents $(\mathrm{N}=310 ; 59 \%$ boys; Mean age $=16.94, \mathrm{SD}=0.65$ )

A cross-sectional study of Israeli

(Efrati, 2019; Study 1) adolescents $(\mathrm{N}=661 ; 49.8 \%$ boys; Mean age $=16.84, \mathrm{SD}=1.29$ )

A cross-sectional study of Israeli

(Efrati, 2019; Study 2) adolescents $(\mathrm{N}=522 ; 43.5 \%$ boys; Mean age $=16.84, \mathrm{SD}=1.29$ )

A cross-sectional study of Israeli

(Efrati, 2019; Study 3) adolescents $(\mathrm{N}=317 ; 49.52 \%$ boys; Mean age $=17.84, \mathrm{SD}=4.23)$

A cross-sectional study of Israeli

(Efrati \& Dannon, 2018) adolescents $(\mathrm{N}=311 ; 59 \%$ boys; Mean age $=16.94, \mathrm{SD}=0.65)$

(Efrati \& Mikulincer, 2018; Study 1)

A cross-sectional study of Israeli adults $(\mathrm{N}=$ $492 ; 50 \%$ men; Mean age $=32.2, \mathrm{SD}=5.3$ )

A cross-sectional study of Israeli adults $(\mathrm{N}=$ $205 ; 50.7 \%$ men; Mean age $=39.9, \mathrm{SD}=$ 9.4)

2018; Study 2, Sample 1)

(Efrati \& Mikulincer, 2018; Study 2, Sample 2)

A cross-sectional study of Israeli adults $(\mathrm{N}=$ 201; $50.8 \%$ men; Mean age $=33.1, \mathrm{SD}=$ 9.1)

(Efrati \& Mikulincer, 2018; Study 3)

(Efrati, Gerber, et al., 2019)
A cross-sectional study of Israeli adults in a Sexaholics Anonymous group $(\mathrm{N}=112$; $95 \%$ men; Mean age $=34.6, \mathrm{SD}=9.25$ )

A cross-sectional study of Israeli adults in a Sexaholics Anonymous group ( $\mathrm{N}=160$; $100 \%$ men)
General CSB as measured by the Kalichman Sexual Compulsivity Scale PPU as measured by a modified form of the Compulsive Internet Use Scale

General CSB as measured by the Sexual Addiction Screening Test and the Brief Pornography Screener

PPU as measured by idiosyncratic measures General CSB as measured by the Individual Based Compulsive Sexual Behavior Scale General CSB as measured by the Individual Based Compulsive Sexual Behavior Scale General CSB as measured by the Individual Based Compulsive Sexual Behavior Scale General CSB as measured by the Individual Based Compulsive Sexual Behavior Scale General CSB as measured by the Individual Based Compulsive Sexual Behavior Scale General CSB as measured by the Individual Based Compulsive Sexual Behavior Scale General CSB as measured by the Individual Based Compulsive Sexual Behavior Scale General CSB as measured by the Individual Based Compulsive Sexual Behavior Scale General CSB as measured by the Individual Based Compulsive Sexual Behavior Scale General CSB as measured by the Individual Based Compulsive Sexual Behavior Scale 
A cross-sectional study of Israeli men in a

Sexaholics Anonymous group $(\mathrm{n}=68$;

Mean age $=32.26, \mathrm{SD}=14.98)$, of sex

(Efrati, Shukron, et al., 2019)

offenders in an Israeli prison $(n=103$; Mean

age $=43.57, \mathrm{SD}=16.59)$ and violent

offenders in an Israeli Prison $(\mathrm{n}=81$, Mean

age $=35.67, \mathrm{SD}=9.98$ )

A cross-sectional study of Israeli adults in a

(Efrati \& Gola, 2018a) $\quad$ Sexaholics Anonymous group $(\mathrm{N}=97 ; 98 \%$

men; Mean age $=30.19, \mathrm{SD}=7.3$ )

A cross-sectional study of Israeli

adolescents $(\mathrm{N}=1,182 ; 42 \%$ boys; Mean

age $=16.68, \mathrm{SD}=1.54)$

A cross-sectional study of Israeli

adolescents $(\mathrm{N}=618 ; 55.3 \%$ boys; Mean

age $=16.69, \mathrm{SD}=1.16$ )

A cross-sectional study of Israeli adults (95\% men) in Sexaholics Anonymous $(\mathrm{n}=$ 65 ; Mean age $=34.6, \mathrm{SD}=9.25)$ and healthy controls $(n=47$; Mean age $=36.78$, $\mathrm{SD}=8.67)$

A cross-sectional study of Israeli

(Efrati \& Gola, 2019b) adolescents $(\mathrm{N}=275 ; 42 \%$ boys; Mean age

$=16.23, \mathrm{SD}=1.18)$

A cross-sectional study of men in the U.K.

$(\mathrm{N}=227$; Mean age $=23.59, \mathrm{SD}=8.70)$

(Egan \& Parmar, 2013)

(Engel, Kessler, et al., 2019)

A cross-sectional study of adults in Germany $(\mathrm{N}=1,194 ; 53 \%$ men; Mean age $=$ $32.99, \mathrm{SD}=10.78 ; 83 \%$ heterosexual)
General CSB as measured by the Individual Based

Compulsive Sexual

Behavior Scale

General CSB as measured by the Individual Based

Compulsive Sexual

Behavior Scale

General CSB as measured

by the Individual Based

Compulsive Sexual

Behavior Scale

General CSB as measured

by the Individual Based

Compulsive Sexual

Behavior Scale

General CSB as measured by the Individual Based

Compulsive Sexual

Behavior Scale

General CSB as measured by the Individual Based

Compulsive Sexual

Behavior Scale

PPU as measured by the

Cyber Pornography Use

Inventory and the Sexual

Addiction Screening Test

Revised

General CSB and Online

CSB as measured by the

Hypersexual Behavior

Inventory and the Short

Internet Addiction Test

revised for cybersex

behavior

General CSB and Online

CSB as measured by the

Hypersexual Behavior

Inventory, the Sexual

Addiction Screening Test

Revised, and the Short

Internet Addiction Test

revised for cybersex

behavior

A cross-sectional study in a psychiatric setting in Spain of adults with gambling disorder $(\mathrm{n}=2190 ; 90.1 \%$ men; Mean age $=$ 42.2, $\mathrm{SD}=13.4)$ in comparison with

General CSB as measured by clinician diagnosis

(Farre et al., 2015) individuals with CSB $(n=59 ; 98.3 \%$ men; 
Mean age $=40.1, \mathrm{SD}=8.8)$ and healthy controls $(\mathrm{n}=93 ; 89.2 \%$ men; Mean age $=$ 31.0, $\mathrm{SD}=9.5$ )

A brief, longitudinal (2 weeks) study of men

(Fernandez et al., 2017) in a university setting in Malaysia $(\mathrm{N}=76$;

Mean age $=22.27, \mathrm{SD}=3.45$ )

A cross-sectional study of heterosexual

(Gil-Llario et al., 2016)

young adults in Spain $(\mathrm{N}=424 ; 39.6 \%$ men;

Mean age $=20.62, \mathrm{SD}=2.62$ )

A cross-sectional study in the U.S. of Latino

(Gilbert \& Rhodes, 2014)

men who have sex with men $(\mathrm{N}=190$;

Mean age $=25.5, \mathrm{SD}=5.4$ )

A cross-sectional sample of men seeking

(Gilliland et al., 2015)

treatment for CSB in the U.S. $(\mathrm{N}=136$;

Mean age $=34.73, \mathrm{SD}=13.06$ )

A cross-sectional sample of undergraduates

(Giordano \& Cecil, 2014) at a university in the U.S. ( $\mathrm{N}=235 ; 58 \%$

men; Mean age $=20.91, \mathrm{SD}=3.56 ; 94.5 \%$ heterosexual)

A cross-sectional sample of undergraduates

(Giordano et al., 2015)

at a university in the U.S. $(\mathrm{N}=235 ; 58 \%$

men; Mean age $=20.91, \mathrm{SD}=3.56 ; 94.5 \%$

heterosexual)

A cross-sectional analysis of heterosexual

(Gola et al., 2016)

men in Poland $(\mathrm{N}=569$; Mean age $=$

28.871, $\mathrm{SD}=6.36$ )

A cross-sectional study of heterosexual men

(Gola, Skorko, et al., 2017)

in Poland seeking treatment for CSB $(\mathrm{n}=$

116 ; Mean age $=28.35, \mathrm{SD}=7.33)$ in

comparison with healthy controls $(n=442$;

Mean age $=28.35, \mathrm{SD}=7.33$ )

PPU as measured by the

Cyber Pornography Use

Inventory-9

General CSB as measured

by the Kalichman Sexual

Compulsivity Scale

General CSB as measured

by the Kalichman Sexual

Compulsivity Scale

General CSB as measured

by the Hypersexual Behavior Inventory

General CSB as measured

by the Hypersexual Behavior

Inventory

General CSB as measured

by the Hypersexual Behavior

Inventory

PPU as measured by the

Sexual Addiction Screening

Test Revised

General CSB as measured

by the Sexual Addiction

Screening Test

A longitudinal functional magnetic

resonance imaging study of heterosexual

(Gola, Wordecha, et al., 2017)

men in Poland seeking treatment for PPU (n

$=28$; Mean age $=30.96, \mathrm{SD}=6.51)$ in

comparison with healthy controls $(n=24$;

Mean age $=30.49, \mathrm{SD}=7.55$ )

A cross-sectional study of college students

(Graham et al., 2016)

in the U.S. $(\mathrm{N}=1,152 ; 47.4 \%$ women;

Mean age $=19.46, \mathrm{SD}=1.79)$

A cross-sectional study in a psychiatric

setting in Spain of adults with compulsive buying behaviors $(\mathrm{n}=110 ; 28.2 \%$ men;

Mean age $=43.3$ ) in comparison with individuals with CSB $(\mathrm{n}=28 ; 96.4 \%$ men;

(Granero et al., 2016)

Mean age $=41.3$ ), internet gaming disorder

$(\mathrm{n}=51 ; 94.1 \%$ men; Mean age $=22)$,

internet addiction $(\mathrm{n}=41 ; 73.2 \%$ men;

Mean age $=31.7$ ) and gambling disorder ( $\mathrm{n}$

$=3,094 ; 89.9 \%$ men; Mean age $=42.9$ )

A cross-sectional study from English

(Greenfield, 1999)

General CSB as measured by the Kalichman Sexual

Compulsivity Scale

General CSB as measured by the Multidimensional

Assessment of Sex and Aggression

General CSB as measured by clinician assessment based on the DSM-IV-TR criteria for Sexual Disorder Not Otherwise Specified

Online CSB as measured by four idiosyncratic questions 
(Grov, Golub, et al., 2010)

(Grov, Parsons, et al., 2010)

(Grov et al., 2014)

(Grubbs et al., 2017; Study 1)

(Grubbs et al., 2017; Study 2)

(Grubbs \& Gola, 2019; Sample 1)

(Grubbs \& Gola, 2019; Sample 2)

(Grubbs \& Gola, 2019; Sample 3)

(Grubbs, Kraus, et al., 2019)

(Grubbs, Grant, et al., 2019; Sample 1)

(Grubbs, Grant, et al., 2019; Sample 2)

(Grubbs, Grant, et al., 2019; Sample 3)

(Grubbs, Grant, et al., 2019; Sample 4)

(Grubbs, Kraus, et al., 2020; Study 1, Sample 1)
An intensive longitudinal study (daily diary study) of gay and bisexual men in the U.S. $(\mathrm{N}=47$, Mean age $=36.2)$

A cross-sectional study of gay and bisexual men in the U.S. $(\mathrm{N}=1,214$; Mean age $=$ $37.4, \mathrm{SD}=11.4)$

A cross-sectional study in the U.S. of men who have sex with men $(\mathrm{N}=2,063)$

A longitudinal (1 year) study of college students in the U.S. $(\mathrm{N}=1,519 ; 67.2 \%$ men; Mean age $=19.3, \mathrm{SD}=1.3$ )

A longitudinal (1 year) study of adult internet users in the U.S. recruited via Mechanical Turk $(\mathrm{N}=713 ; 51.9 \%$ men; Mean age $=30.2, \mathrm{SD}=9.9$ )

A cross-sectional study of undergraduate men in the U.S. $(\mathrm{N}=147$; Mean age $=19.8$, $\mathrm{SD}=3.7$ )

A longitudinal study of men in the U.S. recruited via Mechanical Turk $(\mathrm{N}=433$; Mean age $=33.5, \mathrm{SD}=9.7$ )

A cross-sectional sample of men in the U.S. matched to 2010 Census norms $(\mathrm{N}=297$, Mean age $=46.5, \mathrm{SD}=15.3$ )

A cross-sectional sample of adults in the U.S. matched to 2010 Census norms $(\mathrm{N}=$ 1,$461 ; 59 \%$ men; Mean age $=44.8, \mathrm{SD}=$ 16.7)

A cross-sectional sample of adults in the U.S. recruited via Mechanical Turk $(\mathrm{N}=$ $829 ; 56.7 \%$ men; Mean age $=19.3, \mathrm{SD}=$ $1.8)$

A cross-sectional sample of adults in the U.S. recruited via Mechanical Turk $(\mathrm{N}=$ 424; $52.4 \%$ men; Mean age $=33.6, \mathrm{SD}=$ $9.1)$

A cross-sectional sample of university students in the U.S. $(\mathrm{N}=231 ; 39.8 \%$ men; Mean age $=19.3, \mathrm{SD}=1.8$ )

A cross-sectional sample of adults in the U.S. matched to 2010 Census norms $(\mathrm{N}=$ $736 ; 58.1 \%$ men; Mean age $=48.0, \mathrm{SD}=$ $15.0)$

A cross-sectional sample of undergraduates at a university in the U.S. ( $\mathrm{N}=467 ; 38.5 \%$ men; Mean age $=19.32, \mathrm{SD}=2.45$ )
General CSB as measured by the Kalichman Sexual Compulsivity Scale General CSB as measured by the Kalichman Sexual Compulsivity Scale General CSB as measured by the Kalichman Sexual Compulsivity Scale PPU as measured by the Cyber Pornography Use Inventory 9

PPU as measured by the Cyber Pornography Use Inventory-9

PPU as measured by the Cyber Pornography Use Inventory-4 PPU as measured by the Cyber Pornography Use Inventory-4 PPU as measured by the Cyber Pornography Use Inventory-4 PPU as measured by three items from the Cyber Pornography Use Inventory9

PPU as measured by idiosyncratic true/false questions about selfidentification as a pornography addict PPU as measured by idiosyncratic true/false questions about selfidentification as a pornography addict PPU as measured by idiosyncratic true/false questions about selfidentification as a pornography addict PPU as measured by idiosyncratic true/false questions about selfidentification as a pornography addict PPU as measured by the Cyber Pornography Use Inventory-4 
(Grubbs, Kraus, et al., 2020; Study 1, Sample 2)

(Grubbs, Kraus, et al., 2020; Study 1, Sample 3)

(Grubbs, Kraus, et al., 2020; Study 2)

(Grubbs, Lee, et al., 2020)

(Grubbs, Stauner, et al., 2015; Study 1)

(Grubbs, Stauner, et al., 2015; Study 2)

(Grubbs, Volk, et al., 2015; Study 1)

(Grubbs, Volk, et al., 2015; Study 2)

(Grubbs, Volk, et al., 2015; Study 3)

(Grubbs, Wilt, Exline, \& Pargament, 2018; Study 1)

(Grubbs, Wilt, Exline, \& Pargament, 2018; Study 2)

(Grubbs, Wilt, Exline, Pargament, et al., 2018; Sample 1)

(Grubbs, Wilt, Exline, Pargament, et al., 2018; Sample 2)

(Gullette \& Lyons, 2005)
A cross-sectional sample of adults in the U.S. matched to 2010 Census norms $(\mathrm{N}=$ $739 ; 58 \%$ men; Mean age $=47.9, \mathrm{SD}=$ $15.81)$

A cross-sectional sample of adults in the U.S. matched to 2010 Census Norms $(\mathrm{N}=$ 1,$463 ; 59 \%$ men; Mean age $=45.51, \mathrm{SD}=$ 16.6)

A longitudinal (1 year) study of adults in the U.S. recruited via Mechanical Turk $(\mathrm{N}=$ $850 ; 52.3 \%$ men; Mean age $=33.98, \mathrm{SD}=$ 9.87)

A cross-sectional sample of adults in the U.S. matched to 2016 American Community Survey Norms $(\mathrm{N}=1,424 ; 66.4 \%$ men; Mean age $=43.92, \mathrm{SD}=16.74$ )

A cross-sectional study of adults in the U.S. recruited via Mechanical Turk $(\mathrm{N}=713$; $51.9 \%$ men; Mean age $=30.2, \mathrm{SD}=9.9$ ) A longitudinal study (1 year) of college students in the U.S. $(\mathrm{N}=1,215 ; 67.2 \%$ men; Mean age $=19.3, \mathrm{SD}=1.3$ )

A cross-sectional study of undergraduate students in the U.S. $(\mathrm{N}=269 ; 84.4 \%$ men; Mean age $=19.5, \mathrm{SD}=1.4$ )

A cross-sectional study of adults in the U.S. recruited via Mechanical Turk $(\mathrm{N}=214$; $63.6 \%$ men; Mean age $=31.8, \mathrm{SD}=10.7$ )

A cross-sectional study of university students in a college counseling center setting $(\mathrm{N}=152 ; 67.8 \%$ men; Mean age $=$ 20.3, $\mathrm{SD}=1.8$ )

A longitudinal (1 year) study of undergraduate students in the U.S. $(\mathrm{N}=$ 1,$352 ; 67.7 \%$ men; $90.1 \%$ heterosexual)

A longitudinal (1 year) study of adults in the U.S. recruited via Mechanical Turk ( $\mathrm{N}=$ 793; 48.8\% men; $83.9 \%$ heterosexual)

A longitudinal (1 year) study of undergraduate students in the U.S. ( $\mathrm{N}=$ 1,$507 ; 65.2 \%$ men; Mean age $=19.3, \mathrm{SD}=$ $2.2 ; 90.1 \%$ heterosexual)

A longitudinal (1 year) study of adults in the U.S. recruited via Mechanical Turk $(\mathrm{N}=$ $782 ; 48.8 \%$ men; Mean age $=32.2, \mathrm{SD}=$ 10.3)

A cross-sectional study of university students in the U.S. $(\mathrm{N}=256,39.1 \%$ men; Mean age $=21.6$ )
PPU as measured by the Cyber Pornography Use Inventory-4

PPU as measured by the Brief Pornography Screener

PPU as measured by the Cyber Pornography Use Inventory-4

PPU as measured by the Cyber Pornography Use Inventory-4 and the Brief Pornography Screener PPU as measured by the Cyber Pornography Use Inventory-9

PPU as measured by the Cyber Pornography Use Inventory-9

PPU as measured by the Cyber Pornography Use Inventory-9 PPU as measured by the Cyber Pornography Use Inventory-9 and the Kalichman Sexual Compulsivity Scale PPU as measured by the Cyber Pornography Use Inventory-9 and the Kalichman Sexual Compulsivity Scale PPU as measured by the Cyber Pornography Use Inventory-9

PPU as measured by the Cyber Pornography Use Inventory-9

PPU as measured by the Cyber Pornography Use Inventory-9

PPU as measured by the Cyber Pornography Use Inventory-9

General CSB as measured by the Kalichman Sexual Compulsivity Scale 
(Guyon et al., 2020)

(Halkitis, Green, et al., 2005)

(Halkitis, Wilton, et al., 2005)

(Hall et al., 2020)

(Hallberg et al., 2017) Sweden $(\mathrm{N}=10$; Mean age $=38.9, \mathrm{SD}=$ $8.1)$

A cross-sectional study in the U.S. of HIVpositive men who have sex with men $(\mathrm{N}=$ 980; Mean age $=41, \mathrm{SD}=7.91$ )

A psychoeducational treatment study CSB in the UK $(\mathrm{N}=119$; gender, age, and sexual orientation not reported)

(Hallberg et al., 2019)

(Hardy et al., 2010)

(Harper \& Hodgins, 2016)

(Hart et al., 2016)

(Hart et al., 2020)

(Hartman et al., 2012)

(Hequembourg et al., 2011)

(Herrick et al., 2013)
A treatment study of men in Sweden $(\mathrm{N}=$ 137 ; Mean age $=40, \mathrm{SD}=12$ )
A cross-sectional, retrospective, self-report study of English-speaking users of an online program for treating CSB ( $=138 ; 97 \%$ men; Mean age $=37.97, \mathrm{SD}=12.40$ ) A cross-sectional study of university students in Canada $(\mathrm{N}=191 ; 45 \%$ men; Mean age $=21.05, \mathrm{SD}=2.96$ ) A longitudinal study in the U.S. of HIVpositive men who have sex with men $(\mathrm{N}=$ 59; Mean age $=42.4, \mathrm{SD}=9.0$ )

A sexual education intervention study for HIV positive adult men who have sex with men in Canada (Treatment arm: $\mathrm{n}=89$; Mean age $=40.77, \mathrm{SD}=11.37$; control group: $\mathrm{n}=94$; Mean age $=40.82, \mathrm{SD}=$ 10.7)

A longitudinal study of treatment outcomes in Canada $(\mathrm{N}=57 ; 91.2 \%$ men; Mean age $=$ 39.09, $\mathrm{SD}=8.81$ )

A cross-sectional study in the U.S. of men who have sex with men $(\mathrm{N}=634$; Mean age $=37.7, \mathrm{SD}=11.2$ )

A cross-sectional study in the U.S. of men who have sex with men $(\mathrm{N}=1,551$; Mean
General CSB as measured by the Kalichman Sexual Compulsivity Scale General CSB as measured by an abridged version of the Kalichman Sexual Compulsivity Scale General CSB as measured by an abridged version of the Kalichman Sexual Compulsivity Scale

General CSB as measured by clinician diagnosis

General CSB as measured by the Hypersexual Disorder Current Assessment Scale and the Hypersexual Disorder Screening Inventory General CSB as measured by the Kalichman Sexual Compulsivity Scale, the Hypersexual Disorder Current Assessment Scale, and the Hypersexual Disorder Screening Inventory age $=52$ )
General CSB and PPU as measured by idiosyncratic self-report questions

PPU as measured by the Cyber Pornography Use Inventory

General CSB as measured by the Kalichman Sexual Compulsivity Scale

General CSB as measured by the Kalichman Sexual Compulsivity Scale

General CSB as measured by the Compulsive Sexual Behavior Inventory General CSB as measured by the Kalichman Sexual Compulsivity Scale General CSB as measured by the Compulsive Sexual Behavior Inventory 
(Hoffmann et al., 2014) An experimental study in the U.S. of men who have sex with men $(\mathrm{N}=56)$

A cross-sectional sample of adult male Mechanical Turk users in various countries $(\mathrm{N}=138 ;$ Mean age $=31.75, \mathrm{SD}=10.72$; $87.7 \%$ heterosexual)

A lab-based sexual arousal study of men in the U.S. who have sex with men, comparing men with CSB $(n=81$, Mean age $=38.3$, $\mathrm{SD}=20.2)$ and healthy controls $(\mathrm{n}=130$; Mean age $=33.8, \mathrm{SD}=12.7$ )

A cross-sectional study of university students in the U.S. $(\mathrm{N}=758 ; 21.2 \%$ men; Mean age $=22.4, \mathrm{SD}=4.27 ; 91.8 \%$ heterosexual)

A cross-sectional study in the U.S. of men who have sex with men $(\mathrm{N}=711$, Mean age $=43.86, \mathrm{SD}=13.36$ )

A neuroendocrinological study of

(Jokinen et al., 2017)

(Kafka, 1997)

(Kafka \& Hennen, 1999)

(Kafka \& Hennen, 2003)

(Kalichman \& Cain, 2004)

(Kalichman \& Rompa, 2001)

(Kalichman et al., 2005)

(Kelly et al., 2009)

(Kingston et al., 2018; Study 1) hypersexual men $(\mathrm{n}=54$; Mean age $=39.2)$

in contrast with healthy controls $(\mathrm{n}=33$,

Mean age $=37.5$ ) in Sweden

A cross-sectional study of men in the U.S. with paraphilia $(\mathrm{n}=65$; Mean age $=36.4$, $\mathrm{SD}=10.2 ; 80 \%$ heterosexual $)$ and without paraphilia $(\mathrm{n}=35$; Mean age $=37.1, \mathrm{SD}=$ $8.9 ; 74.3 \%$ heterosexual)

A cross-sectional study of men in the U.S. seeking treatment for sexual disorders $(\mathrm{N}=$ 206; Mean age $=37$ )

A cross-sectional study of men in the U.S. seeking treatment for sexual disorders $(\mathrm{N}=$ 120; Mean age $=37.1, \mathrm{SD}=9.5$ )

A cross-sectional study of adults in the U.S. receiving services related to sexually transmitted infections $(\mathrm{N}=685 ; 71.8 \%$ men; Mean age $=35.7, \mathrm{SD}=10.4$ )

A cross-sectional study of adults in the U.S. with HIV $(\mathrm{N}=287 ; 69 \%$ men; Mean age = 40.3, $\mathrm{SD}=7.4$ )

A cross-sectional study in the U.S. of HIVpositive men $(\mathrm{N}=141$; Mean age $=38.6$, $\mathrm{SD}=7.9$ )

A cross-sectional study of Lesbian/Gay/Bisexual men and women in the U.S. $(\mathrm{N}=1,543 ; 78.7 \%$ men; Men: Mean age $=37.46 ;$ Women: Mean age $=$ 34.03)

A cross-sectional study of university students in Canada $(\mathrm{N}=915 ; 26.7 \%$ men; Men: Mean age $=20.4, \mathrm{SD}=3.6$; Women: Mean age $=19.5, \mathrm{SD}=2.6$ )
General CSB as measured by the Kalichman Sexual Compulsivity Scale PPU as measured by the Brief Pornography Screener, the Problematic Pornography Use Scale

General CSB as measured by clinician diagnosis

General CSB as measured by the Hypersexual Behavior Inventory

General CSB as measured by the Sexual Preoccupation Scale General CSB as measured by the Kalichman Sexual Compulsivity Scale and the Hypersexual Disorder Current Assessment

General CSB as measured by clinician diagnosis

General CSB as measured by clinician diagnosis

General CSB as measured by clinician diagnosis

General CSB as measured by the Kalichman Sexual

Compulsivity Scale

General CSB as measured by the Kalichman Sexual Compulsivity Scale General CSB as measured by the Kalichman Sexual Compulsivity Scale

General CSB as measured by the Kalichman Sexual Compulsivity Scale

General CSB as measured by the Hypersexual Behavior Inventory and the Kalichman Sexual Compulsivity Scale 
A cross-sectional study of adults in Canada

(Kingston et al., 2018; Study 2)

$(\mathrm{N}=694 ; 49.3 \%$ men; Men: Mean age $=$ 28.3, $\mathrm{SD}=8.4$; Women: Mean age $=25.5$, $\mathrm{SD}=8.4)$

(Kingston et al., 2020; Sample 1)

A cross-sectional sample of adults in Canada $(\mathrm{N}=694 ; 49.4 \%$ men $)$

(Kingston et al., 2020; Sample 2)

A cross-sectional sample of adults in Canada $(\mathrm{N}=1,113 ; 42.3 \%$ men $)$

A cross-sectional study of heterosexual men

(Klein, Jurin, et al., 2015)

9.34) and Germany $(\mathrm{n}=195$; Mean age $=$ 34.69; $\mathrm{SD}=10.22$ )

A cross-sectional study of women in

Germany $(\mathrm{N}=988$; Mean age $=24.10, \mathrm{SD}=$ 4.88)

A functional magnetic resonance imaging study of adult men in Germany $(\mathrm{N}=72$; Mean age $=25.6, \mathrm{SD}=4.5$ )

(Klein, Schmidt, et al., 2015)

A cross-sectional study of men in Germany $(\mathrm{N}=8,718$, Mean age $=43.5, \mathrm{SD}=13.7)$

A treatment study of adults in the U.S. $(\mathrm{N}=$ $38 ; 73.6 \%$ men; Mean age $=44.1, \mathrm{SD}=$ $8.88 ; 79 \%$ heterosexual)

A functional magnetic resonance imaging study in Germany of men with CSB $(n=20$;

(Klucken et al., 2016) Mean age $=34.2, \mathrm{SD}=8.6$ ) and healthy controls $(\mathrm{n}=20$; Mean age $=34.9, \mathrm{SD}=$ 9.7)

(Kohut \& Stulhofer, 2018; Sample 1)

A longitudinal (2.5 years) study of adolescent boys in Croatia $(\mathrm{N}=314)$

(Kohut \& Stulhofer, 2018; Sample 2)

(Kor et al., 2014; Study 1)

(Kor et al., 2014; Study 2)

(Kor et al., 2014; Study 3)

A cross-sectional study of heterosexual men in Poland seeking treatment for CSB $(n=$

(Kowalewska et al., 2019) 72 ; Mean age $=35.4, \mathrm{SD}=7.7)$ in comparison with healthy controls $(n=208$; Mean age $=27.8, \mathrm{SD}=5.8$ )
A longitudinal (2.5 years) study of adolescent boys in Croatia ( $\mathrm{N}=197)$

A cross-sectional sample of adults in Israel

$(\mathrm{N}=303 ; 45.2 \%$ men; Mean age $=39.5, \mathrm{SD}$ $=14.5$ )

A cross-sectional sample of adults in Israel

$(\mathrm{N}=300 ; 60 \%$ men; Mean age $=43.85, \mathrm{SD}$ $=14.34$ )

A cross-sectional sample of adults in Israel $(\mathrm{N}=1,720 ; 48.5 \%$ men; Mean age $=39.5$, $\mathrm{SD}=14.2)$
General CSB as measured by the Hypersexual Behavior Inventory and the Kalichman Sexual Compulsivity Scale General CSB as measured by the Hypersexual Behavior Inventory and the Kalichman Sexual Compulsivity Scale General CSB as measured by the Hypersexual Behavior Inventory and the Kalichman Sexual Compulsivity Scale

General CSB as measured by the Hypersexual Disorder Screening Inventory

General CSB as measured by the Hypersexual Behavior Inventory

Online CSB as measured by the Short Interent Addiction Test revised for Sex General CSB as measured by the Hypersexual Behavior Inventory

General CSB as measured by the Garos Sexual Behavior Inventory

General CSB as assessed by clinician interview

PPU as measured by the Compulsive Pornography Consumption Scale PPU as measured by the Compulsive Pornography Consumption Scale PPU as measured by the Problematic Pornography Use Scale PPU as measured by the Problematic Pornography Use Scale PPU as measured by the Problematic Pornography Use Scale

General CSB as measured by the Sexual Addiction Screening Test and PPU as measured by the Brief Pornography Screener 
(Kraus et al., 2016)

A cross-sectional study of men in the U.S.

$(\mathrm{N}=1,298$; Mean age $=34.4, \mathrm{SD}=13.1$; $58 \%$ heterosexual)

(Kraus et al., 2020; Sample 1)

A cross-sectional sampel of U.S. Armed Forces veterans $(\mathrm{N}=220 ; 70.6 \% \mathrm{men}$; Mean age $=25.1, \mathrm{SD}=9.2$ )

A cross-sectional sample of adults in the

(Kraus et al., 2020; Sample 2)

(Kraus et al., 2020; Sample 3)

(Kraus et al., 2020; Sample 4)

(Kraus et al., 2020; Sample 5)

A treatment seeking sample of men in Poland $(\mathrm{N}=105$; Mean age $=32.9, \mathrm{SD}=$ 7.5)

A cross-sectional study of U.S. armed forces veterans $(\mathrm{N}=820 ; 60 \%$ men; Mean age $=$ $35.1, \mathrm{SD}=8.8$ )

A cross-sectional sample of men in the U.S. with PPU related problems $(\mathrm{N}=103$; Mean age $=39.8, \mathrm{SD}=12.1 ; 17 \%$ heterosexual, $70 \%$ gay)

A cross-sectional study of men in the U.S. $(\mathrm{N}=1,298$; Mean age $=34.4, \mathrm{SD}=13.1$; $58 \%$ heterosexual)

(Kraus, Rosenberg, et al., 2017)

A cross-sectional sample of adult men in the U.S. $(\mathrm{N}=229$; Mean age $=33.3, \mathrm{SD}=12.2$; $66 \%$ heterosexual)

A functional magnetic resonance imaging

(Kühn \& Gallinat, 2014) study in Germany of men $(\mathrm{N}=64$; Mean age $=28.9, \mathrm{SD}=6.6$ )
PPU as measured by the

Pornography Craving

Questionnaire and the Hypersexual Behavior Inventory

PPU as measured by the Brief Pornography Screener, the Problematic

Pornography Use Scale, and Hypersexual, Behavior Inventory

PPU as measured by the Cyber Pornography Use Inventory- 9 and the Brief Pornography Screener PPU as measured by the Cyber Pornography Use Inventory- 9 and the Brief Pornography Screener PPU as measured by the Brief Pornography Screener, the Problematic

Pornography Use Scale ,and Hypersexual, Behavior Inventory

PPU as measured by the Brief Pornography Screener, the Problematic

Pornography Use Scale ,and Hypersexual, Behavior Inventory

General CSB as measured by two items from the Minnesota Impulsive Disorders Interview General CSB and PPU as measured by the YaleBrown Obsessive Compulsive Scale adapted for Compulsive Sexual Behaviors

PPU as measured by the Pornography Use Avoidance Self-Efficacy Scale and the Hypersexual Behavior Inventory PPU as measured by the Pornography Use Avoidance Self-Efficacy Scale and the Hypersexual Behavior Inventory

PPU as measured by the Sexual Addiction Screening 
A cross-sectional study in Canada of adults who had survived childhood sexual abuse (n $=324 ; 25.3 \%$ men; Mean age $=28.56$, $\mathrm{SD}=$ 9.92) in comparison with those who had not experienced such abuse $(\mathrm{n}=484 ; 27.5 \%$ men; Mean age $=24.95, \mathrm{SD}=7.03$ )

(Laier \& Brand, 2017; Study 1)

A cross-sectional study of men university students in Germany $(\mathrm{N}=80$; Mean age $=$ $26.41, \mathrm{SD}=6.23$ )

A longitudinal (repeated measures) study of men in Germany $(\mathrm{N}=66$; Mean age $=$ 26.91, $\mathrm{SD}=5.43$ )

An experimental study of heterosexual men in Germany $(\mathrm{N}=171$; Mean age $=24.56$, $\mathrm{SD}=5.22$ )

An experimental study of heterosexual men

(Laier et al., 2013; Study

2)

in Germany with PPU $(\mathrm{n}=25$; Mean age $=$ 23.96, $\mathrm{SD}=2.91)$ in comparison with men without PPU $(\mathrm{n}=25$; Mean age $=22.88$, SD $=1.86$ )

An experimental study of heterosexual

(Laier et al., 2014) women in Germany $(\mathrm{N}=102$; Mean age $=$ $21.83, \mathrm{SD}=2.48$ )

A cross-sectional study of homosexual men

(Laier et al., 2015) in Germany $(\mathrm{N}=71$; Mean age $=29.15, \mathrm{SD}$ $=6.22$ )

(Langstrom \& Hanson, 2006)

(Lee et al., 2009)

(Leonhardt et al., 2018)

(Leonhardt et al., 2020)

A cross-sectional study of adults in Sweden $(\mathrm{N}=2,450 ; 52.2 \%$ men; Age range $=18-60)$

A cross-sectional sample of men university students in the U.S. $(\mathrm{N}=334$; Mean age $=$ $19.54, \mathrm{SD}=2.16 ; 94.6 \%$ heterosexual)

A cross-sectional study of adults in the U.S. recruited via Mechanical Turk $(\mathrm{N}=686$; $51 \%$ men; Mean age $=28.54, \mathrm{SD}=7.85$ ) A cross-sectional sample of adult men in the U.S. recruited via Mechanical Turk $(\mathrm{N}=$
Test and the Internet Sex

Screening Test

General CSB as measured by the Kalichman Sexual Compulsivity Scale

PPU as measured by the short version of the Internet Addiction Test modified for pornography and the Pornography Consumption Inventory

PPU as measured by the short version of the Internet Addiction Test modified for pornography and the Pornography Consumption Inventory

PPU as measured by the Internet Addiction Test modified for cybersex use

PPU as measured by the Internet Addiction Test modified for cybersex use

PPU as measured by the Internet Addiction Test modified for cybersex use Online CSB as measured by the Internet Addiction Test modified for cybersex use, the Hypersexual Behavior Inventory, and the Pornography Consumption Inventory 1,$421 ; 45.7 \%$ men; Mean age $=34.1 ; \mathrm{SD}=$ $10.5)$
General CSB as measured by idiosyncratic measures General CSB as measured by the Kalichman Sexual Compulsivity Scale and the Compulsive Sexual Behavior Inventory General CSB as measured by the Kalichman Sexual Compulsivity Scale

PPU as measured by the Cyber Pornography Use Inventory- 9 
A cross-sectional study of men in the U.S.

$(\mathrm{N}=120$; Mean age $=39.51 ; 88 \%$

heterosexual)

(Levi et al., 2020; Sample

1)

A cross-sectional sample of adults in Israel

$(\mathrm{N}=177 ; 18 \%$ men; Mean age $=33.3, \mathrm{SD}=$ 9.8)

A cross-sectional sample of adults in Israel

$(\mathrm{N}=139 ; 29 \%$ men; Mean age $=24.8 ; \mathrm{SD}=$ $0.3)$

A treatment feasibility study for PPU among adults in the U.S. $(\mathrm{N}=19 ; 90 \%$ men; Mean age $=23.10, \mathrm{SD}=4.48$ )

A cross-sectional study of adults in Poland matched to nationally representative norms $(\mathrm{N}=880 ; 55.1 \%$ men; Mean age $=55.1, \mathrm{SD}$ $=44.9$ )

A cross-sectional study of Polish women seeking treatment for PPU compared to

(Lewczuk et al., 2017) healthy controls $(\mathrm{N}=719$; Mean age $=26.5$, $\mathrm{SD}=5.93 ; 64.25 \%$ heterosexual, $2.64 \%$ lesbian, $11.96 \%$ bisexual, $21.14 \%$ did not report sexuality)

A cross-sectional study of heterosexual men in China $(\mathrm{N}=1,048$; Age range $=18-60)$

A cross-sectional study of women in China $(\mathrm{N}=1,352$; Age ranges $=32.4 \%<21$, $32.6 \% 21-23,35 \%>23$ )

A longitudinal study of a U.S. sample recruited from Mechanical Turk $(\mathrm{N}=320$; $54.8 \%$ men; Mean age $=36.26, \mathrm{SD}=10.18$; $86 \%$ heterosexual, $2.9 \%$ homosexual, $10.1 \%$ bisexual, $0.91 \%$ other; baseline stats)

A cross-sectional study of U.S. undergraduate students ( $\mathrm{N}=390 ; 29.7 \%$ men; $95.4 \%$ heterosexual, $1 \%$ homosexual, $2.6 \%$ bisexual)

An experimental study of heterosexual men in the U.K. with CSB $(n=22$; Mean age $=$ $25.14, \mathrm{SD}=4.68)$ and healthy controls $(\mathrm{n}=$ 44 ; Mean age $=24.16, \mathrm{SD}=5.14$ )

An experimental study of Brazilian men with CSB ( $n=30 ;$ Age range $=20-60 ; 60 \%$ heterosexual) and healthy controls $(\mathrm{n}=30$; Age range $=20-60 ; 86.6 \%$ heterosexual)
General CSB as measured by the Kalichman Sexual Compulsivity Scale

Online CSB as measured by the Sexual Addiction Screening Test Revised Online CSB as measured by the short Internet Addiction Test, modified for online sexual activities and the Sexual Addiction Screening Test Revised

PPU as measured by the Cyber Pornography Use Inventory and the Cognitive and Behavioral Outcomes of Sexual Behavior Scale PPU as measured by the Cyber Pornography Use Inventory-9, the Brief Pornography Screener, and the Hypersexual Behavior Inventory

PPU as measured by the Sexual Addiction Screening Test Revised

General CSB as measured by the Kalichman Sexual Compulsivity Scale General CSB as measured by the Kalichman Sexual Compulsivity Scale

PPU as measured by the Problematic Pornography Use Scale

General CSB as measured by the Kalichman Sexual Compulsivity Scale

General CSB as indicated by psychiatrist diagnosed presence of symptoms

General CSB as measured by the Kalichman Sexual Compulsivity Scale 
A cross-sectional study of men who have sex with men in 17 Latin American

(Mimiaga et al., 2015) countries $(\mathrm{N}=24,274$; Mean age $=30.4$, $\mathrm{SD}$ $=9.1 ; 77.4 \%$ homosexual, $19 \%$ bisexual, $0.5 \%$ heterosexual, $3.1 \%$ unsure/questioning/other) A cross-sectional study of U.S. men who (Miner et al., 2007) have sex with men $(\mathrm{N}=1,026$; Mean age $=$ 28.2)

(Miner et al., 2017)

A cross-sectional study of U.S. men who have sex with men $(\mathrm{N}=242)$

A neuroscience study using diffusion tensor imaging on men with CSB $(\mathrm{n}=8$; Mean age $=44.5, \mathrm{SD}=10.6)$ and healthy controls $(\mathrm{n}=$ 8; Mean age $=43.4, \mathrm{SD}=9.1)$ in the U.S.

A cross-sectional study of U.S. men who have sex with men who have CSB ( $=93$; Mean age $=34.1, \mathrm{SD}=12.8)$ and healthy controls $(\mathrm{n}=149$; Mean age $=38.4, \mathrm{SD}=$ 10.1)

An experimental study of college students in (Moholy et al., 2015) the U.S. $(\mathrm{N}=116 ; 52.6 \%$ men; Mean age $=$ 21.59, $\mathrm{SD}=5.95$ )

A cross-sectional study of U.S. veterans $(\mathrm{N}$

(Moisson et al., 2019) $=283 ; 70.6 \%$ men; Mean age $=35.1, \mathrm{SD}=$ 9.2)

A cross-sectional study of gay and bisexual

(Morgenstern et al., 2011)

(Morrison et al., 2018)

men in the U.S. $(\mathrm{N}=183$; Mean age $=36$, $\mathrm{SD}=8.33 ; 89.6 \%$ homosexual, $10.4 \%$ bisexual)

A cross-sectional study of a clinical sample of Canadian men who have sex with men $(\mathrm{N}$ $=186$; Mean age $=31$ )

A treatment study of gay and bisexual men with CSB in the U.S. $(\mathrm{N}=28$; Mean age $=$ $36.8, \mathrm{SD}=8.2 ; 85.7 \%$ homosexual, $14.3 \%$ bisexual)

A cross-sectional study of heterosexual men $(\mathrm{n}=1061$; Mean age $=32.77, \mathrm{SD}=8.15)$ and women $(\mathrm{n}=240$; Mean age $=38.76$, SD $=9.17$ ) in multiple countries

An experimental study of U.S. men receiving counseling for $\operatorname{CSB}(n=18$; Mean

(Mulhauser et al., 2014) age $=43.22, \mathrm{SD}=14.52)$ and healthy controls $(\mathrm{n}=44$; Mean age $=21.23, \mathrm{SD}=$ 4.55)

(Mulhauser et al., 2018; Study 1)
An experimental study of U.S. adults recruited via Mechanical Turk ( $=369$;
General CSB as measured by the Kalichman Sexual Compulsivity Scale

General CSB as measured by the Compulsive Sexual Behavior Inventory General CSB as measured by the Compulsive Sexual Behavior Inventory

General CSB as measured by the Compulsive Sexual Behavior Inventory

General CSB as measured by the Compulsive Sexual Behavior Inventory

General CSB as measured by the Cognitive and Behavioral Outcomes of Sexual Behavior Scale General CSB as measured by the Hypersexual Behavior Inventory and the Problematic Pornography Use Scale

General CSB as measured by the Kalichman Sexual Compulsivity Scale

General CSB as measured by the Kalichman Sexual Compulsivity Scale General CSB as measured by the Kalichman Sexual Compulsivity Scale and the Compulsive Sexual Behavior Consequences Scale

General CSB as measured by the Kalichman Sexual Compulsivity Scale

General CSB as measured by the Kalichman Sexual Compulsivity Scale

PPU as measured by the Pornography Purchase Task, 
$63.4 \%$ men, $36.3 \%$ women, $\mathrm{n}=1$ nonbinary participant; Mean age $=33.2, \mathrm{SD}=$ 9.5)

(Mulhauser et al., 2018; Study 2)

A cross-sectional study of a clinical sample of men in the U.S. $(\mathrm{N}=39$; Mean age $=$ $46.3, \mathrm{SD}=12.8$ ) the Hypersexual Behavior Inventory, the Cyber Pornography Use Inventory9, and the Problematic Pornography Use Scale PPU as measured by the Pornography Purchase Task, the Hypersexual Behavior Inventory, the Cyber Pornography Use Inventory9, and the Problematic Pornography Use Scale A cross-sectional study of Israeli adults $(\mathrm{N}=$ $85 ; 44.7 \%$ men; Mean age $=26.58, \mathrm{SD}=$ 7.14)

A cross-sectional study of men who have

(Noor et al., 2014; Study

1) sex with men $(\mathrm{N}=240$; Age ranges $=31.5 \%$ $18-24,30.3 \%$ 25-34, $19.5 \% 35-44,18.7>$ 45)

A cross-sectional study of men who have sex with men $(\mathrm{N}=1,165$; Age ranges $=$ $36.2 \% 18-24,31.9 \% 25-34,15.8 \% 35-44$, $16.1 \%>45 ; 82.2 \%$ homosexual, $17.3 \%$ other)

A cross-sectional study of Indonesian college students $(\mathrm{N}=301 ; 58.8 \%$ men; Mean age $=20.11, \mathrm{SD}=1.42$ )

A cross-sectional study of Swedish adults with self-identified CSB $(\mathrm{N}=80 ; 80 \%$ men; Mean age $=38.4, \mathrm{SD}=10.6$ )

A cross-sectional study of a clinical sample of HIV-positive men who have sex with

(O'Dell et al., 2008) $\quad$ men $(\mathrm{N}=637$; Mean age $=42.3, \mathrm{SD}=8.2$; $81.9 \%$ homosexual, $18.1 \%$ bisexual/heterosexual)

A cross-sectional study of U.S. college

(Odlaug \& Grant, 2010) students $(\mathrm{N}=791 ; 32.1 \%$ men; Mean age $=$ $20, \mathrm{SD}=1.25)$

A cross-sectional study of U.S. college

(Odlaug et al., 2013) students $(\mathrm{N}=1,837 ; 42.4 \%$ men; Mean age $=22.6, \mathrm{SD}=5.02$ )

A cross-sectional study of college freshman (Olley, 2008)

(Orzack et al., 2006) in Nigeria $(\mathrm{N}=841 ; 61 \%$ men; Mean age $=$ 20.6, $\mathrm{SD}=2.5$ )

A treatment study of adult men with problematic online sexual behaviors $(\mathrm{N}=$ 35 ; Mean age $=44.5$, range 26-59)
PPU as measured by the Cyber Pornography Use Inventory-9

PPU as measured by the Compulsive Pornography Consumption Scale

PPU as measured by the Compulsive Pornography Consumption Scale

General CSB as measured by the Kalichman Sexual Compulsivity Scale General CSB as measured by the Hypersexual Disorder Screening Inventory, the Kalichman Sexual Compulsivity Scale, and the Cognitive and Behavioral Outcomes of Sexual Behavior Scale

General CSB as measured by the Compulsive Sexual Behavior Inventory

General CSB as measured by the Minnesota Impulsive Disorders Interview General CSB as measured by the Minnesota Impulsive Disorders Interview General CSB as measured by the Kalichman Sexual Compulsivity Scale

Online CSB as measured by clinician-based diagnosis 
A cross-sectional study of gay and bisexual men in the U.S. $(\mathrm{N}=202$; Mean age $=$

(Pachankis et al., 2014) $37.03, \mathrm{SD}=11.35 ; 85.6 \%$ gay/queer/homosexual, $11.9 \%$ bisexual, $2.5 \%$ other non-heterosexual identity)

A cross-sectional study of sexual minority men in the U.S. $(\mathrm{N}=95$; Mean age $=34.86$, $\mathrm{SD}=14.32 ; 80 \%$ homosexual, $10.3 \%$ bisexual, $9.6 \%$ other non-exclusively samesex attracted sexual identities)

A cross-sectional study in the U.S. of men

(Parsons, 2001)

(Parsons \& Bimbi, 2007)

(Parsons, Severino, et al., 2007)

(Parsons et al., 2012)

(Parsons, Millar, et al., 2017)

(Parsons, Rendina, et al., 2017)

(Parsons et al., 2015)

(Parsons et al., 2016)

(Parsons, Kelly, et al., 2007)

(Pekal et al., 2018)
A cross-sectional study of gay and bisexual men in the U.S. $(\mathrm{N}=370$; Mean age $=36.8$, $\mathrm{SD}=11.4$ )

A cross-sectional study of gay and bisexual

$=31.76, \mathrm{SD}=6.27$ )

A cross-sectional study of men who have sex with men in the U.S. $(\mathrm{N}=687$; Mean age $=36.2, \mathrm{SD}=10.17$ )

A cross-sectional study of gay and bisexual men in the U.S. $(\mathrm{N}=183$; Mean age $=36$, $\mathrm{SD}=8.33 ; 89.6 \%$ homosexual, $10.4 \%$ bisexual)

A cross-sectional study of gay and bisexual men in the U.S. $(\mathrm{N}=669$; Mean age $=37.7$, $\mathrm{SD}=11.3 ; 88.8 \%$ homosexual, $8.5 \%$ bisexual)

A cross-sectional study of HIV-negative gay and bisexual men in the U.S. $(\mathrm{N}=1,033$; Mean age $=40.2, \mathrm{SD}=13.8 ; 94.8 \%$ homosexual, $5.2 \%$ bisexual)

A treatment study of HIV-positive gay and bisexual men with CSB in the U.S. $(\mathrm{N}=13$; Mean age $=34.4, \mathrm{SD}=9.6 ; 90.9 \%$ homosexual, $9.1 \%$ bisexual)

A cross-sectional study of gay and bisexual men in the U.S. $(\mathrm{N}=370$; Mean age $=36.8$, $\mathrm{SD}=11.4 ; 88 \%$ gay/queer/homosexual, $12 \%$ bisexual) men in the U.S. $(\mathrm{N}=183$; Mean age $=36$, $\mathrm{SD}=8.33 ; 89.6 \%$ homosexual, $10.4 \%$ bisexual)

An experimental study of college students and a community sample in Germany $(\mathrm{N}=$ 174; $50 \%$ men; Mean age $=23.59, \mathrm{SD}=$ 4.93)
General CSB as measured by the Hypersexual Disorder Screening Inventory

General CSB as measured by the Kalichman Sexual Compulsivity Scale

General CSB as measured by the Kalichman Sexual Compulsivity Scale General CSB as measured by the Kalichman Sexual Compulsivity Scale General CSB as measured by the Kalichman Sexual Compulsivity Scale and the Diagnostic Inventory for Sexual Compulsivity

General CSB as measured by the Kalichman Sexual Compulsivity Scale

General CSB as measured by the Kalichman Sexual Compulsivity Scale

General CSB as measured by the Kalichman Sexual Compulsivity Scale

General CSB as measured by the Kalichman Sexual Compulsivity Scale and the Hypersexual Disorder Screening Inventory General CSB as measured by the Kalichman Sexual Compulsivity Scale and the Hypersexual Disorder Screening Inventory General CSB as measured by the Kalichman Sexual Compulsivity Scale and the Diagnostic Inventory for Sexual Compulsivity PPU as measured by a short version of the Internet Addiction Test modified for sex 
A cross-sectional study of U.S. undergraduate students $(\mathrm{N}=539 ; 69.2 \%$ men; Age ranges $=54.9 \% 18-20,45.1 \% 21$ and older)

A cross-sectional study of U.S.

(Perera et al. 2009b) undergraduate students $(\mathrm{N}=539 ; 69.2 \%$ men; Age ranges $=54.9 \% 18-20,45.1 \% 21$ and older)

A cross-sectional study of U.S.

(Perry et al., 2007)

(Petrican et al., 2015)

(Phillips et al., 2019)

(Pinto et al., 2013)

(Pitpitan et al., 2016)

(Pocknell \& King, 2019)

(Prause et al., 2015)

(Prawiroharjo et al., 2019)

(Raymond et al., 2003)

(Reece, 2003)

(Reece \& Dodge, 2004) undergraduate students $(\mathrm{N}=307 ; 36.8 \%$ men; Mean age $=22.04, \mathrm{SD}=5.66$ )

An experimental study of Canadian college students $(\mathrm{N}=74 ; 35.13 \%$ men; Mean age $=$ 21.72, $\mathrm{SD}=3.57$ )

A cross-sectional study of a U.S. sample of adults recruited through Mechanical Turk (N $=364 ; 55.22 \%$ men; Mean age $=34.6$ )

A cross-sectional study of male college students in Portugal $(\mathrm{N}=152$; Mean age $=$ $22, \mathrm{SD}=2.63 ; 98.7 \%$ heterosexual)

A cross-sectional study of men who have sex with men in Mexico ( $\mathrm{N}=100$; Mean age $=29.7, \mathrm{SD}=8.9 ; 62.3 \%$ homosexual, $37.7 \%$ bisexual/heterosexual)

A cross-sectional study of a U.S. sample of adults recruited through Mechanical Turk (N $=428 ; 52.5 \%$ men; Mean age $=36.30, \mathrm{SD}=$ 11.38)

A neuroscience study using EEG to measure differences between reactions to sexual images in hypersexual adults $(\mathrm{N}=55 ; 75 \%$ men; Mean age $=24.4, \mathrm{SD}=4.9)$ and healthy controls $(\mathrm{N}=67 ; 64.6 \%$ men; Mean age $=24, \mathrm{SD}=6.5$ ) in the U.S.

An experimental study of adolescents with PPU behaviors ( $\mathrm{n}=15 ; 33.33 \%$ men; Mean age $=13.80, \mathrm{SD}=1.26)$ and healthy controls $(\mathrm{n}=15 ; 53.33 \%$ men; Mean age $=13.27$, $\mathrm{SD}=1.26)$

A cross-sectional study of adults in the U.S. who self-perceive their sexual behaviors as addictive or compulsive $(\mathrm{N}=25 ; 92 \%$ men; Mean age $=38, \mathrm{SD}=11$ )

A cross-sectional study of a clinical sample of HIV-positive men who have sex with men $(\mathrm{N}=180$; Mean age $=33.6, \mathrm{SD}=6.9$; $100 \%$ gay or bisexual)

A cross-sectional study of men seeking casual sexual encounters on college campuses in the U.S. $(\mathrm{N}=30$; Age range $=$ $18-43 ; 10 \%$ heterosexual, $70 \%$ homosexual, $16.7 \%$ bisexual, $3.3 \%$ other)
General CSB as measured by the Kalichman Sexual Compulsivity Scale

General CSB as measured by the Kalichman Sexual Compulsivity Scale

General CSB as measured by the Kalichman Sexual Compulsivity Scale

General CSB as measured by the Kalichman Sexual Compulsivity Scale

General CSB as measured by the Hypersexual Behavior Inventory

General CSB as measured by the Compulsive Sexual Behavior Inventory

General CSB as measured by the Kalichman Sexual Compulsivity Scale

General CSB as measured by the Sexual Addiction Screening Test Revised

PPU as measured by the

Kalichman Sexual Compulsivity Scale, the Cognitive and Behavioral Outcomes of Sexual

Behavior Scale, and the Pornography Consumption Effects Scale

PPU as measured by the Pornography Addiction Test

General CSB as measured by the Compulsive Sexual Behavior Inventory

General CSB as measured by the Kalichman Sexual Compulsivity Scale

General CSB as measured by the Kalichman Sexual Compulsivity Scale 
(Reid, 2007)

(Reid, Bramen, et al., 2014)

(Reid \& Carpenter, 2009)

(Reid et al., 2016)

(Reid, Carpenter, Gilliland, et al., 2011)

(Reid, Carpenter, et al., 2012)

(Reid et al., 2008)

(Reid, Cooper, et al., 2012)

(Reid, Cyders, et al., 2014)
A cross-sectional study of a clinical sample of men in the U.S. seeking treatment for $\mathrm{CSB}(\mathrm{N}=67$; Mean age $=32.6, \mathrm{SD}=9.9$; $100 \%$ heterosexual)

A cross-sectional study of a clinical sample of treatment-seeking hypersexual men ( $\mathrm{n}=$ 40; Mean age $=46.6, \mathrm{SD}=11.6 ; 75 \%$ heterosexual, $10 \%$ homosexual, $15 \%$ bisexual) and healthy controls $(n=30$; Mean age $=43.3, \mathrm{SD}=15.6 ; 96.7 \%$ heterosexual, $3.3 \%$ homosexual) in the U.S.

A cross-sectional study of a clinical sample of hypersexual men in the U.S. ( $N=152$;

Mean age $=31.6, \mathrm{SD}=9.3 ; 98 \%$ heterosexual, $1 \%$ homosexual, $1 \%$ bisexual) A cross-sectional study of a clinical sample of hypersexual men in the U.S. who were either highly religious $(\mathrm{n}=52$; Mean age $=$ $39.5, \mathrm{SD}=13.5 ; 94 \%$ heterosexual, $4 \%$ homosexual, $2 \%$ bisexual) or non-religious $(\mathrm{n}=105 ;$ Mean age $=44.3, \mathrm{SD}=10.5 ; 81 \%$ heterosexual, $12 \%$ homosexual, $7 \%$ bisexual)

A cross-sectional study of a clinical sample of men with ADHD seeking treatment for hypersexuality in the U.S. $(\mathrm{N}=81$; Mean age $=31.8, \mathrm{SD}=8.7 ; 98.8 \%$ heterosexual, $1.2 \%$ bisexual)

A longitudinal study (2 weeks) of a clinical sample of adults seeking treatment for hypersexuality, general psychiatric concerns, and substance abuse in the U.S. (hypersexual group: $\mathrm{N}=152 ; 94.7 \%$ men; Mean age $=41.1, \mathrm{SD}=13.0 ; 84.2 \%$ heterosexual, $9.9 \%$ homosexual men, $0.7 \%$ homosexual women, $5.3 \%$ bisexual; baseline stats)

A cross-sectional study of a clinical sample of adults seeking treatment for hypersexuality in the U.S. $(\mathrm{N}=120 ; 96.7 \%$ men; $95.8 \%$ heterosexual, $3.3 \%$

homosexual, $0.8 \%$ bisexual)

A cross-sectional study of a clinical sample seeking treatment for hypersexual behaviors in the U.S. ( $\mathrm{N}=136 ; 85.3 \%$ men; Mean age $=32.4, \mathrm{SD}=11.3 ; 89 \%$ heterosexual, $8.1 \%$ homosexual men, $0.7 \%$ homosexual women, $2.2 \%$ bisexual)

A cross-sectional study of a clinical sample of adults seeking treatment for hypersexual behaviors in the U.S. $(\mathrm{N}=353 ; 74 \%$ men; Mean age $=39.2, \mathrm{SD}=11.1$ )
General CSB as measured by the Kalichman Sexual Compulsivity Scale

General CSB as measured by the Hypersexual Behavior Inventory

General CSB as measured by the Kalichman Sexual Compulsivity Scale

General CSB as measured by the Hypersexual Behavior Inventory

General CSB as measured by the Kalichman Sexual Compulsivity Scale

General CSB as measured by the Hypersexual Behavior Inventory, the Hypersexual Disorder Diagnostic Clinical Interview, the Hypersexual Disorder Questionnaire, the Hypersexual Disorder Course Questionnaire, the Hypersexual Behavior Consequences Scale, and the Sexual Compulsivity Scale

General CSB as measured by the Kalichman Sexual Compulsivity Scale

General CSB as measured by the Hypersexual Behavior Inventory

General CSB as measured by the Hypersexual Behavior Inventory 
A cross-sectional study of a clinical sample of women $(\mathrm{N}=31$; Mean age $=29.9, \mathrm{SD}=$ $10.1 ; 93.5 \%$ heterosexual, $3.2 \%$

(Reid, Dhuffar, et al., 2012)

(Reid, Garos, \&

Carpenter, 2011; Study

1)

(Reid, Garos, \& Carpenter, 2011; Study

2)

homosexual, $3.2 \%$ bisexual) and men $(\mathrm{N}=$ 47 ; Mean age $=41.5, \mathrm{SD}=10.1 ; 78.7 \%$ heterosexual, $19.2 \%$ homosexual, $2.1 \%$ bisexual) seeking treatment for hypersexuality in the U.S.

A cross-sectional study of a clinical sample of U.S. men seeking treatment through a paid online coaching and psychoeducational website for self-identified pornography addiction $(\mathrm{N}=105$; Mean age $=36.5, \mathrm{SD}=$ 12.4)

A cross-sectional study of a clinical sample of men seeking treatment for hypersexuality in the U.S. $(\mathrm{N}=107$; Mean age $=34.7, \mathrm{SD}$ $=9.9 ; 90 \%$ heterosexual, $8 \%$ homosexual, $2 \%$ bisexual)

A longitudinal study (2 weeks) of a clinical sample of adults in the U.S. $(\mathrm{N}=137$; Mean age $=41.5, \mathrm{SD}=12.7 ; 79.6 \%$ heterosexual, $13.1 \%$ homosexual, $7.3 \%$ bisexual) seeking treatment for hypersexuality

A cognitive study of a clinical sample of hypersexual men seeking treatment $(\mathrm{n}=30$;

(Reid, Garos, Carpenter, et al., 2011)

(Reid et al., 2009)

(Reid et al., 2010)

(Reid, Li, Gilliland, et al., 2011; Sample 1)
Mean age $=33, \mathrm{SD}=8 ; 86.7 \%$

heterosexual) and healthy controls $(\mathrm{n}=30$;

Mean age $=28, \mathrm{SD}=6.7 ; 96.7 \%$

heterosexual) in the U.S.

A cross-sectional study of a clinical sample of men seeking treatment for hypersexual behaviors $(\mathrm{n}=71$; Mean age $=30.89, \mathrm{SD}=$ 7.6; $91.5 \%$ heterosexual, $5.6 \%$ homosexual, $2.8 \%$ bisexual $)$ and healthy controls $(n=73$;

Mean age $=25.5, \mathrm{SD}=4.6 ; 95.9 \%$ heterosexual, $2.7 \%$ homosexual, $1.4 \%$ bisexual) in the U.S.

A cognitive study of a clinical sample of treatment-seeking men $(\mathrm{n}=87$; Mean age $=$ $31.4, \mathrm{SD}=8.9 ; 92 \%$ homosexual, $5.7 \%$ homosexual, $2.3 \%$ bisexual) and healthy controls $(\mathrm{n}=92$; Mean age $=26.2, \mathrm{SD}=5.1$; $94.6 \%$ heterosexual, $4.3 \%$ homosexual, $1.1 \%$ bisexual) in the U.S.

A cross-sectional study of a clinical sample of men in the U.S. who were subscribed to
General CSB as measured by the Hypersexual Behavior Inventory

General CSB as measured by the Hypersexual Behavior Inventory

General CSB as measured by the Hypersexual Behavior Inventory

General CSB as measured by the Hypersexual Behavior Inventory, the Hypersexual Disorder Diagnostic Clinical Interview, the Hypersexual Disorder Questionnaire, the Hypersexual Disorder Course Questionnaire, the Hypersexual Behavior Consequences Scale, and the Sexual Compulsivity Scale

General CSB as measured by the Hypersexual Behavior Inventory and the Compulsive Sexual Behavior Inventory

General CSB as measured by the Hypersexual Behavior Inventory

General CSB as measured by the Hypersexual Behavior Inventory

PPU as measured by the Pornography Consumption Inventory 
an online pornography addiction website ( $\mathrm{N}$

$=105$; Mean age $=36.5, \mathrm{SD}=12.4$ )

A cross-sectional study of a clinical sample

(Reid, Li, Gilliland, et al., 2011; Sample 2)

of men seeking treatment for hypersexuality

in the U.S. $(\mathrm{N}=107$; Mean age $=34.7$, SD $=9.9 ; 90 \%$ heterosexual, $8 \%$ homosexual, 2\% bisexual)

A cross-sectional study of a clinical sample

(Reid, Stein, \&

Carpenter, 2011)

of men seeking treatment for hypersexuality

in the U.S. $(\mathrm{N}=95$; Mean age $=31.8, \mathrm{SD}=$

8.26 ; $94 \%$ heterosexual, $5 \%$ homosexual,

$1 \%$ bisexual)

A cross-sectional study of a clinical sample

(Reid, Temko, et al., 2014)

of men seeking treatment for hypersexuality

in the U.S. $(\mathrm{N}=172$; Mean age $=43.4$, SD

$=12.1 ; 83.7 \%$ heterosexual, $8.1 \%$

homosexual, $8.1 \%$ bisexual)

A cross-sectional study of a clinical

(Rendina et al., 2014) population of gay and bisexual men in the

U.S. $(\mathrm{N}=1,532$; Mean age $=35.2, \mathrm{SD}=$ $12.4 ; 75.5 \%$ homosexual, $24.5 \%$ bisexual)

General CSB as measured

by the Hypersexual Behavior

Inventory

General CSB as measured

by the Hypersexual Behavior

Inventory

General CSB as measured

by the Hypersexual Behavior

Inventory

General CSB as measured by the Kalichman Sexual

Compulsivity Scale

General CSB as measured

A longitudinal study of HIV-positive gay

(Rendina et al., 2017)

and bisexual men in the U.S. $(\mathrm{N}=138$;

Mean age $=40.2, \mathrm{SD}=10.1 ; 93.5 \%$

gay/queer/homosexual, $6.5 \%$ bisexual)

A cross-sectional study of HIV-positive gay

(Rendina et al., 2012)

and bisexual men in the U.S. $(\mathrm{N}=127$;

92.9\% homosexual, 7.1\% bisexual)

A longitudinal study (1 year) of gay and

bisexual men in the U.S. $(\mathrm{N}=376$; Mean

(Rendina et al., 2019)

age $=37.8, \mathrm{SD}=11.7 ; 90.8 \%$

gay/queer/homosexual, 9.2\% bisexual;

baseline stats)

A longitudinal cognitive study (30 days) of

gay and bisexual men in the U.S., recruited

(Rendina et al., 2018)

as part of a daily diary study $(\mathrm{N}=334$;

Mean age $=11.5$ )

by the Hypersexual Disorder

Screening Inventory and the

Kalichman Sexual

Compulsivity Scale

General CSB as measured

by the Kalichman Sexual

Compulsivity Scale

General CSB as measured by the Kalichman Sexual

Compulsivity Scale

General CSB as measured by the Kalichman Sexual

Compulsivity Scale

A cross-sectional study of adults in

Germany recruited from universities and

(Rettenberger et al., 2016)

online $(\mathrm{N}=1,749 ; 42.9 \%$ men, $42.9 \%$

women, $0.6 \%$ other; Mean age $=24.42$, SD

$=4.37 ; 83.6 \%$ heterosexual, $3.6 \%$

homosexual, $4.2 \%$ bisexual, $8.6 \%$ other)

A cross-sectional study of adults in the U.S.

(Rhodes et al., 2013) recruited via respondent driven sampling ( $N$

$=190 ; 88.5 \%$ men, $16.3 \%$ transgender men;

Mean age $=25, \mathrm{SD}=5.4$ )

A cross-sectional study of an Australian

(Rissel et al., 2017) nationally representative sample $(\mathrm{N}=$ 20,094; 50\% men; Age range $=16-69$ )

A cross-sectional study of adults in

(Rømer Thomsen et al., 2018)

Denmark $(\mathrm{N}=109 ; 69 \%$ men; Mean age $=$ 21.7, $\mathrm{SD}=2.7$ )

General CSB as measured by the Hypersexual Behavior Inventory

General CSB as measured by the Kalichman Sexual Compulsivity Scale

PPU as measured by a single idiosyncratic item

PPU as measured by the Pornography Craving Questionnaire 
(Rosenberg \& Kraus, 2014)

(Ross et al., 2008)

(Rosser et al., 2014)

(Safren et al., 2018)

(Savard et al., 2020)

(Satinsky et al., 2008)

(Scanavino et al., 2020)

(Scanavino et al., 2018)

(Scanavino et al., 2016)
A cross-sectional study of male undergraduate students $(\mathrm{N}=221$; Mean age $=21.8, \mathrm{SD}=3.8 ; 81 \%$ heterosexual, $16 \%$ homosexual/bisexual, $2 \%$ uncertain)

A cross-sectional study of HIV-positive men who have sex with men in the U.S. $(\mathrm{N}=$ 675; Median age $=42 ; 80 \%$ homosexual, $17 \%$ bisexual, $3 \%$ other/heterosexual)

A cross-sectional study of men who have sex with men in the U.S. $(\mathrm{N}=1,165$; Age ranges $=36.2 \% 18-24,31.9 \% 25-34,15.8 \%$ $35-44,16.1 \% \geq 45 ; 0.5 \%$ heterosexual, $82.6 \%$ homosexual, $11.7 \%$ bisexual, $1.2 \%$ same-gender loving, $2.1 \%$ queer, $1.8 \%$ other)

A longitudinal study (6 months) of men who have sex with men in the U.S. $(\mathrm{N}=197$; Mean age $=37, \mathrm{SD}=11.6 ; 2.5 \%$

heterosexual, $76.6 \%$ homosexual, $18.8 \%$ bisexual, $0.5 \%$ unsure, $1.5 \%$ other; baseline stats)

A cross-sectional study of male sex workers $(\mathrm{n}=60$; Mean age $=23.1, \mathrm{SD}=3.31 ; 100 \%$ homosexual) and gay men $(n=63$; Mean age $=23.75, \mathrm{SD}=3.79)$ in Spain

A psychopharmaceutical treatment study of men with CSB in Sweden $(\mathrm{N}=20$; Mean age $=38.8, \mathrm{Sd}=10.3 ; 70 \%$ heterosexual $)$ A cross-sectional study of men who have sex with men in the U.S. ( $=504$; Mean age $=34.7, \mathrm{SD}=10.61 ; 80 \%$ homosexual, $16 \%$ bisexual, $5 \%$ queer/other)

A cross-sectional study of adults seeking treatment for CSB in Brazil ( $\mathrm{N}=204$; 91.7\% men; Age range $=23-57$ )

A cross-sectional study of a clinical population of men in Brazil $(\mathrm{N}=86$; Mean age $=38.17, \mathrm{SD}=0.95 ; 57 \%$ heterosexual, $26 \%$ homosexual, $17 \%$ bisexual)

A cross-sectional study in Brazil of a clinical population of treatment-seeking men $(\mathrm{n}=88$; Mean age $=38.17, \mathrm{SD}=8.91 ; 58 \%$ heterosexual) and healthy controls $(\mathrm{n}=64$; Mean age $=33.98, \mathrm{SD}=11.4 ; 84.4 \%$ heterosexual)

A cross-sectional study of a clinical population of men in Brazil $(\mathrm{N}=153$; Mean age $=36.4, \mathrm{SD}=13.9 ; 68.6 \%$ heterosexual $)$
PPU as measured by the

Pornography Craving

Questionnaire and the

Kalichman Sexual

Compulsivity Scale

General CSB as measured by the Compulsive Sexual Behavior Inventory

PPU as measured by the Compulsive Pornography

Consumption Scale, the

Compulsive Sexual

Behavior Inventory, and the

Pornography Consumption Effect Scale

General CSB as measured by the Kalichman Sexual Compulsivity Scale

General CSB as measured by the Kalichman Sexual Compulsivity Scale

Hypersexual Disorder: Current Assessment Scale; HBI; K-SCS

General CSB as measured by the Kalichman Sexual Compulsivity Scale

General CSB as measured by the Kalichman Sexual Compulsivity Scale and the Hypersexual Disorder Screening Inventory

General CSB as measured by the Kalichman Sexual

Compulsivity Scale

General CSB as measured by the Kalichman Sexual Compulsivity Scale

General CSB as measured by the Kalichman Sexual Compulsivity Scale, the Hypersexual Disorder Screening Inventory, and the 
A cross-sectional study of undergraduate

(Schatzel-Murphy et al., 2009)

(Schecklmann et al., 2020)

(Schiebener et al., 2015)

(Schmidt et al., 2017)

(Schnarrs et al., 2010)

(Seegers, 2003)

(Semple et al., 2017)

(Semple et al., 2010)

(Semple et al., 2006)

(Seok \& Sohn, 2015)

(Seok \& Sohn, 2018a)

(Seok \& Sohn, 2018b)

(Seok \& Sohn, 2020) students in the U.S. $(\mathrm{N}=186 ; 50 \%$ men; Men: Mean age $=19.9, \mathrm{SD}=1.1$; Women: Mean age $=19.6, \mathrm{SD}=1.4$ )

A study of high-frequency repetitive transcranial magnetic stimulation in heterosexual men in Germany $(\mathrm{N}=19$; Mean age $=23.6, \mathrm{SD}=3.4$ )

An experimental study of men college students in Germany $(\mathrm{N}=104$; Mean age $=$ 24.29; $\mathrm{SD}=3.96$ )

A functional magnetic resonance imaging study of heterosexual men in the U.K. with $\mathrm{CSB}(\mathrm{n}=23$; Mean age $=26.9, \mathrm{SD}=6.22)$ and without $\mathrm{CSB}(\mathrm{n}=69$; Mean age $=25.6$, $\mathrm{SD}=6.55$ )

A cross-sectional study in the U.S. of men who have sex with men $(\mathrm{N}=309$; Mean age $=29.37, \mathrm{SD}=11.33$ )

A cross-sectional study of university students in the U.S. $(\mathrm{N}=240 ; 28.75 \%$ men $)$

A cross-sectional study in Mexico of men who have sex with men $(\mathrm{N}=201$; Mean age $=29.7, \mathrm{SD}=8.7$ )

A cross-sectional study of men in Mexico $(\mathrm{N}=300$; Mean age $=37.8, \mathrm{SD}=9.8)$

A cross-sectional study in the U.S. of HIVpositive men who have sex with men $(\mathrm{N}=$ 217; Mean age $=37.9 ; \mathrm{SD}=7.3$ )

A functional magnetic resonance imaging study of heterosexual men in South Korea with CSB ( $\mathrm{n}=23$; Mean age $=26.12, \mathrm{SD}=$ 4.11 ) in comparison with healthy controls ( $\mathrm{n}$ $=22$; Mean age $=26.27, \mathrm{SD}=3.39$ )

A functional magnetic resonance imaging study of heterosexual men in South Korea with CSB $(\mathrm{n}=23$; Mean age $=26.12, \mathrm{SD}=$ 4.11 ) in comparison with healthy controls (n $=22$; Mean age $=26.27, \mathrm{SD}=3.39$ )

A functional magnetic resonance imaging study of heterosexual men in South Korea with $\operatorname{CSB}(\mathrm{n}=17$; Mean age $=26.92, \mathrm{SD}=$ 4.73 ) in comparison with healthy controls (n $=19$; Mean age $=25.08, \mathrm{SD}=3.53$ )

A functional magnetic resonance imaging study of heterosexual men with CSB in South Korea $(\mathrm{n}=30$; mean age $-28.81, \mathrm{Sd}$ $=5.26)$ compared with healthy controls $(\mathrm{n}=$ 30 ; Mean age $=27.41, \mathrm{SD}=4.01$ )
Compulsive Sexual

Behavior Inventory General CSB as measured by the Multidimensional Assessment of Sex and Aggression Sexual Desire Inventory-2;

Two items from the Questionnaire of Sexual Experience and Behavior PPU as measured by the short version of the Internet Addiction Test modified for sex

General CSB as measured by idiosyncratic measures and clinician diagnosis

General CSB as measured by the Kalichman Sexual Compulsivity Scale General CSB as measured by the Sexual Addiction

Screening Test

General CSB as measured by the Kalichman Sexual Compulsivity Scale General CSB as measured by the Kalichman Sexual Compulsivity Scale General CSB as measured by the Kalichman Sexual Compulsivity Scale General CSB as measured by the Sexual Addiction Screening Test Revised and the Hypersexual Behavior Inventory General CSB as measured by the Sexual Addiction Screening Test Revised and the Hypersexual Behavior Inventory

General CSB as measured by the Sexual Addiction Screening Test Revised and the Hypersexual Behavior Inventory General CSB as measured by the Sexual Addiction Screening Test Revised and the Hypersexual Behavior Inventory 
(Shimoni et al., 2018)

(Sindermann et al., 2018)

(Sinke et al., 2020)

(Sirianni \& Vishwanath, 2016)

(Siu-ming et al., 2019)

(Skegg et al., 2010)

(Sklenarik et al., 2019)

(Sklenarik et al., 2020)

(N. G. Smith et al., 2018)

(P. H. Smith et al., 2014)

(Smolenski et al., 2009)

(Smolenski et al., 2011)

(Snagowski \& Brand, 2015)
A cross-sectional study of adults in Israel (N $=267 ; 70 \%$ men; Mean age $=30.17, \mathrm{SD}=$ 9.8)

A cross-sectional study of university

students in Germany $(\mathrm{N}=472 ; 30.2 \%$ men;

Mean age $=23.19$ )

A functional magnetic resonance imaging study of heterosexual men with CSB in Germany $(\mathrm{n}=38$; Mean age $=36.3, \mathrm{SD}=$ 11.2) compared with healthy controls $(\mathrm{n}=$ 31 ; Mean age $=37.6, \mathrm{SD}=11.17$ )

A cross-sectional study of university students in the U.S. $(\mathrm{N}=340 ; 58 \%$ men $)$

A cross-sectional study of adolescent boys in Hong Kong $(\mathrm{N}=133$; Mean age $=15.99$, $\mathrm{SD}=2.59$ )

A cross-sectional study of young adults in New Zealand ( $\mathrm{N}=940 ; 50.42 \%$ men; Mean age $=32$ )

An experimental study using an approachavoidance task with male undergraduate students in the U.S. $(\mathrm{N}=72$; Mean age $=$ $19.5, \mathrm{SD}=2.4 ; 100 \%$ heterosexual)

An experimental study using an approachavoidance task with heterosexual female undergraduate students in the U.S. $(\mathrm{N}=121$; Mean age $=18.9, \mathrm{SD}=1.1$ )

A cross-sectional study of bisexual men in the U.S. and Canada $(\mathrm{N}=942$; Mean age $=$ 38.97, $\mathrm{SD}=13.94)$

A longitudinal study (6 months) of male veterans in the U.S. $(\mathrm{N}=258$; Mean age $=$ $33.3, \mathrm{SD}=8.2$; baseline stats)

A cross-sectional study of Latino men who have sex with men in the U.S. $(\mathrm{N}=963$; Mean age $=28.2, \mathrm{SD}=7.8$ )

A cross-sectional study of men who have sex with men in the U.S. $(\mathrm{N}=1,699$; Age ranges $=34 \% 18-24,41.16 \% 25-34,16.72 \%$ $35-44,4.79 \% \geq 45$ )

An experimental study of adult men recruited from a university and online in Germany $(\mathrm{N}=123$; Mean age $=23.79, \mathrm{SD}=$ $5.10 ; 100 \%$ heterosexual)
General CSB as measured by the Sexual Addiction Screening Test PPU as measured by a short version of the Internet Addiction Test General CSB as measured by the Sexual Addiction Screening Test Revised and the Hypersexual Behavior Inventory

PPU as measured by idiosyncratic questions about frequency and duration of use

General CSB as measured by the Kalichman Sexual Compulsivity Scale and the Cognitive and Behavioral Outcomes of Sexual Behavior Scale

General CSB as measured by idiosyncratic measures PPU as measured by the Problematic Pornography Use Scale and the Brief Pornography Screener PPU as measured by the Brief Pornography Screener and the Problematic Pornography Consumption Scale

General CSB as measured by the Kalichman Sexual Compulsivity Scale General CSB as measured by the Minnesota Impulsive Disorders Interview General CSB as measured by the Compulsive Sexual Behavior Inventory

General CSB as measured by the Compulsive Sexual Behavior Inventory

Online CSB as measured by the short version of the Internet Addiction Test, modified for online sexual activities, and the Hypersexual Behavior Inventory 
A cross-sectional study of adult men

(Snagowski et al., 2015)

(Spenhoff et al., 2013)

(Stark et al., 2017)

(Steele et al., 2013)

(Storholm et al., 2011)

(Storholm et al., 2016)

(Studer et al., 2019)

(Stulhofer, Bergeron, et al., 2016)

(Stulhofer et al., 2008)

(Stulhofer, Jurin, et al., 2016) recruited from undergraduate classes and online in Germany $(\mathrm{N}=128$; Mean age $=$ $23.88, \mathrm{SD}=4.01 ; 100 \%$ heterosexual)

A cross-sectional study of adult men from multiple countries $(\mathrm{N}=349$; Mean age $=$ $35.8, \mathrm{SD}=11 ; 86.8 \%$ heterosexual)

An experimental study of college students in Germany $(\mathrm{N}=95 ; 50 \%$ men; Mean age $=$ 25.45, $\mathrm{SD}=5.03$ )

A cross-sectional study of homosexual male couples in the U.S. $(\mathrm{N}=344,172$ couples; Mean age $=38.57, \mathrm{SD}=9.34 ; 100 \%$ homosexual)

A neuroscience study of adults in the U.S. $(\mathrm{N}=52 ; 75 \%$ men; Mean age $=24.35, \mathrm{SD}=$ $4.92 ; 45 \%$ heterosexual)

A cross-sectional study of U.S. adults composed of three groups, the Multiple Morbidities Testing Program (MMTP), Counseling and Food Bank Program (CFBP), and Gay Respect Program (GRP) (MMTP: $\mathrm{n}=278,68.48 \%$ men; Mean age $=$ $39.52, \mathrm{SD}=11.87 ; 56.16 \%$ heterosexual, $30.07 \%$ homosexual, $13.77 \%$ bisexual; CFBP: $\mathrm{n}=98,71.43 \%$ men; Mean age $=$ $50.54, \mathrm{SD}=7.61 ; 71.43 \%$ heterosexual, $5.10 \%$ homosexual, $23.47 \%$ bisexual; GRP: $\mathrm{n}=108 ; 100 \%$ men; Mean age $=40.23, \mathrm{SD}$ $=10.48 ; 4.63 \%$ heterosexual, $77.78 \%$ homosexual, $17.57 \%$ bisexual) A cross-sectional study of gay and bisexual men in the U.S. $(\mathrm{N}=509$; Age range $=18$ $19 ; 84.8 \%$ homosexual, $15.2 \%$ bisexual)

A cross-sectional study of adult men in Sweden $(\mathrm{N}=5,332$; Mean age $=25.45$, SD $=1.25 ; 89.2 \%$ heterosexual, $2.3 \%$ homosexual, $8.4 \%$ bisexual)

A cross-sectional study of women in Croatia $(\mathrm{N}=2,599$; Mean age $=28.3, \mathrm{SD}=8.57$; $66.9 \%$ exclusively heterosexual, $5.8 \%$ exclusively homosexual)

A cross-sectional study of adults in Croatia $(\mathrm{N}=1,528 ; 38.2 \%$ men; Mean age $=22, \mathrm{SD}$ $=2.02$ )

A cross-sectional study of adult men in Croatia $(\mathrm{N}=1,998$; Mean age $=34.7, \mathrm{SD}=$ $9.83 ; 66.4 \%$ exclusively heterosexual, $9.3 \%$ exclusively homosexual)
Online CSB as measured by the short version of the Internet Addiction Test, modified for online sexual activities, and the Hypersexual Behavior Inventory

General CSB as measured by the Sexual Addiction Screening Test PPU as measured by the short version of the Internet Addiction Test modified for online sexual activities

General CSB as measured by the Kalichman Sexual Compulsivity Scale

General CSB as measured by the Kalichman Sexual Compulsivity Scale

General CSB as measured by the Compulsive Sexual Behavior Inventory

General CSB as measured by the Compulsive Sexual Behavior Inventory

Online CSB as measured by the Internet Sex Screening Test

General CSB as measured by the Hypersexual Disorder Screening Inventory General CSB as measured by the Kalichman Sexual Compulsivity Scale

General CSB as measured by the Hypersexual Disorder Screening Inventory 
(Štulhofer et al., 2020)

(Stupiansky et al., 2009)

(Sutton et al., 2015)

(Thomas et al., 2020)

(Thompson et al., 2015)

(Tierens et al., 2014)

(Tóth-Király et al., 2019)

(Turban et al., 2020)

(Twohig \& Crosby, 2010) heterosexual)

(Twohig et al., 2009)

(Vaillancourt-Morel et al., 2017)

(Vaillancourt-Morel et al., 2016) heterosexual) $\mathrm{SD}=6.91)$
A longitudinal (6 months) study of adolescent boys in Croatia $(\mathrm{N}=337$; Mean age $=15.8, \mathrm{SD}=0.48$ )

A cross-sectional study of college women in the U.S. $(\mathrm{N}=170$; Mean age $=20.52, \mathrm{SD}=$ 2.46; $96 \%$ heterosexual)

A cross-sectional study of a clinical population in Canada $(\mathrm{N}=115 ; 100 \%$ men; Mean age $=41.5, \mathrm{SD}=11.67$; Sexual orientation recorded for 109 patients: $87 \%$

A cross-sectional sample of internet using adults and university students in Australia $(\mathrm{N}=523 ; 28.3 \%$ men; Mean age $=27, \mathrm{SD}=$ $10.5 ; 83.5 \%$ heterosexual)

A longitudinal study (4 years) of male undergraduate students in the U.S. $(\mathrm{N}=795$; Mean age $=18.56, \mathrm{SD}=0.51$; baseline stats)

A cross-sectional sample of a clinical population in Belgium $(\mathrm{N}=10 ; 100 \%$ men; Mean age $=48.2 ; 90 \%$ heterosexual)

A cross-sectional study of adults in Hungary

$(\mathrm{N}=632 ; 33.4 \%$ men; Mean age $=26.02$,

A cross-sectional sample of dating application users in the U.S. $(\mathrm{N}=515$; $55.3 \%$ men; Mean age $=26.11, \mathrm{SD}=8.28$; $59.2 \%$ heterosexual) in comparison with non-dating application users $(\mathrm{N}=3,688$; $44.2 \%$ men; Mean age $=33.28, \mathrm{SD}=15.01$; $64.4 \%$ heterosexual)

A treatment study of adult men in the U.S. $(\mathrm{N}=28$; Mean age $=29.3, \mathrm{SD}=11.4 ; 100 \%$

A cross-sectional study of adult men in the U.S. $(\mathrm{N}=84$; Mean age $=22)$

A cross-sectional study of Canadian adults $(\mathrm{N}=830 ; 28.2 \%$ men; Mean age $=25.2, \mathrm{SD}$ $=8 ; 81.1 \%$ heterosexual, $5.8 \%$ homosexual, $11.6 \%$ bisexual/other)

A cross-sectional study of Canadian adults $(\mathrm{N}=669 ; 22.1 \%$ men; Mean age $=27.56$, $\mathrm{SD}=9.18 ; 85.8 \%$ heterosexual, $4.0 \%$ homosexual, $8.2 \%$ bisexual)
PPU as measured by the Compulsive Pornography Consumption Scale General CSB as measured by the Kalichman Sexual Compulsivity Scale

General CSB as measured by reviews of patients' charts

General CSB as measured by the Hypersexual Behavior Inventory

General CSB as measured by the Kalichman Sexual Compulsivity Scale General CSB as measured by a questionnaire developed based on Kafka's proposed diagnosis for Hypersexual Behavior Disorder PPU as measured by the Problematic Pornography Consumption Scale

General CSB as measured by the Hypersexual Behavior Inventory

PPU as measured by the Cognitive and Behavioral Outcomes of Sexual Behavior Scale and the Kalichman Sexual Compulsivity Scale PPU as measured by the Cognitive and Behavioral Outcomes of Sexual Behavior Scale and the Kalichman Sexual Compulsivity Scale PPU as measured by the Cyber Pornography Use Inventory. General CSB as measured by the Kalichman Sexual Compulsivity Scale

General CSB as measured by the Kalichman Sexual Compulsivity Scale 
A cross-sectional study of Canadian adults

$(\mathrm{N}=686 ; 23 \%$ men; Mean age $=27.51$, SD

$=9.24 ; 86 \%$ heterosexual, $4 \%$ homosexual, $8 \%$ bisexual)

A cross-sectional study in Spain of a clinical

(Valero-Solis et al., 2018) population (CSB group: $\mathrm{N}=34 ; 100 \%$ men; Mean age $=42.6, \mathrm{SD}=11.9$ )

A cross-sectional study of adults in

Switzerland $(\mathrm{N}=145 ; 60 \%$ men; Mean age $=31 ; 77 \%$ heterosexual, $7.6 \%$ homosexual, $14.5 \%$ bisexual)

A cross-sectional study of gay and bisexual men in the U.S. $(\mathrm{N}=202$; Mean age $=37$,

(Ventuneac et al., 2015)

(Volk et al., 2019)

(Voon et al., 2014)

(Wainberg et al., 2006)

(Walters et al., 2011; Study 1)

A cross-sectional study of Swedish adults $(\mathrm{N}=2101 ; 52.7 \%$ men; Mean age $=36.55$, $\mathrm{SD}=11.80)$

(Walters et al., 2011; Study 2)

A cross-sectional study of U.S. male sex offenders $(\mathrm{N}=716$; Mean age $=37.74, \mathrm{SD}=$ 10.23)

A cross-sectional study of Australian adults $(\mathrm{N}=277$; Cisgender men: $\mathrm{n}=186$, Mean age $=33.31, \mathrm{SD}=10.99$; Cisgender women: $\mathrm{n}=82$, mean age $=26.41, \mathrm{SD}=8.13$;

Transgender men: $\mathrm{n}=2$, Mean age $=22.00$, $\mathrm{SD}=4.24$; Transgender women: $\mathrm{n}=3$, Mean age $=31.33, \mathrm{SD}=2.52$; Other gender: $\mathrm{n}=4$, Mean age $=22.75, \mathrm{SD}=5.50$ )
General CSB as measured by the Kalichman Sexual Compulsivity Scale

General CSB as measured by idiosyncratic items based on Kafka's Hypersexual Behavior Disorder diagnosis proposal for the DSM-IV

Online CSB as measured by the Compulsive Internet Use Scale

General CSB as measured by the Kalichman Sexual Compulsivity Scale

PPU as measured by the Cyber Pornography Use Inventory-9

Online CSB as measured by the Internet Sex Screening Test

General CSB as assessed via clinician interview and diagnosis

General CSB as measured by four self-report variables measuring masturbation frequency, ratio of sexual partners to sexually active years, past year pornography use, and interest in impersonal sex General CSB as measured by the Hypersexuality Rational Scale and the Multidimensional Assessment of Sex and Aggression

General CSB as measured by the Problematic Sexual Behaviors scale and Hypersexual Behavior Inventory 
(Walton \& Bhullar, 2018) Mean age $=31.23, \mathrm{SD}=11.26$; Transgender men: $\mathrm{n}=65$, Mean age $=26.69, \mathrm{SD}=6.74$ Transgender women: $\mathrm{n}=69$, Mean age $=$ 30.46, $\mathrm{SD}=12.09$; Intersex: $\mathrm{n}=7$, Mean age $=33.29, \mathrm{SD}=14.57)$

A cross-sectional study of Australian adults $(\mathrm{N}=510 ; 52.4 \%$ men: Mean age $=36.52$,

(Walton et al., 2017) $\quad \mathrm{SD}=12.66 ; 47.6 \%$ women: Mean age $=$ $30.38, \mathrm{SD}=12.12 ; 76.1 \%$ heterosexual, $12.5 \%$ homosexual/transgender, $11.4 \%$ bisexual)

A cross-sectional study of Australian adults $(\mathrm{N}=510 ; 52.4 \%$ men: Mean age $=36.52$,

(Walton et al., 2016) $\mathrm{SD}=12.66 ; 47.6 \%$ women: Mean age $=$ $30.38, \mathrm{SD}=12.12 ; 76.1 \%$ heterosexual, $12.5 \%$ homosexual, $11.4 \%$ bisexual)

A treatment study (2 years) of Canadian

(Wan et al., 2000)

(X. Wang et al., 2018)

(Y. Wang et al., 2017)

(Z. Wang et al., 2018)

(Weinstein, Katz, et al., 2015)

(Werner et al., 2018)

(Wery, Burnay, et al., 2016) adults $(\mathrm{N}=202 ; 71 \%$ male; Mean age $=38$; baseline stats)

A cross-sectional study of men who have sex with men in China $(\mathrm{N}=547$; Age ranges $=27.1 \%<25,61.5 \% 25-40$ years, $11.4 \%>$ $40 ; 71.2 \%$ homosexual, $28.8 \%$ nonhomosexual)

A cross-sectional study of men who have sex with men in China $(\mathrm{N}=547$; Mean age $=30.5, \mathrm{SD}=8.84 ; 71.3 \%$ homosexual, $28.7 \%$ non-homosexual)

A cross-sectional study of men who have sex with men in China $(\mathrm{N}=547$; Mean age $=30.5, \mathrm{SD}=8.84 ; 1.3 \%$ heterosexual, $71.3 \%$ homosexual, $23.4 \%$ bisexual, $4 \%$ unsure/other) $104 ; 25 \%$ heterosexual men: Mean age $=$ $27.93, \mathrm{SD}=4.97 ; 25 \%$ homosexual men: Mean age $=26.17, \mathrm{SD}=3.13 ; 25 \%$

heterosexual women: Mean age $=29.58, \mathrm{SD}$ $=5.9 ; 25 \%$ homosexual women: Mean age $=$ 24.5, $\mathrm{SD}=1.86$ )

A cross-sectional study of Israeli adults $(\mathrm{N}=$ $267 ; 72 \%$ men: Mean age $=28.16, \mathrm{SD}=6.8$; $28 \%$ women: Mean age $=25.5, \mathrm{SD}=5.13$ )

A cross-sectional study of Croatian adults $(\mathrm{N}=3,028 ; 41 \%$ men: Mean age $=35.6, \mathrm{SD}$ $=9.56 ; 59 \%$ women: Mean age $=28.7, \mathrm{SD}=$ 8.56)

A cross-sectional study of men in multiple countries recruited online $(\mathrm{N}=401$; Mean
A cross-sectional study of Israeli adults $(\mathrm{N}=$
General CSB as measured by the Hypersexual Behavior Inventory

General CSB as measured by the Hypersexual Behavior Inventory

General CSB as measured by the Hypersexual Behavior Inventory

General CSB as measured by the Sexual Addiction Screening Test

General CSB as measured by the Kalichman Sexual Compulsivity Scale

General CSB as measured by the Kalichman Sexual Compulsivity Scale

General CSB as measured by the Kalichman Sexual Compulsivity Scale

General CSB as measured by the Kalichman Sexual

Compulsivity Scale

Online CSB as measured by the Cybersex Addiction Test

General CSB as measured by the Hypersexual Disorder Screening Inventory

Online CSB as measured by the short Internet Addiction 
age $=28.74, \mathrm{SD}=8.80 ; 88.5 \%$ heterosexual, $\quad$ Test, modified for online $9.3 \%$ homosexual, $2.2 \%$ bisexual)

A cross-sectional study in a clinical sexual activities

(Wery, Vogelaere, et al., 2016)

(Wetterneck et al., 2012)

(Wilt et al., 2016)

(Wilton et al., 2018)

(Winters et al., 2009)

(Winters et al., 2010)

(Woolf-King et al., 2013)

(Wordecha et al., 2018)

(Xu et al., 2016)

(Yeagley et al., 2014)

(Zilberman et al., 2018)

(Zilberman et al., 2020)

(Zimmer \& Imhoff, 2020)

(Zlot et al., 2018) population in France $(\mathrm{N}=72 ; 94.4 \%$ men;

Mean age $=40.3, \mathrm{SD}=10.9$ )

A cross-sectional study of U.S. adults from a university as well as the community $(\mathrm{N}=$

494; $30.8 \%$ male; Mean age $=29.5, \mathrm{SD}=$ $9.0 ; 89.8 \%$ heterosexual, $4.5 \%$ homosexual, $5.7 \%$ bisexual)

A cross-sectional study of U.S. undergraduate students $(\mathrm{N}=1,070 ; 68.41 \%$ men; Mean age $=19.33, \mathrm{SD}=2.53$ )

A cross-sectional study of adult men who have sex with men in Canada $(\mathrm{N}=86$; Mean age $=33 ; 94.19 \%$ homosexual, $5.81 \%$ bisexual)

A cross-sectional study of adult men in the

U.S. adults from universities and the community $(\mathrm{N}=49$; Mean age $=27.7, \mathrm{SD}=$ $10.1 ; 90 \%$ heterosexual)

A cross-sectional study of adults in multiple countries, recruited via the internet $(\mathrm{N}=$ 14,$396 ; 44.9 \%$ men; Mean age $=28.9, \mathrm{SD}=$ $8.6 ; 76.3 \%$ heterosexual, $5.9 \%$ homosexual, $12.8 \%$ bisexual, $2.7 \%$ queer)

A cross-sectional study with a representative sample of men who have sex with men in San Francisco $(\mathrm{N}=711)$

A longitudinal (10-week) daily diary study of men seeking treatment for PPU in Poland $(\mathrm{N}=9$; Mean age $=31.7, \mathrm{SD}=4.85)$

A cross-sectional study in China of men who have sex with men $(\mathrm{N}=436$; Mean age $=24.5$ )

A cross-sectional study of U.S. men who have sex with men $(\mathrm{N}=366$; Mean age $=$ $21.46, \mathrm{SD}=1.95$ )

A cross-sectional study of Israeli adults with drug addiction $(\mathrm{n}=58)$, alcohol addiction ( $\mathrm{n}$ $=50)$, gambling disorder $(\mathrm{n}=48), \operatorname{CSB}(\mathrm{n}=$ $65)$, and healthy controls $(n=78)$

A cross-sectional sample of adults in a clinical treatment setting in Israel $(\mathrm{N}=56$; 92.9\% men; age not reported)

A cross-sectional study of adult men in the U.S. $(\mathrm{N}=1,063$; Mean age $=26.86, \mathrm{SD}=$ 6.79)

A cross-sectional study of Israeli adults $(\mathrm{N}=$ $279 ; 45.9 \%$ men; Mean age $=25, \mathrm{SD}=$ 2.75)
General CSB as measured by the Sexual Addiction Screening Test PPU as measured by the Pornography Consumption Effects Scale. General CSB as measured by the Kalichman Sexual Compulsivity Scale PPU as measured by the Cyber Pornography Use Inventory-9

General CSB as measured by the Kalichman Sexual Compulsivity Scale

General CSB as measured by the Kalichman Sexual Compulsivity Scale

General CSB as measured by the Kalichman Sexual Compulsivity Scale

General CSB as measured by the Kalichman Sexual Compulsivity Scale PPU as measured by the Sexual Addiction Test and the Brief Pornography Screener

General CSB as measured by the Kalichman Sexual Compulsivity Scale

General CSB as measured by the Hypersexual Behavior Inventory

General CSB as assessed by the Individual Based

Compulsive Sexual

Behavior Scale

General CSB as measured by the Individual Based

Compulsive Sexual

Behavior Scale

General CSB as measured by the Hypersexual Behavior Inventory

General CSB as measured by the Sexual Addiction Screening Test 
(Zsila et al., 2020)

A large, cross-sectional study of adults in Hungary ( $\mathrm{N}=15,703 ; 64.76 \%$ men; Mean age $=33.42, \mathrm{SD}=11.06$ )
General CSB as measured by the Hypersexual Behavior Consequences Scale 
Supplemental Table 2

Complete listing of included studies $(k=65)$ primarily concerned with cross-sectional samples in clinical settings

\begin{tabular}{|c|c|c|}
\hline Study & Design & Subject of Focus and Measurement \\
\hline $\begin{array}{l}\text { (Achterbergh et } \\
\text { al., 2020) }\end{array}$ & $\begin{array}{l}\text { A sexual education intervention study of adult men } \\
\text { who have sex with men in the Netherlands }(\mathrm{N}= \\
\text { 155) }\end{array}$ & $\begin{array}{l}\text { General CSB as measured by the } \\
\text { Kalichman Sexual Compulsivity Scale }\end{array}$ \\
\hline $\begin{array}{l}\text { (Bőthe et al., } \\
\text { 2020; Sample 3) }\end{array}$ & $\begin{array}{l}\text { A cross-sectional sample in a clinical setting of } \\
\text { adults in Hungary }(\mathrm{N}=266 ; 97 \% \text { men; Mean age } \\
=37.2, \mathrm{SD}=12.3 ; 69.2 \% \text { heterosexual })\end{array}$ & $\begin{array}{l}\text { PPU as measured by the Problematic } \\
\text { Pornography Consumption Inventory }\end{array}$ \\
\hline $\begin{array}{l}\text { (Brakoulias et } \\
\text { al., 2020) }\end{array}$ & $\begin{array}{l}\text { A cross-sectional sample of adults seeking } \\
\text { treatment for obsessive compulsive disorder in } \\
\text { multiple countries }(\mathrm{N}=6,919 ; 51.7 \% \text { men; Mean } \\
\text { age }=34.5, \mathrm{SD}=12.1)\end{array}$ & $\begin{array}{l}\text { General CSB as measured by clinician } \\
\text { diagnosis }\end{array}$ \\
\hline $\begin{array}{l}\text { (Carnes et al., } \\
\text { 2012; Sample 2) }\end{array}$ & $\begin{array}{l}\text { A cross-sectional sample including outpatients }(\mathrm{n} \\
=646 ; 86.8 \% \text { men, Mean age }=43.4, \mathrm{SD}=11.4 ; \\
\text { Women: Mean age }=37.9, \mathrm{SD}=10.8) \text {, inpatients } \\
(\mathrm{n}=63 ; 100 \% \text { men; Men: Mean age }=41.3, \mathrm{SD}= \\
11.2) \text {, and university students }(\mathrm{n}=203 ; 23.2 \% \\
\text { men; Men: Mean age }=21.65, \mathrm{SD}=5.6 ; \text { Women: } \\
\text { Mean age }=19.9, \mathrm{SD}=2.8) \text { in the U.S. }\end{array}$ & $\begin{array}{l}\text { General CSB as measured by the Sexual } \\
\text { Addiction Screening Test Revised and the } \\
\text { brief screening measure PATHOS }\end{array}$ \\
\hline $\begin{array}{l}\text { (Carnes et al., } \\
\text { 2012; Sample 1) }\end{array}$ & $\begin{array}{l}\text { A cross-sectional sample of patients receiving } \\
\text { inpatient treatment for CSB between } 1996 \text { and } \\
2004(\mathrm{n}=1,118 ; 69.6 \% \text { men }) \text { and a sample of } \\
\text { university students }(\mathrm{n}=790 ; 24.3 \% \text { men; Mean } \\
\text { age }=20.60, \mathrm{SD}=3.88)\end{array}$ & $\begin{array}{l}\text { General CSB as measured by the Sexual } \\
\text { Addiction Screening Test Revised and the } \\
\text { brief screening measure PATHOS }\end{array}$ \\
\hline $\begin{array}{l}\text { (Carnes et al., } \\
\text { 2014) }\end{array}$ & $\begin{array}{l}\text { A cross-sectional sample of patients receiving } \\
\text { treatment for CSB in the U.S. }(\mathrm{N}=4,492 ; 88 \% \\
\text { men) }\end{array}$ & $\begin{array}{l}\text { General CSB as measured by the Sexual } \\
\text { Addiction Screening Test Revised and } \\
\text { clinician diagnosis }\end{array}$ \\
\hline $\begin{array}{l}\text { (Chatzittofis et } \\
\quad \text { al., 2017) }\end{array}$ & $\begin{array}{l}\text { A cross-sectional study of hypersexual men }(\mathrm{n}= \\
67 ; \text { Mean age }=39.2, \mathrm{SD}=11.5) \text { in contrast with } \\
\text { healthy controls }(\mathrm{n}=39, \text { Mean age }=37.5, \mathrm{SD}= \\
\text { 11.9) in Sweden }\end{array}$ & $\begin{array}{l}\text { General CSB as measured by the } \\
\text { Hypersexual Disorder Screening } \\
\text { Inventory, the Kalichman Sexual } \\
\text { Compulsivity Scale, and the Hypersexual } \\
\text { Disorder: Current Assessment screening } \\
\text { interview. }\end{array}$ \\
\hline $\begin{array}{l}\text { (Chatzittofis et al., } \\
\text { 2020) }\end{array}$ & $\begin{array}{l}\text { A neuroendocrinological study of hypersexual } \\
\text { men in Sweden }(\mathrm{N}=67 ; \text { Mean age }=39.2, \mathrm{SD}= \\
11.5) \text { in comparison with healthy controls }(\mathrm{N}=39 \text {; } \\
\text { Mean age }=37.5 ; \mathrm{SD}=11.9)\end{array}$ & $\begin{array}{l}\text { General CSB as measured by the } \\
\text { Hypersexual Disorder Screening } \\
\text { Inventory, the Kalichman Sexual } \\
\text { Compulsivity Scale, and the Hypersexual } \\
\text { Disorder: Current Assessment Scale }\end{array}$ \\
\hline $\begin{array}{l}\text { (Coleman et al., } \\
\text { 2000) }\end{array}$ & $\begin{array}{l}\text { A retrospective intervention study on the efficacy } \\
\text { of pharmacological treatment for CSB }(\mathrm{N}=14 \text {; } \\
100 \% \text { men, Mean age }=45)\end{array}$ & $\begin{array}{l}\text { General CSB as measured by clinician } \\
\text { diagnosis }\end{array}$ \\
\hline (Das et al., 2017) & $\begin{array}{l}\text { A cross-sectional survey of adult outpatients of a } \\
\text { psychiatric hospital in India }(\mathrm{N}=75 ; 60 \% \text { men; } \\
\text { Mean age }=26.57, \mathrm{SD}=6.50)\end{array}$ & $\begin{array}{l}\text { PPU as measured by the Pornography } \\
\text { Addiction Screening Tool }\end{array}$ \\
\hline $\begin{array}{l}\text { (Davidson et al., } \\
\text { 2017) }\end{array}$ & $\begin{array}{l}\text { A cross-sectional study of patients in a psychiatric } \\
\text { hospital setting in New Zealand }(\mathrm{N}=100 ; 63 \% \\
\text { men; Mean age }=35.88, \mathrm{SD}=12.54)\end{array}$ & $\begin{array}{l}\text { General CSB as measured by the } \\
\text { Hypersexuality in Psychiatric Conditions } \\
\text { Observer-Rated scale }\end{array}$ \\
\hline $\begin{array}{l}\text { (De Boni et al., } \\
\text { 2018) }\end{array}$ & $\begin{array}{l}\text { A cross-sectional study of men who have sex with } \\
\text { men receiving PrEP treatment in Brazil }(\mathrm{N}=421 \text {; } \\
\text { Mean Age }=29)\end{array}$ & $\begin{array}{l}\text { General CSB as measured by the } \\
\text { Kalichman Sexual Compulsivity Scale }\end{array}$ \\
\hline
\end{tabular}




\begin{tabular}{|c|c|}
\hline $\begin{array}{l}\text { (de Tubino } \\
\text { Scanavino et al., } \\
\text { 2013) }\end{array}$ & $\begin{array}{l}\text { A cross-sectional study of men seeking treatment } \\
\text { for CSB in Brazil }(\mathrm{N}=86 \text {; Mean age }=38.17 \text {, SD } \\
=0.95)\end{array}$ \\
\hline $\begin{array}{l}\text { (do Amaral et } \\
\text { al., 2015) }\end{array}$ & $\begin{array}{l}\text { A cross-sectional study of men seeking treatment } \\
\text { for CSB in Brazil }(\mathrm{N}=69 \text {; Mean age }=35.2, \mathrm{SD}= \\
802)\end{array}$ \\
\hline $\begin{array}{c}\text { (Efrati \& } \\
\text { Mikulincer, } \\
\text { 2018; Study 3) }\end{array}$ & $\begin{array}{l}\text { A cross-sectional study of Israeli adults in a } \\
\text { Sexaholics Anonymous group }(\mathrm{N}=112 ; 95 \% \\
\text { men; Mean age }=34.6, \mathrm{SD}=9.25)\end{array}$ \\
\hline $\begin{array}{l}\text { (Efrati, Gerber, } \\
\text { et al., 2019) }\end{array}$ & $\begin{array}{l}\text { A cross-sectional study of Israeli adults in a } \\
\text { Sexaholics Anonymous group }(\mathrm{N}=160 ; 100 \% \\
\text { men) }\end{array}$ \\
\hline $\begin{array}{l}\text { (Efrati, } \\
\text { Shukron, et al., } \\
\text { 2019) }\end{array}$ & $\begin{array}{l}\text { A cross-sectional study of Israeli men in a } \\
\text { Sexaholics Anonymous group }(\mathrm{N}=68 ; \text { Mean age } \\
=32.26, \mathrm{SD}=14.98) \text {, of sex offenders in an Israeli } \\
\text { prison }(\mathrm{n}=103 ; \text { Mean age }=43.57, \mathrm{SD}=16.59) \\
\text { and violent offenders in an Israeli Prison }(\mathrm{n}=81 ; \\
\text { Mean age }=35.67, \mathrm{SD}=9.98)\end{array}$ \\
\hline $\begin{array}{l}\text { (Efrati \& Gola, } \\
\text { 2018) }\end{array}$ & $\begin{array}{l}\text { A cross-sectional study of Israeli adults in a } \\
\text { Sexaholics Anonymous group }(\mathrm{N}=97 ; 98 \% \text { men; } \\
\text { Mean age }=30.19, \mathrm{SD}=7.3)\end{array}$ \\
\hline $\begin{array}{c}\text { (Efrati \& Gola, } \\
\text { 2019) }\end{array}$ & $\begin{array}{l}\text { A cross-sectional study of Israeli adults }(95 \% \\
\text { men }) \text { in Sexaholics Anonymous }(\mathrm{n}=65 ; \text { Mean age } \\
=34.6, \mathrm{SD}=9.25) \text { and healthy controls }(\mathrm{n}=47 \text {; } \\
\text { Mean age }=36.78, \mathrm{SD}=8.67)\end{array}$ \\
\hline
\end{tabular}

(Engel et al., 2019)

(Farre et al., 2015)

(Granero et al., 2016)

A cross-sectional study of heterosexual men in Germany with CSB $(\mathrm{n}=47$; Mean age $=36.51$, $\mathrm{SD}=11.47$ ) in comparison with healthy controls $(\mathrm{n}=38 ;$ Mean age $=37.92, \mathrm{SD}=12.33)$

A cross-sectional study in a psychiatric setting in Spain of adults with gambling disorder $(n=2,190$; $90.1 \%$ men; Mean age $=42.2, \mathrm{SD}=13.4)$ in comparison with individuals with CSB $(\mathrm{n}=59$; $98.3 \%$ men; Mean age $=40.1, \mathrm{SD}=8.8)$ and healthy controls $(\mathrm{n}=93 ; 89.2 \%$ men; Mean age $=$ 31.0, $\mathrm{SD}=9.5$ )

(Gilliland et al., 2015)

(Gola et al., 2016)

A cross-sectional sample of men seeking treatment for CSB in the U.S. $(\mathrm{N}=136$; Mean age $=34.73$, $\mathrm{SD}=13.06$ )

A cross-sectional analysis of heterosexual men in Poland $(\mathrm{N}=569$; Mean age $=28.87, \mathrm{SD}=6.36)$. A cross-sectional study in Spain in a psychiatric setting of adults with compulsive buying behaviors $(\mathrm{n}=110 ; 28.2 \%$ men; Mean age $=43.3)$ in comparison with individuals with CSB $(\mathrm{n}=28$; $96.4 \%$ men; Mean age $=41.3$ ), internet gaming disorder $(\mathrm{n}=51 ; 94.1 \%$ men, Mean age $=22)$, Internet addiction $(\mathrm{n}=41 ; 73.2 \%$ men; Mean age $=31.7)$ and gambling disorder $(\mathrm{n}=3094 ; 89.9 \%$ men; Mean age $=42.9$ )
General CSB as measured by the Kalichman Sexual Compulsivity Scale

General CSB as measured by clinician diagnosis and the Kalichman Sexual Compulsivity Scale

General CSB as measured by the Individual Based Compulsive Sexual Behavior Scale

General CSB as measured by the Individual Based Compulsive Sexual Behavior Scale

General CSB as measured by the Individual Based Compulsive Sexual Behavior Scale

General CSB as measured by the Individual Based Compulsive Sexual Behavior Scale

General CSB as measured by the Individual Based Compulsive Sexual Behavior Scale

General CSB and Online CSB as measured by the Hypersexual Behavior Inventory, the Sexual Addiction Screening Test Revised, and the Short Internet Addiction Test modified for online sexual behavior

General CSB as measured by clinician diagnosis

General CSB as measured by the Hypersexual Behavior Inventory

PPU as measured by the Sexual Addiction Screening Test Revised

General CSB as measured by clinician assessment based on the DSM-IV-TR criteria for Sexual Disorder Not Otherwise Specified 
(Grubbs et al., 2015; Study 3)

(Hall et al., 2020)

(Hart et al., 2020)

(M. P. Kafka \& Hennen, 1999)

(Martin P. Kafka \&

Hennen, 2003)

(Kalichman \& Cain, 2004)

(Kowalewska et al., 2019)

(Kraus et al., 2015)

(Kraus et al., 2020; Sample 5)

(Morrison et al., 2018)

(Mulhauser et al., 2018; Study 2)

(O'Dell et al., 2008)

(Reece, 2003)

(Reid, 2007)

(Reid \&

Carpenter, 2009)
A cross-sectional study of university students in a college counseling center setting $(\mathrm{N}=152 ; 67.8 \%$ men, Mean age $=20.3, \mathrm{SD}=1.8$ )

A psychoeducational treatment study CSB in the

UK $(\mathrm{N}=119$; gender, age, and sexual orientation not reported)

A sexual education intervention study for HIV positive adult men who have sex with men in Canada (Treatment arm: $\mathrm{n}=89$; Mean age $=$ 40.77, $\mathrm{SD}=11.37$; control group: $\mathrm{n}=94$; Mean age $=40.82, \mathrm{SD}=10.7$ )

A cross-sectional study of men in the U.S. seeking treatment for sexual disorders $(\mathrm{N}=206$, Mean age =37)

A cross-sectional study of men in the U.S. seeking treatment for sexual disorders $(\mathrm{N}=120$, Mean age $=37.1, \mathrm{SD}=9.5$ )

A cross-sectional study of adults in the U.S.

receiving services related to sexually transmitted infections $(\mathrm{N}=685 ; 71.8 \%$ men; Mean age $=35.7$, $\mathrm{SD}=10.4)$

A cross-sectional study of heterosexual men in Poland seeking treatment for CSB $(\mathrm{n}=72$; Mean age $=35.4, \mathrm{SD}=7.7)$ in comparison with healthy controls $(\mathrm{n}=208$; Mean age $=27.8, \mathrm{SD}=5.8)$ A cross-sectional sample of men in the U.S. with PPU related problems $(\mathrm{N}=103$; Mean age $=39.8$, $\mathrm{SD}=12.1 ; 17 \%$ heterosexual, $70 \%$ gay)

A treatment seeking sample of men in Poland $(\mathrm{N}=$ 105 ; Mean age $=32.9, \mathrm{SD}=7.5$ )

A cross-sectional study of a clinical sample of Canadian men who have sex with men $(\mathrm{N}=186$; Mean age $=31$ )

A cross-sectional study of a clinical sample of men in the U.S. $(\mathrm{N}=39$; Mean age $=46.3, \mathrm{SD}=12.8)$

A cross-sectional study of a clinical sample of HIV-positive men who have sex with men $(\mathrm{N}=$ 637 ; Mean age $=42.3, \mathrm{SD}=8.2 ; 81.9 \%$ homosexual, $18.1 \%$ bisexual/heterosexual) A cross-sectional study of a clinical sample of HIV-positive men who have sex with men $(\mathrm{N}=$ 180 ; Mean age $=33.6, \mathrm{SD}=6.9 ; 100 \%$ gay or bisexual)

A cross-sectional study of a clinical sample of men in the U.S. seeking treatment for CSB $(\mathrm{N}=67$; Mean age $=32.6, \mathrm{SD}=9.9 ; 100 \%$ heterosexual) A cross-sectional study of a clinical sample of hypersexual men in the U.S. $(\mathrm{N}=152$; Mean age $=$
PPU as measured by the Cyber Pornography Use Inventory-9 and the Kalichman Sexual Compulsivity Scale

General CSB as measured by clinician diagnosis

General CSB as measured by the Kalichman Sexual Compulsivity Scale

General CSB as measured by clinician diagnosis

General CSB as measured by clinician diagnosis

General CSB as measured by the Kalichman Sexual Compulsivity Scale

General CSB as measured by the Sexual Addiction Screening Test and PPU as measured by the Brief Pornography Screener

General CSB and PPU as measured by the Yale-Brown Obsessive Compulsive Scale adapted for Compulsive Sexual Behaviors PPU as measured by the Brief Pornography Screener, the Problematic Pornography Use Scale , and Hypersexual, Behavior Inventory

General CSB as measured by the Kalichman Sexual Compulsivity Scale

PPU as measured by the Pornography Purchase Task, the Hypersexual Behavior Inventory, the Cyber Pornography Use Inventory 9, and the Problematic Pornography Use Scale

General CSB as measured by the Compulsive Sexual Behavior Inventory

General CSB as measured by the Kalichman Sexual Compulsivity Scale

General CSB as measured by the Kalichman Sexual Compulsivity Scale

General CSB as measured by the Kalichman Sexual Compulsivity Scale 
31.6, $\mathrm{SD}=9.3 ; 98 \%$ heterosexual, $1 \%$

homosexual, $1 \%$ bisexual)

A cross-sectional study of a clinical sample of

treatment seeking hypersexual men $(n=40$; Mean

(Reid, Bramen, $\quad$ age $=46.6, \mathrm{SD}=11.6 ; 75 \%$ heterosexual, $10 \%$

et al., 2014)

homosexual, $15 \%$ bisexual) and healthy controls

$(\mathrm{n}=30$; Mean age $=43.3, \mathrm{SD}=15.6 ; 96.7 \%$

General CSB as measured by the

Hypersexual Behavior Inventory

heterosexual, $3.3 \%$ homosexual) in the U.S.

A cross-sectional study of a clinical sample of hypersexual men in the U.S. who were either

(Reid et al., highly religious $(\mathrm{n}=52$; Mean age $=39.5, \mathrm{SD}=$

2016)

13.5; $94 \%$ heterosexual, $4 \%$ homosexual, $2 \%$

bisexual $)$ or non-religious $(\mathrm{n}=105$; Mean age $=$

General CSB as measured by the

Hypersexual Behavior Inventory

$44.3, \mathrm{SD}=10.5 ; 81 \%$ heterosexual, $12 \%$

homosexual, $7 \%$ bisexual)

(Reid,

A cross-sectional study of a clinical sample of men

Carpenter, et al.,

2011)

with ADHD seeking treatment for hypersexuality

in the U.S. $(\mathrm{N}=81$; Mean age $=31.8, \mathrm{SD}=8.7$;

$98.8 \%$ heterosexual, $1.2 \%$ bisexual)

A cross-sectional study of a clinical sample of

(Reid et al.,

2008)

adults seeking treatment for hypersexuality in the

U.S. $(\mathrm{N}=120 ; 96.7 \%$ men; $95.8 \%$ heterosexual,

$3.3 \%$ homosexual, $0.8 \%$ bisexual)

A cross-sectional study of a clinical sample

(Reid, Cooper, et

al., 2012)

seeking treatment for hypersexual behaviors in the

U.S. $(\mathrm{N}=136 ; 85.3 \%$ men; Mean age $=32.4$, SD

$=11.3 ; 89 \%$ heterosexual, $8.1 \%$ homosexual men,

$0.7 \%$ homosexual women, $2.2 \%$ bisexual)

A cross-sectional study of a clinical sample of

(Reid, Cyders, et adults seeking treatment for hypersexual behaviors

al., 2014)

in the U.S. $(\mathrm{N}=353 ; 74 \%$ men; Mean age $=39.2$,

$\mathrm{SD}=11.1)$

A cross-sectional study of a clinical sample of

women $(n=31$; Mean age $=29.9, \mathrm{SD}=10.1$;

(Reid, Dhuffar, et al., 2012)

93.5\% heterosexual, $3.2 \%$ homosexual, $3.2 \%$

bisexual) and men $(\mathrm{n}=47$; Mean age $=41.5, \mathrm{SD}=$

$10.1 ; 78.7 \%$ heterosexual, $19.2 \%$ homosexual,

$2.1 \%$ bisexual) seeking treatment for

hypersexuality in the U.S.

(Reid, Garos, et

al., 2011; Study

2)

A cross-sectional study of a clinical sample of men

seeking treatment for hypersexuality in the U.S. (N

$=107$; Mean age $=34.7, \mathrm{SD}=9.9 ; 90 \%$

heterosexual, $8 \%$ homosexual, $2 \%$ bisexual)

General CSB as measured by the

Kalichman Sexual Compulsivity Scale

General CSB as measured by the

Kalichman Sexual Compulsivity Scale

General CSB as measured by the

Hypersexual Behavior Inventory

General CSB as measured by the

Hypersexual Behavior Inventory

General CSB as measured by the

Hypersexual Behavior Inventory

General CSB as measured by the

Hypersexual Behavior Inventory

A cross-sectional study of a clinical sample of U.S.

(Reid, Garos, et

al., 2011; Study

1)

men seeking treatment online for self-identified

pornography addiction $(\mathrm{N}=105$; Mean age $=36.5$, $\mathrm{SD}=12.4$ )

A cross-sectional study of a clinical sample of men seeking treatment for hypersexual behaviors $(\mathrm{n}=$

(Reid et al., $\quad 71$; Mean age $=30.89, \mathrm{SD}=7.6 ; 91.5 \%$

2009)

heterosexual, $5.6 \%$ homosexual, $2.8 \%$ bisexual)

and healthy controls $(\mathrm{n}=73$; Mean age $=25.5$, SD

General CSB as measured by the

Hypersexual Behavior Inventory

General CSB as measured by the

Hypersexual Behavior Inventory

$=4.6 ; 95.9 \%$ heterosexual, $2.7 \%$ homosexual,

$1.4 \%$ bisexual) in the U.S. 
A cross-sectional study of a clinical sample of men

(Reid, Li, et al., seeking treatment for hypersexuality in the U.S. (N

2011; Sample 2) $\quad=107$; Mean age $=34.7, \mathrm{SD}=9.9 ; 90 \%$

heterosexual, $8 \%$ homosexual, $2 \%$ bisexual)

A cross-sectional study of a clinical sample of men

(Reid, Li, et al., in the U.S. who were subscribed to an online

2011; Sample 1) pornography addiction website $(\mathrm{N}=105$; Mean

age $=36.5, \mathrm{SD}=12.4$ )

A cross-sectional study of a clinical sample of men

(Reid, Stein, et seeking treatment for hypersexuality in the U.S. (N

al., 2011)

$=95$; Mean age $=31.8, \mathrm{SD}=8.26 ; 94 \%$

heterosexual, $5 \%$ homosexual, $1 \%$ bisexual)

A cross-sectional study of a clinical sample of men

(Reid, Temko, et seeking treatment for hypersexuality in the U.S. (N al., 2014)

$=172$; Mean age $=43.4, \mathrm{SD}=12.1 ; 83.7 \%$

heterosexual, $8.1 \%$ homosexual, $8.1 \%$ bisexual)

A cross-sectional study of a clinical population of

(Rendina et al., gay and bisexual men in the U.S. $(\mathrm{N}=1,532$;

2014) $\quad$ Mean age $=35.2, \mathrm{SD}=12.4 ; 75.5 \%$ homosexual,

$24.5 \%$ bisexual)

(Savard et al., 2020)

A psychopharmaceutical treatment study of men with CSB in Sweden $(\mathrm{N}=20$; Mean age $=38.8$, $\mathrm{Sd}=10.3 ; 70 \%$ heterosexual)

(de Tubino

Scanavino et al.,

2020)

A cross-sectional study of adults seeking treatment

for CSB in Brazil ( $\mathrm{N}=204$; 91.7\% men; Age range $=23-57$ )

A cross-sectional study in Brazil of a clinical

(de Tubino population of treatment seeking men $(n=88$;

Scanavino et al., Mean age $=38.17, \mathrm{SD}=8.91 ; 58 \%$ heterosexual) 2018)

(de Tubino

Scanavino et al., 2013)

(de Tubino

Scanavino et al., 2016)

and healthy controls $(n=64$; Mean age $=33.98$,

$\mathrm{SD}=11.4 ; 84.4 \%$ heterosexual)

A cross-sectional study of a clinical population of men in Brazil $(\mathrm{N}=86$; Mean age $=38.17, \mathrm{SD}=$

$0.95 ; 57 \%$ heterosexual, $26 \%$ homosexual, $17 \%$ bisexual)

A cross-sectional study of a clinical population of men in Brazil $(\mathrm{N}=153$; Mean age $=36.4, \mathrm{SD}=$ $13.9 ; 68.6 \%$ heterosexual)

A cross-sectional study of a clinical population in

(Sutton et al., $\quad$ Canada $(\mathrm{N}=115 ; 100 \%$ men; Mean age $=41.5$, 2015) $\mathrm{SD}=11.67$; Sexual orientation recorded for 109 patients: $87 \%$ heterosexual)

(Tierens et al., 2014)

A cross-sectional sample of a clinical population in Belgium $(\mathrm{N}=10 ; 100 \%$ men; Mean age $=48.2$; $90 \%$ heterosexual)

(Valero-Solis et al., 2018)
A cross-sectional study in Spain of a clinical population (CSB group: $\mathrm{N}=34 ; 100 \%$ men; Mean age $=42.6, \mathrm{SD}=11.9$ )
General CSB as measured by the Hypersexual Behavior Inventory

PPU as measured by the Pornography

Consumption Inventory

General CSB as measured by the Hypersexual Behavior Inventory

General CSB as measured by the Hypersexual Behavior Inventory

General CSB as measured by the Kalichman Sexual Compulsivity Scale

Hypersexual Disorder: Current Assessment Scale; HBI; K-SCS

General CSB as measured by the Kalichman Sexual Compulsivity Scale and the Hypersexual Disorder Screening Inventory

General CSB as measured by the Kalichman Sexual Compulsivity Scale

General CSB as measured by the Kalichman Sexual Compulsivity Scale

General CSB as measured by the Kalichman Sexual Compulsivity Scale, the Hypersexual Disorder Screening Inventory, and the Compulsive Sexual Behavior Inventory

General CSB as measured by reviews of patients' charts.

General CSB as measured by a questionnaire developed based on Kafka's proposed diagnosis for Hypersexual Behavior Disorder.

General CSB as measured by idiosyncratic items based on Kafka's Hypersexual Behavior Disorder diagnosis proposal for the DSM-IV 


\begin{tabular}{|c|l|l|}
\hline $\begin{array}{c}\text { (Wery et al., } \\
\text { 2016) }\end{array}$ & $\begin{array}{l}\text { A cross-sectional study in a clinical population in } \\
\text { France }(\mathrm{N}=72 ; 94.4 \% \text { men; Mean age }=40.3, \mathrm{SD} \\
=10.9)\end{array}$ & $\begin{array}{l}\text { General CSB as measured by the Sexual } \\
\text { Addiction Screening Test }\end{array}$ \\
\hline $\begin{array}{c}\text { (Zilberman et } \\
\text { al., 2018) }\end{array}$ & $\begin{array}{l}\text { A cross-sectional study of Israeli adults with drug } \\
\text { addiction }(\mathrm{n}=58) \text {, alcohol addiction }(\mathrm{n}=50), \\
\text { gambling disorder }(\mathrm{n}=48), \mathrm{CSB}(\mathrm{n}=65), \text { and } \\
\text { healthy controls }(\mathrm{n}=78) .\end{array}$ & $\begin{array}{l}\text { General CSB as assessed by the } \\
\text { Individual Based Compulsive Sexual } \\
\text { Behavior Scale }\end{array}$ \\
\hline $\begin{array}{c}\text { (Zilberman et } \\
\text { al., 2020) }\end{array}$ & $\begin{array}{l}\text { A cross-sectional sample of adults in a clinical } \\
\text { treatment setting in Israel }(\mathrm{N}=56 ; 92.9 \% \text { men; } \\
\text { age not reported) }\end{array}$ & $\begin{array}{l}\text { General CSB as measured by the } \\
\text { Individual Based Compulsive Sexual } \\
\text { Behavior Scale }\end{array}$ \\
\hline
\end{tabular}


Supplemental Table 3

Summary of included longitudinal studies

Study

(Ballester-Arnal et al., 2013)

(Dilley et al., 2008)

(Gola et al., 2017)

(Grov et al., 2010)

(Grubbs \& Gola, 2019; Sample 2)

(Grubbs et al., 2015; Study 2)

(Grubbs et al., 2017; Study 1)

(Grubbs et al., 2017; Study 2)

(Grubbs et al., 2020; Study

2)

(Grubbs, Wilt, Exline, \& Pargament, 2018; Study 1)
Design

Measurement

A cross-sectional study of university students in Spain $(\mathrm{N}=1,196 ; 24.5 \%$ men; Mean age $=20.22$, $\mathrm{SD}=2.11$; $95.5 \%$ heterosexual), with a oneweek longitudinal follow-up $(\mathrm{N}=$ 100)

A longitudinal (12 months) efficacy study for a HIV counseling intervention study among a sample of U.S. men who have sex with men (N $=336$ ).

A brief, longitudinal (2 weeks) study of men in a university setting in Malaysia $(\mathrm{N}=76$; Mean age $=22.27$, $\mathrm{SD}=3.45)$

A longitudinal functional magnetic resonance imaging study of heterosexual men in Poland seeking treatment for PPU $(n=28$; Mean age $=30.96 ; \mathrm{SD}=6.51)$ in comparison with healthy controls $(n=24$, Mean age $=30.49, \mathrm{SD}=7.55$ )

An intensive longitudinal study (30 days; daily diary study) of gay and bisexual men in the U.S. $(\mathrm{N}=47$, Mean age $=36.2$ )

A longitudinal study (1 year) of men in the U.S. recruited via Mechanical Turk $(\mathrm{N}=433$; Mean age $=33.5, \mathrm{SD}$ $=9.7$ )

A longitudinal study (1 year) of college students in the U.S. $(\mathrm{N}=$ 1,$215 ; 67.2 \%$ men, Mean age $=19.3$, $\mathrm{SD}=1.3)$

A longitudinal (1 year) study of college students in the U.S. $(\mathrm{N}=$

General CSB as measured by the Sexual Compulsivity Scale

General CSB as measured by the KSCS

PPU as measured by the Cyber

Pornography Use Inventory-9.

General CSB as measured by the Kalichman Sexual Compulsivity Scale

General CSB as measured by the Kalichman Sexual Compulsivity Scale

PPU as measured by the Cyber Pornography Use Inventory 4

PPU as measured by the Cyber

Pornography Use Inventory 9

1,$519 ; 67.2 \%$ men; Mean age $=19.3, \quad$ Pornography Use Inventory 9 $\mathrm{SD}=1.3)$

A longitudinal (1 year) study of adult internet users in the U.S. recruited via Mechanical Turk $(\mathrm{N}=713 ; 51.9 \%$ men; Mean age $=30.2, \mathrm{SD}=9.9)$

A longitudinal (1 year) study of adults in the U.S. recruited via Mechanical Turk $(\mathrm{N}=850 ; 52.3 \%$ men; Mean age $=33.98, \mathrm{SD}=9.87$ )

A longitudinal (1 year) study of undergraduate students in the U.S. (N PPU as measured by the Cyber $=1,352 ; 67.7 \%$ men; $90.1 \%$ heterosexual)
PPU as measured by the Cyber Pornography Use Inventory 9

PPU as measured by the Cyber Pornography Use Inventory 4

Pornography Use Inventory 9 
(Grubbs, Wilt, Exline, \&

Pargament, 2018; Study 2)

(Grubbs, Wilt, Exline,

Pargament, et al., 2018; Sample 1)

(Grubbs, Wilt, Exline, Pargament, et al., 2018; Sample 2)

(Hart et al., 2016) Sample 1)

(Kohut \& Stulhofer, 2018; Sample 2)

(Laier \& Brand, 2017; Study 2)

(Maddock et al., 2019)

(Noor et al., 2014; Study 1) 2012)

(Reid, Garos, et al., 2012)
A longitudinal (1 year) study of adults in the U.S. recruited via Mechanical Turk $(\mathrm{N}=793 ; 48.8 \%$ men; $83.9 \%$ heterosexual)

A longitudinal (1 year) study of undergraduate students in the U.S. (N PPU as measured by the Cyber $=1,507 ; 65.2 \%$ men; Mean age $=$ $19.3, \mathrm{SD}=2.2 ; 90.1 \%$ heterosexual)

A longitudinal (1 year) study of adults in the U.S. recruited via Mechanical Turk $(\mathrm{N}=782 ; 48.8 \%$ men, Mean age $=32.2, \mathrm{SD}=10.3)$ A longitudinal study (3 months) in the U.S. of HIV positive men who have sex with men $(\mathrm{N}=59$; Mean age $-42.4, \mathrm{SD}=9.0$ )

A longitudinal (2.5 years) study of adolescent boys in Croatia $(n=314)$ A longitudinal (2.5 years) study of adolescent boys in Croatia $(n=197)$

A longitudinal (repeated measures) study of men in Germany $(\mathrm{N}=66$; Mean age $=26.91, \mathrm{SD}=5.43$ )

A longitudinal study (6 months) of a U.S. sample recruited from

Mechanical Turk $(\mathrm{N}=320 ; 54.8 \%$ men; Mean age $=36.26, \mathrm{SD}=10.18$; $86 \%$ heterosexual, $2.9 \%$ gay, $10.1 \%$ bisexual, $0.91 \%$ other; baseline stats) A longitudinal study (7 days) of men who have sex with men $(\mathrm{N}=240$; Age ranges $=31.5 \% 18-24,30.3 \%$ $25-34,19.5 \% 35-44,18.7>45)$

A longitudinal study (2 weeks) of a clinical sample of adults seeking treatment for hypersexuality, general psychiatric concerns, and substance abuse in the U.S. (hypersexual group: $\mathrm{N}=152 ; 94.7 \%$ men; Mean age $=$ $41.1, \mathrm{SD}=13.0 ; 84.2 \%$ heterosexual, $9.9 \%$ gay men, $0.7 \%$ gay women, $5.3 \%$ bisexual; baseline stats)

A longitudinal study (2 weeks) of a clinical sample of adults in the U.S. $(\mathrm{N}=137$; Mean age $=41.5, \mathrm{SD}=$ $12.7 ; 79.6 \%$ heterosexual, $13.1 \%$ gay, $7.3 \%$ bisexual) seeking treatment for hypersexuality

A longitudinal study (6 months) of HIV-positive gay and bisexual men in
PPU as measured by the Cyber

Pornography Use Inventory 9

Pornography Use Inventory 9

PPU as measured by the Cyber

Pornography Use Inventory 9

General CSB as measured by the Kalichman Sexual Compulsivity Scale

PPU as measured by the Compulsive Pornography Consumption Scale PPU as measured by the Compulsive Pornography Consumption Scale PPU as measured by the short version of the Internet Addiction Test modified for pornography and the Pornography Consumption Inventory

PPU as measured by the Problematic Pornography Use Scale

PPU as measured by the Compulsive Pornography Consumption Scale

General CSB as measured by the Hypersexual Behavior Inventory, the Hypersexual Disorder Diagnostic Clinical Interview, the Hypersexual Disorder Questionnaire, the Hypersexual Disorder Course Questionnaire, the Hypersexual Behavior Consequences Scale, and the Sexual Compulsivity Scale General CSB as measured by the Hypersexual Behavior Inventory, the Hypersexual Disorder Diagnostic Clinical Interview, the Hypersexual Disorder Questionnaire, the Hypersexual Disorder Course Questionnaire, the Hypersexual Behavior Consequences Scale, and the Sexual Compulsivity Scale General CSB as measured by the Hypersexual Disorder Screening
(Rendina et al., 2017) 
the U.S. $(\mathrm{N}=138$; Mean age $=40.2$, Inventory and the Kalichman Sexual $\mathrm{SD}=10.1 ; 93.5 \%$

gay/queer/homosexual, $6.5 \%$

bisexual)

A longitudinal cognitive study (1

(Rendina et al., 2018) year) of gay and bisexual men in the U.S., recruited as part of a daily diary study $(\mathrm{N}=334$; Mean age $=11.5)$

A longitudinal study (1 year) of gay and bisexual men in the U.S. $(\mathrm{N}=$ 376 ; Mean age $=37.8, \mathrm{SD}=11.7$; $90.8 \%$ gay/queer/homosexual, $9.2 \%$

General CSB as measured by the

(Rendina et al., 2019) bisexual; baseline stats)

A longitudinal study (6 months) of men who have sex with men in the

(Safren et al., 2018)

(Smith et al., 2014)

(Štulhofer et al., 2020)

(Thompson et al., 2015)

(Wordecha et al., 2018)
U.S. $(\mathrm{N}=197$; Mean age $=37, \mathrm{SD}=$ $11.6 ; 2.5 \%$ heterosexual, $76.6 \%$ gay, $18.8 \%$ bisexual, $.5 \%$ unsure, $1.5 \%$ other; baseline stats)

A longitudinal study (6 months) of male veterans in the U.S. $(\mathrm{N}=258$; Mean age $=33.3, \mathrm{SD}=8.2$; baseline stats)

A longitudinal (6 months) study of adolescent boys in Croatia $(\mathrm{N}=$ 337; Mean age $=15.8, \mathrm{SD}=0.48$ )

A longitudinal study (4 years) of male undergraduate students in the U.S. $(\mathrm{N}=795$; Mean age $=18.56$, SD $=.51$; baseline stats)

A longitudinal (10-week) daily diary study of men seeking treatment for PPU in Poland $(\mathrm{N}=9$; Mean age $=$ 31.7, $\mathrm{SD}=4.85$ )
General CSB as measured by the

Kalichman Sexual Compulsivity Scale
Kalichman Sexual Compulsivity Scale

General CSB as measured by the

Kalichman Sexual Compulsivity Scale

General CSB as measured by the

Minnesota Impulsive Disorders

Interview

PPU as measured by the

Compulsive Pornography

Consumption Scale

General CSB as measured by the

Kalichman Sexual Compulsivity Scale

PPU as measured by the Sexual

Addiction Test and the Brief

Pornography Screener 
Supplemental Table 4

Summary of neuroscience related studies included in the present review

Study

(Banca et al., 2016)

(Brand et al., 2016)

(Chatzittofis et al., 2016)

(Chatzittofis et al., 2020)

(Draps et al., 2020)

(Gola et al., 2017)

(Jokinen et al., 2017)

(Klein et al., 2020)

(Klucken et al., 2016)

(Kühn \& Gallinat, 2014)
Design

A functional magnetic resonance imaging study of men $(\mathrm{n}=22$; Mean Age $=25.14, \mathrm{SD}=4.68 ; 100 \%$ heterosexual) with CSB in the U.K. compared with healthy controls $(\mathrm{n}=$ 40).

A functional magnetic resonance imaging study of heterosexual men in Germany $(\mathrm{N}=19$; Mean age $=25.05$, $\mathrm{SD}=1.43)$

A neuroendocrinological study of hypersexual men $(n=67$; Mean age $=$ 39.2) in contrast with healthy controls $(\mathrm{n}=39$; Mean age $=37.5)$ in Sweden

A neuroendocrinological study of hypersexual men in Sweden $(\mathrm{N}=67$; Mean age $=39.2, \mathrm{SD}=11.5)$ in comparison with healthy controls (N $=39$; Mean age $=37.5 ; \mathrm{SD}=11.9$ )

A functional magnetic resonance imaging study of heterosexual men in Poland $(\mathrm{N}=98$; Mean age $=34.5$, SD $=6.5$ )

A longitudinal functional magnetic resonance imaging study of heterosexual men in Poland seeking treatment for PPU $(n=28$; Mean age $=30.96, \mathrm{SD}=6.51)$ in comparison with healthy controls $(n=24$; Mean age $=30.49, \mathrm{SD}=7.55$ )

A neuroendocrinological study of hypersexual men $(\mathrm{n}=54$; Mean age $=$ 39.2) in contrast with healthy controls $(\mathrm{n}=33$; Mean age $=37.5)$ in Sweden A functional magnetic resonance imaging study of adult men in Germany $(\mathrm{N}=72$; Mean age $=25.6$, $\mathrm{SD}=4.5)$

A functional magnetic resonance imaging study in Germany of men with CSB $(n=20$; Mean age $=34.2$, $\mathrm{SD}=8.6)$ and healthy controls $(\mathrm{n}=$ 20; Mean age $=34.9, \mathrm{SD}=9.7$ )

A functional magnetic resonance imaging study in Germany of men (n $=64$, Mean age $=28.9, \mathrm{SD}=6.6$ )
Subject of Focus and Measurement

General CSB as measured by psychiatrist diagnosed CSB

PPU as measured by the short Internet Addiction Test modified for online sexual activities and general CSB as measured by the Hypersexual Behavior Inventory

General CSB as measured by the Hypersexual Disorder Screening Inventory, the Kalichman Sexual Compulsivity Scale, and the Hypersexual Disorder: Current Assessment screening interview. General CSB as measured by the Hypersexual Disorder Screening Inventory, the Kalichman Sexual Compulsivity Scale, and the Hypersexual Disorder: Current Assessment Scale

General CSB as measured by the Sexual Addiction Screening Test and the Brief Pornography Screener

General CSB as measured by the Kalichman Sexual Compulsivity Scale

General CSB as measured by the Kalichman Sexual Compulsivity Scale and the Hypersexual Disorder Current Assessment

Online CSB as measured by the Short Interent Addiction Test revised for Sex

General CSB as measured by clinician diagnosis

PPU as measured by the Sexual Addiction Screening Test and the Internet Sex Screening Test 
(Miner et al., 2009)

(Prause et al., 2015)

(Schecklmann et al., 2020)

(Schmidt et al., 2017)

(J.-W. Seok \& Sohn, 2015)

(J.-W. Seok \& Sohn, 2018a)

(J.-W. Seok \& Sohn, 2018b)

(J. Seok \& Sohn, 2020)

(Sinke et al., 2020)
A neuroscience study using diffusion tensor imaging on men with CSB $(\mathrm{N}$ $=8$; Mean age $=44.5, \mathrm{SD}=10.6)$ and healthy controls $(\mathrm{N}=8$; Mean age $=$ 43.4, $\mathrm{SD}=9.1$ ) in the U.S.

A neuroscience study using EEG to measure differences between reactions to sexual images in hypersexual adults $(\mathrm{N}=55 ; 75 \%$ men; Mean age $=24.4, \mathrm{SD}=4.9)$ and healthy controls $(\mathrm{N}=67 ; 64.6 \%$ men; Mean age $=24, \mathrm{SD}=6.5$ ) in the U.S.

A study of high-frequency repetitive transcranial magnetic stimulation in heterosexual men in Germany $(\mathrm{N}=$ 19 ; Mean age $=23.6, \mathrm{SD}=3.4$ ) A functional magnetic resonance imaging study of heterosexual men in the U.K. both with CSB $(n=23$; Mean age $=26.9, \mathrm{SD}=6.22)$ and without CSB $(\mathrm{n}=69$; Mean age $=$ 25.6, $\mathrm{SD}=6.55)$

A functional magnetic resonance imaging study of heterosexual men in South Korea with CSB $(n=23$; Mean age $26.12, \mathrm{SD}=4.11)$ in comparison with healthy controls $(n=22$; Mean age $=26.27, \mathrm{SD}=3.39$ )

A functional magnetic resonance imaging study of heterosexual men in South Korea with CSB $(n=23$; Mean age $26.12, \mathrm{SD}=4.11$ ) in comparison with healthy controls $(n=22$; Mean age $=26.27, \mathrm{SD}=3.39$ )

A functional magnetic resonance imaging study of heterosexual men in South Korea with CSB ( $\mathrm{n}=17$; Mean age $26.92, \mathrm{SD}=4.73$ ) in comparison with healthy controls $(\mathrm{n}=19$; Mean age $=25.08, \mathrm{SD}=3.53$ )

A functional magnetic resonance imaging study of heterosexual men with CSB in South Korea $(\mathrm{n}=30$; mean age $-28.81, \mathrm{Sd}=5.26$ ) compared with healthy controls $(\mathrm{n}=$ 30; Mean age $=27.41, \mathrm{SD}=4.01$ )

A functional magnetic resonance imaging study of heterosexual men with CSB in Germany $(\mathrm{n}=38$; Mean age $=36.3, \mathrm{SD}=11.2$ ) compared with healthy controls $(\mathrm{n}=31$; Mean age $=37.6, \mathrm{SD}=11.17$ )
General CSB as measured by the Compulsive Sexual Behavior Inventory

PPU as measured by the Kalichman Sexual Compulsivity Scale, the Cognitive and Behavioral Outcomes of Sexual Behavior Scale, and the Pornography Consumption Effects Scale

General CSB as measured by the Sexual Desire Inventory-2 and items from the Questionnaire of Sexual Experience and Behavior

General CSB as measured by idiosyncratic measures and clinician diagnosis

General CSB as measured by the Sexual Addiction Screening Test Revised and the Hypersexual Behavior Inventory

General CSB as measured by the Sexual Addiction Screening Test Revised and the Hypersexual Behavior Inventory

General CSB as measured by the Sexual Addiction Screening Test Revised and the Hypersexual Behavior Inventory

General CSB as measured by the Sexual Addiction Screening Test Revised and the Hypersexual Behavior Inventory

General CSB as measured by the Sexual Addiction Screening Test Revised and the Hypersexual Behavior Inventory 
(Steele et al., 2013)

(Voon et al., 2014)
A neuroscience study of adults in the U.S. $(\mathrm{N}=52 ; 75 \%$ men; Mean age $=$ 24.35, $\mathrm{SD}=4.92 ; 45 \%$ heterosexual) A functional magnetic resonance imaging study of adult men in the U.K. (CSB treatment group: $\mathrm{n}=19$; Mean age $=25.61, \mathrm{SD}=4.77$; Control group: $\mathrm{n}=19$; Mean age $=$ 23.17, $\mathrm{SD}=5.38 ; 100 \%$ heterosexual)
General CSB as measured by the Kalichman Sexual Compulsivity Scale

Online CSB as measured by the Internet Sex Screening Test 
Supplemental Table 5

Summary of cognitive, experimental, and quasi-experimental studies included in the present review

\begin{tabular}{|c|c|c|c|}
\hline Study & Sample Details & $\begin{array}{c}\text { Subject of Focus and } \\
\text { Measurement }\end{array}$ & $\begin{array}{c}\text { Experimental/Cognitive } \\
\text { Design }\end{array}$ \\
\hline $\begin{array}{l}\text { (Albery et al., } \\
\text { 2017) }\end{array}$ & $\begin{array}{l}\text { A quasi-experimental study of adults } \\
\text { in the U.K. }(\mathrm{N}=55 ; 50.9 \% \text { men; } \\
\text { Mean age }=28.4, \mathrm{SD}=10.4)\end{array}$ & $\begin{array}{l}\text { General CSB as measured by } \\
\text { the Kalichman Sexual } \\
\text { Compulsivity Scale }\end{array}$ & $\begin{array}{l}\text { Modified Stroop Task with } \\
\text { sexual and neutral words }\end{array}$ \\
\hline $\begin{array}{c}\text { (Antons \& Brand, } \\
\text { 2018) }\end{array}$ & $\begin{array}{l}\text { An experimental study of adult men in } \\
\text { Germany }(\mathrm{N}=50 ; \text { Mean age }=23.30 \text {, } \\
\mathrm{SD}=4.08 ; 100 \% \text { heterosexual }) \\
\text { recruited predominantly from a } \\
\text { university setting }\end{array}$ & $\begin{array}{l}\text { Online CSB as measured by the } \\
\text { short version of the Internet } \\
\text { Addiction Test modified for } \\
\text { online sexual activities }\end{array}$ & $\begin{array}{l}\text { Modified Stop-Signal task with } \\
\text { neutral and pornographic } \\
\text { pictures }\end{array}$ \\
\hline $\begin{array}{l}\text { (Brand et al., } \\
\text { 2011) }\end{array}$ & $\begin{array}{l}\text { A quasi-experimental study of } \\
\text { heterosexual men (university students) } \\
\text { in Germany }(\mathrm{N}=89 ; \text { Mean age }= \\
23.98, \mathrm{SD}=4.09)\end{array}$ & $\begin{array}{l}\text { PPU as measured by the } \\
\text { Internet Addiction Test } \\
\text { modified for sexual use of the } \\
\text { internet }\end{array}$ & $\begin{array}{l}\text { Assessment of emotional } \\
\text { reactions to standardized } \\
\text { pictures depicting sexual } \\
\text { behavior }\end{array}$ \\
\hline $\begin{array}{c}\text { (Hoffmann et al., } \\
\text { 2014) }\end{array}$ & $\begin{array}{l}\text { An experimental study in the U.S. of } \\
\text { men who have sex with men with low } \\
\text { sexual compulsivity }(\mathrm{n}=31 \text {; Mean } \\
\text { age }=26.42, \mathrm{SD}=4.84) \text { and high } \\
\text { sexual compulsivity }(\mathrm{n}=25 ; \text { Mean } \\
\text { age }=25.62, \mathrm{SD}=4.95)\end{array}$ & $\begin{array}{l}\text { General CSB as measured by } \\
\text { the Kalichman Sexual } \\
\text { Compulsivity Scale }\end{array}$ & $\begin{array}{l}\text { Classical conditioning } \\
\text { paradigm using olfactory } \\
\text { stimulation paired with sexual } \\
\text { stimuli }\end{array}$ \\
\hline $\begin{array}{l}\text { (Laier et al., 2013; } \\
\text { Study 1) }\end{array}$ & $\begin{array}{l}\text { An experimental study of heterosexual } \\
\text { men in Germany }(\mathrm{N}=171 \text {; Mean age } \\
=24.56, \mathrm{SD}=5.22)\end{array}$ & $\begin{array}{l}\text { PPU as measured by the short } \\
\text { version of the Internet } \\
\text { Addiction Test modified for } \\
\text { sexual use of the internet }\end{array}$ & $\begin{array}{l}\text { A cue reactivity paradigm } \\
\text { using sexually explicit pictures }\end{array}$ \\
\hline $\begin{array}{l}\text { (Laier et al., 2013; } \\
\text { Study 2) }\end{array}$ & $\begin{array}{l}\text { An experimental study of heterosexual } \\
\text { men in Germany with PPU }(\mathrm{n}=25 ; \\
\text { Mean age }=23.96, \mathrm{SD}=2.91) \text { in } \\
\text { comparison with men without } \mathrm{PPU}(\mathrm{n} \\
=25 ; \text { Mean age }=22.88, \mathrm{SD}=1.86)\end{array}$ & $\begin{array}{l}\text { PPU as measured by the short } \\
\text { version of the Internet } \\
\text { Addiction Test modified for } \\
\text { sexual use of the internet }\end{array}$ & $\begin{array}{l}\text { A cue reactivity paradigm } \\
\text { using sexually explicit pictures }\end{array}$ \\
\hline (Laier et al., 2014) & $\begin{array}{l}\text { An experimental study of heterosexual } \\
\text { women in Germany }(\mathrm{N}=102 ; \text { Mean } \\
\text { age }=21.83, \mathrm{SD}=2.48)\end{array}$ & $\begin{array}{l}\text { PPU as measured by the short } \\
\text { version of the Internet } \\
\text { Addiction Test modified for } \\
\text { online sexual activities }\end{array}$ & $\begin{array}{l}\text { Assessment of emotional } \\
\text { reactions, subjective arousal, } \\
\text { and craving in response to } \\
\text { standardized } \\
\text { pictures depicting sexual } \\
\text { behavior }\end{array}$ \\
\hline
\end{tabular}




\begin{tabular}{|c|c|c|c|}
\hline $\begin{array}{l}\text { (Mechelmans et } \\
\text { al., 2014) }\end{array}$ & $\begin{array}{l}\text { An experimental study of heterosexual } \\
\text { men in the U.K. with CSB }(\mathrm{n}=22 ; \\
\text { Mean age }=25.14, \mathrm{SD}=4.68) \text { and } \\
\text { healthy controls }(\mathrm{n}=44 ; \text { Mean age }= \\
24.16, \mathrm{SD}=5.14)\end{array}$ & $\begin{array}{l}\text { General CSB as indicated by } \\
\text { psychiatrist diagnosed presence } \\
\text { of symptoms }\end{array}$ & $\begin{array}{l}\text { Dot probe task assessing } \\
\text { attentional bias to sexually } \\
\text { explicit cues }\end{array}$ \\
\hline $\begin{array}{l}\text { (Messina et al., } \\
\text { 2017) }\end{array}$ & $\begin{array}{l}\text { An experimental study of Brazilian } \\
\text { men with CSB }(\mathrm{n}=30 ; \text { Age range }= \\
20-60 ; 60 \% \text { heterosexual) and healthy } \\
\text { controls }(\mathrm{n}=30 ; \text { Age range }=20-60 ; \\
86.6 \% \text { heterosexual) }\end{array}$ & $\begin{array}{l}\text { General CSB as measured by } \\
\text { the Kalichman Sexual } \\
\text { Compulsivity Scale }\end{array}$ & $\begin{array}{l}\text { Evaluation of decision making } \\
\text { using the Wisconsin Card } \\
\text { Sorting Task and cognitive } \\
\text { flexibility using the Iowa } \\
\text { Gambling Task before and } \\
\text { after watching a pornographic } \\
\text { video }\end{array}$ \\
\hline $\begin{array}{c}\text { (Moholy et al., } \\
\text { 2015) }\end{array}$ & $\begin{array}{l}\text { An experimental study of college } \\
\text { students in the U.S. }(\mathrm{N}=116 ; 52.6 \% \\
\text { men; Mean age }=21.59, \mathrm{SD}=5.95)\end{array}$ & $\begin{array}{l}\text { General CSB as measured by } \\
\text { the Cognitive and Behavioral } \\
\text { Outcomes of Sexual Behavior } \\
\text { Scale }\end{array}$ & $\begin{array}{l}\text { Assessment of ability to control } \\
\text { sexual arousal in response to } \\
\text { pornographic videos }\end{array}$ \\
\hline $\begin{array}{l}\text { (K. R. W. } \\
\text { Mulhauser et al., } \\
\text { 2014) }\end{array}$ & $\begin{array}{l}\text { An experimental study of U.S. men } \\
\text { receiving counseling for CSB }(n=18 \text {; } \\
\text { Mean age }=43.22, \mathrm{SD}=14.52) \text { and } \\
\text { healthy controls }(\mathrm{n}=44 ; \text { Mean age }= \\
21.23, \mathrm{SD}=4.55)\end{array}$ & $\begin{array}{l}\text { General CSB as measured by } \\
\text { the Kalichman Sexual } \\
\text { Compulsivity Scale }\end{array}$ & $\begin{array}{l}\text { Assessment of desire for } \\
\text { pornography as the } \\
\text { hypothetical cost associated } \\
\text { with use increases using the } \\
\text { Pornography Purchase Task }\end{array}$ \\
\hline $\begin{array}{l}\text { (K. Mulhauser et } \\
\text { al., 2018; Study 1) }\end{array}$ & $\begin{array}{l}\text { An experimental study of U.S. adults } \\
\text { recruited via Mechanical Turk }(\mathrm{N}= \\
369 ; 63.4 \% \text { men, } 36.3 \% \text { women; } \mathrm{n}=1 \\
\text { non-binary participant; Mean age }= \\
33.2, \mathrm{SD}=9.5)\end{array}$ & $\begin{array}{l}\text { PPU as measured by the } \\
\text { Pornography Purchase Task, } \\
\text { the Hypersexual Behavior } \\
\text { Inventory, the Cyber } \\
\text { Pornography Use Inventory 9, } \\
\text { and the Problematic } \\
\text { Pornography Use Scale }\end{array}$ & $\begin{array}{l}\text { Decision making assessed } \\
\text { using the Iowa Gambling Task }\end{array}$ \\
\hline $\begin{array}{c}\text { (Pekal et al., } \\
\text { 2018) }\end{array}$ & $\begin{array}{l}\text { An experimental study of college } \\
\text { students and a community sample in } \\
\text { Germany }(\mathrm{N}=174 ; 50 \% \text { men; Mean } \\
\text { age }=23.59, \mathrm{SD}=4.93)\end{array}$ & $\begin{array}{l}\text { PPU as measured by the short } \\
\text { version of the Internet } \\
\text { Addiction Test modified for } \\
\text { online sexual activities }\end{array}$ & $\begin{array}{l}\text { Visual probe task assessing } \\
\text { attentional bias to sexually } \\
\text { explicit cues }\end{array}$ \\
\hline $\begin{array}{c}\text { (Petrican et al., } \\
\text { 2015) }\end{array}$ & $\begin{array}{l}\text { An experimental study of Canadian } \\
\text { college students }(\mathrm{N}=74 ; 35.13 \% \\
\text { men; Mean age }=21.72, \mathrm{SD}=3.57)\end{array}$ & $\begin{array}{l}\text { General CSB as measured by } \\
\text { the Kalichman Sexual } \\
\text { Compulsivity Scale }\end{array}$ & $\begin{array}{l}\text { Gaze-cueing task to evaluate } \\
\text { attractiveness of neutral and } \\
\text { flirtatious faces following a } \\
\text { task to increase feelings of } \\
\text { personal shame }\end{array}$ \\
\hline $\begin{array}{l}\text { (Prawiroharjo et } \\
\text { al., 2019) }\end{array}$ & $\begin{array}{l}\text { An experimental study of adolescents } \\
\text { with problematic pornography use } \\
\text { behaviors }(\mathrm{n}=15 ; 33.33 \% \text { men; Mean }\end{array}$ & $\begin{array}{l}\text { PPU as measured by the } \\
\text { Pornography Addiction Test }\end{array}$ & $\begin{array}{l}\text { Evaluation of impairments in } \\
\text { verbal memory using the } \\
\text { Auditory Verbal Learning Test, }\end{array}$ \\
\hline
\end{tabular}




\begin{tabular}{|c|c|c|c|}
\hline & $\begin{array}{l}\text { age }=13.80, \mathrm{SD}=1.26) \text { and healthy } \\
\text { controls }(\mathrm{n}=15 ; 53.33 \% \text { men; Mean } \\
\text { age }=13.27, \mathrm{SD}=1.03)\end{array}$ & & $\begin{array}{l}\text { visual memory using the Rey- } \\
\text { Osterrieth Complex Figure } \\
\text { Test, and attention using the } \\
\text { Trail Making Test A and B }\end{array}$ \\
\hline $\begin{array}{c}\text { (Sklenarik et al., } \\
\text { 2019) }\end{array}$ & $\begin{array}{l}\text { An experimental study using an } \\
\text { approach-avoidance task with male } \\
\text { undergraduate students in the U.S. }(\mathrm{N} \\
=72 ; \text { Mean age }=19.5, \mathrm{SD}=2.4 ; \\
100 \% \text { heterosexual) }\end{array}$ & $\begin{array}{l}\text { PPU as measured by the } \\
\text { Problematic Pornography Use } \\
\text { Scale and the Brief } \\
\text { Pornography Screener }\end{array}$ & $\begin{array}{l}\text { Modified approach-avoidance } \\
\text { task using neutral and sexually } \\
\text { explicit pictures }\end{array}$ \\
\hline $\begin{array}{c}\text { (Sklenarik et al., } \\
\text { 2020) }\end{array}$ & $\begin{array}{l}\text { An experimental study using an } \\
\text { approach-avoidance task with } \\
\text { heterosexual female undergraduate } \\
\text { students in the U.S. }(\mathrm{N}=121 \text {; Mean } \\
\text { age }=18.9, \mathrm{SD}=1.1)\end{array}$ & $\begin{array}{l}\text { PPU as measured by the } \\
\text { Brief Pornography Screener } \\
\text { and the Problematic } \\
\text { Pornography Consumption } \\
\text { Scale }\end{array}$ & $\begin{array}{l}\text { Modified approach-avoidance } \\
\text { task using neutral and sexually } \\
\text { explicit pictures }\end{array}$ \\
\hline $\begin{array}{l}\text { (Snagowski \& } \\
\text { Brand, 2015) }\end{array}$ & $\begin{array}{l}\text { An experimental study of adult men } \\
\text { recruited from a university and online } \\
\text { in Germany }(\mathrm{N}=123 ; \text { Mean age = } \\
23.79, \mathrm{SD}=5.10 ; 100 \% \text { heterosexual })\end{array}$ & $\begin{array}{l}\text { Online CSB as measured by the } \\
\text { short version of the Internet } \\
\text { Addiction Test modified for } \\
\text { online sexual activities, and the } \\
\text { Hypersexual Behavior } \\
\text { Inventory }\end{array}$ & $\begin{array}{l}\text { Modified approach-avoidance } \\
\text { task using neutral and sexually } \\
\text { explicit pictures }\end{array}$ \\
\hline $\begin{array}{l}\text { (Stark et al., } \\
\text { 2017) }\end{array}$ & $\begin{array}{l}\text { An experimental study of college } \\
\text { students in Germany }(\mathrm{N}=95 ; 50 \% \\
\text { men; Mean age }=25.45, \mathrm{SD}=5.03)\end{array}$ & $\begin{array}{l}\text { PPU as measured by the short } \\
\text { version of the Internet } \\
\text { Addiction Test modified for } \\
\text { online sexual activities }\end{array}$ & $\begin{array}{l}\text { Modified approach-avoidance } \\
\text { task using neutral, positive, } \\
\text { negative, and sexually explicit } \\
\text { pictures }\end{array}$ \\
\hline $\begin{array}{l}\text { (Derbyshire \& } \\
\text { Grant, 2015) }\end{array}$ & $\begin{array}{l}\text { A study of neurocognitive functioning } \\
\text { in adults with } \operatorname{CSB}(\mathrm{n}=13 \text {; no other } \\
\text { demographics reported) in comparison } \\
\text { with healthy controls }(\mathrm{n}=13)\end{array}$ & $\begin{array}{l}\text { General CSB as measured by } \\
\text { the Minnesota Impulsive } \\
\text { Disorders Interview }\end{array}$ & $\begin{array}{l}\text { Assessment of cognitive } \\
\text { flexibility using the } \\
\text { Intradimensional/ } \\
\text { Extradimensional Set-Shift } \\
\text { Task, response inhibition using } \\
\text { a Stop Signal Task, decision } \\
\text { making and risk taking using } \\
\text { the Cambridge gambling task, } \\
\text { and spatial working memory } \\
\text { using the Spatial Working } \\
\text { Memory task }\end{array}$ \\
\hline $\begin{array}{l}\text { (Schiebener et al., } \\
\text { 2015) }\end{array}$ & $\begin{array}{l}\text { An experimental study of male } \\
\text { college students in Germany }(\mathrm{N}= \\
104 ; \text { Mean age }=24.29, \mathrm{SD}=3.96)\end{array}$ & $\begin{array}{l}\text { PPU as measured by the short } \\
\text { version of the Internet }\end{array}$ & $\begin{array}{l}\text { An executive multitasking } \\
\text { paradigm using neutral pictures }\end{array}$ \\
\hline
\end{tabular}




\begin{tabular}{|c|c|c|c|}
\hline & & $\begin{array}{l}\text { Addiction Test modified for } \\
\text { sex }\end{array}$ & $\begin{array}{l}\text { of people in addition to } \\
\text { sexually explicit pictures }\end{array}$ \\
\hline (Reid et al., 2011) & $\begin{array}{l}\text { A cognitive study of a clinical sample } \\
\text { of hypersexual men seeking treatment } \\
(\mathrm{n}=30 ; \text { Mean age }=33, \mathrm{SD}=8 ; \\
86.7 \% \text { heterosexual }) \text { and healthy } \\
\text { controls }(\mathrm{n}=30 ; \text { Mean age }=28, \mathrm{SD}= \\
6.7 ; 96.7 \% \text { heterosexual }) \text { in the U.S. }\end{array}$ & $\begin{array}{l}\text { General CSB as measured by } \\
\text { the Hypersexual Behavior } \\
\text { Inventory and the Compulsive } \\
\text { Sexual Behavior Inventory }\end{array}$ & $\begin{array}{l}\text { Executive deficits assessed by } \\
\text { the Wisconsin Card Sorting } \\
\text { Task in addition to several } \\
\text { subtests of the Delis-Kaplan } \\
\text { Executive Function System: } \\
\text { Color-Word Interference Test, } \\
\text { the Tower Test, the Trail } \\
\text { Making Test, the Verbal } \\
\text { Fluency Test }\end{array}$ \\
\hline (Reid et al., 2010) & $\begin{array}{l}\text { A cognitive study of a clinical sample } \\
\text { of treatment seeking men }(\mathrm{n}=87 \text {; } \\
\text { Mean age }=31.4, \mathrm{SD}=8.9 ; 92 \% \\
\text { heterosexual, } 5.7 \% \text { gay, } 2.3 \% \\
\text { bisexual) and healthy controls }(\mathrm{n}=92 \text {; } \\
\text { Mean age }=26.2, \mathrm{SD}=5.1 ; 94.6 \% \\
\text { heterosexual, } 4.3 \% \text { gay, } 1.1 \% \\
\text { bisexual) in the U.S. }\end{array}$ & $\begin{array}{l}\text { General CSB as measured by } \\
\text { the Hypersexual Behavior } \\
\text { Inventory }\end{array}$ & $\begin{array}{l}\text { An evaluation of overall } \\
\text { executive functioning using the } \\
\text { Behavior Rating Inventory of } \\
\text { Executive Function - Adult } \\
\text { Version }\end{array}$ \\
\hline
\end{tabular}


Supplemental Table 6

Measures in included studies used to assess Problematic Pornography Use or Compulsive Sexual Behavior

\begin{tabular}{|c|c|c|}
\hline Measure & Source & $\begin{array}{l}\text { Number of Times } \\
\text { Cited in Reviewed } \\
\text { Literature as of April } \\
\mathbf{1}^{\text {st }}, 2020\end{array}$ \\
\hline Kalichman Sexual Compulsivity Scale & $\begin{array}{l}\text { (Kalichman \& Rompa, 1995, } \\
\text { 2001) }\end{array}$ & 140 \\
\hline Hypersexual Behavior Inventory & (Reid, Garos, et al., 2011) & 64 \\
\hline $\begin{array}{l}\text { Cyber Pornography Use Inventory (and } \\
\text { modified forms) }\end{array}$ & $\begin{array}{l}\text { (Grubbs et al., 2010, 2015; } \\
\text { Grubbs \& Gola, 2019) }\end{array}$ & 35 \\
\hline $\begin{array}{l}\text { Sexual Addiction Screening Test (and } \\
\text { modified forms) }\end{array}$ & $\begin{array}{l}\text { (Carnes et al., 2010; Carnes et } \\
\text { al., 2014) }\end{array}$ & 33 \\
\hline $\begin{array}{l}\text { Compulsive Sexual Behavior Inventory } \\
\text { (and modified forms) }\end{array}$ & $\begin{array}{l}\text { (Coleman et al., 2001; Miner } \\
\text { et al., 2017) }\end{array}$ & 27 \\
\hline $\begin{array}{l}\text { Internet Addiction Test (and modified } \\
\text { forms) }\end{array}$ & $\begin{array}{l}\text { (Pawlikowski et al., 2013; } \\
\text { Widyanto \& McMurran, } \\
\text { 2004; Young, 1998) }\end{array}$ & 23 \\
\hline Idiosyncratic Measures & $\mathrm{n} / \mathrm{a}$ & 22 \\
\hline Clinician Based Diagnosis & $\mathrm{n} / \mathrm{a}$ & 21 \\
\hline Sexual Impulsivity Scale & (Exner et al., 1992) & 21 \\
\hline $\begin{array}{l}\text { Problematic Pornography Consumption } \\
\text { Scale (and modified forms) }\end{array}$ & (Böthe et al., 2018) & 17 \\
\hline $\begin{array}{l}\text { Individual Based Compulsive Sexual } \\
\text { Behavior Scale }\end{array}$ & (Efrati \& Mikulincer, 2018) & 17 \\
\hline $\begin{array}{l}\text { Hypersexual Disorder Screening } \\
\text { Inventory }\end{array}$ & $\begin{array}{l}\text { (Parsons et al., 2013; Reid, } \\
\text { Carpenter, et al., 2012) }\end{array}$ & 15 \\
\hline Problematic Pornography Use Scale & (Kor et al., 2014) & 15 \\
\hline $\begin{array}{l}\text { Cognitive and Behavioral Outcomes of } \\
\text { Sexual Behavior Scale }\end{array}$ & (McBride et al., 2010) & 9 \\
\hline $\begin{array}{l}\text { Hypersexual Behavior Consequences } \\
\text { Scale }\end{array}$ & (Reid, Garos, et al., 2012) & 9 \\
\hline Pornography Consumption Inventory & (Reid, Li, et al., 2011) & 9 \\
\hline Internet Sex Screening Test & (Delmonico \& Miller, 2003) & 8 \\
\hline Brief Pornography Screener & (Kraus et al., 2020) & 7 \\
\hline Minnesota Impulsive Disorders Interview & (Odlaug \& Grant, 2010) & 7 \\
\hline $\begin{array}{l}\text { Compulsive Pornography Consumption } \\
\text { Scale }\end{array}$ & (Noor et al., 2014) & 5 \\
\hline Pornography Craving Questionnaire & (Kraus \& Rosenberg, 2014) & 5 \\
\hline $\begin{array}{l}\text { Hypersexual Disorder Current } \\
\text { Assessment Scale }\end{array}$ & (Reid, Carpenter, et al., 2012) & 4 \\
\hline $\begin{array}{l}\text { Multidimensional Assessment of Sex and } \\
\text { Aggression }\end{array}$ & (Knight et al., 1994) & 4 \\
\hline $\begin{array}{l}\text { Compulsive Sexual Behavior Disorder } \\
\text { Scale } 19\end{array}$ & (Böthe et al., 2020) & 4 \\
\hline
\end{tabular}




\begin{tabular}{|l|l|l|}
\hline PATHOS & $\begin{array}{l}\text { (Carnes et al., 2012; Johnson } \\
\text { et al., 2013) }\end{array}$ & 3 \\
\hline Compulsive Internet Use Scale & (Meerkerk et al., 2008) & 3 \\
\hline $\begin{array}{l}\text { Diagnostic Interview for Sexual } \\
\text { Compulsivity }\end{array}$ & (Parsons et al., 2007) & 3 \\
\hline $\begin{array}{l}\text { Hypersexual Disorder Questionnaire } \\
\text { Hypersexual Disorder Diagnostic Clinical } \\
\text { Interview }\end{array}$ & (Reid, Carpenter, et al., 2012) & 3 \\
\hline $\begin{array}{l}\text { Pornography Purchase Task } \\
\text { BODIES }\end{array}$ & (Mulhauser et al., 2018) & 2 \\
\hline $\begin{array}{l}\text { Bergen Yale Sex Addiction Scale } \\
\text { Craving Assessment Scale for Behavioral } \\
\text { Addictions - Porn }\end{array}$ & (Cashwell et al., 2018) & 2 \\
\hline Cybersex Addiction Test & (Antrons et al., 2019) & 1 \\
\hline Compulsive Sexual Disorders Interview & (Black et al., 1997) & 1 \\
\hline Garos Sexual Behavior Index & (Garos \& Stock, 1998) & 1 \\
\hline $\begin{array}{l}\text { Hypersexuality in Psychiatric Conditions } \\
\text { Observer-Rated }\end{array}$ & (Davidson et al., 2017) & 1 \\
\hline $\begin{array}{l}\text { Pornography Addiction screening tool } \\
\text { Sexual Preoccupation Scale }\end{array}$ & (Das et al., 2017) & 1 \\
\hline $\begin{array}{l}\text { Yale-Brown Obsessive Compulsive Scale } \\
\text { modified for CSB }\end{array}$ & (Kraus et al., 2015) & 1 \\
\hline & (Young, 2001) & 1 \\
\hline
\end{tabular}


Supplemental Table 7

Summary of studies detailing treatments of compulsive sexual behaviors and problematic pornography use.

\begin{tabular}{|c|c|c|c|}
\hline Study & Design & Subject of Focus and Measurement & Treatment Modality \\
\hline $\begin{array}{l}\text { (Coleman et al., } \\
\text { 2000) }\end{array}$ & $\begin{array}{l}\text { A retrospective intervention study } \\
\text { on the efficacy of pharmacological } \\
\text { treatment for CSB }(\mathrm{N}=14 ; 100 \% \\
\text { men; Mean age }=45)\end{array}$ & $\begin{array}{l}\text { General CSB as measured by clinician } \\
\text { diagnosis }\end{array}$ & $\begin{array}{l}\text { A pharmacotherapy study for general } \\
\text { CSB }\end{array}$ \\
\hline $\begin{array}{c}\text { (Crosby \& Twohig, } \\
\text { 2016) }\end{array}$ & $\begin{array}{l}\text { A treatment study evaluating the } \\
\text { efficacy of Acceptance and } \\
\text { Commitment Therapy in treating } \\
\text { PPU in men in the U.S. }(\mathrm{N}=28 \text {; } \\
\text { Mean age }=29.3, \mathrm{SD}=11.4)\end{array}$ & $\begin{array}{l}\text { PPU as measured by the Kalichman } \\
\text { Sexual Compulsivity Scale and the } \\
\text { Cognitive and Behavioral Outcomes } \\
\text { of Sexual Behavior Scale }\end{array}$ & $\begin{array}{l}\text { Acceptance and commitment therapy } \\
\text { for PPU }\end{array}$ \\
\hline (Hall et al., 2020) & $\begin{array}{l}\text { A psychoeducational treatment } \\
\text { study CSB in the UK }(\mathrm{N}=119 \text {; } \\
\text { gender, age, and sexual orientation } \\
\text { not reported) }\end{array}$ & $\begin{array}{l}\text { General CSB as measured by clinician } \\
\text { diagnosis }\end{array}$ & $\begin{array}{l}\text { A psychoeducational treatment for } \\
\text { general CSB developed by the } \\
\text { authors of the study }\end{array}$ \\
\hline $\begin{array}{l}\text { (Hallberg et al., } \\
\text { 2017) }\end{array}$ & $\begin{array}{l}\text { A treatment feasibility study of } \\
\text { men in } \mathrm{Sweden}(\mathrm{N}=10, \text { Mean age } \\
=38.9, \mathrm{SD}=8.1)\end{array}$ & $\begin{array}{l}\text { General CSB as measured by the } \\
\text { Hypersexual Disorder Current } \\
\text { Assessment Scale and the } \\
\text { Hypersexual Disorder Screening } \\
\text { Inventory }\end{array}$ & $\begin{array}{l}\text { Cognitive behavior therapy for } \\
\text { general CSB }\end{array}$ \\
\hline $\begin{array}{l}\text { (Hallberg et al., } \\
\text { 2019) }\end{array}$ & $\begin{array}{l}\text { A treatment study of men in } \\
\text { Sweden }(N=137 ; \text { Mean age }=40, \\
S D=12)\end{array}$ & $\begin{array}{l}\text { General CSB as measured by the } \\
\text { Kalichman Sexual Compulsivity } \\
\text { Scale, the Hypersexual Disorder } \\
\text { Current Assessment Scale, and the } \\
\text { Hypersexual Disorder Screening } \\
\text { Inventory }\end{array}$ & $\begin{array}{l}\text { Cognitive behavior therapy for } \\
\text { general CSB }\end{array}$ \\
\hline (Hardy et al., 2010) & $\begin{array}{l}\text { A cross-sectional, retrospective, } \\
\text { self-report study of English } \\
\text { speaking users of an online } \\
\text { program for treating CSB }(\mathrm{N}= \\
138 ; 97 \% \text { men; Mean age }=37.97 \text {, } \\
\mathrm{SD}=12.40)\end{array}$ & $\begin{array}{l}\text { General CSB and PPU as measured } \\
\text { by idiosyncratic self-report questions }\end{array}$ & $\begin{array}{l}\text { An online psychoeducational } \\
\text { program for CSB }\end{array}$ \\
\hline $\begin{array}{l}\text { (Hartman et al., } \\
\text { 2012) }\end{array}$ & $\begin{array}{l}\text { A longitudinal study of treatment } \\
\text { outcomes in Canada }(\mathrm{N}=57 ; \\
91.2 \% \text { men; Mean age }=39.09, \mathrm{SD} \\
=8.81)\end{array}$ & $\begin{array}{l}\text { General CSB as measured by the } \\
\text { Compulsive Sexual Behavior } \\
\text { Inventory }\end{array}$ & $\begin{array}{l}\text { Inpatient multi-modal treatment of } \\
\text { CSB }\end{array}$ \\
\hline $\begin{array}{l}\text { (Savard et al., } \\
\text { 2020) }\end{array}$ & $\begin{array}{l}\text { A psychopharmaceutical treatment } \\
\text { study of men with CSB in Sweden }\end{array}$ & $\begin{array}{l}\text { Hypersexual Disorder: Current } \\
\text { Assessment Scale; HBI; K-SCS }\end{array}$ & $\begin{array}{l}\text { A pharmacotherapy study for general } \\
\text { CSB }\end{array}$ \\
\hline
\end{tabular}




\begin{tabular}{|c|c|c|c|}
\hline & $\begin{array}{l}(\mathrm{N}=20 ; \text { Mean age }=38.8, \mathrm{Sd}= \\
10.3 ; 70 \% \text { heterosexual })\end{array}$ & & \\
\hline $\begin{array}{l}\text { (Klontz et al., } \\
\text { 2005) }\end{array}$ & $\begin{array}{l}\text { A treatment study of adults in the } \\
\text { U.S. }(\mathrm{N}=38 ; 73.6 \% \text { men; Mean } \\
\text { age }=44.1, \mathrm{SD}=8.88 ; 79 \% \\
\text { heterosexual })\end{array}$ & $\begin{array}{l}\text { General CSB as measured by the } \\
\text { Garos Sexual Behavior Inventory }\end{array}$ & $\begin{array}{l}\text { Brief, multimodal treatment of } \\
\text { general CSB }\end{array}$ \\
\hline (Levin et al., 2017) & $\begin{array}{l}\text { A treatment feasibility study for } \\
\text { PPU among adults in the U.S. }(\mathrm{N}= \\
19 ; 90 \% \text { men; Mean age }=23.10 \text {, } \\
\text { SD }=4.48)\end{array}$ & $\begin{array}{l}\text { PPU as measured by the Cyber } \\
\text { Pornography Use Inventory and The } \\
\text { Cognitive and Behavioral Outcomes } \\
\text { of Sexual Behavior Scale }\end{array}$ & $\begin{array}{l}\text { Acceptance and Commitment } \\
\text { Therapy for PPU }\end{array}$ \\
\hline $\begin{array}{l}\text { (Muench et al., } \\
\text { 2007; Wainberg et } \\
\text { al., 2006) }\end{array}$ & $\begin{array}{l}\text { A treatment study of gay and } \\
\text { bisexual men with compulsive } \\
\text { sexual behaviors in the U.S. }(\mathrm{N}= \\
28 ; \text { Mean age }=36.8, \mathrm{SD}=8.2 ; \\
85.7 \% \text { homosexual, } 14.3 \% \\
\text { bisexual) }\end{array}$ & $\begin{array}{l}\text { General CSB as measured by the } \\
\text { Kalichman Sexual Compulsivity } \\
\text { Scale and the Compulsive Sexual } \\
\text { Behavior Consequences Scale }\end{array}$ & $\begin{array}{l}\text { A pharmacotherapy study for general } \\
\text { CSB }\end{array}$ \\
\hline $\begin{array}{l}\text { (Orzack et al., } \\
\text { 2006) }\end{array}$ & $\begin{array}{l}\text { A treatment study of adult men } \\
\text { with problematic online sexual } \\
\text { behaviors }(\mathrm{N}=35 ; \text { Mean age }= \\
44.5 \text {, range } 26-59)\end{array}$ & $\begin{array}{l}\text { Online CSB as measured by clinician } \\
\text { based diagnosis }\end{array}$ & $\begin{array}{l}\text { Multimodal group therapy for online } \\
\text { CSB }\end{array}$ \\
\hline $\begin{array}{l}\text { (Parsons et al., } \\
\text { 2017) }\end{array}$ & $\begin{array}{l}\text { A treatment study of HIV-positive } \\
\text { gay and bisexual men with CSB in } \\
\text { the U.S. }(\mathrm{N}=13 \text {; Mean age }=34.4 \text {, } \\
\mathrm{SD}=9.6 ; 90.9 \% \text { homosexual, } \\
9.1 \% \text { bisexual) }\end{array}$ & $\begin{array}{l}\text { General CSB as measured by the } \\
\text { Kalichman Sexual Compulsivity } \\
\text { Scale }\end{array}$ & $\begin{array}{l}\text { Emotion regulation intervention to } \\
\text { improve safe sex practices among } \\
\text { gay and bisexual men }\end{array}$ \\
\hline $\begin{array}{c}\text { (Twohig \& Crosby, } \\
\text { 2010) }\end{array}$ & $\begin{array}{l}\text { A treatment study of adult men in } \\
\text { the U.S. }(N=28 ; \text { Mean age }=29.3 \text {, } \\
S D=11.4 ; 100 \% \text { heterosexual })\end{array}$ & $\begin{array}{l}\text { PPU as measured by the Cognitive } \\
\text { and Behavioral Outcomes of Sexual } \\
\text { Behavior Scale and the Kalichman } \\
\text { Sexual Compulsivity Scale }\end{array}$ & $\begin{array}{l}\text { Acceptance and Commitment } \\
\text { Therapy for PPU }\end{array}$ \\
\hline (Wan et al., 2000) & $\begin{array}{l}\text { A treatment study ( } 2 \text { years) of } \\
\text { Canadian adults }(\mathrm{N}=202 ; 71 \% \\
\text { male; Mean age }=38 ; \text { Baseline } \\
\text { stats) }\end{array}$ & $\begin{array}{l}\text { General CSB as measured by the } \\
\text { Sexual Addiction Screening Test }\end{array}$ & $\begin{array}{l}\text { Inpatient, 12-step based treatment of } \\
\text { general CSB }\end{array}$ \\
\hline
\end{tabular}


References

Achterbergh, R. C. A., van Rooijen, M. S., van den Brink, W., Boyd, A., \& de Vries, H. J. C. (2020). Enhancing helpseeking behaviour among men who have sex with men at risk for sexually transmitted infections: The syn.bas.in randomised controlled trial. Sexually Transmitted Infections, sextrans-2020-054438. https://doi.org/10.1136/sextrans-2020-054438

Albery, I. P., Lowry, J., Frings, D., Johnson, H. L., Hogan, C., \& Moss, A. C. (2017). Exploring the relationship between sexual compulsivity and attentional bias to sex-related words in a cohort of sexually active individuals. European Addiction Research, 23(1), 1-6. https://doi.org/10.1159/000448732

Allen, A., Kannis-Dymand, L., \& Katsikitis, M. (2017). Problematic internet pornography use: The role of craving, desire thinking, and metacognition. Addictive Behaviors, 70, 65-71. https://doi.org/10.1016/j.addbeh.2017.02.001

Andreassen, C. S., Pallesen, S., Griffiths, M. D., Torsheim, T., \& Sinha, R. (2018). The development and validation of the Bergen-Yale Sex Addiction Scale with a large national sample. Frontiers in Psychology, 9, 144. https://doi.org/10.3389/fpsyg.2018.00144

Antons, S., \& Brand, M. (2018). Trait and state impulsivity in males with tendency towards Internet-pornography-use disorder. Addictive Behaviors, 79, 171-177. https://doi.org/10.1016/j.addbeh.2017.12.029

Antons, S., Mueller, S. M., Wegmann, E., Trotzke, P., Schulte, M. M., \& Brand, M. (2019). Facets of impulsivity and related aspects differentiate among recreational and unregulated use of Internet pornography. Journal of Behavioral Addictions, 8(2), 223-233. https://doi.org/10.1556/2006.8.2019.22

Antons, S., Trotzke, P., Wegmann, E., \& Brand, M. (2019). Interaction of craving and functional coping styles in heterosexual males with varying degrees of unregulated Internet-pornography use. Personality and Individual Differences, 149, 237-243. https://doi.org/10.1016/j.paid.2019.05.051

Baggio, S., Starcevic, V., Studer, J., Simon, O., Gainsbury, S. M., Gmel, G., \& Billieux, J. (2018). Technology-mediated addictive behaviors constitute a spectrum of related yet distinct conditions: A network perspective. Psychology of Addictive Behaviors: Journal of the Society of Psychologists in Addictive Behaviors, 32(5), 564-572. https://doi.org/10.1037/adb0000379

Ballester-Arnal, R., Castro Calvo, J., Gil-Llario, M. D., \& Gil-Julia, B. (2017). Cybersex addiction: A study on Spanish college students. Journal of Sex \& Marital Therapy, 43(6), 567-585. https://doi.org/10.1080/0092623X.2016.1208700

Ballester-Arnal, R., Castro-Calvo, J., Giménez-García, C., Gil-Juliá, B., \& Gil-Llario, M. D. (2020). Psychiatric comorbidity in compulsive sexual behavior disorder (CSBD). Addictive Behaviors, 107, 106384. https://doi.org/10.1016/j.addbeh.2020.106384

Ballester-Arnal, R., Gomez-Martinez, S., Llario, M. D.-G., \& Salmeron-Sanchez, P. (2013). Sexual compulsivity scale: Adaptation and validation in the spanish population. Journal of Sex \& Marital Therapy, 39(6), 526-540. https://doi.org/10.1080/0092623X.2012.665816

Baltieri, D. A., de Oliveira, V. H., de Souza Gatti, A. L., Junqueira Aguiar, A. S., \& de Souza Aranha E Silva, R. A. (2016). Factor Structure and Gender Stability of the Brazilian Version of the Pornography Consumption Inventory. Journal of Sex \& Marital Therapy, 42(7), 589-601. https://doi.org/10.1080/0092623X.2015.1113581

Banca, P., Morris, L. S., Mitchell, S., Harrison, N. A., Potenza, M. N., \& Voon, V. (2016). Novelty, conditioning and attentional bias to sexual rewards. Journal of Psychiatric Research, 72, 91-101.

Baranowski, A. M., Vogl, R., \& Stark, R. (2019). Prevalence and Determinants of Problematic Online Pornography Use in a Sample of German Women. The Journal of Sexual Medicine, 16(8), 1274-1282. https://doi.org/10.1016/j.jsxm.2019.05.010

Benotsch, E. G., Kalichman, S. C., \& Kelly, J. A. (1999). Sexual compulsivity and substance use in HIV-seropositive men who have sex with men: Prevalence and predictors of high-risk behaviors. Addictive Behaviors, 24(6), 857-868.

Benotsch, E. G., Kalichman, S. C., \& Pinkerton, S. (2001). Sexual Compulsivity in HIV-Positive Men and Women: Prevalence, Predictors, and Consequences of High-Risk Behaviors. Sexual Addiction \& Compulsivity, 8(2), 8399. https://doi.org/10.1080/10720160127561

Berberovic, D. (2013). Sexual Compulsivity Comorbidity With Depression, Anxiety, and Substance Use in Students From Serbia and Bosnia and Herzegovina. Europe's Journal of Psychology, 9(3), 517-530. https://doi.org/10.5964/ejop.v9i3.595

Berger, J. H., Kehoe, J. E., Doan, A. P., Crain, D. S., Klam, W. P., Marshall, M. T., \& Christman, M. S. (2019). Survey of Sexual Function and Pornography. Military Medicine, 184(11-12), 731-737. https://doi.org/10.1093/milmed/usz079 
Black, D. W., Kehrberg, L. L., Flumerfelt, D. L., \& Schlosser, S. S. (1997). Characteristics of 36 subjects reporting compulsive sexual behavior. The American Journal of Psychiatry, 154(2), 243-249. https://doi.org/10.1176/ajp.154.2.243

Blain, L. M., Muench, F., Morgenstern, J., \& Parsons, J. T. (2012). Exploring the role of child sexual abuse and posttraumatic stress disorder symptoms in gay and bisexual men reporting compulsive sexual behavior. Child Abuse \& Neglect, 36(5), 413-422. https://doi.org/10.1016/j.chiabu.2012.03.003

Blum, A. W., Chamberlain, S. R., \& Grant, J. E. (2018). Quality of life of young adults with non-paraphilic problematic sexual behaviors: An exploratory study. Addictive Behaviors Reports, 8, 164-169. https://doi.org/10.1016/j.abrep.2018.10.003

Blum, A. W., Lust, K., Christenson, G., \& Grant, J. E. (2019). Links between sexuality, impulsivity, compulsivity, and addiction in a large sample of university students. CNS Spectrums, 1-7. https://doi.org/10.1017/S1092852918001591

Borgogna, N. C., \& Aita, S. L. (2019). Problematic Pornography Viewing from a Big-5 Personality Perspective. Sexual Addiction \& Compulsivity, 26(3-4), 293-314. https://doi.org/10.1080/10720162.2019.1670302

Borgogna, N. C., Duncan, J., \& McDermott, R. C. (2018). Is scrupulosity behind the relationship between problematic pornography viewing and depression, anxiety, and stress? Sexual Addiction \& Compulsivity, 25(4), 293-318. https://doi.org/10.1080/10720162.2019.1567410

Borgogna, N. C., Isacco, A., \& McDermott, R. C. (2020). A Closer Examination of the Relationship between Religiosity and Problematic Pornography Viewing in Heterosexual Men. Sexual Addiction \& Compulsivity, O(0), 1-22. https://doi.org/10.1080/10720162.2020.1751361

Borgogna, N. C., Lathan, E. C., \& Mitchell, A. (2018). Is Women's Problematic Pornography Viewing Related to Body Image or Relationship Satisfaction? Sexual Addiction \& Compulsivity, 25(4), 345-366. https://doi.org/10.1080/10720162.2018.1532360

Borgogna, N. C., McDermott, R. C., Berry, A. T., \& Browning, B. R. (2019). Masculinity and problematic pornography viewing: The moderating role of self-esteem. Psychology of Men \& Masculinities.

Borgogna, N. C., McDermott, R. C., Browning, B. R., Beach, J. D., \& Aita, S. L. (2018). How does traditional masculinity relate to men and women's problematic pornography viewing? Sex Roles. https://doi.org/10.1007/s11199-018-0967-8

Bothe, B., Bartok, R., Toth-Kiraly, I., Reid, R. C., Griffiths, M. D., Demetrovics, Z., \& Orosz, G. (2018). Hypersexuality, Gender, and Sexual Orientation: A Large-Scale Psychometric Survey Study. Archives of Sexual Behavior, 47(8), 2265-2276. https://doi.org/10.1007/s10508-018-1201-z

Bothe, B., Koos, M., Toth-Kiraly, I., Orosz, G., \& Demetrovics, Z. (2019). Investigating the Associations Of Adult ADHD Symptoms, Hypersexuality, and Problematic Pornography Use Among Men and Women on a Largescale, Non-Clinical Sample. The Journal of Sexual Medicine, 16(4), 489-499. https://doi.org/10.1016/j.jsxm.2019.01.312

Bothe, B., Kovacs, M., Toth-Kiraly, I., Reid, R. C., Griffiths, M. D., Orosz, G., \& Demetrovics, Z. (2019). The Psychometric Properties of the Hypersexual Behavior Inventory Using a Large-Scale Nonclinical Sample. Journal of Sex Research, 56(2), 180-190. https://doi.org/10.1080/00224499.2018.1494262

Bőthe, B., Lonza, A., Štulhofer, A., \& Demetrovics, Z. (2020). Symptoms of Problematic Pornography Use in a Sample of Treatment Considering and Treatment Non-Considering Men: A Network Approach. The Journal of Sexual Medicine. https://doi.org/10.1016/j.jsxm.2020.05.030

Bőthe, B., Lonza, A., Štulhofer, A., \& Demetrovics, Z. (2020). Symptoms of Problematic Pornography Use in a Sample of Treatment Considering and Treatment Non-Considering Men: A Network Approach. The Journal of Sexual Medicine. https://doi.org/10.1016/j.jsxm.2020.05.030

Bőthe, B., Potenza, M. N., Griffiths, M. D., Kraus, S. W., Klein, V., Fuss, J., \& Demetrovics, Z. (2020). The development of the Compulsive Sexual Behavior Disorder Scale (CSBD-19): An ICD-11 based screening measure across three languages. Journal of Behavioral Addictions, 9(2), 247-258. https://doi.org/10.1556/2006.2020.00034

Böthe, B., Potenza, M. N., Griffiths, M. D., Kraus, S. W., Klein, V., Fuss, J., \& Demetrovics, Z. (2020). The development of the Compulsive Sexual Behavior Disorder Scale (CSBD-19): An ICD-11 based screening measure across three languages. Journal of Behavioral Addictions, 9(2), 247-258. https://doi.org/10.1556/2006.2020.00034

Bőthe, B., Tóth-Király, I., Bella, N., Potenza, M. N., Demetrovics, Z., \& Orosz, G. (2020). Why do people watch pornography? The motivational basis of pornography use. Psychology of Addictive Behaviors. https://doi.org/10.1037/adb0000603 
Bőthe, B., Tóth-Király, I., Bella, N., Potenza, M. N., Demetrovics, Z., \& Orosz, G. (2020). Why do people watch pornography? The motivational basis of pornography use. Psychology of Addictive Behaviors. https://doi.org/10.1037/adb0000603

Bőthe, B., Tóth-Király, I., Demetrovics, Z., \& Orosz, G. (2020). The short version of the Problematic Pornography Consumption Scale (PPCS-6): A reliable and valid measure in general and treatment-seeking populations. The Journal of Sex Research, 1-11.

Bothe, B., Toth-Kiraly, I., Potenza, M. N., Griffiths, M. D., Orosz, G., \& Demetrovics, Z. (2019). Revisiting the Role of Impulsivity and Compulsivity in Problematic Sexual Behaviors. Journal of Sex Research, 56(2), 166-179. https://doi.org/10.1080/00224499.2018.1480744

Bőthe, B., Tóth-Király, I., Potenza, M. N., Orosz, G., \& Demetrovics, Z. (2020). High-Frequency Pornography Use May Not Always Be Problematic. The Journal of Sexual Medicine. https://doi.org/10.1016/j.jsxm.2020.01.007

Bradley, D. F., Grubbs, J. B., Uzdavines, A., Exline, J. J., \& Pargament, K. I. (2016). Perceived addiction to internet pornography among religious believers and nonbelievers. Sexual Addiction \& Compulsivity, 23(2/3), 225-243. rzh. https://doi.org/10.1080/10720162.2016.1162237

Brahim, F. B., Rothen, S., Bianchi-Demicheli, F., Courtois, R., \& Khazaal, Y. (2019). Contribution of sexual desire and motives to the compulsive use of cybersex. Journal of Behavioral Addictions, 8(3), 442-450.

Brakoulias, V., Starcevic, V., Albert, U., Arumugham, S. S., Bailey, B. E., Belloch, A., Borda, T., Dell'Osso, L., Elias, J. A., Falkenstein, M. J., Ferrao, Y. A., Fontenelle, L. F., Jelinek, L., Kay, B., Lochner, C., Maina, G., Marazziti, D., Matsunaga, H., Miguel, E. C., ... Fineberg, N. A. (2020). The rates of co-occurring behavioural addictions in treatment-seeking individuals with obsessive-compulsive disorder: A preliminary report. International Journal of Psychiatry in Clinical Practice, 24(2), 173-175. https://doi.org/10.1080/13651501.2019.1711424

Brakoulias, V., Starcevic, V., Albert, U., Arumugham, S. S., Bailey, B. E., Belloch, A., Borda, T., Dell’Osso, L., Elias, J. A., Falkenstein, M. J., Ferrao, Y. A., Fontenelle, L. F., Jelinek, L., Kay, B., Lochner, C., Maina, G., Marazziti, D., Matsunaga, H., Miguel, E. C., ... Fineberg, N. A. (2020). The rates of co-occurring behavioural addictions in treatment-seeking individuals with obsessive-compulsive disorder: A preliminary report. International Journal of Psychiatry in Clinical Practice, 24(2), 173-175. https://doi.org/10.1080/13651501.2019.1711424

Brand, M., Laier, C., Pawlikowski, M., Schachtle, U., Scholer, T., \& Altstotter-Gleich, C. (2011). Watching pornographic pictures on the Internet: Role of sexual arousal ratings and psychological-psychiatric symptoms for using Internet sex sites excessively. Cyberpsychology, Behavior and Social Networking, 14(6), 371-377. https://doi.org/10.1089/cyber.2010.0222

Brand, M., Snagowski, J., Laier, C., \& Maderwald, S. (2016). Ventral striatum activity when watching preferred pornographic pictures is correlated with symptoms of Internet pornography addiction. NeuroImage, 129, 224232. https://doi.org/10.1016/j.neuroimage.2016.01.033

Brown, M. J., Serovich, J. M., \& Kimberly, J. A. (2016). Outcome Expectancy and Sexual Compulsivity Among Men Who Have Sex with Men Living with HIV. AIDS and Behavior, 20(8), 1667-1674. https://doi.org/10.1007/s10461-016-1361-6

Brown, M. J., Serovich, J. M., \& Kimberly, J. A. (2018). Vengeance, sexual compulsivity and self-efficacy among men who have sex with men living with HIV. AIDS Care, 30(3), 325-329. https://doi.org/10.1080/09540121.2017.1360994

Burri, A. (2017). Sexual Sensation Seeking, Sexual Compulsivity, and Gender Identity and Its Relationship With Sexual Functioning in a Population Sample of Men and Women. The Journal of Sexual Medicine, 14(1), 69-77. https://doi.org/10.1016/j.jsxm.2016.10.013

Carnes, P. J., Green, B. A., Merlo, L. J., Polles, A., Carnes, S., \& Gold, M. S. (2012). PATHOS: a brief screening application for assessing sexual addiction. Journal of Addiction Medicine, 6(1), 29-34. https://doi.org/10.1097/ADM.0b013e3182251a28

Carnes, P. J., Hopkins, T. A., \& Green, B. A. (2014). Clinical Relevance of the Proposed Sexual Addiction Diagnostic Criteria: Relation to the Sexual Addiction Screening Test-Revised. Journal of Addiction Medicine, 8(6), 450-461. https://doi.org/10.1097/ADM.0000000000000080

Carvalho, J., Guerra, L., Neves, S., \& Nobre, P. J. (2015). Psychopathological predictors characterizing sexual compulsivity in a nonclinical sample of women. Journal of Sex \& Marital Therapy, 41(5), 467-480. https://doi.org/10.1080/0092623X.2014.920755

Carvalho, J., Stulhofer, A., Vieira, A. L., \& Jurin, T. (2015). Hypersexuality and high sexual desire: Exploring the structure of problematic sexuality. The Journal of Sexual Medicine, 12(6), 1356-1367. https://doi.org/10.1111/jsm.12865 
Cashwell, C. S., Giordano, A. L., \& Henson, R. A. (2018). BODIES: A Short Sex Addiction Screening Tool for College Students. Journal of College Counseling, 21(3), 265-273. https://doi.org/10.1002/jocc.12108

Castro-Calvo, J., Ballester-Arnal, R., Billieux, J., Gil-Julia, B., \& Gil-Llario, M. D. (2018). Spanish validation of the Sexual Addiction Screening Test. Journal of Behavioral Addictions, 7(3), 584-600. https://doi.org/10.1556/2006.7.2018.57

Castro-Calvo, J., Gil-Llario, M. D., Giménez-García, C., Gil-Juliá, B., \& Ballester-Arnal, R. (2020). Occurrence and clinical characteristics of Compulsive Sexual Behavior Disorder (CSBD): A cluster analysis in two independent community samples. Journal of Behavioral Addictions, 9(2), 446-468. https://doi.org/10.1556/2006.2020.00025

Castro-Calvo, J., Gil-Llario, M. D., Giménez-García, C., Gil-Juliá, B., \& Ballester-Arnal, R. (2020). Occurrence and clinical characteristics of Compulsive Sexual Behavior Disorder (CSBD): A cluster analysis in two independent community samples. Journal of Behavioral Addictions, 9(2), 446-468. https://doi.org/10.1556/2006.2020.00025

Chaney, M. P., \& Blalock, A. C. (2006). Boredom Proneness, Social Connectedness, and Sexual Addiction Among Men Who Have Sex With Male Internet Users. Journal of Addictions \& Offender Counseling, 26(2), 111-122. https://doi.org/10.1002/j.2161-1874.2006.tb00012.x

Chaney, M. P., \& Burns-Wortham, C. M. (2014). The Relationship Between Online Sexual Compulsivity, Dissociation, and Past Child Abuse Among Men Who Have Sex with Men. Journal of LGBT Issues in Counseling, 8(2), 146163. https://doi.org/10.1080/15538605.2014.895663

Chaney, M. P., \& Burns-Wortham, C. M. (2015). Examining Coming Out, Loneliness, and Self-esteem as Predictors of Sexual Compulsivity in Gay and Bisexual Men. Sexual Addiction \& Compulsivity, 22(1), 71-88. https://doi.org/10.1080/10720162.2014.1001543

Chatzittofis, A., Arver, S., Oberg, K., Hallberg, J., Nordstrom, P., \& Jokinen, J. (2016). HPA axis dysregulation in men with hypersexual disorder. Psychoneuroendocrinology, 63, 247-253. https://doi.org/10.1016/j.psyneuen.2015.10.002

Chatzittofis, A., Boström, A. E., Öberg, K. G., Flanagan, J. N., Schiöth, H. B., Arver, S., \& Jokinen, J. (2020). Normal Testosterone but Higher Luteinizing Hormone Plasma Levels in Men With Hypersexual Disorder. Sexual Medicine, 8(2), 243-250. https://doi.org/10.1016/j.esxm.2020.02.005

Chatzittofis, A., Boström, A. E., Öberg, K. G., Flanagan, J. N., Schiöth, H. B., Arver, S., \& Jokinen, J. (2020). Normal Testosterone but Higher Luteinizing Hormone Plasma Levels in Men With Hypersexual Disorder. Sexual Medicine, 8(2), 243-250. https://doi.org/10.1016/j.esxm.2020.02.005

Chatzittofis, A., Savard, J., Arver, S., Oberg, K. G., Hallberg, J., Nordstrom, P., \& Jokinen, J. (2017). Interpersonal violence, early life adversity, and suicidal behavior in hypersexual men. Journal of Behavioral Addictions, 6(2), 187-193. https://doi.org/10.1556/2006.6.2017.027

Chen, L., \& Jiang, X. (2020). The Assessment of Problematic Internet Pornography Use: A Comparison of Three Scales with Mixed Methods. International Journal of Environmental Research and Public Health, 17(2), 488. https://doi.org/10.3390/ijerph17020488

Chen, L., \& Jiang, X. (2020). The Assessment of Problematic Internet Pornography Use: A Comparison of Three Scales with Mixed Methods. International Journal of Environmental Research and Public Health, 17(2), 488. https://doi.org/10.3390/ijerph17020488

Chen, L., Luo, X., Bőthe, B., Jiang, X., Demetrovics, Z., \& Potenza, M. N. (2021). Properties of the Problematic Pornography Consumption Scale (PPCS-18) in community and subclinical samples in China and Hungary. Addictive Behaviors, 112, 106591. https://doi.org/10.1016/j.addbeh.2020.106591

Chen, L., Luo, X., Bőthe, B., Jiang, X., Demetrovics, Z., \& Potenza, M. N. (2021). Properties of the Problematic Pornography Consumption Scale (PPCS-18) in community and subclinical samples in China and Hungary. Addictive Behaviors, 112, 106591. https://doi.org/10.1016/j.addbeh.2020.106591

Chen, L., Yang, Y., Su, W., Zheng, L., Ding, C., \& Potenza, M. N. (2018). The relationship between sexual sensation seeking and problematic Internet pornography use: A moderated mediation model examining roles of online sexual activities and the third-person effect. Journal of Behavioral Addictions, 7(3), 565-573. https://doi.org/10.1556/2006.7.2018.77

Chowdhury, M. R. H. K., Chowdhury, M. R. K., Kabir, R., Perera, N. K. P., \& Kader, M. (2018). Does the addiction in online pornography affect the behavioral pattern of undergrad private university students in Bangladesh? International Journal of Health Sciences, 12(3), 67-74.

Coleman, E., Gratzer, T., Nesvacil, L., \& Raymond, N. C. (2000). Nefazodone and the treatment of nonparaphilic compulsive sexual behavior: A retrospective study. The Journal of Clinical Psychiatry, 61(4), 282-284. 
Coleman, E., Miner, M., Ohlerking, F., \& Raymond, N. (2001). Compulsive sexual behavior inventory: A preliminary study of reliability and validity. Journal of Sex \& Marital Therapy, 27(4), 325-332.

https://doi.org/10.1080/009262301317081070

Coleman, Eli, Horvath, K. J., Miner, M., Ross, M. W., Oakes, M., \& Rosser, B. R. S. (2010). Compulsive sexual behavior and risk for unsafe sex among internet using men who have sex with men. Archives of Sexual Behavior, 39(5), 1045-1053. https://doi.org/10.1007/s10508-009-9507-5

Cooper, A., Delmonico, D. L., \& Burg, R. (2000). Cybersex users, abusers, and compulsives: New findings and implications. Sexual Addiction \& Compulsivity, 7(1-2), 5-29. https://doi.org/10.1080/10720160008400205

Cooper, A., Delmonico, D. L., Griffin-Shelley, E., \& Mathy, R. M. (2004). Online Sexual Activity:An Examination of Potentially Problematic Behaviors. Sexual Addiction \& Compulsivity, 11(3), 129-143. https://doi.org/10.1080/10720160490882642

Cooper, A., Galbreath, N., \& Becker, M. A. (2004). Sex on the Internet: Furthering Our Understanding of Men With Online Sexual Problems. Psychology of Addictive Behaviors, 18(3), 223-230. https://doi.org/10.1037/0893164X.18.3.223

Cooper, A., Griffin-Shelley, E., Delmonico, D. L., \& Mathy, R. M. (2001). Online Sexual Problems: Assessment and Predictive Variables. Sexual Addiction \& Compulsivity, 8(3-4), 267-285. https://doi.org/10.1080/107201601753459964

Cooper, A., Morahan-Martin, J., Mathy, R. M., \& Maheu, M. (2002). Toward an Increased Understanding of User Demographics in Online Sexual Activities. Journal of Sex \& Marital Therapy, 28(2), 105-129. https://doi.org/10.1080/00926230252851861

Cooper, A., Safir, M. P., \& Rosenmann, A. (2006). Workplace Worries: A Preliminary Look at Online Sexual Activities at the Office-Emerging Issues for Clinicians and Employers. CyberPsychology \& Behavior, 9(1), $22-29$. https://doi.org/10.1089/cpb.2006.9.22

Cooper, A., Scherer, C. R., Boies, S. C., \& Gordon, B. L. (1999). Sexuality on the Internet: From sexual exploration to pathological expression. Professional Psychology: Research and Practice, 30(2), 154.

Crosby, J. M., \& Twohig, M. P. (2016). Acceptance and Commitment Therapy for Problematic Internet Pornography Use: A Randomized Trial. Behavior Therapy, 47(3), 355-366. https://doi.org/10.1016/j.beth.2016.02.001

Daneback, K., Ross, M. W., \& Månsson, S.-A. (2006). Characteristics and Behaviors of Sexual Compulsives Who Use the Internet for Sexual Purposes. Sexual Addiction \& Compulsivity, 13(1), 53-67. https://doi.org/10.1080/10720160500529276

Das, A., Sharma, M. K., Thamilselvan, P., \& Marimuthu, P. (2017). Technology Addiction among Treatment Seekers for Psychological Problems: Implication for Screening in Mental Health Setting. Indian Journal of Psychological Medicine, 39(1), 21-27. https://doi.org/10.4103/0253-7176.198939

Davidson, C. K. D., Cheung, G., \& Jansen, K. (2017). Hypersexuality in Psychiatric Conditions Observer-Rated Scale (HIPCORS): Evaluation of Reliability and Validity. Journal of Sex \& Marital Therapy, 43(3), 277-287. https://doi.org/10.1080/0092623X.2016.1149127

De Boni, R. B., Machado, I. K., De Vasconcellos, M. T. L., Hoagland, B., Kallas, E. G., Madruga, J. V., Fernandes, N. M., Cerqueira, N. B., Moreira, R. I., Goulart, S. P., Veloso, V. G., Grinsztejn, B., \& Luz, P. M. (2018). Syndemics among individuals enrolled in the PrEP Brasil Study. Drug and Alcohol Dependence, 185, 168-172. https://doi.org/10.1016/j.drugalcdep.2017.12.016

Delmonico, D., \& Miller, J. (2003). The Internet Sex Screening Test: A comparison of sexual compulsives versus nonsexual compulsives. Sexual and Relationship Therapy, 18(3), 261-276. https://doi.org/10.1080/1468199031000153900

Derbyshire, K. L., \& Grant, J. E. (2015). Neurocognitive findings in compulsive sexual behavior: A preliminary study. Journal of Behavioral Addictions, 4(2), 35-36. https://doi.org/10.1556/2006.4.2015.004

Dew, B. J., \& Chaney, M. P. (2005). The Relationship Among Sexual Compulsivity, Internalized Homophobia, and HIV At-Risk Sexual Behavior in Gay and Bisexual Male Users of Internet Chat Rooms. Sexual Addiction \& Compulsivity, 12(4), 259-273. https://doi.org/10.1080/10720160500362306

Dhuffar, M. K., Pontes, H. M., \& Griffiths, M. D. (2015). The role of negative mood states and consequences of hypersexual behaviours in predicting hypersexuality among university students. Journal of Behavioral Addictions, 4(3), 181-188. https://doi.org/10.1556/2006.4.2015.030

Dickenson, J. A., Gleason, N., Coleman, E., \& Miner, M. H. (2018). Prevalence of distress associated with difficulty controlling sexual urges, feelings, and behaviors in the united states. JAMA Network Open, 1(7), e184468. https://doi.org/10.1001/jamanetworkopen.2018.4468 
Dilley, J. W., Loeb, L., Marson, K., Chen, S., Schwarcz, S., Paul, J., \& McFarland, W. (2008). Sexual Compulsiveness and Change in Unprotected Anal Intercourse: Unexpected Results From a Randomized Controlled HIV Counseling Intervention Study. JAIDS Journal of Acquired Immune Deficiency Syndromes, 48(1), 113-114. https://doi.org/10.1097/QAI.0b013e3181642293

do Amaral, M. L. S., Abdo, C. H. N., Tavares, H., \& Scanavino, M. de T. (2015). Personality among sexually compulsive men who practice intentional unsafe sex in Sao Paulo, Brazil. The Journal of Sexual Medicine, 12(2), 557-566. https://doi.org/10.1111/jsm.12761

Dodge, B., Reece, M., Herbenick, D., Fisher, C., Satinsky, S., \& Stupiansky, N. (2008). Relations between sexually transmitted infection diagnosis and sexual compulsivity in a community-based sample of men who have sex with men. Sexually Transmitted Infections, 84(4), 324-327. https://doi.org/10.1136/sti.2007.028696

Dodge, Brian, Reece, M., Cole, S. L., \& Sandfort, T. G. M. (2004). Sexual compulsivity among heterosexual college students. Journal of Sex Research, 41(4), 343-350. https://doi.org/10.1080/00224490409552241

Downing, M. J. J., Antebi, N., \& Schrimshaw, E. W. (2014). Compulsive use of Internet-based sexually explicit media: Adaptation and validation of the Compulsive Internet Use Scale (CIUS). Addictive Behaviors, 39(6), 1126-1130. https://doi.org/10.1016/j.addbeh.2014.03.007

Draps, M., Sescousse, G., Potenza, M. N., Marchewka, A., Duda, A., Lew-Starowicz, M., Kopera, M., Jakubczyk, A., Wojnar, M., \& Gola, M. (2020). Gray Matter Volume Differences in Impulse Control and Addictive DisordersAn Evidence From a Sample of Heterosexual Males. The Journal of Sexual Medicine. https://doi.org/10.1016/j.jsxm.2020.05.007

Draps, M., Sescousse, G., Potenza, M. N., Marchewka, A., Duda, A., Lew-Starowicz, M., Kopera, M., Jakubczyk, A., Wojnar, M., \& Gola, M. (2020). Gray Matter Volume Differences in Impulse Control and Addictive DisordersAn Evidence From a Sample of Heterosexual Males. The Journal of Sexual Medicine. https://doi.org/10.1016/j.jsxm.2020.05.007

DT Scanavino, M., Ventuneac, A., Caramelli, B., Naufal, L., SD Santos Filho, C., Nisida, I. V., Amaral, M. L., Vieira, J. C., \& Parsons, J. T. (2020). Cardiovascular and psychopathological factors among non-sexually compulsive, sexually compulsive, and hypersexual individuals in Sao Paulo, Brazil. Psychology, Health \& Medicine, 25(1), $121-129$.

Dwulit, A. D., \& Rzymski, P. (2019). Prevalence, Patterns and Self-Perceived Effects of Pornography Consumption in Polish University Students: A Cross-Sectional Study. International Journal of Environmental Research and Public Health, 16(10). https://doi.org/10.3390/ijerph16101861

Efrati, Y. (2018). Adolescent Compulsive Sexual Behavior: Is It a Unique Psychological Phenomenon? Journal of Sex \& Marital Therapy, 44(7), 687-700. https://doi.org/10.1080/0092623X.2018.1452088

Efrati, Y. (2019). God, I Can't Stop Thinking About Sex! The Rebound Effect in Unsuccessful Suppression of Sexual Thoughts Among Religious Adolescents. Journal of Sex Research, 56(2), 146-155. https://doi.org/10.1080/00224499.2018.1461796

Efrati, Y., \& Dannon, P. (2018). Normative and Clinical Self-Perceptions of Sexuality and Their Links to Psychopathology among Adolescents. Psychopathology, 51(6), 380-389. https://doi.org/10.1159/000495842

Efrati, Y., \& Gola, M. (2018a). Compulsive sexual behavior: A twelve-step therapeutic approach. Journal of Behavioral Addictions, 7(2), 445-453. https://doi.org/10.1556/2006.7.2018.26

Efrati, Y., \& Gola, M. (2018b). Understanding and predicting profiles of compulsive sexual behavior among adolescents. Journal of Behavioral Addictions, 7(4), 1004-1014. https://doi.org/10.1556/2006.7.2018.100

Efrati, Y., \& Gola, M. (2019a). The Effect of Early Life Trauma on Compulsive Sexual Behavior among Members of a. The Journal of Sexual Medicine, 16(6), 803-811. https://doi.org/10.1016/j.jsxm.2019.03.272

Efrati, Y., \& Gola, M. (2019b). Adolescents' compulsive sexual behavior: The role of parental competence, parents' psychopathology, and quality of parent-child communication about sex. Journal of Behavioral Addictions, 1-12. https://doi.org/10.1556/2006.8.2019.33

Efrati, Y., \& Mikulincer, M. (2018). Individual-Based Compulsive Sexual Behavior Scale: Its Development and Importance in Examining Compulsive Sexual Behavior. Journal of Sex \& Marital Therapy, 44(3), 249-259. https://doi.org/10.1080/0092623X.2017.1405297

Efrati, Y., Gerber, Z., \& Tolmacz, R. (2019). The Relation of Intra-Psychic and Relational Aspects of the Self to Compulsive Sexual Behavior. Journal of Sex \& Marital Therapy, 1-14. https://doi.org/10.1080/0092623X.2019.1599092 
Efrati, Y., Shukron, O., \& Epstein, R. (2019). Compulsive sexual behavior and sexual offending: Differences in cognitive schemas, sensation seeking, and impulsivity. Journal of Behavioral Addictions, 8(3), 432-441. https://doi.org/10.1556/2006.8.2019.36

Egan, V., \& Parmar, R. (2013). Dirty Habits? Online Pornography Use, Personality, Obsessionality, and Compulsivity. Journal of Sex \& Marital Therapy, 39(5), 394-409. https://doi.org/10.1080/0092623X.2012.710182

Engel, J., Kessler, A., Veit, M., Sinke, C., Heitland, I., Kneer, J., Hartmann, U., \& Kruger, T. H. C. (2019). Hypersexual behavior in a large online sample: Individual characteristics and signs of coercive sexual behavior. Journal of Behavioral Addictions, 8(2), 213-222. https://doi.org/10.1556/2006.8.2019.16

Engel, J., Veit, M., Sinke, C., Heitland, I., Kneer, J., Hillemacher, T., Hartmann, U., \& Kruger, T. H. C. (2019). Same Same but Different: A Clinical Characterization of Men with Hypersexual Disorder in the Sex@Brain Study. Journal of Clinical Medicine, 8(2). https://doi.org/10.3390/jcm8020157

Farre, J. M., Fernandez-Aranda, F., Granero, R., Aragay, N., Mallorqui-Bague, N., Ferrer, V., More, A., Bouman, W. P., Arcelus, J., Savvidou, L. G., Penelo, E., Aymami, M. N., Gomez-Pena, M., Gunnard, K., Romaguera, A., Menchon, J. M., Valles, V., \& Jimenez-Murcia, S. (2015). Sex addiction and gambling disorder: Similarities and differences. Comprehensive Psychiatry, 56, 59-68. https://doi.org/10.1016/j.comppsych.2014.10.002

Fernandez, D. P., Tee, E. Y. J., \& Fernandez, E. F. (2017). Do Cyber Pornography Use Inventory-9 scores reflect actual compulsivity in internet pornography use? Exploring the role of abstinence effort. Sexual Addiction \& Compulsivity, 24(3), 156-179. https://doi.org/10.1080/10720162.2017.1344166

Gil-Llario, M. D., Ruiz-Palomino, E., Ballester-Arnal, R., \& Morell-Mengual, V. (2016). Influence of Sexual Sensation Seeking, Sexual Compulsivity and Sexual Pleasure in Condom Use Among Spanish Youth: Implications For HIV Interventions. Journal of Preventive Medicine and Care, 1(3), 01. https://doi.org/10.14302/issn.2474-3585.jpmc$16-1198$

Gilbert, P. A., \& Rhodes, S. D. (2014). Immigrant sexual minority Latino men in rural North Carolina: An exploration of social context, social behaviors, and sexual outcomes. Journal of Homosexuality, 61(8), 1131-1151. https://doi.org/10.1080/00918369.2014.872507

Gilliland, R., Blue Star, J., Hansen, B., \& Carpenter, B. (2015). Relationship Attachment Styles in a Sample of Hypersexual Patients. Journal of Sex \& Marital Therapy, 41(6), 581-592. https://doi.org/10.1080/0092623X.2014.958787

Giordano, A. L., \& Cecil, A. L. (2014). Religious Coping, Spirituality, and Hypersexual Behavior Among College Students. Sexual Addiction \& Compulsivity, 21(3), 225-239. https://doi.org/10.1080/10720162.2014.936542

Giordano, A. L., Prosek, E. A., Cecil, A. L., \& Brown, J. (2015). Predictors of Hypersexual Behavior Among College Men and Women: Exploring Self-Conscious Emotions. Journal of Addictions \& Offender Counseling, 36(2), 113-125. https://doi.org/10.1002/jaoc.12007

Gola, M., Lewczuk, K., \& Skorko, M. (2016). What Matters: Quantity or Quality of Pornography Use? Psychological and Behavioral Factors of Seeking Treatment for Problematic Pornography Use. The Journal of Sexual Medicine, 13(5), 815-824. https://doi.org/10.1016/j.jsxm.2016.02.169

Gola, M., Skorko, M., Kowalewska, E., Kolodziej, A., Sikora, M., Wodyk, M., Wodyk, Z., \& Dobrowolski, P. (2017). Polish adaptation of Sexual Addiction Screening Test—Revised. Psychiatria polska, 51(1), 95-115. https://doi.org/10.12740/PP/OnlineFirst/61414

Gola, M., Wordecha, M., Sescousse, G., Lew-Starowicz, M., Kossowski, B., Wypych, M., Makeig, S., Potenza, M. N., \& Marchewka, A. (2017). Can Pornography be Addictive? An fMRI Study of Men Seeking Treatment for Problematic Pornography Use. Neuropsychopharmacology, 42(10), 2021-2031. https://doi.org/10.1038/npp.2017.78

Graham, F. J., Walters, G. D., Harris, D. A., \& Knight, R. A. (2016). Is Hypersexuality Dimensional or Categorical? Evidence From Male and Female College Samples. Journal of Sex Research, 53(2), 224-238. https://doi.org/10.1080/00224499.2014.1003524

Granero, R., Fernandez-Aranda, F., Mestre-Bach, G., Steward, T., Bano, M., Del Pino-Gutierrez, A., Moragas, L., Mallorqui-Bague, N., Aymami, N., Gomez-Pena, M., Tarrega, S., Menchon, J. M., \& Jimenez-Murcia, S. (2016). Compulsive Buying Behavior: Clinical Comparison with Other Behavioral Addictions. Frontiers in Psychology, 7, 914. https://doi.org/10.3389/fpsyg.2016.00914

Greenfield, D. N. (1999). Psychological Characteristics of Compulsive Internet Use: A Preliminary Analysis. CyberPsychology \& Behavior, 2(5), 403-412. https://doi.org/10.1089/cpb.1999.2.403

Grov, C., Golub, S. A., Mustanski, B., \& Parsons, J. T. (2010). Sexual compulsivity, state affect, and sexual risk behavior in a daily diary study of gay and bisexual men. Psychology of Addictive Behaviors: Journal of the Society of 
Psychologists in Addictive Behaviors, 24(3), 487-497Achterbergh, R. C. A., van Rooijen, M. S., van den Brink, W., Boyd, A., \& de Vries, H. J. C. (2020). Enhancing help-seeking behaviour among men who have sex with men at risk for sexually transmitted infections: The syn.bas.in randomised controlled trial. Sexually Transmitted Infections, sextrans-2020-054438. https://doi.org/10.1136/sextrans-2020-054438

Grov, C., Parsons, J. T., \& Bimbi, D. S. (2010). Sexual compulsivity and sexual risk in gay and bisexual men. Archives of Sexual Behavior, 39(4), 940-949. https://doi.org/10.1007/s10508-009-9483-9

Grov, C., Rendina, H. J., Breslow, A. S., Ventuneac, A., Adelson, S., \& Parsons, J. T. (2014). Characteristics of men who have sex with men (MSM) who attend sex parties: Results from a national online sample in the USA. Sexually Transmitted Infections, 90(1), 26-32. https://doi.org/10.1136/sextrans-2013-051094

Grubbs, J. B., \& Gola, M. (2019). Is pornography use related to erectile functioning? Results from cross-sectional and latent growth curve analyses. The Journal of Sexual Medicine, 16(1), 111-125. https://doi.org/10.1016/j.jsxm.2018.11.004

Grubbs, J. B., Exline, J. J., Pargament, K. I., Volk, F., \& Lindberg, M. J. (2017). Internet Pornography Use, Perceived Addiction, and Religious/Spiritual Struggles. Archives of Sexual Behavior, 46(6), 1733-1745. https://doi.org/10.1007/s10508-016-0772-9

Grubbs, J. B., Grant, J. T., \& Engelman, J. (2019). Self-identification as a pornography addict: Examining the roles of pornography use, religiousness, and moral incongruence. Sexual Addiction \& Compulsivity, 25(4), $269-292$. https://doi.org/10.1080/10720162.2019.1565848

Grubbs, J. B., Kraus, S. W., \& Perry, S. L. (2019). Self-reported addiction to pornography in a nationally representative sample: The roles of use habits, religiousness, and moral incongruence. Journal of Behavioral Addictions, 8(1), 88-93. https://doi.org/10.1556/2006.7.2018.134

Grubbs, J. B., Kraus, S. W., Perry, S. L., Lewczuk, K., \& Gola, M. (2020). Moral incongruence and compulsive sexual behavior: Results from cross-sectional interactions and parallel growth curve analyses. Journal of Abnormal Psychology, 129(3), 266-278. https://doi.org/10.1037/abn0000501

Grubbs, J. B., Lee, B. N., Hoagland, K. C., Kraus, S. W., \& Perry, S. L. (2020). Addiction or transgression? Moral incongruence and self-reported problematic pornography use in a nationally representative sample. Clinical Psychological Science, online first. https://doi.org/10.1177/2167702620922966

Grubbs, J. B., Stauner, N., Exline, J. J., Pargament, K. I., \& Lindberg, M. J. (2015). Perceived addiction to Internet pornography and psychological distress: Examining relationships concurrently and over time. Psychology of Addictive Behaviors : Journal of the Society of Psychologists in Addictive Behaviors, 29(4), 1056-1067. https://doi.org/10.1037/adb0000114

Grubbs, J. B., Volk, F., Exline, J. J., \& Pargament, K. I. (2015). Internet pornography use: Perceived addiction, psychological distress, and the validation of a brief measure. Journal of Sex \& Marital Therapy, 41(1), 83-106. https://doi.org/10.1080/0092623X.2013.842192

Grubbs, J. B., Wilt, J. A., Exline, J. J., \& Pargament, K. I. (2018). Predicting pornography use over time: Does selfreported "addiction" matter? Addictive Behaviors, 82, 57-64. https://doi.org/10.1016/j.addbeh.2018.02.028

Grubbs, J. B., Wilt, J. A., Exline, J. J., Pargament, K. I., \& Kraus, S. W. (2018). Moral disapproval and perceived addiction to internet pornography: A longitudinal examination. Addiction, 113(3), 496-506. https://doi.org/10.1111/add.14007

Gullette, D. L., \& Lyons, M. A. (2005). Sexual sensation seeking, compulsivity, and HIV risk behaviors in college students. Journal of Community Health Nursing, 22(1), 47-60. https://doi.org/10.1207/s15327655jchn2201_5

Guyon, R., Fernet, M., Canivet, C., Tardif, M., \& Godbout, N. (2020). Sexual self-concept among men and women child sexual abuse survivors: Emergence of differentiated profiles. Child Abuse \& Neglect, 104, 104481. https://doi.org/10.1016/j.chiabu.2020.104481

Guyon, R., Fernet, M., Canivet, C., Tardif, M., \& Godbout, N. (2020). Sexual self-concept among men and women child sexual abuse survivors: Emergence of differentiated profiles. Child Abuse \& Neglect, 104, 104481. https://doi.org/10.1016/j.chiabu.2020.104481

Halkitis, P. N., Green, K. A., Remien, R. H., Stirratt, M. J., Hoff, C. C., Wolitski, R. J., \& Parsons, J. T. (2005). Seroconcordant sexual partnerings of HIV-seropositive men who have sex with men. AIDS (London, England), 19 Suppl 1, S77-86. https://doi.org/10.1097/01.aids.0000167354.09912.83

Halkitis, P. N., Wilton, L., Wolitski, R. J., Parsons, J. T., Hoff, C. C., \& Bimbi, D. S. (2005). Barebacking identity among HIV-positive gay and bisexual men: Demographic, psychological, and behavioral correlates. AIDS (London, England), 19 Suppl 1, S27-35. https://doi.org/10.1097/01.aids.0000167349.23374.a3

Hall, P., Dix, J., \& Cartin, C. (2020). The Effectiveness of Psycho-Educational Group Work in Treating Compulsive 
Sexual Behavior Disorder (CSBD): Clinical Outcomes Using CORE OM and Supplement at Three-Month and Six-Month Follow up. Sexual Addiction \& Compulsivity, 27(1-2), 12-22.

https://doi.org/10.1080/10720162.2020.1751364

Hall, P., Dix, J., \& Cartin, C. (2020). The Effectiveness of Psycho-Educational Group Work in Treating Compulsive Sexual Behavior Disorder (CSBD): Clinical Outcomes Using CORE OM and Supplement at Three-Month and Six-Month Follow up. Sexual Addiction \& Compulsivity, 27(1-2), 12-22. https://doi.org/10.1080/10720162.2020.1751364

Hallberg, J., Kaldo, V., Arver, S., Dhejne, C., \& Öberg, K. G. (2017). A Cognitive-Behavioral Therapy Group Intervention for Hypersexual Disorder: A Feasibility Study. The Journal of Sexual Medicine, 14(7), 950-958. https://doi.org/10.1016/j.jsxm.2017.05.004

Hallberg, J., Kaldo, V., Arver, S., Dhejne, C., Jokinen, J., \& Oberg, K. G. (2019). A Randomized Controlled Study of Group-Administered Cognitive Behavioral Therapy for Hypersexual Disorder in Men. The Journal of Sexual Medicine, 16(5), 733-745. https://doi.org/10.1016/j.jsxm.2019.03.005

Hardy, S. A., Ruchty, J., Hull, T. D., \& Hyde, R. (2010). A Preliminary Study of an Online Psychoeducational Program for Hypersexuality. Sexual Addiction \& Compulsivity, 17(4), 247-269. https://doi.org/10.1080/10720162.2010.533999

Harper, C., \& Hodgins, D. C. (2016). Examining Correlates of Problematic Internet Pornography Use Among University Students. Journal of Behavioral Addictions, 5(2), 179-191. https://doi.org/10.1556/2006.5.2016.022

Hart, T. A., Noor, S. W., Skakoon-Sparling, S., Lazkani, S. N., Gardner, S., Leahy, B., Maxwell, J., Julien, R., Simpson, S., Steinberg, M., \& Adam, B. D. (2020). GPS: A Randomized Controlled Trial of Sexual Health Counseling for Gay and Bisexual Men Living With HIV. Behavior Therapy. https://doi.org/10.1016/j.beth.2020.04.005

Hart, T. A., Noor, S. W., Skakoon-Sparling, S., Lazkani, S. N., Gardner, S., Leahy, B., Maxwell, J., Julien, R., Simpson, S., Steinberg, M., \& Adam, B. D. (2020). GPS: A Randomized Controlled Trial of Sexual Health Counseling for Gay and Bisexual Men Living With HIV. Behavior Therapy. https://doi.org/10.1016/j.beth.2020.04.005

Hart, T. A., Stratton, N., Coleman, T. A., Wilson, H. A., Simpson, S. H., Julien, R. E., Hoe, D., Leahy, B., Maxwell, J., \& Adam, B. D. (2016). A Pilot Trial of a Sexual Health Counseling Intervention for HIV-Positive Gay and Bisexual Men Who Report Anal Sex without Condoms. PloS One, 11(4), e0152762. https://doi.org/10.1371/journal.pone.0152762

Hartman, L. I., Ho, V., Arbour, S., Hambley, J. M., \& Lawson, P. (2012). Sexual Addiction and Substance Addiction: Comparing Sexual Addiction Treatment Outcomes Among Clients With and Without Comorbid Substance Use Disorders. Sexual Addiction \& Compulsivity, 19(4), 284-309. https://doi.org/10.1080/10720162.2012.735515

Hequembourg, A. L., Bimbi, D., \& Parsons, J. T. (2011). Sexual victimization and health-related indicators among sexual minority men. Journal of LGBT Issues in Counseling, 5(1), 2-20. https://doi.org/10.1080/15538605.2011.554603

Herrick, A. L., Lim, S. H., Plankey, M. W., Chmiel, J. S., Guadamuz, T. E., Kao, U., Shoptaw, S., Carrico, A., Ostrow, D., \& Stall, R. (2013). Adversity and syndemic production among men participating in the multicenter AIDS cohort study: A life-course approach. American Journal of Public Health, 103(1), 79-85. https://doi.org/10.2105/AJPH.2012.300810

Hoffmann, H., Goodrich, D., Wilson, M., \& Janssen, E. (2014). The role of classical conditioning in sexual compulsivity: A pilot study. Sexual Addiction \& Compulsivity, 21(2), 75-91. https://doi.org/10.1080/10720162.2014.895460

Ince, C., Yücel, M., Albertella, L., \& Fontenelle, L. F. (2020). Exploring the clinical profile of problematic pornography use. CNS Spectrums, 1-31. https://doi.org/10.1017/S1092852920001686

Ince, C., Yücel, M., Albertella, L., \& Fontenelle, L. F. (2020). Exploring the clinical profile of problematic pornography use. CNS Spectrums, 1-31. https://doi.org/10.1017/S1092852920001686

J. T. Parsons, P. N. H., David Bimbi. (2001). Sexual Compulsivity Among Gay/Bisexual Male Escorts Who Advertise on the Internet. Sexual Addiction \& Compulsivity, 8(2), 101-112. https://doi.org/10.1080/10720160127562

Janssen, E., Prause, N., Swinburne Romine, R., Raymond, N., MacDonald, A., Coleman, E., \& Miner, M. H. (2020). Sexual Responsivity and the Effects of Negative Mood on Sexual Arousal in Hypersexual Men Who Have Sex With Men (MSM). The Journal of Sexual Medicine. https://doi.org/10.1016/j.jsxm.2020.05.005

Janssen, E., Prause, N., Swinburne Romine, R., Raymond, N., MacDonald, A., Coleman, E., \& Miner, M. H. (2020). Sexual Responsivity and the Effects of Negative Mood on Sexual Arousal in Hypersexual Men Who Have Sex With Men (MSM). The Journal of Sexual Medicine. https://doi.org/10.1016/j.jsxm.2020.05.005

Jardin, C., Garey, L., Sharp, C., \& Zvolensky, M. J. (2016). Acculturative Stress and Risky Sexual Behavior: The Roles of Sexual Compulsivity and Negative Affect. Behavior Modification, 40(1-2), 97-119. https://doi.org/10.1177/0145445515613331 
Jerome, R. C., Woods, W. J., Moskowitz, J. T., \& Carrico, A. W. (2016). The Psychological Context of Sexual Compulsivity Among Men Who Have Sex with Men. AIDS and Behavior, 20(2), 273-280.

https://doi.org/10.1007/s10461-015-1083-1

Jokinen, J., Bostrom, A. E., Chatzittofis, A., Ciuculete, D. M., Oberg, K. G., Flanagan, J. N., Arver, S., \& Schioth, H. B. (2017). Methylation of HPA axis related genes in men with hypersexual disorder. Psychoneuroendocrinology, 80, 67-73. https://doi.org/10.1016/j.psyneuen.2017.03.007

Kafka, M. P. (1997). Hypersexual desire in males: An operational definition and clinical implications for males with paraphilias and paraphilia-related disorders. Archives of Sexual Behavior, 26(5), 505-526.

Kafka, M. P., \& Hennen, J. (1999). The paraphilia-related disorders: An empirical investigation of nonparaphilic hypersexuality disorders in outpatient males. Journal of Sex \& Marital Therapy, 25(4), 305-319. https://doi.org/10.1080/00926239908404008

Kafka, Martin P., \& Hennen, J. (2003). Hypersexual desire in males: Are males with paraphilias different from males with paraphilia-related disorders? Sexual Abuse : A Journal of Research and Treatment, 15(4), 307-321. https://doi.org/10.1177/107906320301500407

Kalichman, S. C., \& Rompa, D. (2001). The Sexual Compulsivity Scale: Further development and use with HIV-positive persons. Journal of Personality Assessment, 76(3), 379-395. https://doi.org/10.1207/S15327752JPA7603_02

Kalichman, Seth C., \& Cain, D. (2004). The relationship between indicators of sexual compulsivity and high risk sexual practices among men and women receiving services from a sexually transmitted infection clinic. Journal of Sex Research, 41(3), 235-241. https://doi.org/10.1080/00224490409552231

Kalichman, Seth C., Cherry, C., Cain, D., Pope, H., \& Kalichman, M. (2005). Psychosocial and behavioral correlates of seeking sex partners on the internet among HIV-positive men. Annals of Behavioral Medicine: A Publication of the Society of Behavioral Medicine, 30(3), 243-250. https://doi.org/10.1207/s15324796abm3003_8

Kelly, B. C., Bimbi, D. S., Nanin, J. E., Izienicki, H., \& Parsons, J. T. (2009). Sexual compulsivity and sexual behaviors among gay and bisexual men and lesbian and bisexual women. Journal of Sex Research, 46(4), 301-308. https://doi.org/10.1080/00224490802666225

Kingston, D. A., Olver, M. E., Levaque, E., Sawatsky, M. L., Seto, M. C., \& Lalumière, M. L. (2020). Establishing Canadian metrics for self-report measures used to assess hypersexuality. The Canadian Journal of Human Sexuality, 29(1), 65-78. https://doi.org/10.3138/cjhs.2019-0055

Kingston, D. A., Olver, M. E., Levaque, E., Sawatsky, M. L., Seto, M. C., \& Lalumière, M. L. (2020). Establishing Canadian metrics for self-report measures used to assess hypersexuality. The Canadian Journal of Human Sexuality, 29(1), 65-78. https://doi.org/10.3138/cjhs.2019-0055

Kingston, D. A., Walters, G. D., Olver, M. E., Levaque, E., Sawatsky, M., \& Lalumiere, M. L. (2018). Understanding the Latent Structure of Hypersexuality: A Taxometric Investigation. Archives of Sexual Behavior, 47(8), 2207-2221. https://doi.org/10.1007/s10508-018-1273-9

Klein, S., Kruse, O., Markert, C., Tapia León, I., Strahler, J., \& Stark, R. (2020). Subjective reward value of visual sexual stimuli is coded in human striatum and orbitofrontal cortex. Behavioural Brain Research, 393, 112792. https://doi.org/10.1016/j.bbr.2020.112792

Klein, S., Kruse, O., Markert, C., Tapia León, I., Strahler, J., \& Stark, R. (2020). Subjective reward value of visual sexual stimuli is coded in human striatum and orbitofrontal cortex. Behavioural Brain Research, 393, 112792. https://doi.org/10.1016/j.bbr.2020.112792

Klein, V., Jurin, T., Briken, P., \& Stulhofer, A. (2015). Erectile Dysfunction, Boredom, and Hypersexuality among Coupled Men from Two European Countries. The Journal of Sexual Medicine, 12(11), 2160-2167. https://doi.org/10.1111/jsm.13019

Klein, V., Rettenberger, M., \& Briken, P. (2014). Self-reported indicators of hypersexuality and its correlates in a female online sample. The Journal of Sexual Medicine, 11(8), 1974-1981. https://doi.org/10.1111/jsm.12602

Klein, V., Schmidt, A. F., Turner, D., \& Briken, P. (2015). Are Sex Drive and Hypersexuality Associated with Pedophilic Interest and Child Sexual Abuse in a Male Community Sample? PloS One, 10(7), e0129730. https://doi.org/10.1371/journal.pone.0129730

Klontz, B. T., Garos, S., \& Klontz, P. T. (2005). The Effectiveness of Brief Multimodal Experiential Therapy in the Treatment of Sexual Addiction. Sexual Addiction \& Compulsivity, 12(4), 275-294. https://doi.org/10.1080/10720160500362488

Klucken, T., Wehrum-Osinsky, S., Schweckendiek, J., Kruse, O., \& Stark, R. (2016). Altered Appetitive Conditioning and Neural Connectivity in Subjects With Compulsive Sexual Behavior. The Journal of Sexual Medicine, 13(4), 627-636. https://doi.org/10.1016/j.jsxm.2016.01.013 
Kohut, T., \& Stulhofer, A. (2018). The role of religiosity in adolescents' compulsive pornography use: A longitudinal assessment. Journal Of Sex \& Marital Therapy. https://doi.org/10.1080/0092623X.2018.1466012

Kor, A., Zilcha-Mano, S., Fogel, Y. A., Mikulincer, M., Reid, R. C., \& Potenza, M. N. (2014). Psychometric development of the Problematic Pornography Use Scale. Addictive Behaviors, 39(5), 861-868. https://doi.org/10.1016/j.addbeh.2014.01.027

Kowalewska, E., Kraus, S. W., Lew-Starowicz, M., Gustavsson, K., \& Gola, M. (2019). Which dimensions of human sexuality are related to compulsive sexual behavior disorder (CSBD)? Study using a multidimensional sexuality questionnaire on a sample of polish males. The Journal of Sexual Medicine. https://doi.org/10.1016/j.jsxm.2019.05.006

Kraus, S. W., Gola, M., Grubbs, J. B., Kowalewska, E., Hoff, R. A., Lew-Starowicz, M., Martino, S., Shirk, S. D., \& Potenza, M. N. (2020). Validation of a Brief Pornography Screen across multiple samples. Journal of Behavioral Addictions, 9(2), 259-271. https://doi.org/10.1556/2006.2020.00038

Kraus, S. W., Gola, M., Grubbs, J. B., Kowalewska, E., Hoff, R. A., Lew-Starowicz, M., Martino, S., Shirk, S. D., \& Potenza, M. N. (2020). Validation of a Brief Pornography Screen across multiple samples. Journal of Behavioral Addictions, 9(2), 259-271. https://doi.org/10.1556/2006.2020.00038

Kraus, S. W., Martino, S., \& Potenza, M. N. (2016). Clinical Characteristics of Men Interested in Seeking Treatment for Use of Pornography. Journal of Behavioral Addictions, 5(2), 169-178. https://doi.org/10.1556/2006.5.2016.036

Kraus, S. W., Martino, S., Potenza, M. N., Park, C., Merrel, J. D., \& Hoff, R. A. (2017). Examining Compulsive Sexual Behavior and Psychopathology Among a Sample of Postdeployment U.S. Male and Female Military Veterans. Military Psychology, 29(2), 143-156. https://doi.org/10.1037/mil0000147

Kraus, S. W., Potenza, M. N., Martino, S., \& Grant, J. E. (2015). Examining the psychometric properties of the YaleBrown Obsessive-Compulsive Scale in a sample of compulsive pornography users. Comprehensive Psychiatry, 59, 117-122. https://doi.org/10.1016/j.comppsych.2015.02.007

Kraus, S. W., Rosenberg, H., \& Tompsett, C. J. (2015). Assessment of self-efficacy to employ self-initiated pornography use-reduction strategies. Addictive Behaviors, 40, 115-118. https://doi.org/10.1016/j.addbeh.2014.09.012

Kraus, S. W., Rosenberg, H., Martino, S., Nich, C., \& Potenza, M. N. (2017). The development and initial evaluation of the Pornography-Use Avoidance Self-Efficacy Scale. Journal of Behavioral Addictions, 6(3), 354-363. https://doi.org/10.1556/2006.6.2017.057

Kühn, S., \& Gallinat, J. (2014). Brain structure and functional connectivity associated with pornography consumption: The brain on porn. JAMA Psychiatry, 71(7), 827-834. https://doi.org/10.1001/jamapsychiatry.2014.93

Labadie, C., Godbout, N., Vaillancourt-Morel, M.-P., \& Sabourin, S. (2018). Adult Profiles of Child Sexual Abuse Survivors: Attachment Insecurity, Sexual Compulsivity, and Sexual Avoidance. Journal of Sex \& Marital Therapy, 44(4), 354-369. https://doi.org/10.1080/0092623X.2017.1405302

Laier, C., \& Brand, M. (2017). Mood changes after watching pornography on the Internet are linked to tendencies towards Internet-pornography-viewing disorder. Addictive Behaviors Reports, 5, 9-13. https://doi.org/10.1016/j.abrep.2016.11.003

Laier, C., Pawlikowski, M., Pekal, J., Schulte, F. P., \& Brand, M. (2013). Cybersex addiction: Experienced sexual arousal when watching pornography and not real-life sexual contacts makes the difference. Journal of Behavioral Addictions, 2(2), 100-107. https://doi.org/10.1556/JBA.2.2013.002

Laier, C., Pekal, J., \& Brand, M. (2014). Cybersex addiction in heterosexual female users of internet pornography can be explained by gratification hypothesis. Cyberpsychology, Behavior and Social Networking, 17(8), 505-511. https://doi.org/10.1089/cyber.2013.0396

Laier, C., Pekal, J., \& Brand, M. (2015). Sexual Excitability and Dysfunctional Coping Determine Cybersex Addiction in Homosexual Males. Cyberpsychology, Behavior and Social Networking, 18(10), 575-580. https://doi.org/10.1089/cyber.2015.0152

Langstrom, N., \& Hanson, R. K. (2006). High rates of sexual behavior in the general population: Correlates and predictors. Archives of Sexual Behavior, 35(1), 37-52. https://doi.org/10.1007/s10508-006-8993-y

Lee, T. T. C., Ritchey, K. A., Forbey, J. D., \& Gaither, G. A. (2009). Psychometrics and Comparison of the Compulsive Sexual Behavior Inventory and the Sexual Compulsivity Scale in a Male College Student Sample. Sexual Addiction \& Compulsivity, 16(2), 146-167. https://doi.org/10.1080/10720160902905512

Leonhardt, N. D., Busby, D. M., \& Willoughby, B. J. (2020). Do You Feel in Control? Sexual Desire, Sexual Passion Expression, and Associations with Perceived Compulsivity to Pornography and Pornography Use Frequency. Sexuality Research and Social Policy. https://doi.org/10.1007/s13178-020-00465-7 
Leonhardt, N. D., Busby, D. M., \& Willoughby, B. J. (2020). Do You Feel in Control? Sexual Desire, Sexual Passion Expression, and Associations with Perceived Compulsivity to Pornography and Pornography Use Frequency. Sexuality Research and Social Policy. https://doi.org/10.1007/s13178-020-00465-7

Leonhardt, N. D., Willoughby, B. J., \& Young-Petersen, B. (2018). Damaged Goods: Perception of Pornography Addiction as a Mediator Between Religiosity and Relationship Anxiety Surrounding Pornography Use. Journal of Sex Research, 55(3), 357-368. https://doi.org/10.1080/00224499.2017.1295013

Levert, N. P. (2007). A Comparison of Christian and Non-Christian Males, Authoritarianism, and Their Relationship to Internet Pornography Addiction/Compulsion. Sexual Addiction \& Compulsivity, 14(2), 145-166. https://doi.org/10.1080/10720160701354771

Levi, G., Cohen, C., Kaliche, S., Sharaabi, S., Cohen, K., Tzur-Bitan, D., \& Weinstein, A. (2020). Sexual addiction, compulsivity, and impulsivity among a predominantly female sample of adults who use the internet for sex. Journal of Behavioral Addictions, 9(1), 83-92. https://doi.org/10.1556/2006.2020.00007

Levi, G., Cohen, C., Kaliche, S., Sharaabi, S., Cohen, K., Tzur-Bitan, D., \& Weinstein, A. (2020). Sexual addiction, compulsivity, and impulsivity among a predominantly female sample of adults who use the internet for sex. Journal of Behavioral Addictions, 9(1), 83-92. https://doi.org/10.1556/2006.2020.00007

Levin, M. E., Heninger, S. T., Pierce, B. G., \& Twohig, M. P. (2017). Examining the Feasibility of Acceptance and Commitment Therapy Self-Help for Problematic Pornography Viewing: Results From a Pilot Open Trial. The Family Journal, 25(4), 306-312. https://doi.org/10.1177/1066480717731242

Lewczuk, K., Glica, A., Nowakowska, I., Gola, M., \& Grubbs, J. B. (2020). Evaluating Pornography Problems Due to Moral Incongruence model. The Journal of Sexual Medicine, 17(2), 300-311. https://doi.org/10.1016/j.jsxm.2019.11.259

Lewczuk, K., Szmyd, J., Skorko, M., \& Gola, M. (2017). Treatment seeking for problematic pornography use among women. Journal of Behavioral Addictions, 6(4), 445-456. https://doi.org/10.1556/2006.6.2017.063

Liao, W., Lau, J. T. F., Tsui, H. Y., Gu, J., \& Wang, Z. (2015). Relationship between sexual compulsivity and sexual risk behaviors among Chinese sexually active males. Archives of Sexual Behavior, 44(3), 791-798. https://doi.org/10.1007/s10508-014-0317-z

Luo, M., Zhu, L., Dong, Y., Wang, Z., Shen, Q., Mo, D., Du, L., Zhang, Z., \& Cai, Y. (2018). Sexual compulsivity and its relationship with condomless sex among unmarried female migrant workers in Shanghai, China: A cross-sectional study. BMC Women's Health, 18(1), 181. https://doi.org/10.1186/s12905-018-0670-5

Maddock, M. E., Steele, K., Esplin, C. R., Hatch, S. G., \& Braithwaite, S. R. (2019). What Is the Relationship Among Religiosity, Self-Perceived Problematic Pornography Use, and Depression Over Time? Sexual Addiction \& Compulsivity, 1-28. https://doi.org/10.1080/10720162.2019.1645061

McBride, K. R., Reece, M., \& Sanders, S. A. (2008). Using the Sexual Compulsivity Scale to Predict Outcomes of Sexual Behavior in Young Adults. Sexual Addiction \& Compulsivity, 15(2), 97-115. https://doi.org/10.1080/10720160802035816

Mechelmans, D. J., Irvine, M., Banca, P., Porter, L., Mitchell, S., Mole, T. B., Lapa, T. R., Harrison, N. A., Potenza, M. N., \& Voon, V. (2014). Enhanced Attentional Bias towards Sexually Explicit Cues in Individuals with and without Compulsive Sexual Behaviours. PLoS ONE, 9(8), e105476. https://doi.org/10.1371/journal.pone.0105476

Messina, B., Fuentes, D., Tavares, H., Abdo, C. H. N., \& Scanavino, M. de T. (2017). Executive Functioning of Sexually Compulsive and Non-Sexually Compulsive Men Before and After Watching an Erotic Video. The Journal of Sexual Medicine, 14(3), 347-354. https://doi.org/10.1016/j.jsxm.2016.12.235

Mimiaga, M. J., Biello, K. B., Robertson, A. M., Oldenburg, C. E., Rosenberger, J. G., O’Cleirigh, C., Novak, D. S., Mayer, K. H., \& Safren, S. A. (2015). High prevalence of multiple syndemic conditions associated with sexual risk behavior and HIV infection among a large sample of Spanish- and Portuguese-speaking men who have sex with men in Latin America. Archives of Sexual Behavior, 44(7), 1869-1878. https://doi.org/10.1007/s10508-0150488-2

Miner, M. H., Coleman, E., Center, B. A., Ross, M., \& Rosser, B. R. S. (2007). The compulsive sexual behavior inventory: Psychometric properties. Archives of Sexual Behavior, 36(4), 579-587. https://doi.org/10.1007/s10508006-9127-2

Miner, M. H., Raymond, N., Coleman, E., \& Swinburne Romine, R. (2017). Investigating Clinically and Scientifically Useful Cut Points on the Compulsive Sexual Behavior Inventory. The Journal of Sexual Medicine, 14(5), 715720. https://doi.org/10.1016/j.jsxm.2017.03.255 
Miner, M. H., Raymond, N., Mueller, B. A., Lloyd, M., \& Lim, K. O. (2009). Preliminary investigation of the impulsive and neuroanatomical characteristics of compulsive sexual behavior. Psychiatry Research, 174(2), 146-151. https://doi.org/10.1016/j.pscychresns.2009.04.008

Miner, M. H., Romine, R. S., Raymond, N., Janssen, E., MacDonald, A. 3rd, \& Coleman, E. (2016). Understanding the Personality and Behavioral Mechanisms Defining Hypersexuality in Men Who Have Sex With Men. The Journal of Sexual Medicine, 13(9), 1323-1331. https://doi.org/10.1016/j.jsxm.2016.06.015

Moholy, M., Prause, N., Proudfit, G. H., S Rahman, A., \& Fong, T. (2015). Sexual desire, not hypersexuality, predicts self-regulation of sexual arousal. Cognition \& Emotion, 29(8), 1505-1516. https://doi.org/10.1080/02699931.2014.993595

Moisson, J., Potenza, M. N., Shirk, S. D., Hoff, R. A., Park, C. L., \& Kraus, S. W. (2019). Psychopathology and Hypersexuality among Veterans with and without Histories of Alcohol-use Disorders. The American Journal on Addictions, 28(5), 398-404.

Morgenstern, J., Muench, F., O’Leary, A., Wainberg, M., Parsons, J. T., Hollander, E., Blain, L., \& Irwin, T. (2011). NonParaphilic Compulsive Sexual Behavior and Psychiatric Co-morbidities in Gay and Bisexual Men. Sexual Addiction \& Compulsivity, 18(3), 114-134. https://doi.org/10.1080/10720162.2011.593420

Morrison, S. A., Yoong, D., Hart, T. A., MacPherson, P., Bogoch, I., Sivarajah, V., Gough, K., Naccarato, M., \& Tan, D. H. S. (2018). High prevalence of syndemic health problems in patients seeking post-exposure prophylaxis for sexual exposures to HIV. PloS One, 13(5), e0197998. https://doi.org/10.1371/journal.pone.0197998

Muench, F., Morgenstern, J., Hollander, E., Irwin, T., O’Leary, A., Parsons, J. T., Wainberg, M. L., \& Lai, B. (2007). The Consequences of Compulsive Sexual Behavior: The Preliminary Reliability and Validity of the Compulsive Sexual Behavior Consequences Scale. Sexual Addiction \& Compulsivity, 14(3), 207-220. https://doi.org/10.1080/10720160701480493

Muise, A., Milhausen, R. R., Cole, S. L., \& Graham, C. (2013). Sexual Compulsivity in Heterosexual Married Adults: The Role of Sexual Excitation and Sexual Inhibition in Individuals not Considered "High-Risk." Sexual Addiction \& Compulsivity, 20(3), 192-209. https://doi.org/10.1080/10720162.2013.786661

Mulhauser, K. R. W., Struthers, W. M., Hook, J. N., Pyykkonen, B. A., Womack, S. D., \& MacDonald, M. (2014). Performance on the Iowa Gambling Task in a Sample of Hypersexual Men. Sexual Addiction \& Compulsivity, 21(2), 170-183. https://doi.org/10.1080/10720162.2014.908333

Mulhauser, K., Miller Short, E., \& Weinstock, J. (2018). Development and psychometric evaluation of the Pornography Purchase Task. Addictive Behaviors, 84, 207-214. https://doi.org/10.1016/j.addbeh.2018.04.016

Niazof, D., Weizman, A., \& Weinstein, A. (2019). The contribution of ADHD and attachment difficulties to online pornography use among students. Comprehensive Psychiatry, 93, 56-60.

Noor, S. W., Simon Rosser, B. R., \& Erickson, D. J. (2014). A Brief Scale to Measure Problematic Sexually Explicit Media Consumption: Psychometric Properties of the Compulsive Pornography Consumption (CPC) Scale among Men who have Sex with Men. Sexual Addiction \& Compulsivity, 21(3), 240-261.

https://doi.org/10.1080/10720162.2014.938849

Nugroho, R. M., \& Afiyanti, Y. (2019). Sexual Compulsivity among Indonesian College Students. Comprehensive Child and Adolescent Nursing, 42(sup1), 38-46. https://doi.org/10.1080/24694193.2019.1577924

O’Dell, B. L., Rosser, B. R. S., Miner, M. H., \& Jacoby, S. M. (2008). HIV prevention altruism and sexual risk behavior in HIV-positive men who have sex with men. AIDS and Behavior, 12(5), 713-720. https://doi.org/10.1007/s10461-007-9321-9

Oberg, K. G., Hallberg, J., Kaldo, V., Dhejne, C., \& Arver, S. (2017). Hypersexual Disorder According to the Hypersexual Disorder Screening Inventory in Help-Seeking Swedish Men and Women With Self-Identified Hypersexual Behavior. Sexual Medicine, 5(4), e229-e236. https://doi.org/10.1016/j.esxm.2017.08.001

Odlaug, B. L., \& Grant, J. E. (2010). Impulse-control disorders in a college sample: Results from the self-administered Minnesota Impulse Disorders Interview (MIDI). Primary Care Companion to the Journal of Clinical Psychiatry, 12(2). https://doi.org/10.4088/PCC.09m00842whi

Odlaug, B. L., Lust, K., Schreiber, L. R. N., Christenson, G., Derbyshire, K., Harvanko, A., Golden, D., \& Grant, J. E. (2013). Compulsive sexual behavior in young adults. Annals of Clinical Psychiatry: Official Journal of the American Academy of Clinical Psychiatrists, 25(3), 193-200.

Olley, B. O. (2008). Child sexual abuse, harmful alcohol use and age as determinants of sexual risk behaviours among freshmen in a Nigerian university. African Journal of Reproductive Health, 12(2), 75-88. 
Orzack, M. H., Voluse, A. C., Wolf, D., \& Hennen, J. (2006). An Ongoing Study of Group Treatment for Men Involved in Problematic Internet-Enabled Sexual Behavior. CyberPsychology \& Behavior, 9(3), 348-360. https://doi.org/10.1089/cpb.2006.9.348

Pachankis, J. E., Rendina, H. J., Ventuneac, A., Grov, C., \& Parsons, J. T. (2014). The role of maladaptive cognitions in hypersexuality among highly sexually active gay and bisexual men. Archives of Sexual Behavior, 43(4), 669-683. https://doi.org/10.1007/s10508-014-0261-y

Parmenter, J. G., Crowell, K. A., \& Galliher, R. V. (2020). Subjective Importance of Masculinity as a Factor in Understanding Risky Sexual Attitudes and Behaviors among Sexual Minority Men. Sex Roles, 82(7), 463-472.

Parsons, J, T., \& Bimbi, D. S. (2007). Intentional unprotected anal intercourse among sex who have sex with men: Barebacking-From behavior to identity. AIDS and Behavior, 11(2), 277-287. https://doi.org/10.1007/s10461006-9135-1

Parsons, J. T., Grov, C., \& Golub, S. A. (2012). Sexual compulsivity, co-occurring psychosocial health problems, and HIV risk among gay and bisexual men: Further evidence of a syndemic. American Journal of Public Health, 102(1), 156-162. https://doi.org/10.2105/AJPH.2011.300284

Parsons, J. T., Kelly, B. C., Bimbi, D. S., Muench, F., \& Morgenstern, J. (2007). Accounting for the social triggers of sexual compulsivity. Journal of Addictive Diseases, 26(3), 5-16. https://doi.org/10.1300/J069v26n03_02

Parsons, J. T., Millar, B. M., Moody, R. L., Starks, T. J., Rendina, H. J., \& Grov, C. (2017). Syndemic conditions and HIV transmission risk behavior among HIV-negative gay and bisexual men in a U.S. national sample. Health Psychology: Official Journal of the Division of Health Psychology, American Psychological Association, 36(7), 695-703. https://doi.org/10.1037/hea0000509

Parsons, J. T., Rendina, H. J., Moody, R. L., Gurung, S., Starks, T. J., \& Pachankis, J. E. (2017). Feasibility of an Emotion Regulation Intervention to Improve Mental Health and Reduce HIV Transmission Risk Behaviors for HIVPositive Gay and Bisexual Men with Sexual Compulsivity. AIDS and Behavior, 21(6), 1540-1549. https://doi.org/10.1007/s10461-016-1533-4

Parsons, J. T., Rendina, H. J., Moody, R. L., Ventuneac, A., \& Grov, C. (2015). Syndemic production and sexual compulsivity/hypersexuality in highly sexually active gay and bisexual men: Further evidence for a three group conceptualization. Archives of Sexual Behavior, 44(7), 1903-1913. https://doi.org/10.1007/s10508-015-0574-5

Parsons, J. T., Rendina, H. J., Ventuneac, A., Moody, R. L., \& Grov, C. (2016). Hypersexual, Sexually Compulsive, or Just Highly Sexually Active? Investigating Three Distinct Groups of Gay and Bisexual Men and Their Profiles of HIV-Related Sexual Risk. AIDS and Behavior, 20(2), 262-272. https://doi.org/10.1007/s10461-015-1029-7

Parsons, J. T., Severino, J. P., Grov, C., Bimbi, D. S., \& Morgenstern, J. (2007). Internet Use among Gay and Bisexual Men with Compulsive Sexual Behavior. Sexual Addiction \& Compulsivity, 14(3), 239-256. https://doi.org/10.1080/10720160701480659

Pekal, J., Laier, C., Snagowski, J., Stark, R., \& Brand, M. (2018). Tendencies toward Internet-pornography-use disorder: Differences in men and women regarding attentional biases to pornographic stimuli. Journal of Behavioral Addictions, 7(3), 574-583. https://doi.org/10.1556/2006.7.2018.70

Perera, B., Reece, M., Monahan, P., Billingham, R., \& Finn, P. (2009a). Relations between substance use and personal dispositions towards out-of-control sexual behaviors among young adults. International Journal of Sexual Health, 21(2), 87-95.

Perera, B., Reece, M., Monahan, P., Billingham, R., \& Finn, P. (2009b). Childhood Characteristics and Personal Dispositions to Sexually Compulsive Behavior Among Young Adults. Sexual Addiction \& Compulsivity, 16(2), 131-145. https://doi.org/10.1080/10720160902905421

Perry M, Accordino MP, \& Hewes RL. (2007). An investigation of Internet use, sexual and nonsexual sensation seeking, and sexual compulsivity among college students. Sexual Addiction \& Compulsivity, 14(4), 321-335. rzh.

Petrican, R., Burris, C. T., \& Moscovitch, M. (2015). Shame, sexual compulsivity, and eroticizing flirtatious others: An experimental study. Journal of Sex Research, 52(1), 98-109. https://doi.org/10.1080/00224499.2013.829796

Phillips, L. C., Moen, C. E., DiLella, N. M., \& Volk, F. A. (2019). The Moderating Influence of Self-Compassion on the Relationship between Shame Tendency and Hypersexuality. Sexual Addiction \& Compulsivity, 26(1-2), $103-125$.

Pinto, J., Carvalho, J., \& Nobre, P. J. (2013). The relationship between the FFM personality traits, state psychopathology, and sexual compulsivity in a sample of male college students. The Journal of Sexual Medicine, 10(7), 1773-1782. https://doi.org/10.1111/jsm.12185

Pitpitan, E. V., Smith, L. R., Goodman-Meza, D., Torres, K., Semple, S. J., Strathdee, S. A., \& Patterson, T. L. (2016). "Outness" as a Moderator of the Association Between Syndemic Conditions and HIV Risk-Taking Behavior 
Among Men Who Have Sex with Men in Tijuana, Mexico. AIDS and Behavior, 20(2), 431-438. https://doi.org/10.1007/s10461-015-1172-1

Pocknell, V., \& King, A. R. (2019). Personality Inventory for the DSM-5 (Brief Form) Predictors of Sexual Addiction. Sexual Addiction \& Compulsivity, 26(3-4), 315-332. https://doi.org/10.1080/10720162.2019.1645059

Prause, N., Steele, V. R., Staley, C., Sabatinelli, D., \& Hajcak, G. (2015). Modulation of late positive potentials by sexual images in problem users and controls inconsistent with "porn addiction". Biological Psychology, 109, 192-199. https://doi.org/10.1016/j.biopsycho.2015.06.005

Prawiroharjo, P., Ellydar, H., Pratama, P., Edison, R. E., Suaidy, S. E. I., Amani, N. Z., \& Carissima, D. (2019). Impaired Recent Verbal Memory in Pornography-Addicted Juvenile Subjects. Neurology Research International, 2019, e2351638. https://doi.org/10.1155/2019/2351638

Raymond, N. C., Coleman, E., \& Miner, M. H. (2003). Psychiatric comorbidity and compulsive/impulsive traits in compulsive sexual behavior. Comprehensive Psychiatry, 44(5), 370-380. https://doi.org/10.1016/S0010440X(03)00110-X

REECE, M. (2003). Sexual Compulsivity and HIV Serostatus Disclosure Among Men Who Have Sex with Men. Sexual Addiction \& Compulsivity, 10(1), 1-11. https://doi.org/10.1080/10720160309048

REECE, M., \& DODGE, B. (2004). Exploring Indicators of Sexual Compulsivity Among Men Who Cruise for Sex on Campus. Sexual Addiction \& Compulsivity, 11(3), 87-113. https://doi.org/10.1080/10720160490521222

Reid, R. C. (2007). Assessing Readiness to Change among Clients Seeking Help for Hypersexual Behavior. Sexual Addiction \& Compulsivity, 14(3), 167-186. https://doi.org/10.1080/10720160701480204

Reid, R. C., \& Carpenter, B. N. (2009). Exploring relationships of psychopathology in hypersexual patients using the. Journal of Sex \& Marital Therapy, 35(4), 294-310. https://doi.org/10.1080/00926230902851298

Reid, R. C., Bramen, J. E., Anderson, A., \& Cohen, M. S. (2014). Mindfulness, emotional dysregulation, impulsivity, and stress proneness among hypersexual patients. Journal of Clinical Psychology, 70(4), 313-321. https://doi.org/10.1002/jclp.22027

Reid, R. C., Carpenter, B. N., \& Hook, J. N. (2016). Investigating correlates of hypersexual behavior in religious patients. Sexual Addiction \& Compulsivity, 23(2-3), 296-312. https://doi.org/10.1080/10720162.2015.1130002

Reid, R. C., Carpenter, B. N., Gilliland, R., \& Karim, R. (2011). Problems of self-concept in a patient sample of hypersexual men with attention-deficit disorder. Journal of Addiction Medicine, 5(2), 134-140. https://doi.org/10.1097/ADM.0b013e3181e6ad32

Reid, R. C., Carpenter, B. N., Hook, J. N., Garos, S., Manning, J. C., Gilliland, R., Cooper, E. B., McKittrick, H., Davtian, M., \& Fong, T. (2012). Report of findings in a DSM-5 field trial for hypersexual disorder. The Journal of Sexual Medicine, 9(11), 2868-2877.

Reid, R. C., Carpenter, B. N., Spackman, M., \& Willes, D. L. (2008). Alexithymia, emotional instability, and vulnerability to stress proneness in patients seeking help for hypersexual behavior. Journal of Sex \& Marital Therapy, 34(2), 133-149. https://doi.org/10.1080/00926230701636197

Reid, R. C., Cooper, E. B., Prause, N., Li, D. S., \& Fong, T. W. (2012). Facets of perfectionism in a sample of hypersexual patients. The Journal of Nervous and Mental Disease, 200(11), 990-995. https://doi.org/10.1097/NMD.0b013e3182718d67

Reid, R. C., Cyders, M. A., Moghaddam, J. F., \& Fong, T. W. (2014). Psychometric properties of the Barratt Impulsiveness Scale in patients with gambling disorders, hypersexuality, and methamphetamine dependence. Addictive Behaviors, 39(11), 1640-1645. https://doi.org/10.1016/j.addbeh.2013.11.008

Reid, R. C., Dhuffar, M. K., Parhami, I., \& Fong, T. W. (2012). Exploring facets of personality in a patient sample of hypersexual women compared with hypersexual men. Journal of Psychiatric Practice, 18(4), 262-268. https://doi.org/10.1097/01.pra.0000416016.37968.eb

Reid, R. C., Garos, S., \& Carpenter, B. N. (2011). Reliability, validity, and psychometric development of the Hypersexual Behavior Inventory in an outpatient sample of men. Sexual Addiction \& Compulsivity, 18(1), 30-51. https://doi.org/10.1080/10720162.2011.555709

Reid, R. C., Garos, S., \& Fong, T. (2012). Psychometric development of the hypersexual behavior consequences scale. Journal of Behavioral Addictions, 1(3), 115-122. https://doi.org/10.1556/JBA.1.2012.001

Reid, R. C., Garos, S., Carpenter, B. N., \& Coleman, E. (2011). A surprising finding related to executive control in a patient sample of hypersexual men. The Journal of Sexual Medicine, 8(8), 2227-2236.

https://doi.org/10.1111/j.1743-6109.2011.02314.x

Reid, R. C., Harper, J. M., \& Anderson, E. H. (2009). Coping strategies used by hypersexual patients to defend against the painful effects of shame. Clinical Psychology \& Psychotherapy, 16(2), 125-138. https://doi.org/10.1002/cpp.609 
Reid, R. C., Karim, R., McCrory, E., \& Carpenter, B. N. (2010). Self-reported differences on measures of executive function and hypersexual behavior in a patient and community sample of men. The International Journal of Neuroscience, 120(2), 120-127. https://doi.org/10.3109/00207450903165577

Reid, R. C., Li, D. S., Gilliland, R., Stein, J. A., \& Fong, T. (2011). Reliability, validity, and psychometric development of the pornography consumption inventory in a sample of hypersexual men. Journal of Sex \& Marital Therapy, 37(5), 359-385. https://doi.org/10.1080/0092623X.2011.607047

Reid, R. C., Stein, J. A., \& Carpenter, B. N. (2011). Understanding the roles of shame and neuroticism in a patient sample of hypersexual men. The Journal of Nervous and Mental Disease, 199(4), 263-267. https://doi.org/10.1097/NMD.0b013e3182125b96

Reid, R. C., Temko, J., Moghaddam, J. F., \& Fong, T. W. (2014). Shame, rumination, and self-compassion in men assessed for hypersexual disorder. Journal of Psychiatric Practice, 20(4), 260-268. https://doi.org/10.1097/01.pra.0000452562.98286.c5

Rendina, H. J., Breslow, A. S., Grov, C., Ventuneac, A., Starks, T. J., \& Parsons, J. T. (2014). Interest in couples-based voluntary HIV counseling and testing in a national U.S. sample of gay and bisexual men: The role of demographic and HIV risk factors. Archives of Sexual Behavior, 43(1), 149-159. https://doi.org/10.1007/s10508013-0226-6

Rendina, H. J., Gamarel, K. E., Pachankis, J. E., Ventuneac, A., Grov, C., \& Parsons, J. T. (2017). Extending the Minority Stress Model to Incorporate HIV-Positive Gay and Bisexual Men's Experiences: A Longitudinal Examination of Mental Health and Sexual Risk Behavior. Annals of Behavioral Medicine: A Publication of the Society of Behavioral Medicine, 51(2), 147-158. https://doi.org/10.1007/s12160-016-9822-8

Rendina, H. J., Golub, S. A., Grov, C., \& Parsons, J. T. (2012). Stigma and sexual compulsivity in a community-based sample of HIV-positive gay and bisexual men. AIDS and Behavior, 16(3), 741-750. https://doi.org/10.1007/s10461-011-0048-2

Rendina, H. J., Lopez-Matos, J., Wang, K., Pachankis, J. E., \& Parsons, J. T. (2019). The Role of Self-Conscious Emotions in the Sexual Health of Gay and Bisexual Men: Psychometric Properties and Theoretical Validation of the Sexual Shame and Pride Scale. Journal of Sex Research, 56(4-5), 620-631. https://doi.org/10.1080/00224499.2018.1453042

Rendina, H. J., Millar, B. M., Dash, G., Feldstein Ewing, S. W., \& Parsons, J. T. (2018). The Somatic Marker Hypothesis and Sexual Decision Making: Understanding the Role of Iowa Gambling Task Performance and Daily Sexual Arousal on the Sexual Behavior of Gay and Bisexual Men. Annals of Behavioral Medicine, 52(5), 380-392. https://doi.org/10.1093/abm/kax006

Rettenberger, M., Klein, V., \& Briken, P. (2016). The Relationship Between Hypersexual Behavior, Sexual Excitation, Sexual Inhibition, and Personality Traits. Archives of Sexual Behavior, 45(1), 219-233. https://doi.org/10.1007/s10508-014-0399-7

Rhodes, S. D., Martinez, O., Song, E.-Y., Daniel, J., Alonzo, J., Eng, E., Duck, S., Downs, M., Bloom, F. R., Allen, A. B., Miller, C., \& Reboussin, B. (2013). Depressive symptoms among immigrant Latino sexual minorities. American Journal of Health Behavior, 37(3), 404-413. https://doi.org/10.5993/AJHB.37.3.13

Rissel, C., Richters, J., Visser, R. O. de, McKee, A., Yeung, A., \& Caruana, T. (2017). A profile of pornography users in Australia: Findings from the Second Australian Study of Health and Relationships. Journal of Sex Research, 54(2), 227-240. https://doi.org/10.1080/00224499.2016.1191597

Rømer Thomsen, K., Callesen, M. B., Hesse, M., Kvamme, T. L., Pedersen, M. M., Pedersen, M. U., \& Voon, V. (2018). Impulsivity traits and addiction-related behaviors in youth. Journal of Behavioral Addictions, 7(2), 317-330. https://doi.org/10.1556/2006.7.2018.22

Rosenberg, H., \& Kraus, S. (2014). The relationship of "passionate attachment" for pornography with sexual compulsivity, frequency of use, and craving for pornography. Addictive Behaviors, 39(5), 1012-1017. https://doi.org/10.1016/j.addbeh.2014.02.010

Ross, M. W., Rosser, B. R. S., \& Neumaier, E. R. (2008). The relationship of internalized homonegativity to unsafe sexual behavior in. AIDS Education and Prevention: Official Publication of the International Society for AIDS Education, 20(6), 547-557. https://doi.org/10.1521/aeap.2008.20.6.547

Rosser, B. R. S., Noor, S. W., \& Iantaffi, A. (2014). Normal, Problematic and Compulsive Consumption of Sexually Explicit Media: Clinical Findings using the Compulsive Pornography Consumption (CPC) Scale among Men who have Sex with Men. Sexual Addiction \& Compulsivity, 21(4), 276-304. https://doi.org/10.1080/10720162.2014.959145 
Safren, S. A., Blashill, A. J., Lee, J. S., O’Cleirigh, C., Tomassili, J., Biello, K. B., Mimiaga, M. J., \& Mayer, K. H. (2018). Condom-use self-efficacy as a mediator between syndemics and condomless sex in men who have sex with men (MSM). Health Psychology: Official Journal of the Division of Health Psychology, American Psychological Association, 37(9), 820-827. https://doi.org/10.1037/hea0000617

Salmeron-Sanchez, P., Ballester-Arnal, R., Gil-Llario, M. D., \& Morell-Mengual, V. (2017). Sexual Compulsivity and Sexual Sensation Seeking: A Preliminary Approach Among Male Sex Workers Compared to Gay Men in Spain. Journal of Sex \& Marital Therapy, 43(1), 56-67. https://doi.org/10.1080/0092623X.2015.1114547

Satinsky, S., Fisher, C., Stupiansky, N., Dodge, B., Alexander, A., Herbenick, D., \& Reece, M. (2008). Sexual compulsivity among men in a decentralized MSM community of the Midwestern United States. AIDS Patient Care and STDs, 22(7), 553-560. https://doi.org/10.1089/apc.2007.0255

Savard, J., Öberg, K. G., Chatzittofis, A., Dhejne, C., Arver, S., \& Jokinen, J. (2020). Naltrexone in Compulsive Sexual Behavior Disorder: A Feasibility Study of Twenty Men. The Journal of Sexual Medicine, 17(8), 1544-1552. https://doi.org/10.1016/j.jsxm.2020.04.318

Savard, J., Öberg, K. G., Chatzittofis, A., Dhejne, C., Arver, S., \& Jokinen, J. (2020). Naltrexone in Compulsive Sexual Behavior Disorder: A Feasibility Study of Twenty Men. The Journal of Sexual Medicine, 17(8), 1544-1552. https://doi.org/10.1016/j.jsxm.2020.04.318

Scanavino, M. D. T., Ventuneac, A., Abdo, C. H. N., Tavares, H., Amaral, M. L. S., Messina, B., Reis, S. C., Martins, J. P. L. B., \& Parsons, J. T. (2018). Sexual compulsivity, anxiety, depression, and sexual risk behavior among treatment-seeking men in Sao Paulo, Brazil. Revista Brasileira de Psiquiatria (Sao Paulo, Brazil : 1999), 40(4), 424-431. https://doi.org/10.1590/1516-4446-2017-2476

Scanavino, Marco de T., Ventuneac, A., Rendina, H. J., Abdo, C. H. N., Tavares, H., Amaral, M. L. S. do, Messina, B., Reis, S. C. dos, Martins, J. P. L. B., Gordon, M. C., Vieira, J. C., \& Parsons, J. T. (2016). Sexual Compulsivity Scale, Compulsive Sexual Behavior Inventory, and Hypersexual Disorder Screening Inventory: Translation, Adaptation, and Validation for Use in Brazil. Archives of Sexual Behavior, 45(1), 207-217. https://doi.org/10.1007/s10508-014-0356-5

Scanavino, Marco de Tubino, Ventuneac, A., Abdo, C. H. N., Tavares, H., do Amaral, M. L. S., Messina, B., dos Reis, S. C., Martins, J. P. L. B., \& Parsons, J. T. (2013). Compulsive sexual behavior and psychopathology among treatment-seeking men in Sao Paulo, Brazil. Psychiatry Research, 209(3), 518-524. https://doi.org/10.1016/j.psychres.2013.01.021

Schatzel-Murphy, E. A., Harris, D. A., Knight, R. A., \& Milburn, M. A. (2009). Sexual coercion in men and women: Similar behaviors, different predictors. Archives of Sexual Behavior, 38(6), 974-986. https://doi.org/10.1007/s10508-009-9481-y

Schecklmann, M., Sakreida, K., Oblinger, B., Langguth, B., \& Poeppl, T. B. (2020). Repetitive Transcranial Magnetic Stimulation as a Potential Tool to Reduce Sexual Arousal: A Proof of Concept Study. The Journal of Sexual Medicine, 17(8), 1553-1559. https://doi.org/10.1016/j.jsxm.2020.05.002

Schecklmann, M., Sakreida, K., Oblinger, B., Langguth, B., \& Poeppl, T. B. (2020). Repetitive Transcranial Magnetic Stimulation as a Potential Tool to Reduce Sexual Arousal: A Proof of Concept Study. The Journal of Sexual Medicine, 17(8), 1553-1559. https://doi.org/10.1016/j.jsxm.2020.05.002

Schiebener, J., Laier, C., \& Brand, M. (2015). Getting stuck with pornography? Overuse or neglect of cybersex cues in a multitasking situation is related to symptoms of cybersex addiction. Journal of Behavioral Addictions, 4(1), 1421. https://doi.org/10.1556/JBA.4.2015.1.5

Schmidt, C., Morris, L. S., Kvamme, T. L., Hall, P., Birchard, T., \& Voon, V. (2017). Compulsive sexual behavior: Prefrontal and limbic volume and interactions. Human Brain Mapping, 38(3), 1182-1190. https://doi.org/10.1002/hbm.23447

Schnarrs, P. W., Rosenberger, J. G., Satinsky, S., Brinegar, E., Stowers, J., Dodge, B., \& Reece, M. (2010). Sexual compulsivity, the Internet, and sexual behaviors among men in a rural area of the United States. AIDS Patient Care and STDs, 24(9), 563-569. https://doi.org/10.1089/apc.2010.0117

Seegers, J. A. (2003). The Prevalence of Sexual Addiction Symptoms on the College Campus. Sexual Addiction \& Compulsivity, 10(4), 247-258. https://doi.org/10.1080/713775413

Semple, S. J., Pitpitan, E. V., Goodman-Meza, D., Strathdee, S. A., Chavarin, C. V., Rangel, G., Torres, K., \& Patterson, T. L. (2017). Correlates of condomless anal sex among men who have sex with men (MSM) in Tijuana, Mexico: The role of public sex venues. PloS One, 12(10), e0186814. https://doi.org/10.1371/journal.pone.0186814 
Semple, S. J., Strathdee, S. A., Gallardo Cruz, M., Robertson, A., Goldenberg, S., \& Patterson, T. L. (2010). Psychosexual and social-cognitive correlates of sexual risk behavior among male clients of female sex workers in Tijuana, Mexico. AIDS Care, 22(12), 1473-1480. https://doi.org/10.1080/09540121003758648

Semple, S. J., Zians, J., Grant, I., \& Patterson, T. L. (2006). Sexual compulsivity in a sample of HIV-positive methamphetamine-using gay and bisexual men. AIDS and Behavior, 10(5), 587-598. https://doi.org/10.1007/s10461-006-9127-1

Seok, J.-W., \& Sohn, J.-H. (2015). Neural Substrates of Sexual Desire in Individuals with Problematic Hypersexual Behavior. Frontiers in Behavioral Neuroscience, 9, 321. https://doi.org/10.3389/fnbeh.2015.00321

Seok, J.-W., \& Sohn, J.-H. (2018a). Altered Prefrontal and Inferior Parietal Activity During a Stroop Task in Individuals With Problematic Hypersexual Behavior. Frontiers in Psychiatry, 9, 460. https://doi.org/10.3389/fpsyt.2018.00460

Seok, J.-W., \& Sohn, J.-H. (2018b). Gray matter deficits and altered resting-state connectivity in the superior temporal gyrus among individuals with problematic hypersexual behavior. Brain Research, 1684, 30-39. https://doi.org/10.1016/j.brainres.2018.01.035

Seok, J., \& Sohn, J.-H. (2020). Response inhibition during processing of sexual stimuli in males with problematic hypersexual behavior. Journal of Behavioral Addictions, 9(1), 71-82. https://doi.org/10.1556/2006.2020.00003

Seok, J., \& Sohn, J.-H. (2020). Response inhibition during processing of sexual stimuli in males with problematic hypersexual behavior. Journal of Behavioral Addictions, 9(1), 71-82. https://doi.org/10.1556/2006.2020.00003

Shimoni, L., Dayan, M., Cohen, K., \& Weinstein, A. (2018). The contribution of personality factors and gender to ratings of sex addiction among men and women who use the Internet for sex purpose. Journal of Behavioral Addictions, 7(4), 1015-1021. https://doi.org/10.1556/2006.7.2018.101

Sindermann, C., Sariyska, R., Lachmann, B., Brand, M., \& Montag, C. (2018). Associations between the dark triad of personality and unspecified/specific forms of Internet-use disorder. Journal of Behavioral Addictions, 7(4), 985992. https://doi.org/10.1556/2006.7.2018.114

Sinke, C., Engel, J., Veit, M., Hartmann, U., Hillemacher, T., Kneer, J., \& Kruger, T. H. C. (2020). Sexual cues alter working memory performance and brain processing in men with compulsive sexual behavior. NeuroImage: Clinical, 27, 102308. https://doi.org/10.1016/j.nicl.2020.102308

Sinke, C., Engel, J., Veit, M., Hartmann, U., Hillemacher, T., Kneer, J., \& Kruger, T. H. C. (2020). Sexual cues alter working memory performance and brain processing in men with compulsive sexual behavior. NeuroImage: Clinical, 27, 102308. https://doi.org/10.1016/j.nicl.2020.102308

Sirianni, J. M., \& Vishwanath, A. (2016). Problematic Online Pornography Use: A Media Attendance Perspective. The Journal of Sex Research, 53(1), 21-34. https://doi.org/10.1080/00224499.2014.980496

Siu-ming, T., Phyllis, K. W., Cherry, H. T., Kan Kwok, D., \& Lau, C. D. (2019). Sexual compulsivity, sexual selfconcept, and cognitive outcomes of sexual behavior of young Chinese Hong Kong males with compulsive sexual behavior: Implications for intervention and prevention. Children and Youth Services Review, 104, 104400. https://doi.org/10.1016/j.childyouth.2019.104400

Skegg, K., Nada-Raja, S., Dickson, N., \& Paul, C. (2010). Perceived "out of control" sexual behavior in a cohort of young adults from the Dunedin Multidisciplinary Health and Development Study. Archives of Sexual Behavior, 39(4), 968-978. https://doi.org/10.1007/s10508-009-9504-8

Sklenarik, S., Potenza, M. N., Gola, M., \& Astur, R. S. (2020). Approach bias for erotic stimuli among heterosexual female college students who use pornography. Addictive Behaviors, 108, 106438. https://doi.org/10.1016/j.addbeh.2020.106438

Sklenarik, S., Potenza, M. N., Gola, M., \& Astur, R. S. (2020). Approach bias for erotic stimuli among heterosexual female college students who use pornography. Addictive Behaviors, 108, 106438. https://doi.org/10.1016/j.addbeh.2020.106438

Sklenarik, S., Potenza, M. N., Gola, M., Kor, A., Kraus, S. W., \& Astur, R. S. (2019). Approach bias for erotic stimuli in heterosexual male college students who use pornography. Journal of Behavioral Addictions, 8(2), 234-241. https://doi.org/10.1556/2006.8.2019.31

Smith, N. G., Mohr, J. J., \& Ross, L. E. (2018). The role of bisexual-specific minority stressors in sexual compulsivity among bisexual men. Sexual and Relationship Therapy, 33(1-2), 81-96. https://doi.org/10.1080/14681994.2017.1386301

Smith, P. H., Potenza, M. N., Mazure, C. M., McKee, S. A., Park, C. L., \& Hoff, R. A. (2014). Compulsive sexual behavior among male military veterans: Prevalence and associated clinical factors. Journal of Behavioral Addictions, 3(4), 214-222. https://doi.org/10.1556/JBA.3.2014.4.2 
Smolenski, D. J., Ross, M. W., Risser, J. M. H., \& Rosser, B. R. S. (2009). Sexual compulsivity and high-risk sex among Latino men: The role of internalized homonegativity and gay organizations. AIDS Care, 21(1), 42-49. https://doi.org/10.1080/09540120802068803

Smolenski, D. J., Stigler, M. H., Ross, M. W., \& Rosser, B. R. S. (2011). Direct and indirect associations between internalized homonegativity and high-risk sex. Archives of Sexual Behavior, 40(4), 785-792. https://doi.org/10.1007/s10508-010-9705-1

Snagowski, J., \& Brand, M. (2015). Symptoms of cybersex addiction can be linked to both approaching and avoiding pornographic stimuli: Results from an analog sample of regular cybersex users. Frontiers in Psychology, 6, 653. https://doi.org/10.3389/fpsyg.2015.00653

Snagowski, J., Wegmann, E., Pekal, J., Laier, C., \& Brand, M. (2015). Implicit associations in cybersex addiction: Adaption of an Implicit Association Test with pornographic pictures. Addictive Behaviors, 49, 7-12. https://doi.org/10.1016/j.addbeh.2015.05.009

Spenhoff, M., Kruger, T. H. C., Hartmann, U., \& Kobs, J. (2013). Hypersexual behavior in an online sample of males: Associations with personal distress and functional impairment. The Journal of Sexual Medicine, 10(12), 29963005. https://doi.org/10.1111/jsm.12160

Stark, R., Kruse, O., Snagowski, J., Brand, M., Walter, B., Klucken, T., \& Wehrum-Osinsky, S. (2017). Predictors for (problematic) use of internet sexually explicit material: Role of trait sexual motivation and implicit approach tendencies towards sexually explicit material. Sexual Addiction \& Compulsivity, 24(3), 180-202. https://doi.org/10.1080/10720162.2017.1329042

Starks, T. J., Grov, C., \& Parsons, J. T. (2013). Sexual compulsivity and interpersonal functioning: Sexual relationship quality and sexual health in gay relationships. Health Psychology: Official Journal of the Division of Health Psychology, American Psychological Association, 32(10), 1047-1056. https://doi.org/10.1037/a0030648

Steele, V. R., Staley, C., Fong, T., \& Prause, N. (2013). Sexual desire, not hypersexuality, is related to neurophysiological responses elicited by sexual images. Socioaffective Neuroscience \& Psychology, 3, 20770. https://doi.org/10.3402/snp.v3i0.20770

Storholm, E. D., Fisher, D. G., Napper, L. E., Reynolds, G. L., \& Halkitis, P. N. (2011). Proposing a tentative cut point for the Compulsive Sexual Behavior Inventory. Archives of Sexual Behavior, 40(6), 1301-1308. https://doi.org/10.1007/s10508-010-9712-2

Storholm, E. D., Satre, D. D., Kapadia, F., \& Halkitis, P. N. (2016). Depression, Compulsive Sexual Behavior, and Sexual Risk-Taking Among Urban Young Gay and Bisexual Men: The P18 Cohort Study. Archives of Sexual Behavior, 45(6), 1431-1441. https://doi.org/10.1007/s10508-015-0566-5

Studer, J., Marmet, S., Wicki, M., \& Gmel, G. (2019). Cybersex use and problematic cybersex use among young Swiss men: Associations with sociodemographic, sexual, and psychological factors. Journal of Behavioral Addictions, $1-10$.

Stulhofer, A., Bergeron, S., \& Jurin, T. (2016). Is High Sexual Desire a Risk for Women's Relationship and Sexual WellBeing? Journal of Sex Research, 53(7), 882-891. https://doi.org/10.1080/00224499.2015.1084984

Stulhofer, A., Jelovica, V., \& Ružić, J. (2008). Is Early Exposure to Pornography a Risk Factor for Sexual Compulsivity? Findings from an Online Survey among Young Heterosexual Adults. International Journal of Sexual Health, 20(4), 270-280. https://doi.org/10.1080/19317610802411870

Stulhofer, A., Jurin, T., \& Briken, P. (2016). Is High Sexual Desire a Facet of Male Hypersexuality? Results from an Online Study. Journal of Sex \& Marital Therapy, 42(8), 665-680. https://doi.org/10.1080/0092623X.2015.1113585

Štulhofer, A., Rousseau, A., \& Shekarchi, R. (2020). A Two-Wave Assessment of the Structure and Stability of SelfReported Problematic Pornography Use Among Male Croatian Adolescents. International Journal of Sexual Health, 32(2), 151-164. https://doi.org/10.1080/19317611.2020.1765940

Štulhofer, A., Rousseau, A., \& Shekarchi, R. (2020). A Two-Wave Assessment of the Structure and Stability of SelfReported Problematic Pornography Use Among Male Croatian Adolescents. International Journal of Sexual Health, 32(2), 151-164. https://doi.org/10.1080/19317611.2020.1765940

Stupiansky, N. W., Reece, M., Middlestadt, S. E., Finn, P., \& Sherwood-Laughlin, C. (2009). The Role of Sexual Compulsivity in Casual Sexual Partnerships among College Women. Sexual Addiction \& Compulsivity, 16(3), 241-252. https://doi.org/10.1080/10720160903202760

Sutton, K. S., Stratton, N., Pytyck, J., Kolla, N. J., \& Cantor, J. M. (2015). Patient Characteristics by Type of Hypersexuality Referral: A Quantitative Chart Review of 115 Consecutive Male Cases. Journal of Sex \& Marital Therapy, 41(6), 563-580. https://doi.org/10.1080/0092623X.2014.935539 
Thomas, J., Katsikitis, M., Allen, A., \& Kannis-Dymand, L. (2020). Desire Thinking and Metacognition Associated with Dsyregulated Sexuality. Sexual Addiction \& Compulsivity, 27(1-2), 119-134. https://doi.org/10.1080/10720162.2020.1772155

Thomas, J., Katsikitis, M., Allen, A., \& Kannis-Dymand, L. (2020). Desire Thinking and Metacognition Associated with Dsyregulated Sexuality. Sexual Addiction \& Compulsivity, 27(1-2), 119-134. https://doi.org/10.1080/10720162.2020.1772155

Thompson, M. P., Kingree, J. B., Zinzow, H., \& Swartout, K. (2015). Time-Varying Risk Factors and Sexual Aggression Perpetration Among Male College Students. The Journal of Adolescent Health : Official Publication of the Society for Adolescent Medicine, 57(6), 637-642. https://doi.org/10.1016/j.jadohealth.2015.08.015

Tierens, E., Vansintejan, J., Vandevoorde, J., \& Devroey, D. (2014). Diagnosis and treatment of participants of support groups for hypersexual disorder. Archivio Italiano Di Urologia, Andrologia: Organo Ufficiale [Di] Societa Italiana Di Ecografia Urologica e Nefrologica, 86(3), 175-182. https://doi.org/10.4081/aiua.2014.3.175

Tóth-Király, I., Vallerand, R. J., Bőthe, B., Rigó, A., \& Orosz, G. (2019). Examining sexual motivation profiles and their correlates using latent profile analysis. Personality and Individual Differences, 146, 76-86. https://doi.org/10.1016/j.paid.2019.04.002

Turban, J. L., Passell, E., Scheuer, L., \& Germine, L. (2020). Use of Geosocial Networking Applications Is Associated With Compulsive Sexual Behavior Disorder in an Online Sample. The Journal of Sexual Medicine, 17(8), 1574 1578. https://doi.org/10.1016/j.jsxm.2020.03.020

Turban, J. L., Passell, E., Scheuer, L., \& Germine, L. (2020). Use of Geosocial Networking Applications Is Associated With Compulsive Sexual Behavior Disorder in an Online Sample. The Journal of Sexual Medicine, 17(8), 1574 1578. https://doi.org/10.1016/j.jsxm.2020.03.020

Twohig, M. P., \& Crosby, J. M. (2010). Acceptance and commitment therapy as a treatment for problematic internet pornography viewing. Behavior Therapy, 41(3), 285-295. https://doi.org/10.1016/j.beth.2009.06.002

Twohig, M. P., Crosby, J. M., \& Cox, J. M. (2009). Viewing Internet Pornography: For Whom is it Problematic, How, and Why? Sexual Addiction \& Compulsivity, 16(4), 253-266. https://doi.org/10.1080/10720160903300788

Vaillancourt-Morel, M.-P., Blais-Lecours, S., Labadie, C., Bergeron, S., Sabourin, S., \& Godbout, N. (2017). Profiles of Cyberpornography Use and Sexual Well-Being in Adults. The Journal of Sexual Medicine, 14(1), $78-85$. https://doi.org/10.1016/j.jsxm.2016.10.016

Vaillancourt-Morel, M.-P., Dugal, C., Poirier Stewart, R., Godbout, N., Sabourin, S., Lussier, Y., \& Briere, J. (2016). Extradyadic Sexual Involvement and Sexual Compulsivity in Male and Female Sexual Abuse Survivors. Journal of Sex Research, 53(4-5), 614-625. https://doi.org/10.1080/00224499.2015.1061633

Vaillancourt-Morel, M.-P., Godbout, N., Labadie, C., Runtz, M., Lussier, Y., \& Sabourin, S. (2015). Avoidant and compulsive sexual behaviors in male and female survivors of childhood sexual abuse. Child Abuse \& Neglect, 40, 48-59. https://doi.org/10.1016/j.chiabu.2014.10.024

Valero-Solis, S., Granero, R., Fernandez-Aranda, F., Steward, T., Mestre-Bach, G., Mallorqui-Bague, N., Martin-Romera, V., Aymami, N., Gomez-Pena, M., Del Pino-Gutierrez, A., Bano, M., Moragas, L., Menchon, J. M., \& JimenezMurcia, S. (2018). The Contribution of Sex, Personality Traits, Age of Onset and Disorder Duration to Behavioral Addictions. Frontiers in Psychiatry, 9, 497. https://doi.org/10.3389/fpsyt.2018.00497

Varfi, N., Rothen, S., Jasiowka, K., Lepers, T., Bianchi-Demicheli, F., \& Khazaal, Y. (2019). Sexual Desire, Mood, Attachment Style, Impulsivity, and Self-Esteem as Predictive Factors for Addictive Cybersex. JMIR Mental Health, 6(1), e9978. https://doi.org/10.2196/mental.9978

Ventuneac, A., Rendina, H. J., Grov, C., Mustanski, B., \& Parsons, J. T. (2015). An item response theory analysis of the sexual compulsivity scale and its correspondence with the hypersexual disorder screening inventory among a sample of highly sexually active gay and bisexual men. The Journal of Sexual Medicine, 12(2), 481-493. https://doi.org/10.1111/jsm.12783

Volk, F., Floyd, C. G., Bohannon, K. E., Cole, S. M., McNichol, K. M., Schott, E. A., \& Williams, Z. D. R. (2019). The Moderating Role of the Tendency to Blame Others in the Development of Perceived Addiction, Shame, and Depression in Pornography Users. Sexual Addiction \& Compulsivity, 26(3-4), 239-261. https://doi.org/10.1080/10720162.2019.1670301

Voon, V., Mole, T. B., Banca, P., Porter, L., Morris, L., Mitchell, S., Lapa, T. R., Karr, J., Harrison, N. A., Potenza, M. N., \& Irvine, M. (2014). Neural correlates of sexual cue reactivity in individuals with and without compulsive sexual behaviours. PLoS ONE, 9(7). 
Wainberg, M. L., Muench, F., Morgenstern, J., Hollander, E., Irwin, T. W., Parsons, J. T., Allen, A., \& O’Leary, A. (2006). A double-blind study of citalopram versus placebo in the treatment of compulsive sexual behaviors in gay and bisexual men. The Journal of Clinical Psychiatry, 67(12), 1968-1973. https://doi.org/10.4088/JCP.v67n1218

Walters, G. D., Knight, R. A., \& Langstrom, N. (2011). Is hypersexuality dimensional? Evidence for the DSM-5 from general population and clinical samples. Archives of Sexual Behavior, 40(6), 1309-1321. https://doi.org/10.1007/s10508-010-9719-8

Walton, M. T. (2019). Incongruence as a variable feature of problematic sexual behaviors in an online sample of selfreported "sex addiction". Archives of Sexual Behavior, 48(2), 443-447. https://doi.org/10.1007/s10508-018-13055

Walton, M. T., \& Bhullar, N. (2018). Hypersexuality, Higher Rates of Intercourse, Masturbation, Sexual Fantasy, and Early Sexual Interest Relate to Higher Sexual Excitation/Arousal. Archives of Sexual Behavior, 47(8), $2177-2183$. https://doi.org/10.1007/s10508-018-1230-7

Walton, M. T., Cantor, J. M., \& Lykins, A. D. (2017). An Online Assessment of Personality, Psychological, and Sexuality Trait Variables Associated with Self-Reported Hypersexual Behavior. Archives of Sexual Behavior, 46(3), 721733. https://doi.org/10.1007/s10508-015-0606-1

Walton, M. T., Lykins, A. D., \& Bhullar, N. (2016). Sexual Arousal and Sexual Activity Frequency: Implications for Understanding Hypersexuality. Archives of Sexual Behavior, 45(4), 777-782. https://doi.org/10.1007/s10508-0160727-1

Wan, M., Finlayson, R., \& Rowles, A. (2000). Sexual Dependency Treatment Outcome Study. Sexual Addiction \& Compulsivity, 7(3), 177-196. https://doi.org/10.1080/10720160008400217

Wang, X., Wang, Z., Jiang, X., Li, R., Wang, Y., Xu, G., Zou, H., \& Cai, Y. (2018). A cross-sectional study of the relationship between sexual compulsivity and unprotected anal intercourse among men who have sex with men in shanghai, China. BMC Infectious Diseases, 18(1), 465. https://doi.org/10.1186/s12879-018-3360-x

Wang, Y., Wang, Z., Jia, M., Liang, A., Yuan, D., Sun, Z., Gan, F., Wang, Y., Cai, Y., \& Zhang, Z. (2017). Association between a syndemic of psychosocial problems and unprotected anal intercourse among men who have sex with men in Shanghai, China. BMC Infectious Diseases, 17(1), 46. https://doi.org/10.1186/s12879-016-2132-8

Wang, Z., Zhao, X., Zhang, Z., Luo, M., Shen, Q., Dong, Y., Wang, Y., \& Cai, Y. (2018). Co-Occurring Psychosocial Problems and Multiple Sexual Partners among Men Who Have Sex with Men in Shanghai, China: A Syndemic Approach. Journal of Sex Research, 55(7), 892-901. https://doi.org/10.1080/00224499.2017.1399333

Weinstein, A. M., Zolek, R., Babkin, A., Cohen, K., \& Lejoyeux, M. (2015). Factors Predicting Cybersex Use and Difficulties in Forming Intimate Relationships among Male and Female Users of Cybersex. Frontiers in Psychiatry, 6, 54. https://doi.org/10.3389/fpsyt.2015.00054

Weinstein, A., Katz, L., Eberhardt, H., Cohen, K., \& Lejoyeux, M. (2015). Sexual compulsion—Relationship with sex, attachment and sexual orientation. Journal of Behavioral Addictions, 4(1), 22-26.

Werner, M., Stulhofer, A., Waldorp, L., \& Jurin, T. (2018). A Network Approach to Hypersexuality: Insights and Clinical Implications. The Journal of Sexual Medicine, 15(3), 373-386. https://doi.org/10.1016/j.jsxm.2018.01.009

Wery, A., Burnay, J., Karila, L., \& Billieux, J. (2016). The Short French Internet Addiction Test Adapted to Online Sexual Activities: Validation and Links With Online Sexual Preferences and Addiction Symptoms. Journal of Sex Research, 53(6), 701-710. https://doi.org/10.1080/00224499.2015.1051213

Wery, A., Vogelaere, K., Challet-Bouju, G., Poudat, F.-X., Caillon, J., Lever, D., Billieux, J., \& Grall-Bronnec, M. (2016). Characteristics of self-identified sexual addicts in a behavioral addiction outpatient clinic. Journal of Behavioral Addictions, 5(4), 623-630. https://doi.org/10.1556/2006.5.2016.071

Wetterneck, C. T., Burgess, A. J., Short, M. B., Smith, A. H., \& Cervantes, M. E. (2012). The role of sexual compulsivity, impulsivity, and experiential avoidance in internet pornography use. Psychological Record, 62(1), 3-17.

Wilt, J. A., Cooper, E. B., Grubbs, J. B., Exline, J. J., \& Pargament, K. I. (2016). Associations of perceived addiction to internet pornography with religious/spiritual and psychological functioning. Sexual Addiction \& Compulsivity, 23(2-3), 260-278. https://doi.org/10.1080/10720162.2016.1140604

Wilton, J., Noor, S. W., Schnubb, A., Lawless, J., Hart, T. A., Grennan, T., Fowler, S., Maxwell, J., \& Tan, D. H. S. (2018). High HIV risk and syndemic burden regardless of referral source among MSM screening for a PrEP demonstration project in Toronto, Canada. BMC Public Health, 18(1), 292. https://doi.org/10.1186/s12889-0185180-8

Winters, J., Christoff, K., \& Gorzalka, B. B. (2009). Conscious regulation of sexual arousal in men. Journal of Sex Research, 46(4), 330-343. https://doi.org/10.1080/00224490902754103 
Winters, J., Christoff, K., \& Gorzalka, B. B. (2010). Dysregulated sexuality and high sexual desire: Distinct constructs? Archives of Sexual Behavior, 39(5), 1029-1043. https://doi.org/10.1007/s10508-009-9591-6

Woolf-King, S. E., Rice, T. M., Truong, H.-H. M., Woods, W. J., Jerome, R. C., \& Carrico, A. W. (2013). Substance use and HIV risk behavior among men who have sex with men: The role of sexual compulsivity. Journal of Urban Health : Bulletin of the New York Academy of Medicine, 90(5), 948-952. https://doi.org/10.1007/s11524-0139820-0

Wordecha, M., Wilk, M., Kowalewska, E., Skorko, M., Lapinski, A., \& Gola, M. (2018). "Pornographic binges" as a key characteristic of males seeking treatment for compulsive sexual behaviors: Qualitative and quantitative 10-weeklong diary assessment. Journal of Behavioral Addictions, 7(2), 433-444. https://doi.org/10.1556/2006.7.2018.33

Xu, W., Zheng, L., Liu, Y., \& Zheng, Y. (2016). Sexual sensation seeking, sexual compulsivity, and high-risk sexual behaviours among gay/bisexual men in Southwest China. AIDS Care, 28(9), 1138-1144. https://doi.org/10.1080/09540121.2016.1153587

Yeagley, E., Hickok, A., \& Bauermeister, J. A. (2014). Hypersexual behavior and HIV sex risk among young gay and bisexual men. Journal of Sex Research, 51(8), 882-892. https://doi.org/10.1080/00224499.2013.818615

Zilberman, N., Yadid, G., Efrati, Y., \& Rassovsky, Y. (2020). Who becomes addicted and to what? Psychosocial predictors of substance and behavioral addictive disorders. Psychiatry Research, 291, 113221. https://doi.org/10.1016/j.psychres.2020.113221

Zilberman, N., Yadid, G., Efrati, Y., \& Rassovsky, Y. (2020). Who becomes addicted and to what? Psychosocial predictors of substance and behavioral addictive disorders. Psychiatry Research, 291, 113221. https://doi.org/10.1016/j.psychres.2020.113221

Zilberman, N., Yadid, G., Efrati, Y., Neumark, Y., \& Rassovsky, Y. (2018). Personality profiles of substance and behavioral addictions. Addictive Behaviors, 82, 174-181. https://doi.org/10.1016/j.addbeh.2018.03.007

Zimmer, F., \& Imhoff, R. (2020). Abstinence from Masturbation and Hypersexuality. Archives of Sexual Behavior. https://doi.org/10.1007/s10508-019-01623-8

Zlot, Y., Goldstein, M., Cohen, K., \& Weinstein, A. (2018). Online dating is associated with sex addiction and social anxiety. Journal of Behavioral Addictions, 7(3), 821-826. https://doi.org/10.1556/2006.7.2018.66

Zsila, Á., Bőthe, B., Demetrovics, Z., Billieux, J., \& Orosz, G. (2020). Further exploration of the SUPPS-P impulsive behavior scale's factor structure: Evidence from a large Hungarian sample. Current Psychology, 39(1), 378-388. https://doi.org/10.1007/s12144-017-9773-7 